\title{
EMERGING CAPABILITIES AND FIRM PERFORMANCE IN THE CLOUD COMPUTING ENVIRONMENT
}

A Dissertation

Submitted to

the Temple University Graduate Board

\author{
In Partial Fulfillment \\ of the Requirements for the Degree \\ DOCTOR OF BUSINESS ADMINISTRATION
}

Jean-Luc B. Alarcon

Diploma Date May 2018

Examining Committee Members:

Paul A. Pavlou, Advisory Chair, MIS and Strategic Management

Pallavi Chitturi, Statistical Science

Ronald Anderson, Finance 


\begin{abstract}
New capabilities required to succeed in the new Cloud environment represent a radical change for software companies, which have to transition from selling on-the-premises software products to providing subscription-based cloud services (aka Software-as-aService or SaaS). While emerging SaaS vendors have led the exponential growth of the market, the traditional software industry has been disrupted. The purpose of this dissertation is to analyze which capabilities are driving the performance of software firms in today's cloud-computing environment by drawing upon the resource-based view (RBV) of the firm. What is the optimum spending across the primary firm capabilities (e.g., service delivery, R\&D, marketing and sales) to maximize financial performance? This dissertation focuses on publicly-traded SaaS companies using publicly-available information from financial databases, corporate investor relations materials, and industry research. It is comprised of two essays. The first essay is a quantitative study based on secondary data. The second essay includes an extensive literature review, an analysis of in-depth interviews of practitioners, and mini case studies. Together, the essays contribute to RBV theory and provide useful insights to help assess the quality of execution of SaaS growth strategies and improve financial planning and performance in the software industry for the cloud computing environment. Although the results come from firms in the SaaS industry, the findings from this study could cautiously generalize to firms in other emerging technology industries. The dissertation concludes with a detailed agenda for future research.
\end{abstract}

Key words: Cloud, Software, SaaS, capabilities, spending patterns, firm performance. 


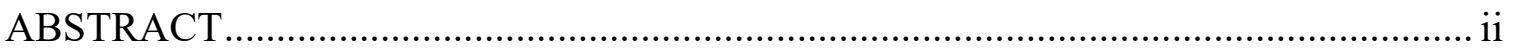

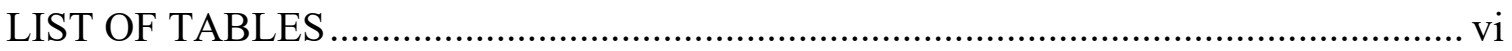

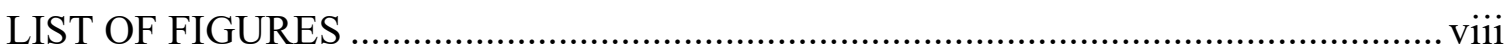

CHAPTER 1

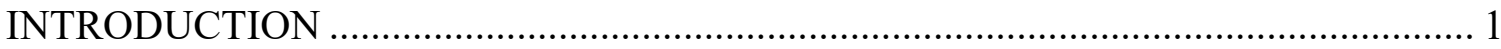

\section{CHAPTER 2}

ESSAY ONE: THE CONTRIBUTIONS OF CAPABILITIES TO FIRM

PERFORMANCE IN THE CLOUD COMPUTING ENVIRONMENT ........................... 3

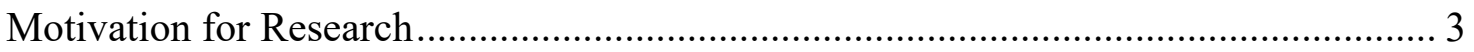

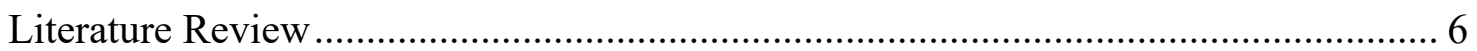

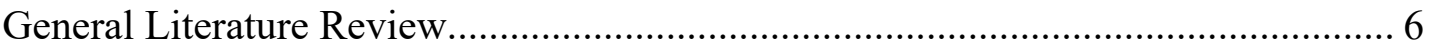

Literature Specific to the Software Industry........................................................... 10

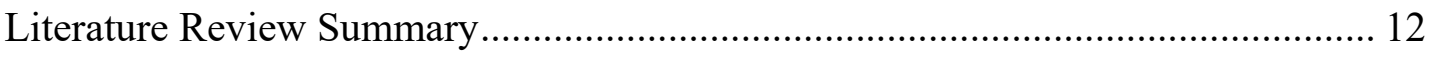

Conceptual Model and Hypotheses......................................................................... 13

The Role of Growth and EBITDA in Business Valuation ........................................ 17

The Role of Resource Allocation in Firm Performance (Growth and EBITDA)...... 19

Research Methodology / Data Collection .................................................................... 24

Data Collection ............................................................................................ 24

Description of Variables and Measures............................................................. 25

Foreign Currency Conversion ............................................................................. 26

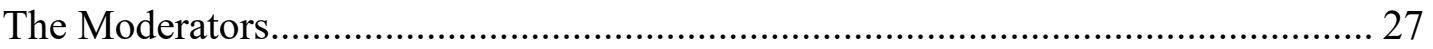

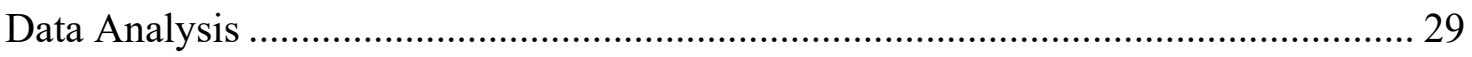

The Role of Growth and EBITDA in Business Valuations (H1) ............................... 29

The Role of Gross Margin (Service Delivery Efficiency) in Firm Performance (H2)

The Role of R\&D in Firm Performance (H3) ...................................................... 35

The Role of Marketing \& Sales in Firm Performance (H4) ....................................... 37

The Role of Consistency of Spending Patterns in Firm Performance (H5) .............. 40 
The Moderating Effect of the Firm's Development Stage ..................................... 42

The Moderating Effect of the Firm's Specialization .............................................. 46

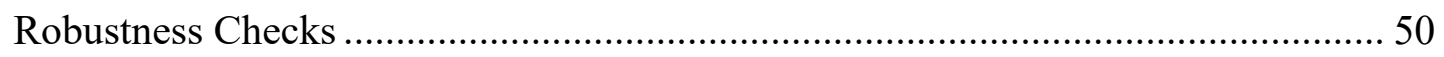

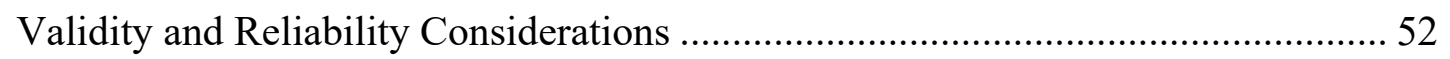

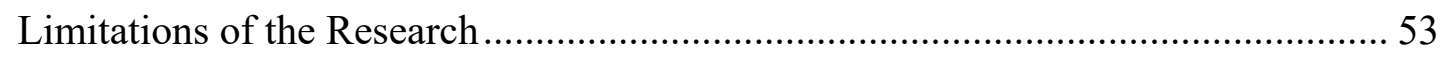

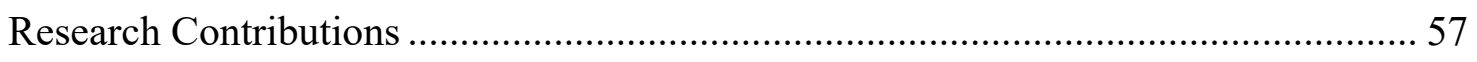

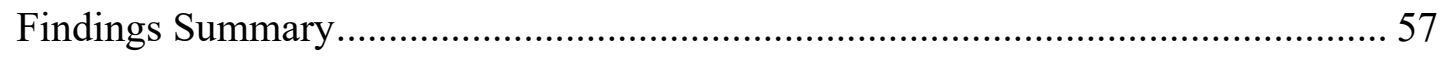

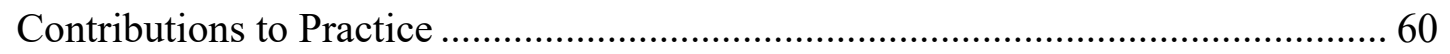

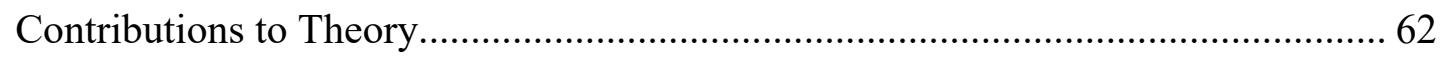

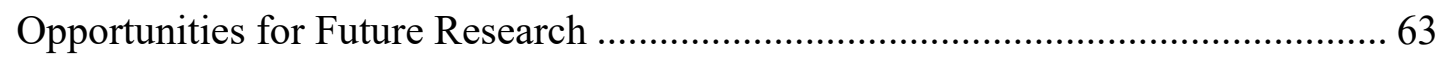

CHAPTER 3

ESSAY TWO: OPTIMIZING GROWTH STRATEGIES IN THE CLOUD

COMPUTING ENVIRONMENT (INSIGHTS FROM THE LITERATURE AND FROM

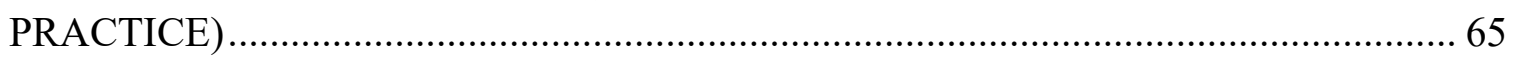

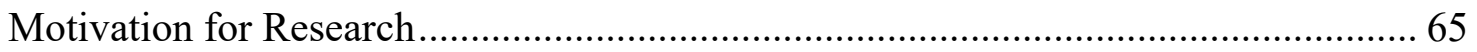

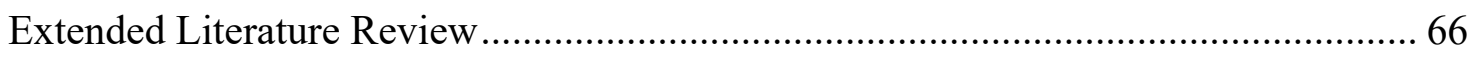

Emergence of New Literature on Resource Allocation Optimization....................... 67

The Role of Other Factors Influencing the Relationship between Resource Allocation and Firm Performance ............................................................................... 70

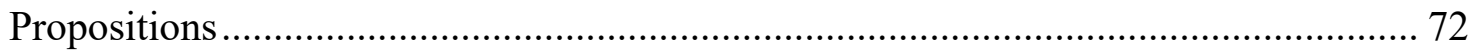

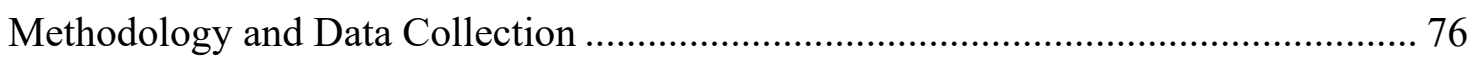

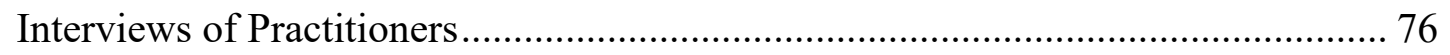

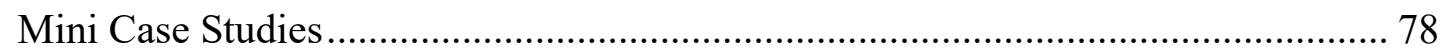

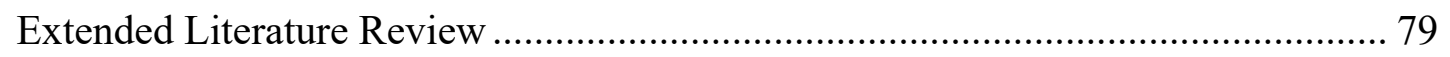

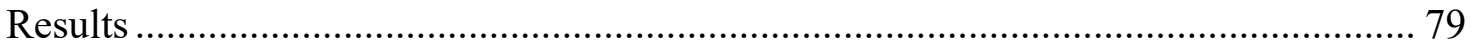

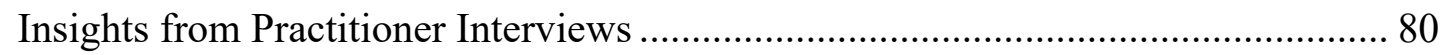

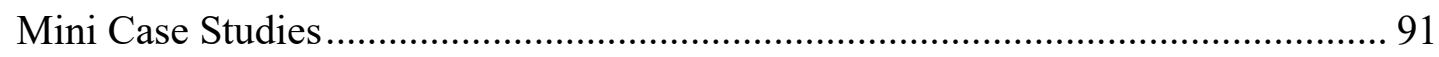

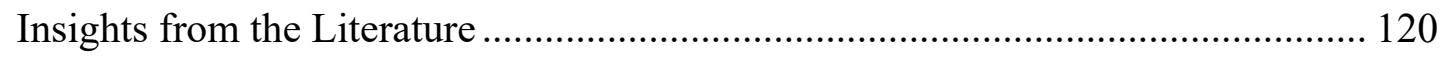

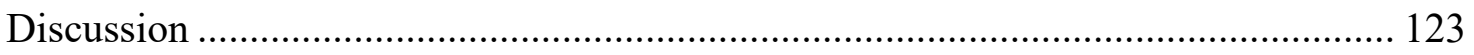

Research Agenda for Future Research ......................................................... 131

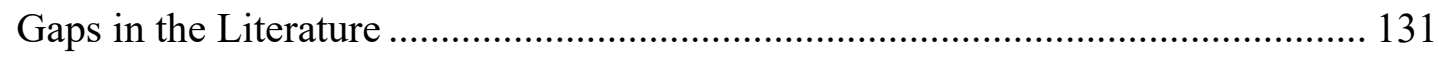

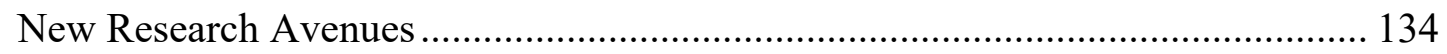


CHAPTER 4

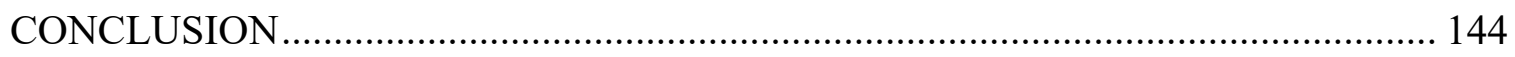

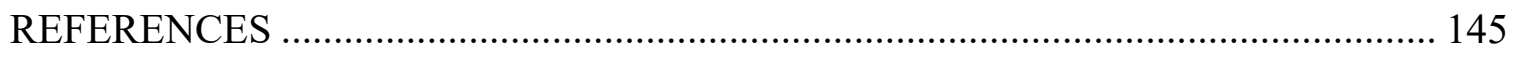

APPENDICES

A. IMPACT OF SAAS MODEL ON CAPABILITIES ………………………….... 152

B. THE MODERATING EFFECT OF THE FIRM'S DEVELOPMENT STAGE .... 154

C. THE MODERATING EFFECT OF THE FIRM'S DEVELOPMENT STAGE

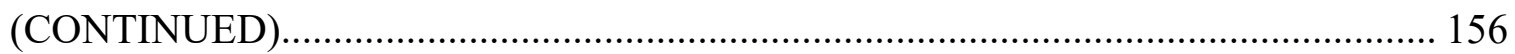

D. THE MODERATING EFFECT OF THE FIRM'S SPECIALIZATION ............... 157

E. THE MODERATING EFFECT OF THE FIRM'S SPECIALIZATION

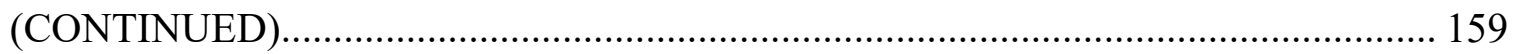

F. BOX PLOTS AND HISTOGRAMS .............................................................. 160

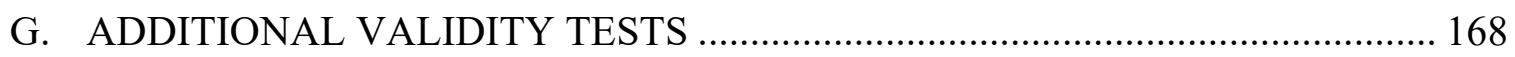

H. DISCUSSIONS WITH PRACTITIONERS - STUDY DESIGN ............................ 170

I. INSIGHTS FROM THE LITERATURE (EXTENDED LITERATURE REVIEW) TABLES OF KEY FINDINGS AND MANAGERIAL IMPLICATIONS..................... 174

J. FROM THE EXTENDED LITERATURE REVIEW - GAPS AND NEW

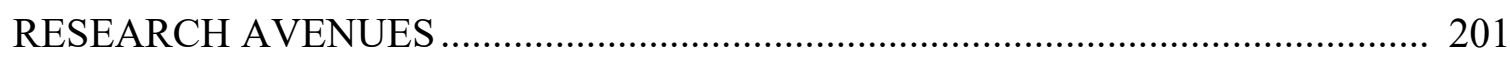




\section{LIST OF TABLES}

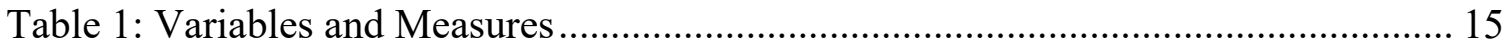

Table 2: Hypothesis Testing Summary ............................................................................. 29

Table 3: Results of the Influence of Growth and EBITDA on Business Valuation ......... 30

Table 4: Correlations of Growth and EBITDA to Business Valuation ........................... 31

Table 5: Premium in Business Valuation Achieved by Profitable Vs. Nonprofitable Firms at a Comparable 30\% Annual Growth ....................................................................... 32

Table 6: Relationship between R\&D and Performance Factor - Testing of Non-Linearity

Using a Quadratic Effect in the Model ....................................................................... 36

Table 7: Relationship between M\&S and Performance Factor - Testing of Non-Linearity

Using a Quadratic Effect in the Model ........................................................................... 39

Table 8: Influence of Consistency in Spending Patterns Over Time on Firm Performance

- Regression Analysis (Without Double Negatives and Outliers) ................................. 42

Table 9: Differences in Resource Allocations between Early Stage and At Scale Firms. 44

Table 10: Differences in Resource Allocations between Generalist and Vertical Firms . 47

Table 11: Differences between High and Low Performers ........................................... 51

Table 12: Differences between Pure-Play and Hybrid Firms ........................................ 52

Table 13: Example of R\&D Expenditure Reporting.................................................. 56

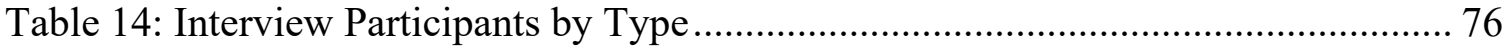

Table 15: Feedback from Practitioners - Quotation Examples ....................................... 80

Table 16: Practitioners' Comments on the Originality and Relevance of the Study -

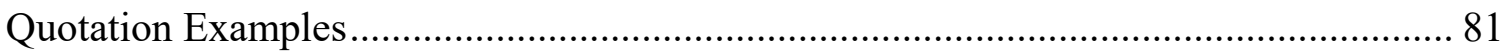

Table 17: Real-life Examples Cited by Practitioners - Quotation Examples .................. 82

Table 18: Managerial Implications Cited by Practitioners - Quotation Examples .......... 84

Table 19: Practitioners' Opinion on the Generalizability of the Study - Quotation

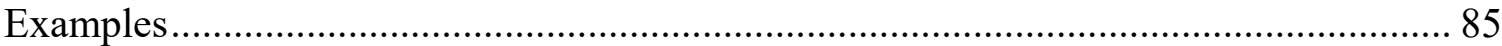

Table 20: Practitioners' Opinion on the Limitations of the Study - Quotation Examples 86

Table 21: Practitioners' Suggestions for New Research Questions - Quotation Examples

Table 22: Practitioners' Suggestions for New Measures or Factors - Quotation Examples

89

Table 23: Veeva Systems - Performance Summary ................................................... 92

Table 24: Veeva Systems - Spending Patterns.............................................................. 93

Table 25: Veeva Systems - Spending Patterns over a Longer Period ............................. 94

Table 26: Ellie Mae - Performance Summary........................................................... 96

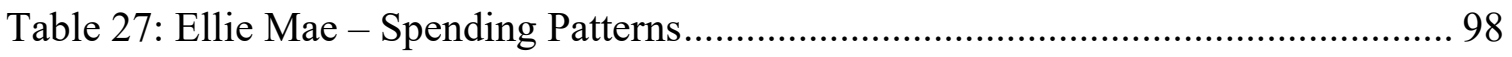


Table 28: Ellie Mae - Spending Patterns over a Longer Period..................................... 99

Table 29: Covisint - Performance Summary ......................................................... 101

Table 30: Covisint - Spending Patterns .................................................................... 103

Table 31: Covisint - Spending Patterns over a Longer Period ...................................... 104

Table 32: BroadVision - Performance Summary ........................................................ 106

Table 33: BroadVision - Spending Patterns .................................................................. 107

Table 34: BroadVision - Spending Patterns over a Longer Period .............................. 108

Table 35: Salesforce - Performance Summary .......................................................... 109

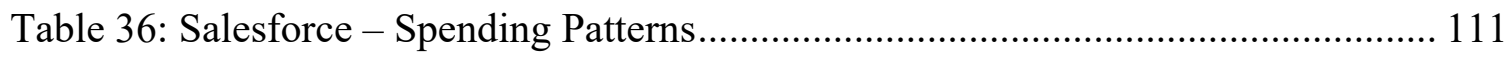

Table 37: Salesforce - Spending Patterns over a Longer Period................................... 112

Table 38: Box - Performance Summary ................................................................. 115

Table 39: Box - Spending Patterns.............................................................................. 116

Table 40: Box - Spending Patterns over a Longer Period.......................................... 118

Table 41: Summary of Gaps and New Research Avenues ......................................... 135

Table 42: Moderating Effect of the Firm's Development Stage on the Relationships to

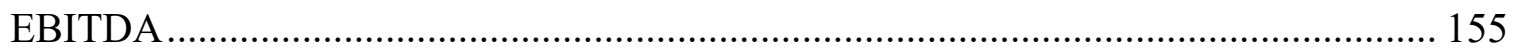

Table 43: Moderating Effect of the Firm's Development Stage on the Relationships to

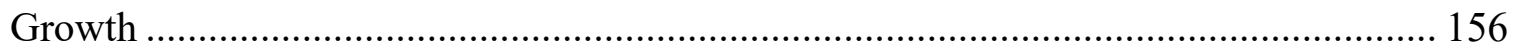

Table 44: Moderating Effect of the Firm's Specialization on the Relationships to

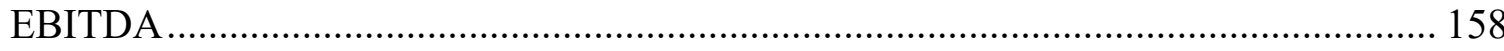

Table 45: Moderating Effect of the Firm's Specialization on the Relationships to Growth

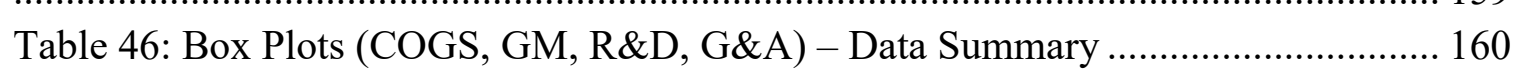

Table 47: Box Plot (EBITDA) - Data Summary ..................................................... 161

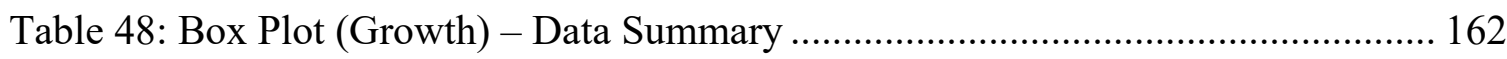

Table 49: Box Plot (Enterprise Value) - Data Summary ........................................... 163

Table 50: Extended Literature Review - Key Findings............................................. 175

Table 51: Extended Literature Review - Managerial Implications ............................... 189

Table 52: Extended Literature Review - Gaps and New Research Avenues ................. 202 


\section{LIST OF FIGURES}

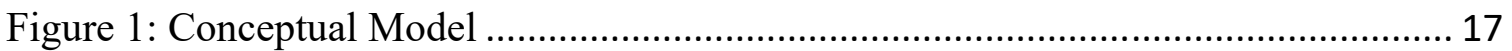

Figure 2: Role of Growth and EBITDA in Business Valuation ................................... 30

Figure 3: Role of Service Delivery Efficiency in Firm Performance ............................. 34

Figure 4: Role of Spending in Product Development Capability (R\&D) in Firm

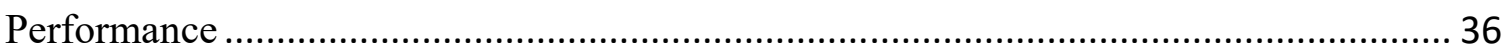

Figure 5: Role of Spending in Marketing and Distribution Capability (M\&S) in Firm

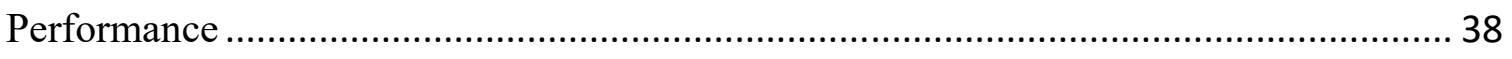

Figure 6: Role of Consistency in Spending Patterns Over Time in Firm Performance.... 41

Figure 7: The Moderating Effect of the Firm's Development Stage ............................. 43

Figure 8: The Moderating Effect of the Firm's Specialization..................................... 48

Figure 9: Veeva Systems - Spending Patterns ......................................................... 95

Figure 10: Ellie Mae - Spending Patterns (Last 10 Years) ........................................ 100

Figure 11: Covisint - Spending Patterns ................................................................ 105

Figure 12: BroadVision - Spending Patterns (Last 10 Years) ..................................... 108

Figure 13: Salesforce - Spending Patterns (Last 10 Years) ...................................... 113

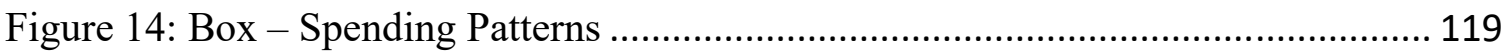

Figure 15: Box Plots (COGS, GM, R\&D, G\&A) .................................................. 160

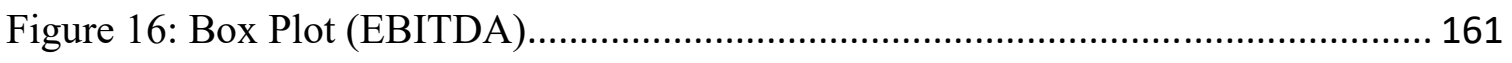

Figure 17: Box Plot (Growth) ................................................................................. 162

Figure 18: Box Plot (Enterprise Value) ................................................................. 163

Figure 19: Average COGS (as a \% of Revenue) Histogram ........................................ 164

Figure 20: Average Gross Margin (as a \% of Revenue) Histogram .............................. 164

Figure 21: Average R\&D Spending (as a \% of Revenue) Histogram ........................... 165

Figure 22: Average M\&S Spending (as a \% of Revenue) Histogram ........................... 165

Figure 23: Average G\&A Spending (as a \% of Revenue) Histogram ........................... 166

Figure 24: Average EBITDA (as a \% of Revenue) Histogram ................................... 166

Figure 25: Average Growth Histogram .................................................................. 167

Figure 26: Average Enterprise Value (Revenue Multiple) Histogram ......................... 167 


\section{CHAPTER 1}

\section{INTRODUCTION}

The Software-as-a-Service (SaaS) business model represents a radical change in the way software firms are operating, transforming the way firms produce, deliver, and distribute software. SaaS created a significant market opportunity for new entrants who have disrupted the industry. This emerging technology market has attracted significant investments in the industry and SaaS has grown rapidly to become one of the hottest technology markets in terms of firm valuations and venture capital investments today. In this environment, business valuations are primarily driven by revenue multiples. It is not uncommon for SaaS firms to be valued at five times revenue or more while firms are not profitable and haven't yet proven their path to long-term profitability.

As a result, managers of SaaS firms (Owners, CEOs, CFOs) are struggling to find the right balance between growth and profitability and answer questions such as: What is the role of profitability in firm performance in the SaaS industry? As business valuations are primarily driven by revenue multiples, why not focus on revenue growth and ignore profitability? If so, to what extent? How much should we invest in R\&D and marketing and sales? Is there an optimum resource allocation approach to optimize long term firm performance? Everyone has a different opinion on these questions among executives of the firm and the Board of directors, often turning to the $\mathrm{CFO}$ for data and answers.

This problem of practice, combined with the relative dearth of literature on resource allocation optimization strategies in an emerging technology market such as SaaS, triggered the initial motivation for the topic of this dissertation. 
This dissertation comprises two essays:

- Essay One is a quantitative study on the effects of spending in key firm capabilities (e.g., service delivery, R\&D, and marketing and sales) on the performance of SaaS firms in today's cloud-computing environment by drawing upon the resource-based view (RBV) of the firm. The study is based on a sample of 128 publicly-traded SaaS firms and publicly-available data collected from financial databases, corporate investor relations materials, and industry research.

- Essay Two provides additional insights from the literature and from practice on resource allocation optimization in an emerging technology market such as SaaS. The study is based on an extended literature review, interviews of practitioners, and mini case studies. It concludes with a detailed research agenda for future research.

By analyzing the resource allocation (i.e., spending) among these key capabilities and its effect on firm performance, this research seeks to improve our understanding of the effects of these key capabilities by examining their contribution to the firm's financial performance. In this dissertation, the firm's financial performance is measured by the following variables: the firm's revenue growth, its earnings (before interest, tax, depreciation and amortization), and its enterprise value.

From a practitioner's standpoint, the research provides useful insights to improve resource allocation decision making and firm performance in an emerging technology industry such as the SaaS industry. 


\section{CHAPTER 2}

\section{ESSAY ONE: THE CONTRIBUTIONS OF CAPABILITIES TO FIRM PERFORMANCE IN THE CLOUD COMPUTING ENVIRONMENT}

\section{Motivation for Research}

The software industry is going through significant changes with the emergence of new technologies such as cloud computing, social media, and big data analytics. One of the major drivers of the current transformation of the industry is the rapid growth ${ }^{1}$ of Softwareas a-Service (SaaS), also referred to as cloud-based software, a relatively new Internetbased business model that has disrupted the industry and caused traditional software vendors to incorporate this new way of producing, selling, and delivering software in their business strategies (Trusculescu et al., 2015).

SaaS can generally be defined as a cloud computing service in which IT resources, including computing power, data storage, software applications, and technical infrastructure, are delivered to users through a network (Ma and Kauffman, 2014). In other words, instead of purchasing a perpetual license to use the software along with an annual maintenance fee for support and upgrades, clients pay a fixed subscription fee that can be

\footnotetext{
${ }^{1}$ By 2019, cloud applications subscription revenues could make up 35\% of the total addressable market opportunity (Pang, 2015). The SaaS market is growing faster than the traditional software market and demand for SaaS is expected to continue to accelerate over the next three years (IDC, 2014). Recent research from Gartner (2015) indicates that the majority of spending in enterprise application software is going towards modernizing, functionally expanding or substituting long-standing business and office applications with cloud-based software-as-a-service.
} 
monthly, quarterly, or annual and that includes not only the use of the software but also hosting (computer power and data storage) and other services (upgrades, support, etc.). The concept originated in the late 1990s, under the broader category of ASP (application service provider) solutions. However, the ASP model was initially more of an outsourcing-type service model as opposed to a pure, native software delivery model. The fundamental difference between ASP and SaaS is SaaS's multitenant software architecture. In a pure SaaS model, all client firms access the same instance of the application. In addition, SaaS applications are new applications designed for the SaaS environment and leveraging the latest Web technologies (versus legacy client-server applications migrated to a hosted environment for access via the Internet).

The SaaS model represents a radical change in the way software firms operate (Boillat and Legner, 2013). The changes affect the way firms produce, the way they deliver, and the way they distribute software (Appendix A).

However, as many new SaaS firms have emerged over the past 10-15 years and as traditional software firms have incorporated the new model as well (organically or via acquisition), there are still a lot of questions about their profitability. SaaS firms have to invest heavily in capabilities and processes to guarantee service quality (Fan et al., 2009). Traditional software firms have been historically more profitable than SaaS firms (McKinsey, 2007). There are also significant differences in profitability among SaaS firms.

Extensive research has been published on the SaaS model. However, existing research has been primarily focused on the adoption of subscription-based cloud services (or SaaS) and their benefits for user organizations. Research on the impact of SaaS on software vendors 
is more limited, however, and concentrated on the competitive dynamics among SaaS vendors (Ma and Kauffman, 2014) or the comparative analysis of business models at conceptual level (Boillat and Legner, 2013). Ge and Huang (2014), who compared economies of scale between SaaS and traditional software models, found differences in labor contributions between the two models and suggested that future research to further understand the productivity contribution of the different types of employees (marketing, R\&D, etc.) would be of interest. A gap exists in the literature in the understanding of the financial implications of the SaaS model for software companies, in particular the effect of SaaS capabilities on firm performance. Which key capabilities are driving the performance of software (SaaS) firms in today's cloud-based software business environment?

The purpose of this research is to fill this gap and increase our understanding of the contribution of key capabilities (e.g., service delivery, $R \& D$, marketing and sales) to firm performance in a rapidly-growing technology industry (SaaS). By analyzing the resource allocation (i.e., spending) among key capabilities and its effects on firm performance, this research seeks to improve our understanding of the productivity value of these key capabilities (i.e., their contribution to financial performance).

The research focuses on the effects of capabilities on firm performance in the cloud-based software environment. The audience of this research consists of researchers from the disciplines of strategic management, information systems, and finance and practitioners looking for insights to optimize SaaS firm performance.

Using the resource-based view (RBV) of the firm approach, this research aims to analyze and find the optimal level of spending in key capabilities (e.g., service delivery, R\&D, 
marketing and sales) which will improve firm performance in the SaaS industry. The unit of analysis is the firm in the rapidly growing SaaS industry.

The scope of this study is limited to publicly traded SaaS companies in the enterprise application software market. Ultimately, with the collaboration of private equity and growth equity firms interested in the topic, the research could be extended to privately held companies. In addition, other SaaS markets or market segments could be considered for further research (e.g., the Financial Technology "FinTech" market segment).

\section{Literature Review}

\section{General Literature Review}

Existing literature on the effects of capabilities on competitive advantage and firm performance provides a useful frame of reference to analyze these effects in the context of an emerging industry such as the cloud-based software industry.

For example, Chen et al. (2010) analyzed the competitive moves of high performing organizations and their competitors, specifically the actions they take in R\&D or marketing or other areas to advance their competitive position. According to their research, high performers engage more frequent R\&D moves than their competitors to keep their product ahead of the competition with a primary goal to expand into new markets. However, high performers which already have reached market dominance in their established market are also concerned about maintaining their status quo. Thus, they are more conservative in their established market and, as a result, they are exposed to risks of disruption from their competitors. 
The software industry exemplifies these phenomena. Indeed, in the software industry, two types of rivals can be distinguished today:

- Traditional software vendors: the software market is currently dominated by large vendors such as SAP, Oracle, and Microsoft (now offering both traditional software and cloud-based software in response to recent market changes)

- Pure-play SaaS vendors (the disruptors) such as Salesforce, NetSuite (acquired by Oracle in 2016), Workday, and Marketo (acquired by Vista Equity Partners in 2016); all cloud-based software vendors which have led the rapid growth of the SaaS segment of the software industry over the recent years.

The current rivalry among these software vendors illustrates the competitive dynamics mentioned above. Transitioning from client server software architectures to cloud-based software architectures, SAP, Oracle, and Microsoft have been slow to respond to market changes due to issues such as a major shift in capabilities required to succeed in the new business model and cannibalization of revenues in their traditional software business. In the meantime, the pure-play SaaS vendors (the disruptors) have been more aggressive, engaging more competitive moves in their established market (leading innovation and promoting cloud-based software solutions) to disrupt their rivals.

Large, traditional software vendors are also experiencing challenges in strategic change management and core rigidities as analyzed in the literature by authors such as LeonardBarton (1992), Rosenbloom (2000), and Hamilton et al. (2014). For example, LeonardBarton (1992) analyzed the tension between innovation and status quo and conducted a study of twenty projects in five companies (Ford, Hewlett-Packard, and others) to analyze 
the effects of core capabilities and core rigidities on change management practices, referring to the way core capabilities inhibit innovation as a paradox of core capabilities. In this study, one of the five studied companies indicated using benchmarking against bestin-class capabilities to challenge current knowledge and model alternative new capabilities.

Indeed, as capabilities affect firm performance (Barney, 1991; Barney et al., 2001; Lee et al., 2001) and change is a constant (Helfat and Winter, 2011), keeping up with best-in-class capabilities is essential for firms to maintain and sustain a competitive advantage. As business models are shifting from the traditional software business model to the SaaS model, software companies must reassess and align their capabilities to optimize their performance in the current competitive environment.

Creating or adapting to new dynamic capabilities generally requires significant investments and business transformations, which might involve phases of organizational struggles with core rigidities, crisis, and regained momentum such as the waves of revolutionary technology changes experienced by NCR from 1938 to 1978 (i.e., transitions from mechanical technology to electronics and then to computing) in Rosenbloom's NCR case study (Rosenbloom, 2000). It also requires keeping an eye on the financial metrics of the business to remain competitive. In the NCR example, in the mid-1960s, the company's delay in fully converting to electronics and its business decision to continue to manufacture all the components of its products (while competitors had fully converted to electronics and outsourced all their components) caused the company to lose its competitiveness, incurring costs that were significantly higher than competitors. The costs of its components were double the prices charged by subcontractors. In addition, at the time, NCR was still investing in its old technologies. 
The phenomenon of over-investment in core capabilities was analyzed by Hamilton et al. in a recent study (2014). The study showed that the relationship between capabilities and performance is not linear but an inverted U-shaped relationship (curvilinear relationship). In other words, an increase in firm core capabilities (capacity growth) initially improves firm performance but subsequently performance deteriorates when core capabilities have reached an over-investment stage. This finding is particularly relevant to the software industry as companies might find themselves over-investing in core capabilities in this fastpaced changing environment, failing to recognize that the market has shifted. Instead, companies can avoid over-investing in core capabilities by staying on top of market trends and the competition, and by aligning their spending and investments with best-in-class resource allocation strategies.

As Barney et al. put it in their research paper on the resource-based view of the firm in 2001 (Barney et al., 2001): "the value of a particular set of capabilities must be evaluated in the market context within which a firm is operating. If that market context changes radically, what were valuable capabilities may no longer be valuable".

Another dimension of over-investment is timing of the spending relative to company size and stage of growth. The software industry learned important lessons from the dotcom burst in the early 2000s. In the 1990s, e-commerce and e-business technologies emerged, and many dotcom companies were formed to take advantage of the massive market opportunity, raising capital at an exponential rate, achieving rapid growth in the space, and creating an investment bubble in the industry. Literature that analyzed the dotcom failures identified the spending spree of dotcom organizations (i.e., spending without any consideration of timing of investments nor financial discipline) as one of the causes. In 
their research paper, Razi et al. (2004) refer to this cause of failure as the "free-spending pattern" of many dotcoms to support high growth at all cost, overspending in marketing and IT to grow quickly. The paper cites the example of Furniture.com, which despite significant losses in 1999 (\$46 million, for revenues of $\$ 10.9$ million), was spending a disproportionate amount of money (\$33.9 million) on sales and marketing, which was three times the cost of product development, general and administrative expenses combined. The company's aggressive marketing effort helped triple its sales revenue, but also put the company out of business as the company quickly ran out of cash and had to file for bankruptcy in late 2000. The paper mentions other business failure examples such as Pets.com, Boo.com and Drkoop.com.

\section{Literature Specific to the Software Industry}

Extensive research has been published on cloud-based technologies and the SaaS model. However, existing research has been primarily focusing on the adoption of SaaS and its benefits for user organizations. An illustration of this research stream is a recent paper from David Rader (2012) on the strategic benefits of cloud computing. The paper summarizes the benefits of cloud computing (compared to on-premises computing) in five points: easy end-user startup; access anywhere, anytime; rapid scalability; pay only what you use, and plug-ins (community enabling quick access to additional capabilities via third-party applications and tools). As the paper highlights, cloud computing offers flexibility to organizations and scalability at a lower cost, enabling businesses to grow with fewer resources than their larger rivals, which generally rely on more rigid capabilities. 
Research on the impact of SaaS on software companies themselves is more limited and concentrated on the competitive dynamics among SaaS vendors. Ma and Kauffman (2014) analyzed pricing and service quality strategies of SaaS vendors and demonstrated that vendors that can increase switching costs can charge a higher price over time and achieve higher profits. Vendors can gain exclusive lock-in power by differentiating their service quality strategy and gaining knowledge of a customer's business data. However, the effect of lock-in power can also be adverse if the client organization is not achieving higher value. The authors suggested that SaaS vendors should build profitability by retaining valuable clients and implementing beneficial and non-adversarial lock-in strategies. They also suggested that SaaS vendors should enhance the efficiency of their software development capabilities so that improvements in quality can be achieved at a lower cost over time.

As financial advisory research firm Montclare indicated in its white paper (Montclare, 2014):

Delayed cash flows as well as the ability of customers to opt out of renewing their software subscription agreement puts a huge pressure on SaaS companies to provide solutions that are better, faster, and less expensive. This has encouraged a culture that is not only focused on process efficiency but also on institutional devotion to customers (Montclare, 2014, p. 7).

Boillat and Legner (2013) investigated cloud computing's implications on enterprise software vendors' business models, including how traditional software vendors such as SAP or Oracle are transitioning from on-premises software to cloud computing, and compared their strategies, capabilities, and business models with pure-play SaaS vendors, such as Salesforce and NetSuite. The study provides a conceptualization of the differences among the various configurations of software business models from traditional to pureplay SaaS and platform as a service (PaaS). PaaS refers to the additional layer of services 
via which SaaS vendors provide access to a community of third party add-ons developed by partners (i.e., ecosystem allowing third party vendors to develop and sell add-on services to the community of users of the core SaaS system).

Ge and Huang (2014) compared economies of scale between SaaS and traditional software models. They suggested that SaaS firms have smaller economies of scale than traditional software vendors, mainly because SaaS firms offer simultaneously a software application and the IT infrastructure management service (e.g., hosting) that supports their clients. In the traditional software model, the cost of replication of the software is negligible, which explains the historically high margins of traditional vendors such as SAP, Oracle, and Microsoft. They also observed a lower return on R\&D investment of SaaS firms relative to their traditional counterparts. As a result, they found that the most efficient SaaS firms were spending less in R\&D (as a \% of revenue) while the most efficient traditional counterparts were spending more. Furthermore, they observed that the most efficient SaaS firms were maintaining their advertising expenses at a consistent level. Finally, they found differences in labor contributions between the two models and suggested future research to better understand the productivity contribution of the different types of employees (marketing, R\&D, etc.) would be of interest.

\section{Literature Review Summary}

In summary, the transformation the software industry is currently undergoing with the new cloud environment exemplifies the theories and research findings of existing literature on the effects of capabilities on firm performance (Barney, 1991; Barney et al., 2001; Lee et al., 2001), rivalry (Chen et al., 2010), and core rigidities and strategic change management 
(Leonard-Barton, 1992; Rosenbloom, 2000; Helfat and Winter, 2011; Hamilton et al., 2014), as well as the causes and risks of a technology bubble (Razi et al., 2004). SaaS firms have disrupted traditional software firms, which also have to adapt. At the same time, the SaaS model is still emerging and questions about its profitability remain. A clear gap exists in the understanding of the financial implications of the SaaS model for software firms, in particular the effect of various SaaS capabilities on firm performance. Indeed, existing literature specific to the software industry has primarily focused on the adoption of SaaS from a user firm perspective. Research on the impact of SaaS on software vendors is more limited. Ge and Huang (2014) showed that SaaS firms (and therefore software firms adopting the SaaS model) have a different cost structure. The authors identified the need for a deeper understanding of productivity contributions of functions such as $R \& D$ and marketing as an opportunity for new research. My goal is to address this gap.

This research is particularly relevant at a time when the SaaS industry is still in development stage. The market is vastly dominated by traditional software vendors and most SaaS companies have yet to prove the profitability of their business models. There is a clear need to rationalize spending strategies among SaaS firms (and traditional software firms transitioning to the new business model) to improve the way they time their investments with their business growth and to optimize firm performance.

\section{Conceptual Model and Hypotheses}

Capital invested in SaaS firms is wasted if SaaS firms are not efficient in directing these financial resources toward building unique capabilities that will lead to a sustainable 
competitive advantage (cost or differentiation) and superior firm performance. This requires firms to establish a strong financial discipline and make financial metrics a key part of their business culture. Consequences of poor management of financial resources include lack of profitability, lower business valuations, funding of losses with additional capital that is expensive and dilutes founders and early investors, and ultimately business failures as firms run out of cash and funding sources.

This research aims to address this business problem by offering insights into the factors that lead to higher performance in the SaaS industry. As indicated earlier, although the focus of this study is on the SaaS industry, the approach and findings are potentially relevant to firms in other emerging technology industries.

As the SaaS industry is still in development stage and many of SaaS firms are not profitable yet, three factors can be used to measure firm performance today:

- $\quad$ The firm valuation: the enterprise's value.

- $\quad$ Revenue growth: the firm's year-over-year (YOY) growth rate.

- Efficiency: the firm's efficiency, which can be measured by its EBITDA (earnings before interest, tax, depreciation and amortization). EBITDA is a widely accepted measure of firm performance today (Brockman and Russell, 2012; Gray and Vogel, 2012).

In fact, business valuation is influenced by revenue growth and efficiency, and both revenue growth and efficiency are influenced by the resource allocation of the firm: i.e., the allocation of spending among key capabilities (primarily service delivery, R\&D and product development, marketing and sales) relative to pricing (revenue). 
The following variables and measures are proposed (Table 1).

Table 1: Variables and Measures

\begin{tabular}{|c|c|c|c|}
\hline $\begin{array}{c}\text { Variable } \\
\text { Type }\end{array}$ & Variable & Measure & Relationships \\
\hline $\begin{array}{l}\text { Independent } \\
\text { variable }\end{array}$ & R\&D spending & $\begin{array}{l}\text { R\&D as a \% } \\
\text { of revenue } \\
\text { (R\&D } \\
\text { intensity) }\end{array}$ & $\begin{array}{l}\text { Beyond a certain level of R\&D intensity, R\&D } \\
\text { spending has diminishing returns on firm } \\
\text { performance: revenue growth and EBITDA, which } \\
\text { both influence business valuation. }\end{array}$ \\
\hline $\begin{array}{l}\text { Independent } \\
\text { variable }\end{array}$ & $\begin{array}{l}\text { Marketing \& } \\
\text { Sales (M\&S) } \\
\text { spending }\end{array}$ & $\begin{array}{l}\text { M\&S as a \% } \\
\text { of revenue } \\
\text { (M\&S } \\
\text { intensity) }\end{array}$ & $\begin{array}{l}\text { Beyond a certain level of M\&S intensity, M\&S } \\
\text { spending has diminishing returns on firm } \\
\text { performance: revenue growth and EBITDA, which } \\
\text { both influence business valuation. }\end{array}$ \\
\hline $\begin{array}{l}\text { Independent } \\
\text { variable }\end{array}$ & $\begin{array}{l}\text { Gross Margin } \\
\text { (GM), which } \\
\text { reflects the firm's } \\
\text { efficiency in Cost } \\
\text { of Goods Sold } \\
\text { (COGS) spending } \\
\text { (i.e., service } \\
\text { delivery costs) } \\
\text { relative to pricing } \\
\text { (Revenue) }\end{array}$ & $\begin{array}{l}\mathrm{GM} \text { as a } \% \\
\text { of revenue }\end{array}$ & $\begin{array}{l}\text { GM \% of revenue corresponds to 1-COGS \% of } \\
\text { revenue (COGS intensity). GM has a positive } \\
\text { relationship on firm performance, which leads to } \\
\text { higher business valuation. In other words, the } \\
\text { higher GM as a \% of revenue, the higher firm } \\
\text { performance, and ultimately business valuation. } \\
\text { (COGS spending has a negative relationship effect } \\
\text { on firm performance, which leads to lower business } \\
\text { valuation. In other words, the higher COGS } \\
\text { intensity, the lower firm performance and business } \\
\text { valuation. }\end{array}$ \\
\hline $\begin{array}{l}\text { Independent } \\
\text { variable }\end{array}$ & $\begin{array}{l}\text { Spending in } \\
\text { General \& } \\
\text { Administrative } \\
\text { Expenses (G\&A) }\end{array}$ & $\begin{array}{l}\text { G\&A as a } \% \\
\text { of revenue } \\
\text { (G\&A } \\
\text { intensity) }\end{array}$ & $\begin{array}{l}\text { G\&A spending has a negative relationship effect on } \\
\text { firm performance, which leads to lower business } \\
\text { valuation. In other words, the higher G\&A } \\
\text { intensity, the lower firm performance and business } \\
\text { valuation. }\end{array}$ \\
\hline $\begin{array}{l}\text { Dependent } \\
\text { variable }^{2}\end{array}$ & Revenue growth & $\begin{array}{l}\text { Year-over- } \\
\text { Year (YOY) } \\
\text { growth rate }\end{array}$ & $\begin{array}{l}\text { Revenue growth has a positive relationship effect } \\
\text { on business valuation. The higher revenue growth, } \\
\text { the higher business valuation. }\end{array}$ \\
\hline $\begin{array}{l}\text { Dependent } \\
\text { variable }^{3}\end{array}$ & $\begin{array}{l}\text { Earnings Before } \\
\text { Interest, Tax, } \\
\text { Depreciation and } \\
\text { Amortization } \\
\text { (EBITDA) }\end{array}$ & $\begin{array}{l}\text { EBITDA as } \\
\text { a } \% \text { of } \\
\text { revenue }\end{array}$ & $\begin{array}{l}\text { EBITDA has a positive relationship effect on } \\
\text { business valuation. The higher EBITDA, the higher } \\
\text { business valuation. }\end{array}$ \\
\hline
\end{tabular}

${ }^{2}$ Relative to independent variables above.

${ }^{3}$ Relative to independent variables above.

${ }^{4}$ The revenue multiple (EV/Rev) measure is chosen for this research rather than the EBITDA multiple (EBITDA/Rev) because a large number of SaaS companies are not profitable yet. The EBITDA multiple measure is not applicable to firms in negative EBITDA or breakeven position. The revenue multiple is applicable to all companies. 
Table 1: Variables and Measures (Continued)

\begin{tabular}{|l|l|l|l|}
\hline $\begin{array}{l}\text { Dependent } \\
\text { variable } \\
\text { valuation }\end{array}$ & $\begin{array}{l}\text { Business } \\
\text { value (EV) } \\
\text { measured as } \\
\text { a revenue } \\
\text { multiple }\end{array}$ & $\begin{array}{l}\text { Business valuation is driven by both revenue } \\
\text { growth and EBITDA. }\end{array}$ \\
\hline $\begin{array}{l}\text { Moderating } \\
\text { variable } \\
\text { (moderator) }\end{array}$ & Firm stage & $\begin{array}{l}2 \text { stages: } \\
\text { "early stage" } \\
\text { or "at scale" } \\
\text { based on an } \\
\text { annual } \\
\text { revenue } \\
\text { threshold. }\end{array}$ & $\begin{array}{l}\text { This moderator influences the effects of R\&D and } \\
\text { M\&S on firm performance. Compared to "at scale" } \\
\text { companies, "early stage" companies spend more in } \\
\text { R\&D and M\&S (as a \% of revenue) to achieve the } \\
\text { same or lower performance. }\end{array}$ \\
\hline $\begin{array}{l}\text { Moderating } \\
\text { variable } \\
\text { (moderator) }\end{array}$ & $\begin{array}{l}\text { Cross-industry } \\
\text { vs. specialized in } \\
\text { one vertical }\end{array}$ & $\begin{array}{l}\text { Whether or } \\
\text { not the firm } \\
\text { is } \\
\text { specializing } \\
\text { on one } \\
\text { industry } \\
\text { vertical. }\end{array}$ & $\begin{array}{l}\text { This moderator influences the effect of M\&S on } \\
\text { firm performance. Compared to cross-industry } \\
\text { companies, specialized companies spend less in } \\
\text { M\&S to achieve the same or higher performance. }\end{array}$ \\
\hline
\end{tabular}

Not included are measures such as return on assets (ROA) or return on equity (ROE), in

order to keep the analysis focused on the most relevant measures. In addition, measures such as ROA or ROE are not typically used for software firms. Indeed, software firms rely primarily on intangible assets which are not accounted for in these types of measures and they tend to reinvest much of their profits to fund their growth (Suarez et al., 2013).

The proposed model is summarized hereafter (Figure 1). 


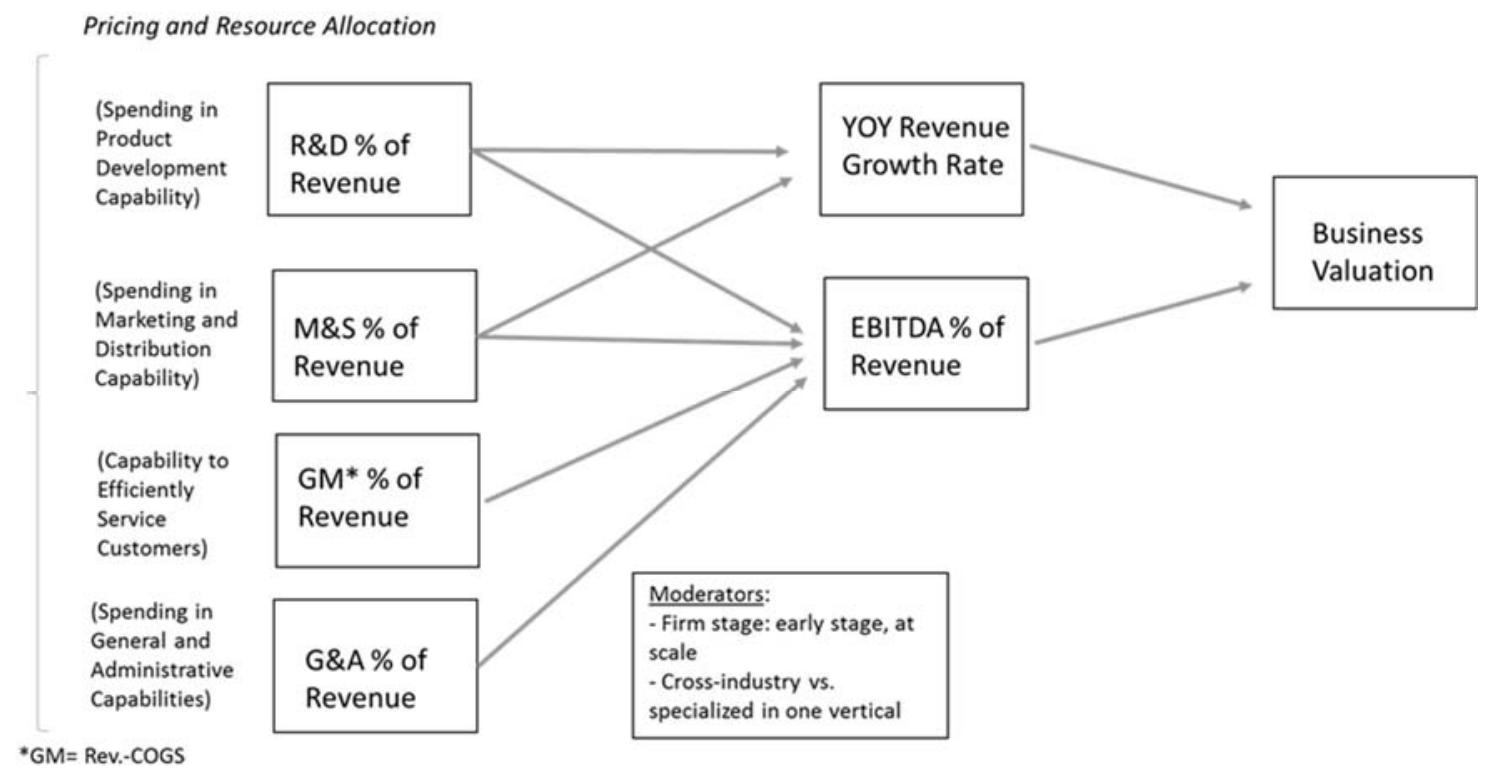

Figure 1: Conceptual Model

Note: refer to the prior table for a summary description of the relationships among variables and the effects of the moderators on these relationships.

A more detailed description of these relationships follows along with my hypotheses.

\section{The Role of Growth and EBITDA in Business Valuation}

It is commonly accepted among investment professionals that revenue growth drives business valuations in the SaaS industry. The relationship between revenue growth and business valuation has also been documented in various SaaS industry reports provided by investment and financial advisory firms (Openview, 2013; River Cities, 2014). Indeed, there is a positive relationship between revenue growth and business valuation, namely, the higher the revenue growth, the higher the business valuation. However, revenue growth is only one factor affecting business valuation. Summarizing the dynamics of SaaS 
business valuations to revenue growth would be an oversimplification. Other factors are at play.

Among them, EBITDA has received less attention in the SaaS industry among investment professionals in recent years. Indeed, many investment professionals have downplayed the role of EBITDA in determining the performance and the value of a firm in an emerging technology industry such as the SaaS industry.

Here is for example an excerpt from the River Cities (2014) study:

Interestingly, only 14 of the 39 (or 29\%) SaaS companies that went public in the past three years had positive EBITDA at the time of their IPO. For comparison, 20 out of 27 (or 74\%) companies that went public prior to 2011 had positive EBITDA. We attribute this phenomenon to the notion that public equity investors have recognized the SaaS market opportunity and accepted the belief that market leaders with fast-growing companies will be rewarded with premium valuations, even at the expense of near-term profitability (River Cities, 2014, p. 9).

However, the literature generally refers to efficiency as a key operating performance indicator in the software industry, including in the SaaS environment (e.g., Ge and Huang, 2014; Ma and Kauffman, 2014). This would indicate that EBITDA has a significant influence on firm performance, even in an emerging technology market such as the SaaS industry.

As financial advisory research firm Montclare (2014) indicated in its SaaS white paper:

Best-in-class firms are laser focused on all aspects of efficiently delivering solutions, how it is developed, sold, priced, packaged, used by customers as well as innovating in the areas of operations, support, and even billing (Montclare, 2014, p.8).

Therefore, Hypothesis \# 1 is as follows: 
Hypothesis \# 1: SaaS company valuations are influenced by both YOY growth and EBITDA, not only YOY revenue growth.

\section{The Role of Resource Allocation in Firm Performance (Growth and EBITDA)}

In this study, the effects of capabilities on firm performance are analyzed by examining the relationships between the relative spending in key capabilities and the outcomes in terms of both revenue growth and profitability, and then ultimately on the firm's enterprise value. The particular focus is on spending patterns in three key capabilities relevant to the SaaS industry:

- Service delivery: the capability to efficiently service customers (measured by the cost of goods sold [COGS] as a percentage of revenue),

- $\quad$ R\&D: the product development capability (measured by the R\&D spending as a percentage of revenue), and

- Marketing \& Sales (M\&S): the marketing, sales, and product distribution capability (measured by the $\mathrm{M} \& \mathrm{~S}$ spending as a percentage of revenue).

These capabilities are further discussed in Appendix A.

Also included are general \& administrative (G\&A) expenses to offer a complete view of the firm's operating expenses and their respective effect on firm performance.

Total Operating Expenses $=$ COGS $+R \& D+M \& S+G \& A$.

The more efficient a firm is with its COGS expenses relative to pricing (revenue), the higher its growth margin (GM). The GM simply consists of revenue minus COGS expenses. Therefore, a convenient way to measure a firm's efficiency in delivering its 
products and services and supporting and retaining its customers is to measure its gross $\operatorname{margin}(\mathrm{GM})$.

$$
G M=\text { Revenue }- \text { COGS (also called cost of service or COS) }
$$

It is commonly accepted in the industry that the GMs achieved by SaaS companies generally range from $60 \%$ to $85+\%$. A study of public SaaS companies in their "predevelopment" phase (pre-\$50 million in revenue) from growth equity firm River Cities (2014) indicates that the median gross margin of these companies is $67 \%$. According to a study of private SaaS companies from investment bank and capital markets firm Pacific Crest (2015), the median gross margin of SaaS companies surveyed is $74 \%$ (excluding companies with less than $\$ 2.5$ million in revenue). The same survey conducted a year later (Pacific Crest, 2016) indicated a similar result of $75 \%$ for the median gross margin of the SaaS companies surveyed.

It can be expected that high performers among SaaS companies achieve the highest GM $\%$. Therefore, Hypothesis \# 2 is as follows:

Hypothesis \# 2: The higher the firm's Gross Margin percentage, the higher its overall performance.

Regarding R\&D expenses, the River Cities (2014) study of public SaaS companies indicates that median "pre-development" SaaS companies spend between $17 \%$ and $60 \%$ of their revenue in $R \& D$ depending on their growth stage, with smaller firms spending more. According to the study of private SaaS companies from Pacific Crest (2015), the median R\&D spend is $24 \%$ of revenue (excluding companies with less than $\$ 2.5$ million in revenue). The same survey conducted a year later (Pacific Crest, 2016) indicated a similar 
result of $26 \%$ for the median R\&D spend among the SaaS companies surveyed. According to investment bank Siemer and Associates (Siemer, 2013), best practice R\&D spend for SaaS firms that have reached scale is around $10 \%$.

Spending as a percentage of revenue or other spending ratios are frequently used in the literature. They are commonly referred to as spending intensity or investment intensity. In this study, R\&D intensity is defined as R\&D expenses as a percentage of revenue. In addition, it is hypothesized that high performers among SaaS firms time their investments in $\mathrm{R} \& \mathrm{D}$ according to their revenue growth (i.e., adjust spending according to revenue growth) to avoid over-spending and optimize return on investment. High performers spend an optimum percentage of their revenue in $R \& D$. In other words, there are diminishing returns to firm performance beyond a certain level of $R \& D$ intensity. That certain level of spending would be the amount of spending intensity beyond which the positive effect of R\&D spending on firm performance significantly diminishes or turns negative. Therefore, Hypothesis \# 3 is as follows:

Hypothesis \# 3: The relationship between $R \& D$ intensity and firm performance is indicative of diminishing returns: there is an amount of spending intensity beyond which the positive effect of $R \& D$ spending on firm performance diminishes or turns negative.

Regarding Marketing \& Sales (M\&S) expenses, the River Cities (2014) study of public SaaS companies indicates that median "pre-development" SaaS companies spend between $45 \%$ and $100+\%$ of their revenue in M\&S depending on their growth stage, with smaller firms spending more. A study from venture capital firm Openview Venture Partners (Openview, 2013) found an average M\&S spend of approximately $40 \%$ of revenues among 
private SaaS companies in expansion phase. According to the study of private SaaS companies from Pacific Crest (2015), the median spend in M\&S is 32\% of revenues (excluding companies with less than $\$ 2.5$ million in revenue). The same survey conducted a year later (Pacific Crest, 2016) indicated a similar result of 35\% for the median M\&S spend among the SaaS companies surveyed.

As mentioned earlier, spending as a percentage of revenue is a frequently used variable in the literature, and it is commonly referred to as spending intensity or investment intensity. In this study, $M \& S$ intensity is defined as $M \& S$ expenses as a percentage of revenue. As for R\&D, it is hypothesized that high performers among SaaS firms time their investments in $\mathrm{M} \& \mathrm{~S}$ according to their revenue growth (i.e., adjust spending according to revenue growth) to avoid over-spending and optimize return on investment. High performers spend an optimum percentage of their revenue in M\&S. In other words, there are diminishing returns to firm performance beyond a certain level of M\&S spending. That certain level of spending would be the amount of spending intensity beyond which the positive effect of M\&S spending on firm performance significantly diminishes or turns negative. Therefore, Hypothesis \# 4 is proposed as follows:

Hypothesis \# 4: The relationship between M\&S intensity and firm performance is indicative of diminishing returns: there is an amount of spending intensity beyond which the positive effect of M\&S spending on firm performance diminishes or turns negative.

Finally, not only do best performers meet the benchmarks above at a given point in time, but they also exhibit consistent spending patterns over time in these four capability areas (COGS, R\&D, M\&S, G\&A). Consistency means that the firm's spending intensity in each 
category (COGS, R\&D, M\&S, G\&A) is the same year over year. This can be tested by considering the firm's financial results over the last three years and creating a new variable consisting of the average standard deviation among the four independent variables (COGS intensity, R\&D intensity, S\&M intensity, and G\&A intensity) over the three-year period.

Therefore, Hypothesis \# 5 is proposed as follows:

Hypothesis \# 5: SaaS firms that achieve the highest overall performance are the most consistent in terms of spending patterns: their spending patterns in (a) COGS, (b) R\&D, (c) M\&S, and (d) G\&A are consistent over the years. 


\section{Research Methodology / Data Collection}

A quantitative research methodology (regression analysis) approach was used for this study, with a plan to further extend the research to include additional review of latest industry research and discussions with practitioners in the field to collect their perspectives and validate my approach and findings.

\section{Data Collection}

For data collection, the study focused on publicly-traded SaaS firms, using publicly available financial information from the Edgar database (to access relevant data from the firms' SEC filings). For firms that are publicly traded outside the US, a search of relevant data was conducted from investor relations materials (i.e., annual reports) on the firms' websites to the extent that the relevant data is available in English and to the extent that information on the firm value is also available.

The following data was collected:

- $\quad$ List of SaaS companies

- For each company, annual financial metrics for the last three fiscal years:

o Revenue

o COGS expenses (service delivery cost)

o $\mathrm{GM}(=$ Revenue - COGS $)$

o R\&D spending

o M\&S spending

o G\&A spending 
o EBITDA (= Operating Income or EBIT + Depreciation and Amortization)

- $\quad$ Enterprise value of each company as of July 15, 2016

- Whether the company has a cross industry model or is specialized in one vertical.

For the list of SaaS firms, the study used the 500 largest SaaS firms as identified by Apps Run the World, an IT research firm formed by former IDC analyst, Albert Pang. The list is publicly available on the firm's website (source: Cloud Top 500 Applications Vendors. Apps Run the World. https://www.appsruntheworld.com). Out of this list (extracted as of April 27, 2016), 104 firms were publicly traded in the US and 43 firms were publicly traded in other countries. The analysis focused on these firms with a goal to create a dataset of at least 100 companies (after eliminating firms for which relevant data is not available). The list also contains information on the markets where each firm competes, including the industry if the firm is specialized in a vertical market. This information was used for the moderating variable on the industry specialization. Regarding business valuations (i.e., enterprise value of each firm), the study used the firm's enterprise value as reported via Yahoo Finance or equivalent for firms publicly traded in other countries (if their enterprise value information is not available via Yahoo Finance) as of July 15, 2016.

This data collection effort resulted in a dataset of 128 unique firms.

\section{Description of Variables and Measures}

The following variables and measures were used to test the hypotheses:

- RevM = Enterprise Value (EV) measured as the Revenue Multiple (or EV/Revenue). 
- $\mathrm{AVGEB}=\mathrm{EBITDA}$ measured as the average EBITDA $\%$ of revenue over the prior three fiscal years.

- $\quad$ YOYG also referred to as AVGYOYG = Year over year (YOY) growth measured as the average YoY revenue growth over the prior three fiscal years (i.e., average of growth from year 1 to year 2 and growth from year 2 to year 3 ).

- $\quad$ Performance Factor $(\mathrm{PF})=\mathrm{YOYG} *$ AVGEB.

- $\quad \mathrm{AVGGM}=$ Gross margin $(\mathrm{GM})$ measured as the average $\mathrm{GM} \%$ of revenue over the prior three fiscal years.

- $\quad \mathrm{AVGRD}=$ average $\mathrm{R} \& \mathrm{D} \%$ of revenue over the prior 3 fiscal years.

- $\quad \mathrm{AVGSM}=$ average $\mathrm{M} \& \mathrm{~S} \%$ of revenue over the prior 3 fiscal years.

- $\quad$ AVGGA = average G\&A \% of revenue over the prior 3 fiscal years.

- $\quad$ AVGSTD = average standard deviation among the four proposed independent variables (COGS intensity, R\&D intensity, S\&M intensity, and G\&A intensity) over the past three years.

\section{Foreign Currency Conversion}

For international companies reporting their financials in a foreign currency, the conversion of financial data was made at the exchange rates as of July 15, 2016, corresponding to the date of the valuation of the firms. All three years of financial data were converted at that rate. This is to control for foreign currency fluctuations, as the US dollar has generally appreciated over the prior three years against most currencies.

For example, the Euro and the British Pound depreciated significantly against the US dollar during the period. By converting the financials at the historical rates, the growth rates of 
the foreign firms would have been lower due to the conversion. Converting all historical data at the same rate (rate of as July 15, 2016 - date of the valuation analysis) provides a snapshot view of firm performance without the effect of currency depreciation over time and thus allows to preserve the actual growth rate of these firms on apple-to-apple comparison basis with US firms.

\section{The Moderators}

Two primary moderating variables were identified: the firm's development stage and the firm's cross-industry orientation vs. industry specialization.

\section{The Firm's Development Stage}

The development stage of the firm is likely to influence the relationship between the resource allocation and the firm performance. In the early stage of their development, firms generally invest significantly in their infrastructure and their sales cycles (from sales prospecting to sales closing) may be longer as the firms are creating momentum (i.e., creating brand recognition, customer references) from the ground up. In other words, at early stage, firms might have to invest more (as a $\%$ of their revenue) for firm performance results that will take longer to materialize compared to more established firms.

Therefore, two types of firms are distinguished in the analysis:

- $\quad$ Early stage firms

- Firms that are at scale.

To determine if a firm is early stage or at scale, the study used the criteria of firm size, measured in terms of annual revenue. For example, firms that have reached at least $\$ 50$ 
million in annual revenue would be considered at scale. Firms that have not reached that revenue threshold would be considered early stage. Providing a more precise definition (i.e., measure) of a firm at scale is part of the objectives of the analysis.

\section{The Firm's Cross-industry Orientation vs. Industry Specialization}

As indicated earlier (in the Introduction), the scope of this research paper is limited to publicly traded SaaS companies in the enterprise application software market. The enterprise software market is defined as the business-to-business (B2B) market (e.g., enterprise resource planning, customer relationship management, business intelligence, etc.) as opposed to the business-to-consumer (B2C) market (e.g., personal finance, entertainment and video game software). Among firms competing in the enterprise application software market, another factor that influences the relationship between resource allocation and firm performance is whether the firm is addressing all industries (cross-industry orientation) or whether the firm is specialized in a particular vertical (e.g., healthcare, higher education, public sector, mortgage industry). For example, firms that are specialized in a particular industry might be able to achieve higher growth rates with less spending in marketing and sales (as a \% of revenue) relative to firms addressing all industries. This is due to the fact that specialized vendors have the advantage to address a much smaller market, which can be prospected using a smaller and more targeted sales channel. Spending patterns in R\&D and their effect on firm performance might also be different in the case of firms focused on a vertical market compared to firms that are addressing all industries (cross-industry oriented). Providing a better understanding of the influence of this moderating variable on the relationship between resource allocation and firm performance is part of the objectives of the analysis. 


\section{Data Analysis}

Regression analysis was used to test the hypotheses. The findings of the study are summarized hereafter.

Table 2: Hypothesis Testing Summary

\begin{tabular}{|l|l|}
\hline \multicolumn{1}{|c|}{ Hypotheses } & \multicolumn{1}{|c|}{ Findings } \\
\hline $\begin{array}{l}\text { H1: SaaS company valuations are influenced by both YOY growth and EBITDA, not } \\
\text { only YOY revenue growth. }\end{array}$ & Supported \\
\hline $\begin{array}{l}\text { H2: The higher the firm's Gross Margin percentage, the higher its overall } \\
\text { performance. }\end{array}$ & Not Supported \\
\hline $\begin{array}{l}\text { H3: The relationship between R\&D intensity and firm performance is indicative of } \\
\text { diminishing returns: there is an amount of spending intensity beyond which the } \\
\text { positive effect of R\&D spending on firm performance diminishes or turns negative. }\end{array}$ & Supported \\
\hline $\begin{array}{l}\text { H4: The relationship between M\&S intensity and firm performance is indicative of } \\
\text { diminishing returns: there is an amount of spending intensity beyond which the } \\
\text { positive effect of M\&S spending on firm performance diminishes or turns negative. }\end{array}$ & Supported \\
\hline $\begin{array}{l}\text { H5: SaaS firms that achieve the highest overall performance are the most consistent } \\
\text { in terms of spending patterns: their spending patterns in COGS, R\&D, M\&S, and } \\
\text { G\&A are consistent over the years. }\end{array}$ & Supported \\
\hline
\end{tabular}

\section{The Role of Growth and EBITDA in Business Valuations (H1)}

Even in an emerging industry such as the SaaS industry, business valuations are influenced by both revenue growth and EBITDA, not just revenue growth. 
Submodel 1:

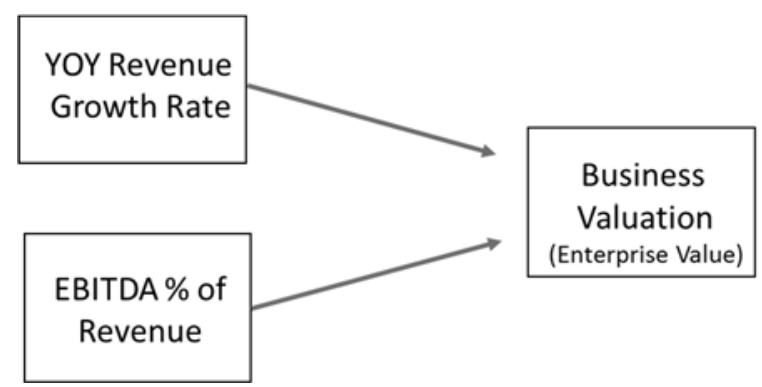

Figure 2: Role of Growth and EBITDA in Business Valuation

This is demonstrated by the following regression analysis (Table 3).

Table 3: Results of the Influence of Growth and EBITDA on Business Valuation

\begin{tabular}{|l|cccc|}
\cline { 2 - 5 } \multicolumn{1}{c|}{} & \multicolumn{4}{c|}{ Dependent Variable: RevM } \\
\hline \multirow{3}{*}{ Predictor } & B & SE B & t & p-value \\
\cline { 2 - 5 } Intercept & 2.41 & 0.29 & 8.19 & 0.00 \\
AVGEB & 4.55 & 0.67 & 6.82 & 0.00 \\
AVGYOYG & 9.83 & 1.01 & 9.78 & 0.00 \\
\hline R $^{2}$ & \multicolumn{5}{c}{0.44} \\
F & \multicolumn{5}{c}{0.21} \\
p-value & \multicolumn{5}{c}{0.00} \\
\hline
\end{tabular}

The regression equation is:

$Y=a+b X 1+c X 2$

$\operatorname{RevM}=2.41+4.55($ AVGEB $)+9.83(Y O Y G)$ 
The correlations among the variables (Table 4) indicate that growth and profitability (EBITDA) are correlated to the enterprise value by coefficients of respectively 0.48 and 0.11 .

Table 4: Correlations of Growth and EBITDA to Business Valuation

\begin{tabular}{|l|ccc|}
\cline { 2 - 4 } \multicolumn{1}{c|}{} & AVGEB & AVGYOYG & RevM \\
\hline AVGEB & 1 & & \\
\hline AVGYOYG & $(0.56)$ & 1 & 1 \\
\hline RevM & 0.11 & 0.48 & \\
\hline
\end{tabular}

The regression equation is statistically significant at confidence level of $99 \%$ (p value $<0.01)$.

The model's R square score is 0.44 (or $44 \%$ ), which represents the percentage of the variation in the dependent variable (here, the revenue multiple) that is explained by the model. $(\mathrm{R}$-square $=$ explained variation $/$ total variation $)$.

Using this regression equation and the data from the sample, it can be demonstrated that SaaS firms that are both growing and profitable achieve a premium in terms of business valuation. As shown in Table 5, at a comparable annual growth of $30 \%$ in the sample, a profitable SaaS firm achieved on average a business valuation 32\% higher than a nonprofitable SaaS firm. 
Table 5: Premium in Business Valuation Achieved by Profitable Vs. Nonprofitable Firms at a Comparable 30\% Annual Growth

\begin{tabular}{|c|c|}
\hline Examples & Business Valuation Outcomes \\
\hline 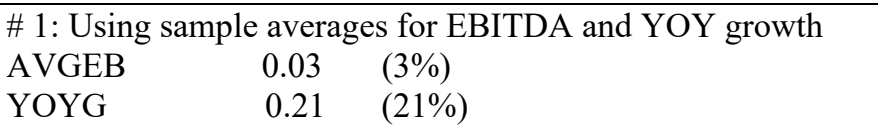 & $\begin{array}{l}\text { RevM }=2.41+4.55(0.03)+9.83 \\
(0.21) \\
\underline{\operatorname{RevM}=4.59}\end{array}$ \\
\hline $\begin{array}{lcc}\text { \# 2: Using top } & 25 \% \text { performers' averages } \\
\text { AVGEB } & 0.23 & (23 \%) \\
\text { YOYG } & 0.30 & (30 \%)\end{array}$ & $\begin{array}{l}\text { RevM }=2.41+4.55(0.23)+9.83 \\
(0.30) \\
\underline{\operatorname{RevM}}=6.38\end{array}$ \\
\hline $\begin{array}{l}\text { \# 3: Using bottom } 25 \% \text { performers' averages } \\
\text { AVGEB }(0.11) \\
\begin{array}{lll}\text { YOYG } & (-11 \%) & \\
\text { YOY } & 0.07 & (7 \%)\end{array}\end{array}$ & $\begin{array}{l}\text { RevM }=2.41+4.55(-0.11)+9.83 \\
(0.07) \\
\underline{\text { RevM }=2.63}\end{array}$ \\
\hline $\begin{array}{l}\text { \# 4: Using top 25\% performers' average for YOY growth and } \\
\text { bottom 25\% performers' average in EBITDA } \\
\begin{array}{lcl}\text { AVGEB } & (0.11) & (-11 \%) \\
\text { YOYG } & 0.30 & (30 \%)\end{array}\end{array}$ & $\begin{array}{l}\text { RevM }=2.41+4.55(-0.11)+9.83 \\
(0.30) \\
\underline{\operatorname{RevM}=4.84}\end{array}$ \\
\hline \multicolumn{2}{|c|}{$\begin{array}{l}\text { Premium achieved by high performers in both YoY growth and EBITDA instead of only YOY growth } \\
\text { (Example \# } 4 \text { compared to Example \# 2) } \\
\text { RevM diff. } \quad 1.54 \quad(=6.38-4.84) \\
\begin{array}{l}\text { Premium } \quad 32 \% \\
\text { At same growth rate }(30 \%) \text {, high performers in EBITDA achieve a 32\% premium in enterprise value. }\end{array} \\
\text { At }\end{array}$} \\
\hline
\end{tabular}

Therefore, based on these results, it was concluded that Hypothesis \#1 (H1) was supported.

\section{The Role of Gross Margin (Service Delivery Efficiency) in Firm Performance (H2)}

The correlations between gross margin (revenue minus service delivery cost) and the three dependent variables of the model (EBITDA, YOY revenue growth, and business valuation) were first examined.

No relationship between gross margin (GM) and YOY growth was found. The correlation between these 2 variables is -0.045 or nearly 0 . 
There were positive relationships between GM and EBITDA (correlation coef.: 0.24) and between GM and business valuation (correlation coef.: 0.17 ).

Two regressions were run, one between GM and EBITDA and one between GM and business valuation. The regression equations were statistically significant at respectively $99 \%$ confidence level $(\mathrm{p}$ value $=0.01)$ and $90 \%$ confidence level ( $\mathrm{p}$ value $<0.1)$. However, the R square scores were low in both cases $(0.06$ and 0.03$)$.

The analysis was then extended to explore whether the reason for this lack of support was due to the moderating variables. Indeed, it would appear to make sense that the disparity in GM might be due to the firm's development stage, as early stage firms have not achieved economies of scale yet. The disparity in GM could also have been explained by the differences in GM between generalist firms and firms specialized in one vertical. Therefore, the same two regressions above were computed using the moderating variables: firm development stage and firm specialization. First, to control for firm development stage, I ran the regressions for companies at scale only (companies with revenues of $\$ 100$ million or more - see The Moderating Effect of the Firm's Development Stage section later in this chapter for the definition of a firm at scale). Both regressions had low $\mathrm{R}$ square scores $(0.00$ and 0.03$)$ and were not statistically significant. I repeated the exercise with generalist firms only (excluding vertical firms), and again, I found regression results with low R square scores (0.09 and 0.05). After removing an outlier, one of the regressions was not statistically significant and the R square score was further reduced to 0.01 instead of 0.09 . 
I reached a similar conclusion when examining the dual effect of GM on YOY growth and EBITDA. As discussed earlier in this chapter, firm performance is the result of both YOY growth and EBITDA. To further validate my findings regarding the effect of GM on firm performance, I created a variable called Performance Factor (PF), consisting of YOYG multiplied by EBITDA (i.e., AVGEB) as defined earlier.

Submodel 2:

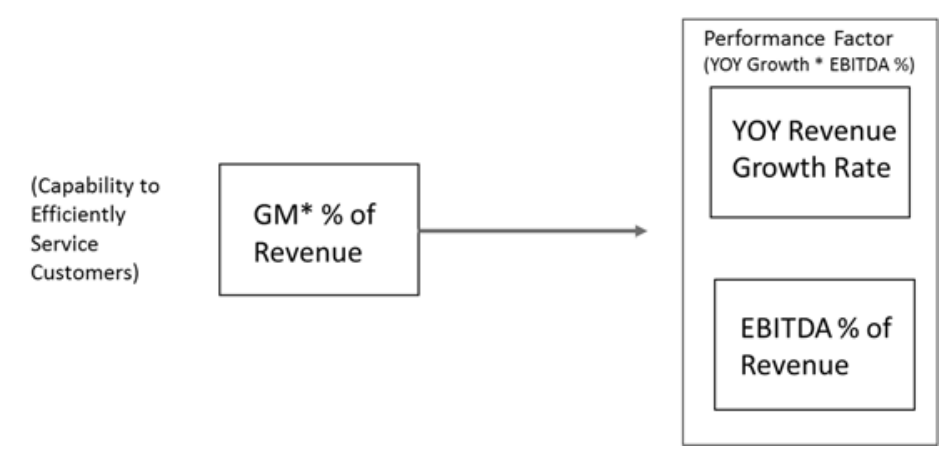

Figure 3: Role of Service Delivery Efficiency in Firm Performance

I ran the regression analysis between GM and PF. Again, the regression equation was statistically significant ( $\mathrm{p}$ value $<0.01$ ), however, the $\mathrm{R}$ square score was low $(0.07)$.

In conclusion, although there was some positive correlation between GM and firm performance in terms of EBITDA or business valuation (revenue multiple), GM explained little of the variance in firm performance (based on the small R squares and/or the fact that the regressions were not statistically significant).

For additional insights into the GM patterns among the various types of firms in the dataset, refer also to the two Moderating Effect sections and the Robustness Checks section later in this Chapter. 


\section{The Role of R\&D in Firm Performance (H3)}

My research indicates that $R \& D$ intensity ( $R \& D$ spending as a $\%$ of revenue) has a positive and a negative relationship on firm performance depending on the dependent variable considered: YOY growth or EBITDA.

I initially analyzed the relationships between R\&D spending (intensity) and each possible dependent variable individually using the same measures as defined earlier: YOY revenue growth (YOYG), EBITDA as a \% of revenue (AVGEB), and business valuation (RevM).

I found a positive relationship between R\&D spending and YOY growth and a negative relationship between R\&D spending and EBITDA: R\&D spending was positively correlated with YOY growth (correlation coef.: 0.43 ) and negatively correlated with EBITDA (correlation coef.: -0.74).

I confirmed the relationships with these two dependent variables individually by running two distinct regressions: one between R\&D spending (AVGRD) and YOY revenue growth (AVGYOYG) and one between R\&D spending (AVGRD) and EBITDA (AVGEB). In both cases, the regression equation was statistically significant at $99 \%$ confidence level ( $p$ value $<0.01$ ), with $R$ square scores of respectively 0.18 and 0.54 .

I also examined the relationship between R\&D spending and business valuation. I found no direct relationship between these two variables: the correlation coefficient was 0.03 and the regression equation was not statistically significant.

Again, as discussed earlier in this chapter, firm performance is the result of both YOY growth and EBITDA. To measure the effect of R\&D spending on firm performance, I 
created a variable called Performance Factor (PF), consisting of YOYG multiplied by EBITDA (i.e., AVGEB).

\section{Submodel 3:}
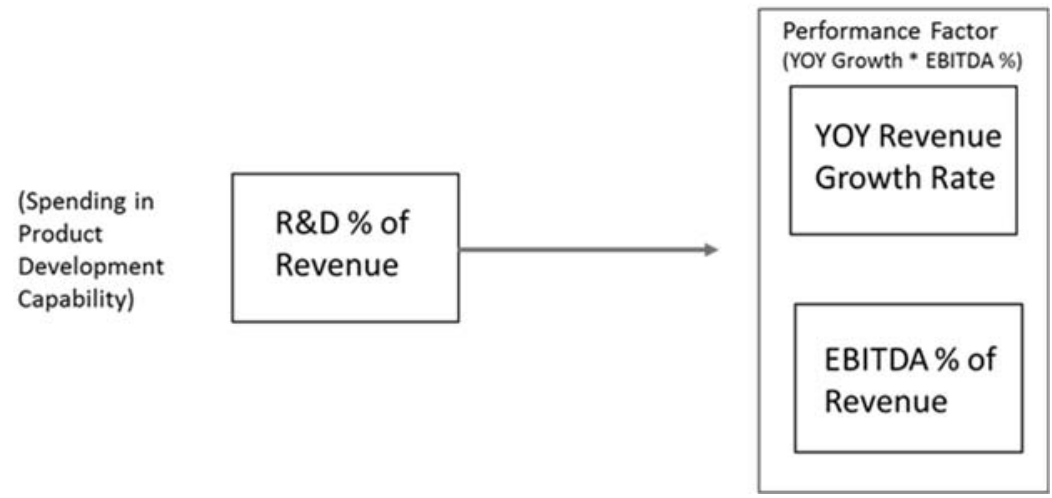

Figure 4: Role of Spending in Product Development Capability (R\&D) in Firm Performance

I found that the relationship is not linear and that it is indicative of a downward slope after a certain level of R\&D spending. I tested the non-linearity using a quadratic effect in the model. The results indicated a $\mathrm{R}$ square of 0.61 for the non-linear regression compared to a $\mathrm{R}$ square of 0.30 using a linear regression (Table 6).

Table 6: Relationship between R\&D and Performance Factor - Testing of Non-Linearity Using a Quadratic Effect in the Model

\begin{tabular}{|c|c|c|}
\cline { 2 - 3 } \multicolumn{1}{c|}{} & Linear & Non-linear (quadratic) \\
\hline Regression & $\mathrm{Y}=-2.15 \mathrm{X}+0.35$ & $\mathrm{Y}=-10.20 \mathrm{X}^{2}+3.75 \mathrm{X}-0.29$ \\
\hline R Squared & 0.30 & 0.61 \\
\hline
\end{tabular}


The optimum was computed using a quadratic function and the related Vertex formula. The result indicated that the optimum $\mathrm{R} \& \mathrm{D}$ spending is approximately $17.5 \%$ among the firms in the sample.

$$
\begin{aligned}
& Y=a X^{2}+b X+c \\
& \text { Vertex }=-b / 2 a \\
& \text { Vertex }=0.175
\end{aligned}
$$

For further validation, I excluded the double negatives (six cases with a positive performance factor resulting from the multiplication between two negative values: a negative growth and a negative EBITDA) and I removed the outliers (five cases spending more than $40 \%$ of their revenue in $\mathrm{R} \& \mathrm{D})$. The results confirmed the non-linearity and the diminishing return effects.

Additional validity tests were performed, as described in Appendix G. Based on these tests, H3 was supported.

\section{The Role of Marketing \& Sales in Firm Performance (H4)}

As it was the case for $R \& D$, the findings indicate that Marketing \& Sales $(M \& S)$ intensity (M\&S spending as a \% of revenue) has a positive and a negative relationship on firm performance depending on the dependent variable considered: YOY growth or EBITDA.

There is a positive relationship between M\&S spending (intensity) and YOY growth and a negative relationship between M\&S spending and EBITDA: M\&S spending is positively correlated with YOY growth (correlation coef.: 0.62) and a negative correlation with EBITDA (correlation coef.: -0.83). 
As it was done earlier for $\mathrm{R} \& \mathrm{D}$, the relationships with these two dependent variables (individually) were confirmed by running two distinct regressions: one between M\&S spending (AVGSM) and YOY revenue growth (AVGYOYG) and one between M\&S spending (AVGSM) and EBITDA (AVGEB). In both cases, the regression equation was statistically significant at $99 \%$ confidence level ( $\mathrm{p}$ value $<0.01$ ), with $\mathrm{R}$ square scores of respectively 0.38 and 0.69 .

Regarding the relationship between M\&S spending and business valuation, again no direct relationship between these two variables was found: the correlation coefficient was 0.01 and the regression equation was not statistically significant.

To measure the effect of M\&S spending on firm performance, the study used the Performance Factor (PF) as defined earlier (YOYG multiplied by EBITDA).

\section{Submodel 4:}

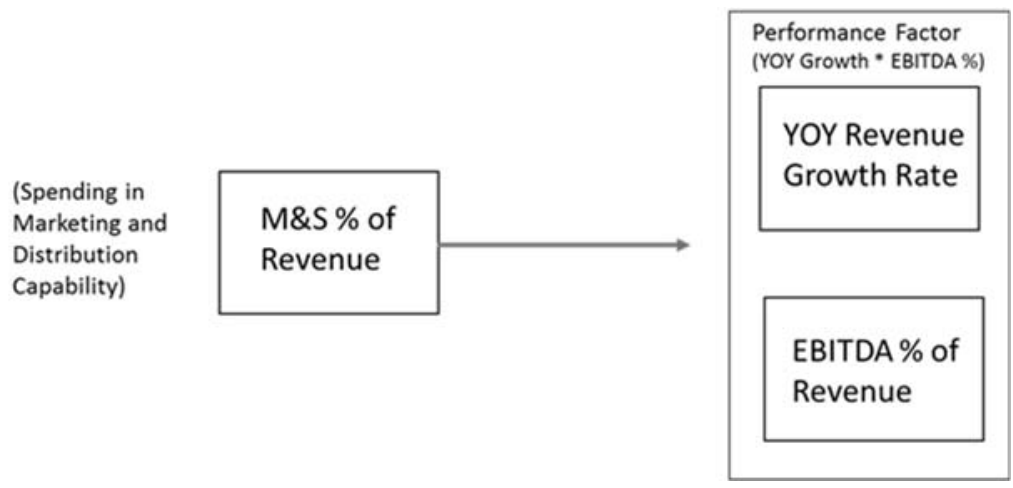

Figure 5: Role of Spending in Marketing and Distribution Capability (M\&S) in Firm Performance

As previously, it was found that the relationship was not linear and that it was indicative of a downward slope after a certain level of M\&S spending intensity. The non-linearity 
was again tested using a quadratic effect in the model. The results indicated a $\mathrm{R}$ square of 0.93 for the non-linear regression compared to a $\mathrm{R}$ square of 0.51 using a linear regression (Table 7).

Table 7: Relationship between M\&S and Performance Factor - Testing of Non-Linearity Using a Quadratic Effect in the Model

\begin{tabular}{|c|c|c|}
\cline { 2 - 3 } \multicolumn{1}{c|}{} & Linear & Non-linear (quadratic) \\
\hline Regression & $\mathrm{Y}=-1.41 \mathrm{X}+0.44$ & $\mathrm{Y}=-2.18 \mathrm{X}^{2}+1.30 \mathrm{X}-0.15$ \\
\hline R Squared & 0.51 & 0.93 \\
\hline
\end{tabular}

The optimum was also computed using a quadratic function and the related Vertex formula. The result indicated that the optimum M\&S spending is approximately $30 \%$ in the sample.

$$
\begin{aligned}
& Y=a X^{2}+b X+c \\
& \text { Vertex }=-b / 2 a \\
& \text { Vertex }=0.299
\end{aligned}
$$

The same procedure (as described in the previous section) was used to validate the existence of diminishing returns, by excluding the double negatives and removing the outliers in the dataset (two cases spending respectively $105 \%$ and $162 \%$ of their revenue in $\mathrm{M} \& \mathrm{~S})$. The results confirmed the non-linearity and the diminishing return effects.

Additional validity tests on the diminishing returns of $M \& S$ spending to firm performance are discussed in Appendix G.

Based on these results, it was concluded that $\mathrm{H} 4$ was supported. 


\section{The Role of Consistency of Spending Patterns in Firm Performance (H5)}

To measure consistency in spending patterns (as a $\%$ of revenue) over time in order to test Hypothesis \# 5, I created a variable (AVGSTD) consisting of the average standard deviation among the four independent variables during the three year-period as defined earlier (in the Description of Variables and Measures section).

The more consistent the spending patterns (i.e., same percentages of spending in each category each year), the smaller the average standard deviation. The more inconsistent the spending patterns (i.e., different percentages of spending in each category each year), the higher the average standard deviation.

The effect of the average standard deviation on EBITDA was analyzed and a strong negative relationship between these two variables was found with a correlation coefficient of -0.86 and regression statistics showing a $\mathrm{R}$ square score of 0.74 with a $\mathrm{p}$ value $<.01$.

The sample included a clear outlier in EBITDA result (one case with an average EBITDA loss of $-255 \%$ ). The analysis above was repeated without the outlier and the negative relationship was confirmed with a correlation coefficient of -0.71 and regression statistics showing a $\mathrm{R}$ square score of 0.50 with a $\mathrm{p}$ value $<.01$.

As firm performance requires both YOY growth and EBITDA, the Performance Factor (YOYG * AVGEB) was again used as a measure of firm performance. 
Submodel 5:
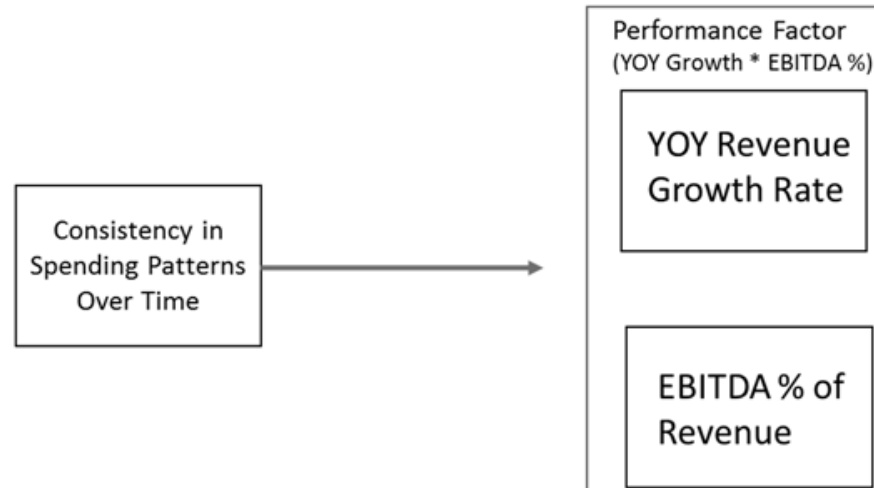

Figure 6: Role of Consistency in Spending Patterns Over Time in Firm Performance

A high, negative correlation was found between the average standard deviation (AVGSTD) and firm performance (PF) of - 0.95 . The higher the average standard deviation, the lower the performance. The strong relationship is confirmed by the regression statistics which indicate a $\mathrm{R}$ square of 0.90 with $\mathrm{p}$ value $<.01$.

Hypothesis \# 5 was retested by removing the double negatives and the outliers in the data (three cases with an average standard deviation above 10\%) and repeated the analysis. The results, although not as pronounced, confirmed the negative relationship with a correlation of -0.51 and regression statistics indicating an $\mathrm{R}$ squared value of 0.26 with $\mathrm{p}$ value $<.01$ (Table 8). 
Table 8: Influence of Consistency in Spending Patterns Over Time on Firm Performance - Regression Analysis (Without Double Negatives and Outliers)

\begin{tabular}{|c|c|c|c|c|}
\hline \multirow[b]{3}{*}{ Predictor } & \multicolumn{4}{|c|}{ Dependent Variable: PF } \\
\hline & \multicolumn{4}{|c|}{ Model } \\
\hline & B & SE B & $\mathbf{t}$ & p-value \\
\hline Intercept & 0.05 & 0.01 & 3.82 & 0.00 \\
\hline AVGSTD & -2.74 & 0.50 & -5.47 & 0.00 \\
\hline $\mathbf{R}^{2}$ & \multicolumn{4}{|c|}{0.26} \\
\hline $\mathbf{F}$ & \multicolumn{4}{|c|}{29.94} \\
\hline p-value & \multicolumn{4}{|c|}{0.00} \\
\hline
\end{tabular}

Additional validity tests were performed as described in the Appendix G.

In conclusion of these results, it was deducted that H5 was supported.

\section{The Moderating Effect of the Firm's Development Stage}

One of the moderators in the model is whether the firm is at an early stage of its development or at scale. I argued that the development stage of the firm influences the relationship between the resource allocation and the firm performance. In their early stage, firms might have to invest more (as a $\%$ of their revenue) to achieve a certain firm performance level that will take longer to materialize compared to more established firms. Consequently, early stage firms tend to be unprofitable (negative EBITDA) while at scale firms tend to be profitable (positive EBITDA).

SPSS was used to analyze the moderating variables. In all SPSS analyses, items with missing data were excluded. Based on the descriptive statistics below, the results seem to indicate that whether the firm is early stage or at scale influences the resource allocation as 
a $\%$ of revenue, with the early stage firms spending relatively more in COGS, R\&D, M\&S, and G\&A.

Submodel 6:

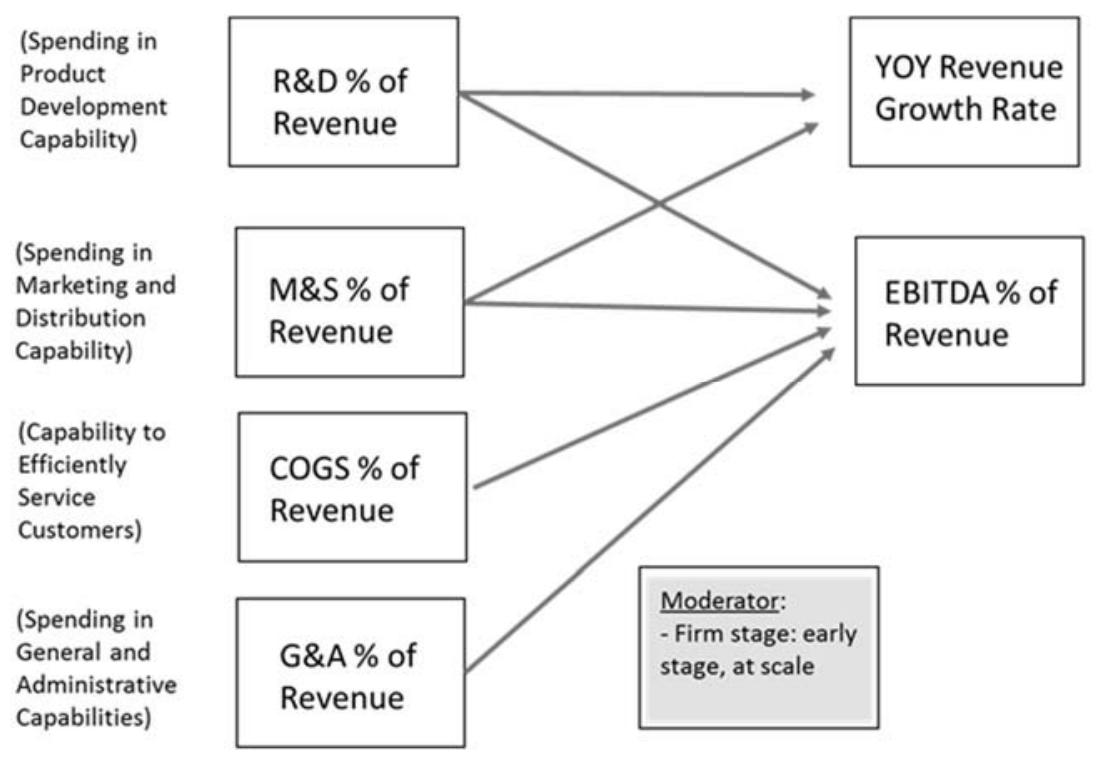

Figure 7: The Moderating Effect of the Firm's Development Stage

I considered two definitions of firms at scale: 1 - firms with revenues of $\$ 50$ million or more (based on the most recent year results), and; 2- firms of \$100 million or more (based on the most recent year results). I found that the second definition provided a clearer divide between early stage and at scale firms. Indeed, the difference in EBITDA profitability between the two subpopulations (early stage vs. at scale) was more meaningful using $\$ 100$ million as the revenue threshold instead of using $\$ 50$ million. This is because, using AVGEB as a measure, there are as many unprofitable firms under $\$ 100$ million in the dataset (53\%) as under $\$ 50$ million (55\%). $\$ 100$ million seems to be a better indicator of the threshold at which firms tend to turn to profitability. It is interesting to note, however, 
that still $26 \%$ of firms above $\$ 100$ million are not profitable (using AVGEB as a measure). Therefore, the following definition for firms at scale was chosen: SaaS firms with revenues of $\$ 100$ million or more (based on the most recent year results).

The descriptive statistics are summarized in Table 9. To measure the differences in allocations between the two populations, I used the median, which is an adequate measure as it is less sensitive to outliers than the mean. As evidenced in Table 9, early stage firms spend higher percentages of their revenues in all expense categories compared to at-scale firms.

Table 9: Differences in Resource Allocations between Early Stage and At Scale Firms

\begin{tabular}{|l|l|r|r|r|r|r|r|}
\cline { 3 - 8 } \multicolumn{2}{c|}{} & EBITDA & COGS & GM & R\&D & M\&S & \multicolumn{1}{c|}{ G\&A } \\
\hline \multirow{2}{*}{ At Scale } & $\mathrm{N}$ & 78 & 78 & 78 & 78 & 78 & 78 \\
\cline { 2 - 8 } & Median & $10.1 \%$ & $32.5 \%$ & $67.5 \%$ & $16.4 \%$ & $33.5 \%$ & $17.2 \%$ \\
\hline \multirow{2}{*}{ Early Stage } & $\mathrm{N}$ & 17 & 17 & 17 & 17 & 17 & 17 \\
\cline { 2 - 8 } & Median & $-13.3 \%$ & $40.0 \%$ & $60.0 \%$ & $18.2 \%$ & $36.4 \%$ & $22.6 \%$ \\
\hline \multirow{2}{*}{ Total } & $\mathrm{N}$ & 95 & 95 & 95 & 95 & 95 & 95 \\
\cline { 2 - 8 } & Median & $6.6 \%$ & $34.1 \%$ & $65.9 \%$ & $16.8 \%$ & $33.6 \%$ & $18.2 \%$ \\
\hline
\end{tabular}

Then, the moderating effects of the firm's development stage on resource allocation were examined by running a regression analysis using a "At scale" dummy variable to assess the strength and statistical significance of these moderating effects.

For this regression analysis, the focus was initially on the effects of the variables on EBITDA. Then, it was extended to the analysis of their effects on YOY growth as per the model (Submodel 6).

The measures for these variables were as follows:

- EBITDA variable: AVGEB. 
- YOY growth variable: YOYG (also referred to as AVGYOYG).

- GM variable: AVGGM.

- R\&D variable: AVGRD.

- M\&S variable: AVGSM.

- G\&A variable: AVGGA.

- At Scale dummy variable (moderator): $1=\$ 100$ million in revenue or more; $0=$ less than $\$ 100$ million in revenue (based on the most recent year results).

- $\mathrm{AVGGM}^{*}$ S100: GM variable multiplied by moderator.

- AVGRD*S100: R\&D variable multiplied by moderator.

- AVGSM*S100: M\&S variable multiplied by moderator.

- AVGGA*S100: G\&A variable multiplied by moderator.

The regression analysis indicated that, although the overall model was statistically significant $(\mathrm{R}$ square $=0.93$; $\mathrm{p}$-value $<0.01$ ), the individual moderating effects (i.e., effects of moderator and moderating factors: AVGGM*S100, AVGRD*S100, etc.) were not statistically significant when all variables were included in the model (Appendix B - Model $1)$.

Collinearity among the variables might have contributed to this result. After eliminating the most insignificant variables, the analysis arrived at a simpler regression model showing improved statistical significance for the moderator and the moderating effects on R\&D and M\&S relationships (Appendix B - Model 2).

In the simpler regression model, the moderator effect on the relationship between $R \& D$ and EBITDA (i.e., AVGRD*S100) was statistically significant (p-value $<0.05$ ). The 
moderating effect on the relationship between M\&S and EBITDA (AVGSM*S100) was statistically significant at a $\mathrm{p}$-value $<0.01$. And the moderator (AtScale_S100M_Dummy) was statistically significant at a $p$-value $<0.01$.

The same exercise was repeated with YOY growth as a dependent variable (instead of EBITDA) and arrived at a simplified regression model with only M\&S and its related moderating effects as individual statistically significant variables (Appendix C). In the regression model, the moderator effect on the relationship between M\&S and YOY Growth $(\mathrm{AVGSM} * \mathrm{~S} 100)$ was statistically significant $(\mathrm{p}$-value $=0.01)$ and the moderator (AtScale_S100M_Dummy) was also statistically significant (p-value $<0.01$ ).

In conclusion, there are differences in resource allocation between early stage and at scale firms based on the descriptive statistics. However, the regression analysis indicates that the moderating effect of the variable is statistically significant primarily in the relationship between M\&S spending and firm performance (for both dependent variables EBITDA and YOY growth). It is also statistically significant in the relationship between R\&D and EBITDA.

\section{The Moderating Effect of the Firm's Specialization}

The second moderator in the model is whether the firm is specialized in a vertical or a generalist selling across multiple industries. As discussed earlier, firms that are specialized in a particular industry spend less in marketing and sales (as a $\%$ of revenue) relative to firms addressing all industries because they address a much smaller market, which can be prospected using a smaller and more targeted sales channel. This is demonstrated in Table 
10, with generalist firms spending 35\% of their revenue in $M \& S$ as per the median of that sub-population compared to a median of $25 \%$ for firms that are specialized in one vertical.

Table 10: Differences in Resource Allocations between Generalist and Vertical Firms

\begin{tabular}{|l|l|r|r|r|r|r|r|}
\cline { 3 - 8 } \multicolumn{2}{c|}{} & EBITDA & COGS & GM & R\&D & M\&S & \multicolumn{1}{c|}{ G\&A } \\
\hline \multirow{3}{*}{ Generalist } & $\mathrm{N}$ & 72 & 72 & 72 & 72 & 72 & 72 \\
\cline { 2 - 8 } & Median & $4.4 \%$ & $32.9 \%$ & $67.1 \%$ & $17.4 \%$ & $35.3 \%$ & $17.5 \%$ \\
\hline \multirow{3}{*}{ Vertical } & $\mathrm{N}$ & 23 & 23 & 23 & 23 & 23 & 23 \\
\cline { 2 - 8 } & Median & $12.1 \%$ & $40.0 \%$ & $60.0 \%$ & $15.1 \%$ & $25.0 \%$ & $20.6 \%$ \\
\cline { 2 - 8 } & $\mathrm{N}$ & 95 & 95 & 95 & 95 & 95 & 95 \\
\cline { 2 - 8 } & Median & $6.6 \%$ & $34.1 \%$ & $65.9 \%$ & $16.8 \%$ & $33.6 \%$ & $18.2 \%$ \\
\hline
\end{tabular}

Table 10 indicates differences in spending patterns in other expense categories. For example, the cost of service (COGS) seems to be higher for vertical firms (median of $40 \%$ compared to $32.9 \%$ for generalist firms), which would be consistent with the fact that they can achieve smaller economies of scale (as their market is smaller than the market of generalist firms, which serve multiple industries).

Finally, as it was done for the prior moderating variable, the moderating effect of the firm's specialization on resource allocation was examined by running a regression analysis using a "Vertical" dummy variable. 
Submodel 7:

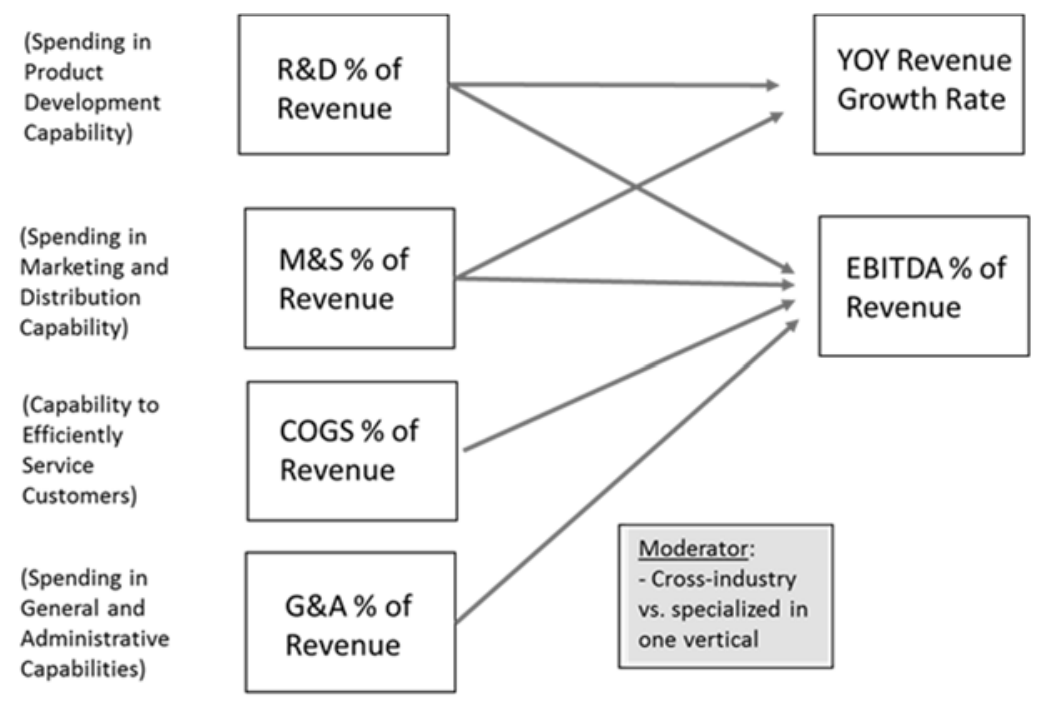

Figure 8: The Moderating Effect of the Firm's Specialization

A similar procedure was used for the variables and measures, creating the moderator variable and moderator factors for the independent variables:

- Vertical dummy variable (moderator): $1=$ specialized in one vertical; $0=$ generalist (serving multiple industries)

- AVGGM*VERT: GM variable multiplied by moderator.

- AVGRD*VERT: R\&D variable multiplied by moderator.

- AVGSM*VERT: M\&S variable multiplied by moderator.

- AVGGA*VERT: G\&A variable multiplied by moderator.

Again, the regression analysis indicated that, although the overall model was statistically significant ( $\mathrm{R}$ squared value of $0.92 ; \mathrm{p}$-value $<0.01$ ), the individual moderating effects (i.e., effects of moderator and moderating factors: AVGGM*VERT, AVGRD*VERT, etc.) 
were not statistically significant when all variables were included in the model (Appendix D - Model 1).

After eliminating the most insignificant variables, the simpler regression model including the moderator and the moderating effects on the R\&D and M\&S relationships was still not statistically significant at individual variable level for the moderator and the moderating factors (AVGRD*VERT and AVGSM*VERT). In other words, in the simpler regression model, the moderator (Vertical Dummy) and both the moderator effect on the relationship between R\&D and EBITDA (AVGRD*VERT) and the moderator effect on the relationship between M\&S and EBITDA (AVGSM*VERT) were not statistically significant (Appendix D - Model 2).

The exercise was repeated with YOY growth as a dependent variable (instead of EBITDA) and arrived at a simplified regression model with only M\&S and its related moderating effects. However, even in this simpler regression model, the individual moderator and moderating factor were not statistically significant (Appendix E). Indeed, in this regression model, neither the moderator effect on the relationship between M\&S and YOY Growth (AVGSM*VERT) or the moderator (Vertical Dummy) were statistically significant.

In conclusion, differences seem to exist in resource allocation between the two subpopulations of specialized (i.e., vertical) and generalist firms, based on the descriptive statistics. However, the moderating effects of the variable do not appear to be statistically significant, based on the regression analysis. 


\section{Robustness Checks}

Additional analyses were conducted to gain further insights from the data. In particular, it appeared appropriate and relevant to examine the resource allocation patterns of high performers versus low performers. It also appeared appropriate and relevant to distinguish between "pure-play" versus hybrid SaaS companies.

\section{$\underline{\text { High Performers vs Low Performers }}$}

Using the SPSS dataset, SaaS firms were ranked using their performance factor (YOYG * AVGEB) from the highest to the lowest. Firms with double negatives (negative growth and negative EBITDA) were placed at the bottom of the ranking. Two subpopulations were then defined: the high performers, consisting of the top half of the ranking, and the low performers, consisting of the bottom half of the ranking.

As shown in Table 11, the high performers achieve a median YOY growth of $19 \%$ and a median of $20 \%$ EBITDA. Their median business valuation is 5.3 times revenue. In contrast, the low performers achieve a median YOY growth of $24 \%$ and a median of $-14 \%$ EBITDA. Their median business valuation is lower at 3.4 times revenue. The high performers achieve a higher median GM (69\% compared to 64\%) and are more efficient in all expense categories based on the comparison of the medians between the two subpopulations. 
Table 11: Differences between High and Low Performers

\begin{tabular}{|l|l|l|l|l|r|r|r|r|r|}
\cline { 2 - 11 } \multicolumn{2}{c|}{} & $\begin{array}{c}\text { Business } \\
\text { Val. } \\
\text { (Rev. } \\
\text { Multiple) }\end{array}$ & $\begin{array}{c}\text { YOY } \\
\text { Growth }\end{array}$ & EBITDA & COGS & GM & R\&D & M\&S & G\&A \\
\hline \multirow{2}{*}{$\begin{array}{l}\text { High } \\
\text { performer }\end{array}$} & $\mathrm{N}$ & 47 & 47 & 47 & 47 & 47 & 47 & 47 & 47 \\
\cline { 2 - 12 } & Median & 5.280 & $19.0 \%$ & $19.7 \%$ & $31.0 \%$ & $69.0 \%$ & $14.0 \%$ & $25.1 \%$ & $16.1 \%$ \\
\hline $\begin{array}{l}\text { Low } \\
\text { performer }\end{array}$ & $\mathrm{N}$ & 48 & 48 & 48 & 48 & 48 & 48 & 48 & 48 \\
\cline { 2 - 13 } & Median & 3.355 & $24.0 \%$ & $-14.1 \%$ & $36.0 \%$ & $64.0 \%$ & $20.3 \%$ & $40.7 \%$ & $21.0 \%$ \\
\hline \multirow{2}{*}{ Total } & $\mathrm{N}$ & 95 & 95 & 95 & 95 & 95 & 95 & 95 & 95 \\
\cline { 2 - 11 } & Median & 4.350 & $19.4 \%$ & $6.6 \%$ & $34.1 \%$ & $65.9 \%$ & $16.8 \%$ & $33.6 \%$ & $18.2 \%$ \\
\hline
\end{tabular}

Pure-Play vs. Hybrid SaaS Firms

It is interesting to compare the patterns between two types of firms:

- "Pure-play" vendors: as discussed in the literature review, these vendors focus exclusively on the SaaS model and tend to be the disruptors.

- Hybrid vendors: these vendors tend to be the ones that are transitioning to the SaaS model from the on-premises software model. As a result, these vendors offer a combination of both SaaS and on-premises software solutions.

To categorize firms between these two subpopulations, a pure-play SaaS firm is defined as a firm which revenue is primarily (99\%) SaaS product-related (such as SaaS subscription, license, and/or transaction revenue and related services) as of the time when the data was collected as per their public filings, as opposed to hybrid firms which report both revenues from on-premises software products and revenues from SaaS products in their financials as per their public filings. Each firm's public filings were reviewed to determine whether 
this definition was met and the two subpopulations were created accordingly. One firm was classified as "Other" due to the prominence of managed services among its revenues.

As Table 12 shows, pure-play vendors achieved a significantly higher growth (median YOY growth of $31 \%$ compared to $10 \%$ for hybrid vendors) and higher business valuation (median revenue multiple of 5.5 times compared to 3.5 times). They are also less profitable (median EBITDA of $-11 \%$ compared to $19 \%$ ), which makes sense as pure-play vendors tend to be smaller and less established firms than hybrid vendors. It is interesting to note that the difference in GM (i.e., revenue minus service delivery cost) between the two subpopulations is relatively less meaningful than the difference in spending patterns in areas such as R\&D and M\&S.

Table 12: Differences between Pure-Play and Hybrid Firms

\begin{tabular}{|c|c|c|c|c|c|c|c|c|c|}
\hline & & $\begin{array}{c}\text { Business } \\
\text { Val. } \\
\text { (Rev. } \\
\text { Multiple) } \\
\end{array}$ & $\begin{array}{c}\text { YOY } \\
\text { Growth }\end{array}$ & EBITDA & COGS & GM & R\&D & M\&S & G\&A \\
\hline \multirow{2}{*}{$\begin{array}{l}\text { Pure } \\
\text { Play }\end{array}$} & $\mathrm{N}$ & 48 & 48 & 48 & 48 & 48 & 48 & 48 & 48 \\
\hline & Median & 5.485 & $31.4 \%$ & $-10.8 \%$ & $34.3 \%$ & $65.7 \%$ & $19.2 \%$ & $41.2 \%$ & $20.1 \%$ \\
\hline \multirow[t]{2}{*}{ Hybrid } & $\mathrm{N}$ & 46 & 46 & 46 & 46 & 46 & 46 & 46 & 46 \\
\hline & Median & 3.520 & $9.9 \%$ & $18.8 \%$ & $33.7 \%$ & $66.3 \%$ & $14.9 \%$ & $24.7 \%$ & $15.6 \%$ \\
\hline \multirow[t]{2}{*}{ Other } & $\mathrm{N}$ & 1 & 1 & 1 & 1 & 1 & 1 & 1 & 1 \\
\hline & Median & 1.230 & $-3.7 \%$ & $-11.5 \%$ & $66.3 \%$ & $33.7 \%$ & $8.3 \%$ & $20.4 \%$ & $21.4 \%$ \\
\hline \multirow[t]{2}{*}{ Total } & $\mathrm{N}$ & 95 & 95 & 95 & 95 & 95 & 95 & 95 & 95 \\
\hline & Median & 4.350 & $19.4 \%$ & $6.6 \%$ & $34.1 \%$ & $65.9 \%$ & $16.8 \%$ & $33.6 \%$ & $18.2 \%$ \\
\hline
\end{tabular}

Additional descriptive statistics from the dataset including box plots and histograms are provided in Appendix F.

\section{Validity and Reliability Considerations}

Additional validity tests as part of this research are discussed in Appendix G. 
More research is needed to further assess the validity and the reliability of my findings, including examining any potential validity issues from the various dimensions of research validity (i.e., conclusion, internal, construct, and external validities) as well as assessing the validity of cause effect-relationships (internal validity). For example, further research should evaluate the need to lag the data one more year to further confirm temporal precedence (e.g., add one year or average data only years $1 \& 2$ and show that findings are similar).

In addition, my findings should be further triangulated with:

- Feedback from informal discussions with practitioners in the field as discussed earlier in the methodology section (Research Methodology / Data Collection).

- Prior research (on the effects of gross margin efficiency, R\&D spending and M\&S spending on firm performance) that might have reached similar or different conclusions in other industries.

\section{Limitations of the Research}

\section{$\underline{\text { General Limitations }}$}

The research has several limitations. As discussed earlier, this research initially focuses on publicly-traded SaaS firms, primarily in North America. Out of the 128 firms surveyed, 95 are publicly traded in the US and 33 are publicly traded internationally. Further research would be needed to extend the research to privately-held companies and foreign firms in other regions of the world. 
The sampling frame used a ranking of the Top 500 SaaS firms by Apps Run the World (Pang, A., 2015), a leading IT research firm in the SaaS industry founded by former IDC analyst Albert Pang. The ranking is focusing on enterprise SaaS solution providers also referred to as business-to-business (B2B) solution providers (e.g., Finance, ERP, supply chain management, customer relationship management, etc.). However, the ranking might have introduced a bias by considering only the top providers in the various enterprise markets: i.e., low performers might have been under-represented in the sample. Some of the vendors in the rankings provide both SaaS and traditional software offerings. I was not able to segregate the financial metrics between the two types of revenues and considered the financial metrics of the firm as a whole. In addition, further research would be needed to extend the analysis to SaaS firms in the business-to-consumer (B2C) segment of the SaaS market (game software, personal finance, etc.).

\section{$\underline{\text { R\&D Spending Measure Limitation }}$}

R\&D expenses were taken as reported in the income statement of the firms. For firms that capitalize R\&D (i.e., software development expenditures), further research would require analyzing these expenditures to deduct the portion amortized and add back the portion that was capitalized, to the extent that this level of information is available in the firm's financial reports or can be obtained by other means.

Out of the 128 companies in the sample, 84 companies $(66 \%)$ capitalize some of their software development expenditures and 44 companies (34\%) expense them all.

For an apple-to-apple comparison between firms that capitalize and firms that do not capitalize, it is important to consider the entire software development expenditure. 
Considering only the capitalized portion of the expenditure would not be adequate in my opinion as it would represent only a partial portion of the software development costs: indeed, due to accounting standards, only a limited portion of the software development expenditures can be capitalized, For example, under US GAAP, all expenses prior to the feasibility date and after the release date cannot be capitalized, only significant enhancements (i.e., new functionality) are eligible for capitalization (FASB, 2016; KPMG, 2012). Preliminary research necessary to arrive at the determination of the feasibility of the new software or new functionality cannot be capitalized. Bug fixes and performance enhancements that follow the release date cannot be capitalized as well as general software maintenance (such as updates to the software as a result of changes in laws and regulations). Finally, the accounting of software developments that are paid for by clients (such as to enhance the software, to develop integrations with other software products used by the client, or accelerate the product roadmap) generally follows a different standard (in US GAAP, ASC 605 35, related to contract accounting) under which the related expenditures are expensed as revenue from the software-development arrangement is recognized (Grant Thornton, 2010).

Examine the example below (Table 13) representing the R\&D expenditures as reported by one of the companies included in the study. The R\&D amounts considered in the study are reflected in the line highlighted in blue (below). Considering only the capitalized portion (line reported in the Cash Flow Statement) would result in considering a significantly lower amount, which would not be comparable to companies that do not capitalize.

Unfortunately, companies do not always provide the details below. In absence of these details, my approach has been to use the expense as reported in the Income Statement (line 
highlighted below). As indicated above, further research would be needed to obtain the missing information and refine the analysis by using $R \& D$ amounts adjusted as follows:

$R \& D$ expenditure $=R \& D$ expense - amortization of software development + capitalized software development.

\section{Table 13: Example of R\&D Expenditure Reporting}

\section{Consolidated Statements of Operations - USD (\$) shares in Thousands, $\$$ in Thousands}

Income Statement

Research and development (period expense)

Cash Flow Statement

Amortization of software development costs

Capitalized software development costs
12 Months Ended

Dec. 31， Dec. 31， Dec. 31, $2015 \quad 2014 \quad 2013$

$29,307 \quad 22,379 \quad 12,605$

$\begin{array}{rrr}6,595 & 5,834 & 4,964 \\ (10,083) & (11,010) & (6,169)\end{array}$

\section{$\underline{\text { Other Limitations }}$}

Measure of standard deviation: to measure consistency in spending patterns (as a \% of revenue) over time and to test $\mathrm{H} 5$, the analysis used a variable consisting of the average standard deviation among the four independent variables (COGS intensity, R\&D intensity, S\&M intensity, and G\&A intensity) during the three year-period (AVGSTD). Further research could examine the consistency of spending patterns at quarterly level during the three-year period (as opposed to using the annual spending levels).

Diversified firms: diversified firms such as those providing both hardware and software (e.g., IBM, Oracle, Siemens, EMC) were excluded from the sample due to the lack of financial data regarding their software business as a standalone business. 
Service delivery costs: as indicated in the study, I did not find a significant relationship between service delivery costs and firm performance due to the disparity of the firms' levels of efficiency in the sample. Potential explanations include the heterogeneity of business models, disparity in revenue composition (e.g., proportion of professional services as a percentage of total revenues) or differences in hosting cost structures between companies that own their infrastructure and companies that outsource their infrastructure). Understanding these differences and their effects on firm performance would be a valuable, new research topic,

Quantitative research method: this study is based on a quantitative research method and cross-sectional data. Further research could include case studies and longitudinal studies. For example, a study to help managers improve the process by which resource allocation decisions are made within an organization competing in an emerging technology market would be particularly relevant. For those interested in the IT implications of implementing a SaaS strategy, a deeper dive into the transformation and changes involved at the software organization would be of great interest as well.

\section{Research Contributions}

\section{Findings Summary}

This study attempts to increase our understanding of the contribution of key capabilities (e.g., service delivery, $R \& D$, marketing and sales) to firm performance in a rapidlygrowing technology industry (SaaS). By analyzing the resource allocation (i.e., spending) among key capabilities and its effects on firm performance, this research seeks to improve 
our understanding of the productivity value of these key capabilities (i.e., their contribution to financial performance).

There is a tendency among managers of firms in emerging technology markets (where business valuations are driven by revenue multiples) to over-emphasize revenue growth and neglect the role of profitability in the assessment of their performance, and ultimately their enterprise value. Managers also face significant difficulty in making resource allocation decisions to strike the right balance between growth and profitability. The research helps managers of SaaS / software firms (i.e., owners, CEOs, CFOs) to answer the following question: By spending in key capabilities to achieve growth and profitability, is there an optimum resource allocation approach to maximize the firm's financial performance?

The findings of this study can be summarized as follows:

- In this study, the effects of the proposed key capabilities (e.g., service delivery, R\&D, marketing and sales) on firm performance are analyzed by examining the relationships between the spending in these capabilities and the financial performance outcomes in terms of both revenue growth and profitability, and then ultimately on the firm's enterprise value. A description of the variables and measures is provided in the Conceptual Model and Hypotheses section.

- As firms are building and scaling up their new capabilities (service delivery, R\&D, $\mathrm{M} \& S$ ) in the new cloud computing environment, they should manage an optimum balance between revenue growth and profitability. Firms should not underscore the role of profitability (measured in this research using the EBITDA measure) in 
business valuation, even in a rapidly growing industry, such as SaaS. At comparable growth rates, firms that achieve positive EBITDA generally achieve higher business valuations. For example, notably, at a comparable annual growth of $30 \%$ in the sample, profitable SaaS firms achieved a business valuation approximately $30 \%$ higher than non-profitable SaaS firms.

- Both R\&D (i.e., relative spending in product development capability) and M\&S (i.e., relative spending in marketing and distribution capability) have diminishing returns on firm performance. While I did not find a significant relationship between service delivery costs and firm performance due to the disparity of firms' levels of efficiency in the sample, the analysis indicates that firms that invest at optimum levels in R\&D and M\&S are more likely to achieve higher financial performance. Overspending or spending too fast relative to revenue growth results in diminishing returns on firm performance and puts the firm at a risk of running out of capital.

- Firms that maintain consistent resource allocation patterns over time achieve a higher financial performance.

- The development stage of the firm moderates the resource allocation's effects on firm performance.

- The firm's specialization does not appear to be a statistically significant moderator of the resource allocation's effects on firm performance. However, differences in spending patterns exist between generalist and specialized firms (e.g., firms who are specialized in a vertical tend to spend less in M\&S). 
- Finally, the research highlights differences in spending patterns between high and low performers and between pure-play and hybrid SaaS firms (i.e., firms who offer a combination of both SaaS and on-premises software solutions).

\section{Contributions to Practice}

This research helps managers of software firms optimize resource allocation among key capabilities (in particular, service delivery, $R \& D$, and $M \& S$ ), align their spending strategies with growth and improve financial planning in a cloud computing environment. As discussed earlier in the literature review summary, this research is particularly relevant at a time when the SaaS industry is still in development stage and most SaaS firms have yet to prove the profitability of their business models.

Specific recommendations for practitioners can be summarized as follows:

- SaaS firms (and software firms transitioning to the Cloud) should use financial metrics on key capabilities (e.g., service delivery, R\&D, marketing and sales) in their efforts to drive firm performance in their industry. This study focused on key capabilities from a financial operations perspective. SaaS firms might want to consider additional financial and non-financial measures on other capabilities (e.g., customer contract acquisition and retention, human capital, partner networks) as they see fit. However, the capabilities examined in this study are a good place to start.

- Firms should time their spending with corresponding growth to avoid overspending and/or wasting capital. They should resist the temptation of investing too much ahead of revenue. Revenue growth achievement (as the firm invests) is the 
validation that the technology being built by the firm is being adopted by the market and that the investments continue to be relevant to market expectations. The same is true about marketing and sales. Hiring too many marketing and sales people too quickly results in inefficiencies as training, product readiness, service delivery resource availability, infrastructure scalability enhancements, and other internal efforts are generally necessary until these new hires can become productive resources for the firm. A progressive and coordinated increase in marketing and sales capability, validated by ongoing revenue growth, is necessary to optimize performance.

- Firms should make resource allocation decisions toward an optimum mix of spending (i.e., the mix of spending that leads to the highest financial performance in terms of revenue growth and profitability, and ultimately enterprise value).

- Firms should maintain consistent spending patterns over time for long-term performance. Indeed, firms should adopt a progressive approach in building and scaling up their capabilities. As a result, their spending in capabilities (e.g., R\&D, marketing and sales) as a percentage of revenue should be maintained at relatively the same level year-over-year (as opposed to going up and down in an uncontrolled way).

For practitioners, this research provides useful insights to help assess the quality of execution of SaaS growth strategies and to improve financial planning in the software industry. Indeed, this study provides helpful information in terms of business metrics for benchmarking purposes as well as a better understanding of the effects of spending patterns 
on firm performance. This analysis helps improve the way firms plan their resources to optimize their performance, and ultimately their business valuation.

\section{Contributions to Theory}

This research contributes to the RBV and related literature on the effect of capabilities (e.g., service delivery, $R \& D, M \& S$ ) on firm performance in the context of SaaS firms in cloud computing. Specifically, it contributes to further understanding the linkage between resource allocation and firm performance, and ultimately firm valuation.

Although the research is focused on firms from the SaaS industry, the approach and findings from this research are potentially relevant to firms in other emerging technology industries. Indeed, the phenomenon of over-emphasis on revenue growth which results in overspending (in pursuit of accelerated growth) at the cost of significant losses is a problem that is often found among firms in emerging and rapidly growing industries, not just in the SaaS industry. In these industries, business valuations tend to be driven by revenue multiples (instead of a combination of revenue and EBITDA multiples or other valuation methods).

This research attempts to show that, even when business valuation is measured by revenue multiples, firms that are EBITDA positive generally achieve a premium in business valuation compared to firms that are EBITDA negative. In addition, the research attempts to show that overspending or spending too fast relative to revenue growth results in diminishing returns on firm performance.

Evidence of the negative effects of a "spending spree" on firm performance was already provided by the dotcom burst in the early 2000s. In the 1990s, e-commerce and e-business 
technologies emerged, and many dotcom companies were formed to take advantage of the massive market opportunity, raising capital at an exponential rate, achieving rapid growth in the space, and creating an investment bubble in the industry. Literature that analyzed dotcom failures (Razi et al., 2004) identified the spending spree of dotcom organizations (i.e., spending without any consideration of timing of investments nor financial discipline) as one of the key causes of failure.

The SaaS industry shares similar characteristics as many other emerging technology industries where firms tend to be valued at high revenue multiples and where a significant number of the firms are new entrants and are not profitable. Therefore, it would be logical to infer that similar findings might be reached with data collected from firms in other emerging technology industries. Thus, I propose that the findings from this study could cautiously generalize to firms in other emerging technology industries.

\section{Opportunities for Future Research}

To further validate the generalizability of the study, testing of its hypotheses in other emerging technology industries such as big data and analytics, the internet of things, digital banking and mobile financial services, and healthcare technology would be valuable.

In addition, this study is limited to publicly traded firms. The findings are useful to publicly traded companies as well as privately held companies seeking an IPO or an M\&A transaction (such as an acquisition by a private equity firm or a larger company) down the road. Future research opportunities could lead to including privately held companies in the dataset for comparisons between publicly traded companies and privately held companies. This could be achieved by working with venture capital firms interested in analyzing the 
performance of their portfolio companies (and their readiness for an exit: IPO or M\&A) using the same methodology. In addition, this effort could be augmented by collaborating with benchmarking firms interested in the approach. Benchmarking firms (or financial institutions providing benchmarking research) that have expertise in the SaaS industry include OPEXEngine, Siemer, River Cities, and Openview. 


\title{
CHAPTER 3
}

\section{ESSAY TWO: OPTIMIZING GROWTH STRATEGIES IN THE CLOUD COMPUTING ENVIRONMENT (INSIGHTS FROM THE LITERATURE AND FROM PRACTICE)}

\begin{abstract}
Motivation for Research
Understanding the dynamics between resource allocation and firm performance, and ultimately business valuation, is essential for business owners and managers, especially those involved with growing organizations or organizations aspiring to grow in emerging technology industries such as the SaaS industry.
\end{abstract}

The purpose of this second essay is to complement and extend the findings of the first study with additional insights from the literature and from practice.

The research questions of this second essay can be summarized as follows:

To what extent can the findings of the quantitative study (first essay) be generalized and what additional managerial insights can be derived from the literature and the practitioners' perspective to optimize resource allocation and the financial performance of SaaS firms?

To answer these questions, a qualitative approach was followed and included the following tasks:

1. Completed an extended literature review for further assessment of the generalizability of the study and additional insights from the literature that might 
be relevant to practice. The extended literature review also contributed to confirm the novelty and originality of the study from an academic research perspective.

2. Interviewed more than a dozen practitioners in the field to collect their feedback and thoughts on the results of the study, and

3. Illustrated the findings of the study using mini case studies.

For this second essay, the main objectives were:

- To draw relevant managerial insights and best practices from the literature;

- To provide further support for the generalizability of the findings of the quantitative research study;

- To engage practitioners in phone discussions to obtain their feedback on the results of the quantitative study, to validate the analysis from a practitioner's perspective, and to enrich the research with insights coming from practice;

- To illustrate the findings with concrete examples using cases from the sample of the quantitative study (first essay); and finally,

- To propose a research agenda for future research in the field.

In the following sections, I will present my key findings from the extended literature review, my propositions, methodology, and results, which will lead me to a discussion and a research agenda for future research.

\section{Extended Literature Review}

Current literature on the effects of resource allocation and firm performance indicates that the relationships between spending in capabilities and firm performance are relatively 
complex. I will summarize hereafter the recent literature in two sub-sections: the emergence of new literature on resource allocation optimization; and the role of other factors influencing the relationship between resource allocation and firm performance.

\section{Emergence of New Literature on Resource Allocation Optimization}

The phenomenon of diminishing returns on spending in capabilities such as R\&D or marketing beyond an optimum level seems to have gained interest among researchers recently. There seems to be a growing call for more research to improve our understanding of how to optimize the financial performance of a growth organization from a resource allocation perspective. Indeed, a new stream of research is challenging the existing literature by pointing out its lack of consistency or questioning its relevance in the modern, fast-paced, technology-driven economy. For example, Lantz et al. (2005) discuss the lack of consensus in the literature on the effect of R\&D spending on firm performance, highlighting contradictory results from the literature. According to them, firms with an intensive investment strategy in R\&D have significantly lower financial performance. In a recent article, Yeh et al. (2010) studied whether there is an optimal level of R\&D investment at which point firms attain their maximum level of performance or whether firms should invest as much as they possibly can in R\&D. The article provides a summary of prior studies that have investigated the relationship between R\&D and firm performance and concludes that studies that have investigated the R\&D spending optimization issue are scant. The authors explain that R\&D should not be treated as an unlimited investment and that there is a level beyond which increased $R \& D$ expenditure does not yield proportional rewards. For the authors, R\&D threshold values vary across different industries. They 
emphasize that deciding on the direction and level of R\&D should not be made random and intuitive.

Other recent research found diminishing returns of spending in $R \& D$ or marketing to firm performance. Eisenmann (2006) analyzed the accelerated growth strategies of internet firms and the effect of their investments on their long-term performance. The internet firms' investments were measured in terms of their spending levels at time of IPO. Their long-term performance was measured by their market value as of the end of 2001, twenty months after the burst of the dotcom bubble. The study showed that internet firms spent heavily in marketing to accelerate growth and it demonstrated an inverted U-shaped relationship between marketing spending and ROI (measured in terms of the long-term return on the invested capital).

Ugur et al. (2016) found that survival time increases with $R \& D$ intensity (i.e., $R \& D$ spending as a percentage of sales) at decreasing rates and eventually falls as R\&D intensity exceeds an optimum level. They showed that R\&D intensity is associated with longer survival times when R\&D-active firms are in more concentrated industries. They discuss that smaller firms that focus on growth as a means of enhancing market share face a higher risk of exit, likely due to a gap between their growth ambitions and growth management capacity.

In his recent article, Krcal (2014) proposed a model to explain an inverted U-relationship between profitability and innovation (measured in terms of R\&D expenditures). For the author, the nonlinear relationship is influenced by industry factors and firm-specific factors. $R \& D$ expenditures are constrained by firm factors such as credit constraints (i.e., 
access to financing). Each firm chooses R\&D expenditures that maximize its expected profit subject to the $R \& D$-expenditure constraints. The return on $R \& D$ expenditures varies depending on industry factors (intensity of competition, etc.) and firm-specific factors (competitive position, innovation capability). The model proposes that, as R\&D expenditures increase, profits and technology gap first increase then decrease. The technology gap is defined by the author as the average difference between the profits of the leaders and the other firms in the industry due to technology and/or other firm-specific factors.

Lin (2014) studied the effect of diversity of R\&D sources on industrial performance at industry level. The diversity of $R \& D$ sources was defined by Lin as the level of diversification of $R \& D$ knowledge sources and was measured by the $R \& D$ expenditures by private and public sectors of the industry. The author found that the relationship between diversity of $R \& D$ sources and industrial performance was an inverted U-shaped relationship. For the author, an optimal level of $R \& D$ diversity of $R \& D$ sources exists. Industrial performance decreases as diversity of $R \& D$ sources increases after the optimal level.

Capasso et al. (2015) analyzed the effect of R\&D expenditure on firm growth and found that, while a higher level of $R \& D$ expenditure has a positive effect on firm growth, it does not reduce the likelihood of a bad performance. The study compared R\&D behaviors between exiting firms and surviving ones and suggested the need for an optimum balance. This study found that exiting firms have a more extreme R\&D behavior than surviving ones. It explained that firms' overinvestment given their internal resources and the uncertainty regarding the success of the innovative process can also lead to firm death. The 
same phenomenon of overinvestment among growth firms was analyzed by Tokic in his two-part article on the relationships between R\&D and advertising spending and the market value of internet firms during the late 1990s and 2000 (Tokic, 2004, 2005). For Tokic, the value of a growth firm is a function of $R \& D$ investments, advertising investments, earnings and volatility. He explains that the overvaluations of internet firms during the bubble and the burst that followed was caused by investors who focused solely on the value of growth and ignored the negative profitability of internet firms in their valuation estimations. For him, the main reason for the negative profitability of internet firms was the over-investment in $\mathrm{R} \& \mathrm{D}$ and advertising.

\section{The Role of Other Factors Influencing the Relationship between Resource} Allocation and Firm Performance

In addition to these efforts to enhance our understanding of the relationship between resource allocation and firm performance, recent literature further explores the role of other factors that influence this relationship. These factors include firm size, market characteristics, and other factors.

\section{$\underline{\text { Firm Size }}$}

Firm size is a factor that is commonly used in the literature to analyze the differences in investment strategies or spending patterns among firms and their relationships to firm performance. For example, Ciftci and Cready (2011) analyzed the effects of scale on R\&D performance. Their study showed that the effects of R\&D on earnings, earnings volatility (variability) and market returns vary depending on firm size. They found that R\&D investments by larger firms are associated with higher future earnings and less uncertainty 
(measured in terms of lower earnings variability). Joglekar and Levesque (2009) studied the relationships between Marketing and R\&D spending and business valuation within the context of a startup. The authors proposed a conceptual model to optimize resource allocation across successive stages of startup growth to minimize equity dilution and maximize business valuation. Levesque et al. $(2012 ; 2010)$ examined the spending patterns of pre-IPO firms compared to established firms relative to their revenue growth and showed differences between the two types of firms.

\section{Market Characteristics}

Market characteristics represent another factor of interest in the literature. For example, Fung (2004) examined the effect of R\&D effort on productivity at industry level and highlighted sectorial differences in the productivity of R\&D activities. Demirel and Mazzucato (2012) analyzed the impact of R\&D investments on firm growth in the US pharmaceutical industry between 1950 and 2008, a period during which the size composition of firms and the characteristics of innovation evolved significantly, and concluded that the effects of $\mathrm{R} \& \mathrm{D}$ vary based on firm and market characteristics. Other recent articles referring to firm and industry-specific market factors include Krcal (2014), Ugur et al. (2016), Yeh et al. (2010), and Lin (2014).

\section{Other Factors}

Other factors emerging from the recent literature include the firm's performance measurement ability (e.g., O'Sullivan et al., 2009), the firm's strategic posture and entrepreneurial orientation (e.g., Mousa et al., 2015; Koellinger, 2008), the firm's need to operate a major shift or radical change (Mudambi and Swift, 2014), the role of acquisitions 
as a complement or substitute of internal resources (e.g., Wagner, 2016; Sahaym et al., 2010;2009), the revenue composition or business model (e.g., Suarez et al., 2013; Heredia et al., 2015), the investor base and the role of venture capital (e.g., Sahaym et al., 2010;2009; Boer, 2002), and the country, socio-economic, and political environment (e.g., Coccia, 2009). More details about the extended literature review are provided in Appendix I.

In conclusion, my review of the recent literature confirms that there is significant interest among researchers in further understanding the linkage between resource allocation and firm performance in growth organizations, particularly in fast paced, technology driven firms. My research contributes to this new stream of research. This research is relevant to both technology and non-technology firms. Indeed, technology has become a prominent part of business strategies in many industries. In other words, understanding these dynamics will become more and more critical, not only for technology firms, but also all firms investing in technology markets to compete in the new digital economy.

\section{Propositions}

Building on my extended literature review and on the conceptual model presented earlier (in the quantitative study), I suggest that a timed and disciplined approach to growth (as opposed to an aggressive and erratic growth acceleration strategy) will lead to greater rewards for firms competing in the new cloud environment and that this approach is generalizable to other emerging technology contexts. More specifically, I offer the following generalizable propositions. 
$\underline{\text { Strive for Continuous Profitable Growth or a Clear Path to Profitability Instead of "Growth }}$ $\underline{\text { at all Cost" }}$

In an emerging technology market (where business valuations are driven by revenue multiples), revenue growth is a dominant factor in determining the performance of a firm and ultimately its enterprise value. However, firms should resist the temptation of "growth at all cost". The quantitative study demonstrated that, even in emerging technology markets such as SaaS, firms that were both growing and profitable achieve a premium in business valuation (Hypothesis \# 1). In addition, the study suggested that financial discipline measured in terms of consistency in spending patterns over time leads to superior performance (Hypothesis \# 5) and I concluded that firms should time or calibrate their spending with corresponding growth to avoid overspending and/or wasting capital. As outlined in the extended literature review, recent studies (e.g., Tokic, 2004, 2005; Joglekar and Levesque, 2009; Capasso et al., 2015) provide similar insights on the risks of overspending in an emerging technology market and the importance of not losing sight of profitability in this type of business environment. Based on these findings, I propose that profitability or a clear path to profitability is critical to success even in a market where business valuations are driven by revenue multiples.

Proposition \# 1: Profitability or a clear path to profitability positively influences firm performance, even in an emerging technology market (i.e., where business valuations are driven by revenue multiples). It's not just about revenue growth. 


\section{Pursue Optimum R\&D and M\&S Spending Levels}

My quantitative study examined the relationships between spending in key capabilities and firm performance. As mentioned earlier in the study, I did not find a significant relationship between service delivery costs and firm performance due to the disparity of firms' levels of efficiency in the sample (Hypothesis \# 2). Therefore, in this second essay, I opted to focus on the effects of R\&D spending (Hypothesis \# 3) and M\&S spending (Hypothesis \# 4). For both variables, I found that their relationship to firm performance is subject to diminishing returns beyond optimum levels. I also showed that the cost structures and spending patterns vary depending on the firm's size or growth stage (e.g., early stage vs. at stage firms) and other firm characteristics (e.g., vertical vs. cross-industry firms). Although the study's context, method, and approach were different than those used in other studies, some of the latest literature seems to reach similar conclusions (e.g., Eisenmann, 2006; Yeh et al., 2010; Krcal, 2014; Ugur et al., 2016), while providing additional insights into other firm-specific or market-specific factors that might influence the spending patterns and the optimum levels. Therefore, based on these findings, I offer the following two generalizable propositions:

Proposition \# 2a: In an emerging technology market, firms that pursue optimum R\&D and M\&S spending levels achieve higher long-term firm performance.

Proposition \# 2b: In an emerging technology market, firms that pursue "growth at all cost”, in either R\&D or M\&S or both, achieve lower long-term firm performance. 


\section{$\underline{\text { Generalizability }}$}

The dynamics described in the quantitative study are not unique to SaaS firms and can cautiously generalize to firms in other emerging technology markets as discussed earlier (refer to the Research Contributions section). I found similar outcomes in the recent literature, which studied these phenomena (i.e., over-emphasis on revenue growth and overspending behaviors in emerging technology markets) in other sectors. For example, Eisenmann (2006) examined the growth strategies and spending behaviors of internet companies in the United States and proposed that the generalizability of his study was not limited to internet companies as boom-bust valuation cycles occur regularly. He concluded that we might expect to see similar outcomes in other industries when speculative excess leads investors to place undue emphasis on revenue and market share growth. For the author, the shape of the inverted U-shaped relationships will vary depending on the differences in profitability in each industry. The study from Yeh et al. (2010) on the optimum level of R\&D intensity (spending as a percentage of revenue) was based on a sample of IT and electronic firms in Taiwan. For the authors, R\&D threshold values vary across different industries. For Krcal (2014) also, the relationship between R\&D expenditures and firm performance is non-linear and the phenomenon is likely to generalize across multiple industries. The article from Joglekar and Levesque (2009), which suggested a model to optimize resource allocation across successive stages of startup growth (to minimize equity dilution and maximize business valuation), used a case study in the software industry that was unrelated to SaaS. The case study was based on a manufacturer of electronic design automation (EDA). In their article, the authors discuss 
that the underlying resource-allocation tradeoff is a common phenomenon and that, therefore, their study may apply to firms in other contexts.

Based on these findings, I formulate the following proposition:

Proposition \# 3: Generalizability of the outcomes of this study to other contexts than SaaS is true, subject to differences in spending and firm performance levels depending on the industry.

\section{Methodology and Data Collection}

The methodology and data collection approach for this essay is summarized in the following sections.

\section{Interviews of Practitioners}

For the discussions with practitioners, senior executives were interviewed via one-on-one phone conversations at more than a dozen companies (thirteen in total), including investment bankers, private equity firms, accounting and business valuation companies, and CFOs in the field. The breakup of the participants by type is summarized in Table 14.

Table 14: Interview Participants by Type

\begin{tabular}{|l|r|}
\hline CFO & 3 \\
\hline Investment Banker & 5 \\
\hline Private Equity Firm & 2 \\
\hline Accounting/Valuation Firm & 3 \\
\hline Total & $\mathbf{1 3}$ \\
\hline
\end{tabular}


The author of the dissertation (myself), who served as the interviewer, is also the CFO of a technology company. An initial list of 21 contacts was created from my personal contacts in the industry, all located in the United States. Out of the 21 contacts invited to participate in the interview, 13 were able to complete the interview, 6 did not respond, and 2 declined. The interviews were completed between mid-June and August 2017.

Participants received an email invitation to participate in the interview, including the list of questions to be discussed during the call. After the participants confirmed their interest in participating, a phone interview was setup with each of them. The length of the phone interview was approximately 30-45 minutes. A summary of the quantitative study along with a draft copy of the research paper was sent ahead of the call. The summary consisted of a PDF version of the presentation of the study (approximately twenty slides, including appendices). During the first 5-10 minutes of the call, the interviewer summarized the key findings of the study and answered any clarification questions. The following 20-30 minutes of the call were spent on collecting feedback using seven open questions. For further details on the phone interview process, please refer to the study design summarized in Appendix H.

Notes from the interviews were taken by the interviewer for each of the seven open questions. All the interview notes were then analyzed and coded using the Atlas.ti software. My main goal with the coding was to identify the themes that could be induced from the interview notes to help summarize the responses and insights from the practitioners. 


\section{Mini Case Studies}

My approach for the mini case studies was to select six cases of SaaS firms among the sample of the quantitative study as follows:

- Two firms among those that achieved the highest performance and business valuation in the sample: Veeva Systems and Ellie Mae,

- Two firms among those that achieved the lowest performance and business valuation in the sample: Covisint and Broadvision,

- Two other firms:

o Salesforce: one of the first SaaS firms that emerged on the market and one of the most well-known SaaS firms in the industry;

o Box: an example of a SaaS firm pursuing an accelerated growth strategy at the cost of heavy losses, selected among the top spenders in R\&D and $\mathrm{M} \& \mathrm{~S}$ in the sample.

To gain further insights about how these firms arrived at where they are now, I collected financial data on these firms from the date of their initial public offering (IPO) to their most recent fiscal year as well as other relevant information about these firms from secondary sources such as SEC filings, press releases, trade publications, and blog articles. (Data collection for these mini case studies occurred between September and the end of 2017). This approach allowed me to analyze their resource allocation patterns over a longer period than the three years selected for the quantitative study (first essay). The period included the fiscal years prior to the IPO as reported by the firms in their SEC filings at the time of IPO (prospectus or Form S-1). The financial data prior to the IPO provided useful insights into 
the financial metrics of these firms while they were still private and preparing themselves for their IPO.

\section{Extended Literature Review}

For the extended literature review, my approach was to search, identify, and analyze recent academic research on the relationships between resource allocation and firm performance, with a focus on $R \& D$ and $M \& S$ investments in new markets and the outcomes in terms of firm performance, and ultimately business valuation. I followed an interdisciplinary approach by searching any relevant literature across all disciplines, including strategy management, information systems, finance, marketing, and economics.

I analyzed the literature and identified key findings and managerial implications that may either confirm or extend the results of the study. I also examined how the literature might provide additional support for the generalizability of my quantitative study. Finally, I created a research agenda highlighting interesting and novel new research avenues for researchers interested in exploring new approaches in the understanding of the effects of resource allocation on firm performance in emerging technology markets.

\section{Results}

In this section, I will present the key results from the practitioner interviews, the mini case studies, and the key managerial insights derived from the literature. 


\section{Insights from Practitioner Interviews}

The first question I asked the practitioners was: What are your thoughts on the findings

of this research? All respondents indicated that the results made sense based on their own experience. Examples of quotations are provided hereafter as an illustration:

Table 15: Feedback from Practitioners - Quotation Examples

\begin{tabular}{|l|l|}
\hline \multicolumn{1}{|c|}{ Question 1: What are your thoughts on the findings of this research? } \\
\hline \multicolumn{1}{|c|}{$\begin{array}{l}\text { Agrees with the } \\
\text { results of the study. }\end{array}$} & $\begin{array}{l}\text { Qveration Examples } \\
\text { optimum level of Opex to achieve scale and profitability. }\end{array}$ \\
\cline { 2 - 3 } & $\begin{array}{l}\text { I found the study interesting. I agree with the need for growth vs. EBITDA } \\
\text { balance. }\end{array}$ \\
\cline { 2 - 3 } & $\begin{array}{l}\text { I wasn't surprised by the findings. I came to the same conclusions through my } \\
\text { years of experience working with software companies. }\end{array}$ \\
\cline { 2 - 3 } & $\begin{array}{l}\text { It is refreshing to see some correlation between profitability and valuation, that } \\
\text { it is not all about growth. This is something that I was always justifying to my } \\
\text { clients when we were going over their valuation and the market comps (i.e., } \\
\text { comparables). }\end{array}$ \\
\cline { 2 - 3 } & $\begin{array}{l}\text { I agree. At software and SaaS companies I worked for in the past, we were } \\
\text { always calibrating our spending as a \% of revenue to make sure that nothing } \\
\text { was out of whack. We were always making sure that we were in line with our } \\
\text { budgeted allocations based on the progress we were making on revenues. This } \\
\text { was primarily driven by our CEO and our Board of Directors. }\end{array}$ \\
\cline { 2 - 3 } & $\begin{array}{l}\text { I am glad that your study and our research are coming to the same conclusion } \\
\text { that to achieve the highest valuations, you really need both growth and } \\
\text { profitability. }\end{array}$ \\
\cline { 2 - 3 } \\
$\begin{array}{l}\text { I agree with your finding regarding the role of both growth and EBITDA...Your } \\
\text { other findings are also spot on. }\end{array}$ \\
\hline
\end{tabular}

In addition, the interviewees commented on the originality of the study and its relevance from their perspective. Examples of quotations follow in Table 16. 
Table 16: Practitioners' Comments on the Originality and Relevance of the Study Quotation Examples

\begin{tabular}{|l|l|}
\hline \multicolumn{1}{|c|}{ Question 1: What are your thoughts on the findings of this research? (Cont.) } \\
\hline \multicolumn{1}{|c|}{$\begin{array}{l}\text { Comments about the } \\
\text { originality of the } \\
\text { study. }\end{array}$} & $\begin{array}{l}\text { Quotation Examples } \\
\text { and it's interesting that the study shows that the incremental investment } \\
\text { generates lower returns above a certain level. For M\&S, a company needs to } \\
\text { determine how much and where to spend in M\&S to achieve to the highest } \\
\text { returns in terms of sales growth and normalize the business growth. }\end{array}$ \\
\cline { 2 - 3 } & $\begin{array}{l}\text { I found the last finding about the consistency of spending patterns over time } \\
\text { particularly interesting. I would not have expected this, only when companies } \\
\text { have reached steady state. I also liked the breakups between vertical vs } \\
\text { horizontal and pure-play SaaS vs hybrid companies. }\end{array}$ \\
\cline { 2 - 3 } & $\begin{array}{l}\text { What you have done is not found in other studies. Other studies provide } \\
\text { benchmark data. Your study is going beyond that. }\end{array}$ \\
\cline { 2 - 3 } & $\begin{array}{l}\text { One finding that was surprising to me was that I would not have expected to } \\
\text { see a correlation between profitability and business valuation in the SaaS } \\
\text { market. But the study does a good job at demonstrating that profitability is } \\
\text { relevant even in the SaaS market. }\end{array}$ \\
\hline $\begin{array}{l}\text { Comments about the } \\
\text { relevance of the study. }\end{array}$ & $\begin{array}{l}\text { This is interesting research. It is very relevant to what we do. Please keep me } \\
\text { in the loop. When you're done with the research, if there was something we } \\
\text { could share with our clients, it would be very valuable. }\end{array}$ \\
\cline { 2 - 3 } & $\begin{array}{l}\text { Your research is helpful to a CFO because it provides evidence that a logical } \\
\text { approach in spend allocation will result in better results and it gives the } \\
\text { company good guidelines on how to allocate based on where you are as a } \\
\text { business. }\end{array}$ \\
\cline { 2 - 3 } & $\begin{array}{l}\text { I found the study very interesting. The idea to invest at optimal level is } \\
\text { generally understood but it's hard to quantify. }\end{array}$ \\
\cline { 2 - 3 } & $\begin{array}{l}\text { The study is very relevant for every company in this industry as well as in } \\
\text { other industries. Managers can derive rules of thumb from the data based on } \\
\text { their characteristics. It provides like a roadmap to successfully grow a SaaS } \\
\text { business. This is the right type of approach. }\end{array}$ \\
\hline
\end{tabular}

The real-life examples provided by the interviewees are particularly helpful in illustrating some of the managerial implications discussed in my study. Below are examples cited by the practitioners (Table 17). 
Table 17: Real-life Examples Cited by Practitioners - Quotation Examples

\begin{tabular}{|c|c|}
\hline \multicolumn{2}{|c|}{ Question 1: What are your thoughts on the findings of this research? (Cont.) } \\
\hline Code & $\begin{array}{l}\text { Quotation Examples } \\
\end{array}$ \\
\hline \multirow[t]{8}{*}{$\begin{array}{l}\text { Discusses real-life } \\
\text { examples. }\end{array}$} & $\begin{array}{l}\text { I just completed a project with a SaaS company ... They are a hybrid company } \\
\text { moving to SaaS. We were discussing multiples and we were facing similar } \\
\text { questions. How much do you need to invest? The main issue in their case was } \\
\text { how many sales people do we need? They have very long sales cycles, like 12- } \\
18 \text { months for a substantial customer. Adding too many sales people too quickly } \\
\text { puts a lot of burden on the cash of the company. They have competitive price } \\
\text { pressures from pure-play SaaS companies, so they have no choice but to move } \\
\text { to the cloud. }\end{array}$ \\
\hline & $\begin{array}{l}\text { I spoke to a PE firm the other day, they told me that for smaller deals, they } \\
\text { don't even look at EBITDA, just revenue growth... They only look at EBITDA } \\
\text { for the larger deals.... As the company grows, cash flow breakeven is a critical } \\
\text { thing to manage. }\end{array}$ \\
\hline & $\begin{array}{l}\text { When I talk to CEOs about the importance of profitability, the question I get all } \\
\text { the time is what is the right trade-off? I tell them that they should maximize the } \\
\text { aggregate of growth rate and EBITDA \%, but then, they ask me how much } \\
\text { growth they should be looking for and at what cost. }\end{array}$ \\
\hline & $\begin{array}{l}\text { My clients are always struggling with this. They see these market comps, based } \\
\text { on publicly traded company data, and they just look at revenues and it's often a } \\
\text { struggle to explain it. }\end{array}$ \\
\hline & $\begin{array}{l}\text { I have a client who has been trying to go public for } 2 \text { years now, but they have } \\
\text { not been able to convince their investors that they were ready. Their investors } \\
\text { want them to improve their margins first. }\end{array}$ \\
\hline & $\begin{array}{l}\text { We had a Board member who was particularly knowledgeable about how to } \\
\text { grow a software business and adequate spend levels in R\&D, M\&S, etc. based } \\
\text { on experience and market research he had access to. We had a successful exit } \\
\text { and our financial discipline certainly was part of it. We were definitely } \\
\text { EBITDA positive... }\end{array}$ \\
\hline & $\begin{array}{l}\text { They started with a basic product, they didn't try to do it all at once. They } \\
\text { started to acquire customers with the basic product, then they added more } \\
\text { modules over time. }\end{array}$ \\
\hline & $\begin{array}{l}\text { They have been growing strongly and consistently, like at } 30 \% \text { or so, but now, } \\
\text { they are seeing significant pressure from an activist investor to show } \\
\text { profitability. }\end{array}$ \\
\hline
\end{tabular}

Furthermore, an interviewee provided an interesting comment as an additional insight on the issue of the necessary balance between growth and profitability, pointing out that the 
economic environment is likely to influence the premium on profitability in business valuations. His point was that in bad times, the premium is likely to be higher.

The second question I asked the practitioners was: What do you think are the main practical implications for business managers? The answers collected from the interviews can be summarized in 5 main implications for business managers:

- They need to control costs as the firm is growing,

- They need to optimize returns on the firm's R\&D and M\&S spending,

- They need to optimize the firm's capital efficiency,

- They need to optimize the firm's growth strategy, and

- They need to benchmark the firm's performance.

Examples of quotations for each of these implications are provided in Table 18. 
Table 18: Managerial Implications Cited by Practitioners - Quotation Examples

\begin{tabular}{|c|c|}
\hline Code & Quotation Examples \\
\hline \multirow{3}{*}{$\begin{array}{l}\text { Need to control } \\
\text { costs as the firm } \\
\text { is growing. }\end{array}$} & $\begin{array}{l}\text { The main business implication is that managers should control their costs as they } \\
\text { grow their business. }\end{array}$ \\
\hline & $\begin{array}{l}\text { You hear about these companies that raise a bunch of money, don't spend it wisely, } \\
\text { and run out of money. This data gives them like a roadmap to avoid these types of } \\
\text { mistakes. }\end{array}$ \\
\hline & $\begin{array}{l}\text { A CFO of a SaaS company today must be on top of how to manage the spend in the } \\
\text { company. He or she must promote and follow a disciplined approach. }\end{array}$ \\
\hline \multirow[t]{2}{*}{$\begin{array}{l}\text { Need to optimize } \\
\text { returns on } R \& D \\
\text { and } M \& S \\
\text { spending. }\end{array}$} & $\begin{array}{l}\text { The most interesting point for business managers from the study is to try to } \\
\text { determine the effect of the marginal spend in these different expense buckets. What } \\
\text { happens if I increase spending in M\&S or R\&D? The thing you control the most as a } \\
\text { business manager is expenses, so, these are very important questions. }\end{array}$ \\
\hline & $\begin{array}{l}\text { It's important to find the point of optimum return for the company. These few more } \\
\text { points in growth are the most expensive. PE firms know that better than anyone else. } \\
\text { They have built their business on investing in companies and turn them into more } \\
\text { efficient organizations and improving ROI. They are doing this not just for M\&S but } \\
\text { also R\&D and the other operating costs. }\end{array}$ \\
\hline \multirow[t]{3}{*}{$\begin{array}{l}\text { Need to optimize } \\
\text { capital efficiency. }\end{array}$} & $\begin{array}{l}\text { To get there, companies need to bootstrap themselves out of having to keep raising } \\
\text { capital because capital is expensive... It is important that companies don't set } \\
\text { themselves up for trouble and show path to profitability. Growth acceleration } \\
\text { strategies may be the reason for raising capital but soon after having invested the } \\
\text { capital raised, they should breakeven as quickly as possible. }\end{array}$ \\
\hline & $\begin{array}{l}\text { Companies need to show profitability at some point or they get pressure from their } \\
\text { investors. }\end{array}$ \\
\hline & $\begin{array}{l}\text { There is an incredible risk of investing without proving that the product you are } \\
\text { building will sell. The same is true for marketing. You can advertise all you want, } \\
\text { but if the product doesn't sell or doesn't work, it won't be effective. }\end{array}$ \\
\hline \multirow[t]{2}{*}{$\begin{array}{l}\text { Need to optimize } \\
\text { growth strategy. }\end{array}$} & $\begin{array}{l}\text { Businesses need to get to scale without putting themselves at risk of running out of } \\
\text { cash. There is a scale point after which the business achieves a higher "flow down" } \\
\text { to the bottom line (i.e., a higher percentage of gross margin flowing to EBITDA). }\end{array}$ \\
\hline & $\begin{array}{l}\text { The main implication is that managers need to find out what the optimal level of } \\
\text { spending in R\&D and marketing is for their organization depending on its } \\
\text { characteristics. R\&D and M\&S are the most critical pieces. }\end{array}$ \\
\hline \multirow{3}{*}{$\begin{array}{l}\text { Need to } \\
\text { benchmark the } \\
\text { firm's } \\
\text { performance. }\end{array}$} & $\begin{array}{l}\text { If I were a business manager, I would want to see how my firm compares with your } \\
\text { dataset. }\end{array}$ \\
\hline & $\begin{array}{l}\text { Knowing how and where other firms are spending their money is extremely helpful } \\
\text { for managers. It allows them to avoid making poor mistakes. }\end{array}$ \\
\hline & $\begin{array}{l}\text { Managers that use KPIs to monitor their business are the most successful. KPIs are } \\
\text { important in measuring the success of the business and that success translates into a } \\
\text { higher business valuation. }\end{array}$ \\
\hline
\end{tabular}


My third question to the practitioners was: Do you think that these findings would be applicable or generalizable to companies in other industries and contexts?

Feedback from the practitioners on the generalizability of the study was generally positive, subject to variations in resource allocation numbers and other nuances (12 out of the 13 interviewees responded positively, 1 was unsure). Some of the interviewees pointed out that the SaaS model itself is currently extending to other industries. Examples of quotations are provided in Table 19.

Table 19: Practitioners' Opinion on the Generalizability of the Study - Quotation Examples

\begin{tabular}{|l|l|}
\hline $\begin{array}{l}\text { Question 3: Do you think that these findings would be applicable or generalizable to companies in } \\
\text { other industries and contexts? }\end{array}$ \\
\hline \multicolumn{1}{|c|}{ Code } & \multicolumn{1}{c|}{ Quotation Examples } \\
\hline $\begin{array}{l}\text { Potentially } \\
\text { generalizable to other } \\
\text { industries subject to } \\
\text { variations in numbers } \\
\text { and/or other nuances. }\end{array}$ & $\begin{array}{l}\text { Yes, the general concepts from the study should be applicable to other } \\
\text { industries, except that the percentages and performance metrics will be } \\
\text { different. }\end{array}$ \\
\cline { 2 - 3 } & $\begin{array}{l}\text { I think that this type of research would apply to other emerging industries } \\
\text { where businesses are valued based on multiples of revenue. The same } \\
\text { guidelines might apply. }\end{array}$ \\
\cline { 2 - 3 } $\begin{array}{l}\text { Yes, I think it would be applicable to other industries, depending on the } \\
\text { industry. In other industries, the spend categories would be different but the } \\
\text { relevance of a logical approach to resource allocation would apply. }\end{array}$ \\
\hline $\begin{array}{l}\text { Potentially } \\
\text { generalizable to other } \\
\text { industries offering } \\
\text { cloud-based } \\
\text { services. }\end{array}$ & $\begin{array}{l}\text { You could argue that more and more companies from other sectors are } \\
\text { becoming SaaS businesses themselves, with Cloud-based services and } \\
\text { recurring revenues. You see this more and more in the services industries, } \\
\text { especially in the B2B world. }\end{array}$ \\
\cline { 2 - 3 } & $\begin{array}{l}\text { SaaS is just a way to deploy resources more effectively. The research would } \\
\text { apply to any industry that is like-minded, for example, some data processing } \\
\text { firms or data providers or others have business models similar to the SaaS } \\
\text { model, with recurring revenues, stickiness, high margins, and high customer } \\
\text { retentions. }\end{array}$ \\
\hline
\end{tabular}


The fourth question to the practitioners was: What do you perceive as the main

\section{limitations of the research?}

The main perceived limitations of the study were its limitation to publicly traded firms and its quantitative method approach. The interviewees expressed significant interest in qualitative research studies to go deeper in the understanding of how to successfully address the issues highlighted by the quantitative study. Examples of quotations follow in

Table 20.

Table 20: Practitioners' Opinion on the Limitations of the Study - Quotation Examples

\begin{tabular}{|l|l|}
\hline \multicolumn{1}{|c|}{ Question 4: What do you perceive as the main limitations of the research? } \\
\hline \multicolumn{1}{|c|}{ Quotation Examples } \\
\hline $\begin{array}{l}\text { Quantitative study } \\
\text { approach, a qualitative } \\
\text { approach would allow } \\
\text { to go deeper in the } \\
\text { understanding of } \\
\text { "how". }\end{array}$ & $\begin{array}{l}\text { You could go deeper into the expense buckets to really understand how } \\
\text { companies are investing and achieving better results than others. You could } \\
\text { also drill down into companies to better understand their story and their } \\
\text { strategies, what they have done differently, how they operate their business. }\end{array}$ \\
\cline { 2 - 3 } & $\begin{array}{l}\text { It's a quantitative analysis. There are also many qualitative factors that are } \\
\text { not included in the study. How long the company has been in business, how } \\
\text { large is their total addressable market, what type of investors are backing the } \\
\text { company, management's history, etc. }\end{array}$ \\
\cline { 2 - 3 } $\begin{array}{l}\text { The study does not go into the detailed reasons behind some of these } \\
\text { findings. }\end{array}$ \\
\hline traded firms. & $\begin{array}{l}\text { The study covers only publicly traded companies, which tend to be larger } \\
\text { organizations. Smaller companies are not represented in the study. }\end{array}$ \\
\cline { 2 - 3 } & $\begin{array}{l}\text { The study is limited to publicly traded companies. You have a lot of SaaS } \\
\text { companies that never make it to an IPO. They stay private, get bought, or go } \\
\text { out of business. Your data is skewed toward the mature portion of an } \\
\text { emerging industry. }\end{array}$ \\
\cline { 2 - 3 } & $\begin{array}{l}\text { The study is limited to public companies. I can see how CFOs of private } \\
\text { companies may say that this is not applicable to them because they are not a } \\
\text { public company. }\end{array}$ \\
\hline
\end{tabular}


Table 20: Practitioners' Opinion on the Limitations of the Study - Quotation Examples (Continued)

\begin{tabular}{|l|l|}
\hline Other limitations. & $\begin{array}{l}\text { (Code: Limited to 3 years of spending data history). Your financial data is } \\
\text { back 3 years. I wonder what the effects might be if you would extend the } \\
\text { period to a longer cycle, more years. Would you reach similar results? }\end{array}$ \\
\cline { 2 - 3 } & $\begin{array}{l}\text { (Code: Does not include comparisons among various software market } \\
\text { segments or verticals). The study is limited to the software industry in } \\
\text { general. You have vertical firms but you don't drill down within each } \\
\text { industry. It would be interesting to see if there are industry-specific } \\
\text { characteristics within each vertical. }\end{array}$ \\
\hline $\begin{array}{l}\text { (Code: Does not include an analysis of the capital invested to achieve scale). } \\
\text { It would be interesting to examine the impact of VC funding. You would } \\
\text { expect that companies that receive VC funding spend more aggressively in } \\
\text { R\&D and M\&S than the others... In addition, it would be interesting to } \\
\text { know how much it costs companies to achieve scale. By scale, I mean } \\
\text { EBITDA breakeven. I would look at capital invested since inception to } \\
\text { achieve scale. }\end{array}$ \\
\hline $\begin{array}{l}\text { (Code: Centered on financial aspects). The study is centered on the financial } \\
\text { aspects. }\end{array}$ \\
\hline
\end{tabular}

My fifth question was: Are there any additional questions that you think would be valuable to address as a next step or as an extension of this research?

Suggestions from the practitioners included:

- $\quad$ Adding a qualitative study

- Adding a longitudinal study

- Analyzing the scale effects at a more granular level

- Adding a study on privately-held companies, and

- Adding software vertical-focused studies.

Examples of quotations are provided hereafter (Table 21). 
Table 21: Practitioners' Suggestions for New Research Questions - Quotation Examples

\begin{tabular}{|c|c|}
\hline Code & Quotation Examples \\
\hline \multirow[t]{3}{*}{$\begin{array}{l}\text { Adding a } \\
\text { qualitative study. }\end{array}$} & $\begin{array}{l}\text { I would go deeper into the expense buckets. How do companies spend their } \\
\text { money and how do they become profitable? }\end{array}$ \\
\hline & $\begin{array}{l}\text { If you work for a company that is EBITDA negative, what happens? You are } \\
\text { certainly constrained by more limited resources and what you can afford to spend. } \\
\text { You could analyze this type of situation; what companies do in these } \\
\text { circumstances and best practices to turn the company to profitability. What are the } \\
\text { implications of being cash flow negative? What to do? Etc. }\end{array}$ \\
\hline & $\begin{array}{l}\text { Another area that would be interesting is to break-up the SaaS business within } \\
\text { hybrid companies and compare that to pure-play SaaS companies. I know they } \\
\text { generally don't report the details in their filings. This would require probably } \\
\text { more of a qualitative research approach. }\end{array}$ \\
\hline \multirow[t]{2}{*}{$\begin{array}{l}\text { Adding a } \\
\text { longitudinal } \\
\text { study. }\end{array}$} & $\begin{array}{l}\text { A time series analysis would be extremely powerful. For example, you could } \\
\text { analyze a set of } 4-5 \text { companies, } \ldots \text { and analyze what their spending and } \\
\text { performance were at various stages of their life cycle. }\end{array}$ \\
\hline & $\begin{array}{l}\text { The study is based on point in time data for the business valuation. I wonder if the } \\
\text { results would be different if business valuations were measured at different points } \\
\text { in time. With different dates, I wonder if some of the findings would still hold } \\
\text { true. }\end{array}$ \\
\hline \multirow[t]{2}{*}{$\begin{array}{l}\text { Analyzing scale } \\
\text { effects at a more } \\
\text { granular level. }\end{array}$} & $\begin{array}{l}\text { Another thought is analyzing the scale effect at a more granular level: multiple } \\
\text { stages to highlight for example the characteristics of large market caps, companies } \\
\text { that have a market cap of } \$ 5 \mathrm{~B} \text { of more vs others. }\end{array}$ \\
\hline & $\begin{array}{l}\text { You might want to look at whether the data shows scale in R\&D and G\&A. } \\
\text { Intuitively, based on my experience, I would expect to see these percentages } \\
\text { decline over time as the company grows. }\end{array}$ \\
\hline \multirow{2}{*}{$\begin{array}{l}\text { Adding a study on } \\
\text { privately-held } \\
\text { companies. }\end{array}$} & Adding privately held companies would be extremely helpful. \\
\hline & It would be interesting to compare the results with privately-held companies. \\
\hline $\begin{array}{l}\text { Adding software } \\
\text { vertical-focused } \\
\text { studies. }\end{array}$ & Again, industry-focused analyses would be interesting. \\
\hline
\end{tabular}

To explore additional ideas or suggestions for future research with the practitioners, I asked them the following question (sixth question): Are there any other measures of performance or factors that you think would be valuable to include in the research?

This question triggered a lot of new ideas and suggestions among the interviewees. I would summarize them in two groups: 
- Adding operating measures or factors: to explore the role of potential nonfinancial factors such as customer retention, accounting policies, product life cycle, competition, market shares, or other non-financial factors.

- Adding capital investment related measures or factors: to explore the role of capital related factors such as the role of acquisitions, characteristics of the investor base, or the size of the capital invested.

Examples of quotations are provided hereafter (Table 22).

Table 22: Practitioners' Suggestions for New Measures or Factors - Quotation Examples

\begin{tabular}{|c|c|}
\hline \multicolumn{2}{|c|}{$\begin{array}{l}\text { Question 6: Are there any other measures of performance or factors that you think would be } \\
\text { valuable to include in the research? }\end{array}$} \\
\hline Code & Quotation Examples \\
\hline \multirow{7}{*}{$\begin{array}{l}\text { Adding } \\
\text { operating } \\
\text { measures or } \\
\text { factors. }\end{array}$} & $\begin{array}{l}\text { Beyond the financial metrics covered in the study, they can use qualitative measures } \\
\text { such as the customer acquisition cost (CAC) and other similar measures. }\end{array}$ \\
\hline & $\begin{array}{l}\text { Another measure of performance would be customer retention. Retention is a huge } \\
\text { driver of performance for SaaS companies. }\end{array}$ \\
\hline & $\begin{array}{l}\text { Another suggestion would be to elaborate on accounting policies of the firms in the } \\
\text { sample so that we know if any of the differences in accounting policies might } \\
\text { influence the results. For example, whether the firm capitalizes R\&D or not and } \\
\text { whether it would affect the results. Another example would be to consider } \\
\text { incorporating deferred revenue and unbilled revenue to see if this might have an } \\
\text { impact. }\end{array}$ \\
\hline & $\begin{array}{l}\text { US GAAP revenue recognition rules will change soon .... It would be interesting to } \\
\text { examine how this will impact the financial performance of SaaS companies. }\end{array}$ \\
\hline & $\begin{array}{l}\text { If the company has a product that is highly mature, how much should it spend in } \\
\text { R\&D as a \% of revenue? }\end{array}$ \\
\hline & $\begin{array}{l}\text { Market share is likely to influence the spending allocation. For example, how much } \\
\text { a firm that has a } 50 \% \text { market share should spend in R\&D compared to a firm that } \\
\text { has a } 5 \% \text { market share? Other factors could be the competitors. }\end{array}$ \\
\hline & $\begin{array}{l}\text { Non-financial aspects are also important and influence business valuations, like the } \\
\text { competition, the industry characteristics, the type of clientele such as SMB (small } \\
\text { and medium business) vs. enterprise clients, the management team, the type of sales } \\
\text { channel such as direct and indirect, and R\&D characteristics such as where R\&D is } \\
\text { located, offshore vs onshore R\&D. }\end{array}$ \\
\hline
\end{tabular}


Table 22: Practitioners' Suggestions for New Measures or Factors - Quotation Examples

\section{(Continued)}

\begin{tabular}{|c|c|}
\hline & $\begin{array}{l}\text { There is also the comparison between US and international firms. It would be } \\
\text { interesting to reveal the differences. }\end{array}$ \\
\hline & $\begin{array}{l}\text { We are investing in our own IT infrastructure. This gives us better margins than if } \\
\text { we were moving to an outsourced solution. It would be interesting to examine the } \\
\text { Capex (Capital Expenditures) and their impact on performance or how Capex might } \\
\text { influence the results. }\end{array}$ \\
\hline \multirow{5}{*}{$\begin{array}{l}\text { Adding capital } \\
\text { investment } \\
\text { related } \\
\text { measures or } \\
\text { factors. }\end{array}$} & $\begin{array}{l}\text { I think that capital invested and capital efficiency measures would be interesting to } \\
\text { add. }\end{array}$ \\
\hline & $\begin{array}{l}\text { One measure I am thinking about is ROI (return on investment). What is the ROI of } \\
\text { R\&D investments made by SaaS companies? }\end{array}$ \\
\hline & $\begin{array}{l}\text { You should also consider adding M\&A as a variable in the model... You will find } \\
\text { that acquisitions is a major feature. A lot of companies are not efficient in R\&D and } \\
\text { acquire instead of building themselves. Especially, large and profitable companies } \\
\text { are particularly active in M\&A. }\end{array}$ \\
\hline & You could look also at the investor base; who are the primary investors? \\
\hline & $\begin{array}{l}\text { Sometimes, business valuations are straightforward. You take a SaaS business that is } \\
\text { not profitable, you look at their growth and their revenue metrics... But sometimes, } \\
\text { business valuations can be more complex. For example, a company may not grow as } \\
\text { fast as you would expect, let's say less than a certain threshold..., then you look at } \\
\text { the EBITDA and you apply an EBITDA multiple. It would be interesting to analyze } \\
\text { this threshold and determine things like at what point do you start using the } \\
\text { EBITDA multiple? }\end{array}$ \\
\hline
\end{tabular}

Finally, my seventh question was more of a wrap-up question (Any other thoughts you

would like to add?). Interviewees generally answered it by reemphasizing a few key points or suggestions they made earlier and thanking the interviewer for the opportunity to participate in the review of the study.

In conclusion, the interviews were extremely helpful in bringing the results of the study into the context of the practitioners, who provided rich insights into the relevance of the research from their perspective and potential additional new research avenues, which I will 
discuss later in this dissertation as part of my section on the research agenda for future research.

\section{Mini Case Studies}

In this section, I will expose the results from the six cases selected from the sample, for purpose of illustrating the findings of my quantitative study. The six cases consist of Veeva Systems, Ellie Mae, Covisint, BroadVision, Salesforce, and Box and are summarized hereafter.

\section{The Case of Veeva Systems}

Veeva Systems (Veeva) was a top 10-performer in the sample in terms of both Performance Factor (0.09) and Enterprise Value: the firm was valued at over 10 times revenue (more than $\$ 4$ billion) as of the time of the measure in my quantitative analysis study (July 15 , 2016), one of the highest valuations in the sample in terms of revenue multiple. The case of Veeva provides an example of a strong firm valuation achieved as a result of both revenue growth and profitability. 
Table 23: Veeva Systems - Performance Summary

\begin{tabular}{|l|r|l|}
\hline \multicolumn{2}{|c|}{ Veeva Systems - Performance Summary } \\
\hline RevM & \multicolumn{1}{c|}{ Result } & \\
\hline FY Revenue (\$M) & 10.1 & $\begin{array}{l}\text { RevM = Enterprise Value (EV) measured as the Revenue Multiple } \\
\text { (or EV/Revenue) as of July } 15,2016 .\end{array}$ \\
\hline AVGYOYG & 409 & Annual revenue reported in prior fiscal year. \\
\hline AVGEB & $40 \%$ & $\begin{array}{l}\text { YOYG also referred to as AVGYOYG = average YoY revenue } \\
\text { growth over the prior three fiscal years. }\end{array}$ \\
\hline PF & $22 \%$ & $\begin{array}{l}\text { AVGEB = average EBITDA \% of revenue over the prior three } \\
\text { fiscal years. }\end{array}$ \\
\hline ROF* & 0.09 & PF (Performance Factor) = YOYG * AVGEB \\
\hline
\end{tabular}

* ROF is alternative measure to PF (for validity testing) discussed in Appendix G.

Veeva is a leading provider of industry cloud solutions for the life sciences industry. The firm was formed in 2007 and provides applications for multichannel customer relationship management, content management, master data management, and customer data. A strategic partner of Salesforce for the life sciences industry, the company counts approximately 1,800 employees and over 500 customers, including pharmaceuticals, biotechnology, medical products, contract sales organizations, and contract research organizations. As part of the strategic agreement, Salesforce provides hosting infrastructure, data center, and platform-level services for portions of Veeva's applications. Veeva's competitors include Oracle, Microsoft, OpenText, IBM, Informatica, QuintilesIMS, Medidata Solutions, Parexel International, BioClinica, Sparta Technologies, and Reltio.

The company completed its initial public offering (IPO) in October 2013 at a market capitalization of approximately $\$ 2$ billion (IPO Preview: Veeva Systems (2013, October 15). 
The firm has invested significantly in research and development (R\&D) to expand its offerings over time as well as in marketing and sales (M\&S) to promote its solutions to new and existing customers, in its service delivery capability (e.g., professional services) to ensure the continued success of its customers' implementations, and in other operational and administrative functions to support its rapid growth. At the same time, the firm did not pursue a "growth at all cost" and instead adopted a progressive approach by timing its spending with its growth.

To illustrate the consistency of spending patterns of high performers (discussed in my quantitative study), we can examine below Veeva's track record of spending (as a \% of revenue) over the three year-period of my analysis.

Table 24: Veeva Systems - Spending Patterns

\begin{tabular}{|c|c|c|c|c|}
\hline \multirow{2}{*}{\multicolumn{5}{|c|}{$\begin{array}{l}\text { Veeva Systems } \\
\text { Type of SaaS firm: Pure Play, Vertical (Life Sciences) }\end{array}$}} \\
\hline & & & & \\
\hline & Year 1 & Year 2 & Year 3 & STD \\
\hline Revenue (\$M) & 210 & 313 & 409 & \\
\hline COGS & $39 \%$ & $37 \%$ & $35 \%$ & 0.02 \\
\hline GM & $61 \%$ & $63 \%$ & $65 \%$ & \\
\hline$R \& D$ & $13 \%$ & $13 \%$ & $16 \%$ & 0.02 \\
\hline$M \& S$ & $20 \%$ & $18 \%$ & $20 \%$ & 0.01 \\
\hline G\&A & $10 \%$ & $10 \%$ & $10 \%$ & 0.00 \\
\hline AVG STD & & & & 0.01 \\
\hline \begin{tabular}{|l|} 
EBITDA \\
\end{tabular} & $20 \%$ & $24 \%$ & $21 \%$ & \\
\hline AVGYOYG & $40 \%$ & & & \\
\hline Revenue Multiple & 10.1 & & & \\
\hline
\end{tabular}

Over the three years, the firm achieved an impressive revenue growth (from \$210M in Year 1 to $\$ 409 \mathrm{M}$ in year 3) while improving its gross margin from $61 \%$ to $65 \%$ and keeping its R\&D spending below 20\% (of revenue) and Marketing and Sales (M\&S) at around 20\%. This relatively low spending level in M\&S (compared to a median spending of 
approximately $34 \%$ in the sample) is an illustration that vertical SaaS firms spend less in M\&S than generalist SaaS firms as explained earlier in my quantitative study. General and administrative (G\&A) expenses were maintained flat at 10\% of revenue. Overall, spending levels were relatively consistent over the 3 year-period with an average standard deviation of 0.01 .

When examining the spending patterns during a longer period than the 3 year-period used in my quantitative study, we confirm that the progressive and disciplined approach has been part of the company's growth strategy for several years prior to my study (Table 25). The average standard deviation is 0.03 for both pre-IPO and post-IPO periods. The increase from the earlier 0.01 score is primarily due to the longer period and the scale effect in the service delivery capability: i.e., decrease in cost of goods sold (COGS) from $46 \%$ in 2010 to $32 \%$ in 2017 . See also Figure 9.

Table 25: Veeva Systems - Spending Patterns over a Longer Period

\begin{tabular}{|c|c|c|c|c|c|c|c|c|c|c|}
\hline \multicolumn{11}{|l|}{ Veeva Systems } \\
\hline \multirow[b]{2}{*}{$\begin{array}{l}\text { Year-e nded: } \\
\text { January }\end{array}$} & \multirow[b]{2}{*}{2010} & \multirow[b]{2}{*}{2011} & \multirow[b]{2}{*}{2012} & \multirow{2}{*}{\begin{tabular}{|r|} 
IPO year \\
2013 \\
\end{tabular}} & \multicolumn{3}{|c|}{$\begin{array}{c}3 \text { year-period scope of } \\
\text { quantitative study (Ess ay One) }\end{array}$} & \multirow[b]{2}{*}{2017} & \multirow[b]{2}{*}{$\begin{array}{c}\text { Pre-IPO } \\
\text { STD }\end{array}$} & \multirow[b]{2}{*}{$\begin{array}{c}\text { Post-IPO } \\
\text { STD }\end{array}$} \\
\hline & & & & & 2014 & 2015 & 2016 & & & \\
\hline $\operatorname{Rev}(\$ M)$ & 13 & 29 & 61 & 130 & 210 & 313 & 409 & 544 & & \\
\hline COGS & $46 \%$ & $42 \%$ & $47 \%$ & $44 \%$ & $39 \%$ & $37 \%$ & $35 \%$ & $32 \%$ & 0.03 & 0.05 \\
\hline GM & $54 \%$ & $58 \%$ & $53 \%$ & $56 \%$ & $61 \%$ & $63 \%$ & $65 \%$ & $68 \%$ & & \\
\hline R\&D & $13 \%$ & $12 \%$ & $13 \%$ & $11 \%$ & $13 \%$ & $13 \%$ & $16 \%$ & $18 \%$ & 0.00 & 0.03 \\
\hline M\&S & $29 \%$ & $19 \%$ & $20 \%$ & $15 \%$ & $20 \%$ & $18 \%$ & $20 \%$ & $21 \%$ & 0.05 & 0.02 \\
\hline G\&A & $5 \%$ & $9 \%$ & $9 \%$ & $6 \%$ & $10 \%$ & $10 \%$ & $10 \%$ & $9 \%$ & 0.02 & 0.01 \\
\hline EBITDA & $8 \%$ & $18 \%$ & $11 \%$ & $24 \%$ & $20 \%$ & $24 \%$ & $21 \%$ & $22 \%$ & & \\
\hline YOY Growth & & $120 \%$ & $110 \%$ & $111 \%$ & $62 \%$ & $49 \%$ & $31 \%$ & $33 \%$ & & \\
\hline AVG STD & & & & & & & & & 0.03 & 0.03 \\
\hline \multicolumn{11}{|l|}{ Acquisitions } \\
\hline 2013 & \multicolumn{8}{|c|}{ AdvantageMS in Jun. 2013} & & \\
\hline 2015 & \multicolumn{8}{|c|}{$\begin{array}{l}\text { Key Opinion Leader (KOL) business and products of Qforma, Inc. and } \\
\text { Mederi AG in Mar. 2015; Zinc Ahead in Sep. } 2015\end{array}$} & & \\
\hline
\end{tabular}


The table above also includes Veeva's recent acquisitions, illustrating a point discussed in the extended literature review section and the insights from the practitioner interviews (earlier in this section) regarding the role of acquisitions as a complement or a substitute of internal resources, which I will discuss again later in my final section on the proposed research agenda for future research.

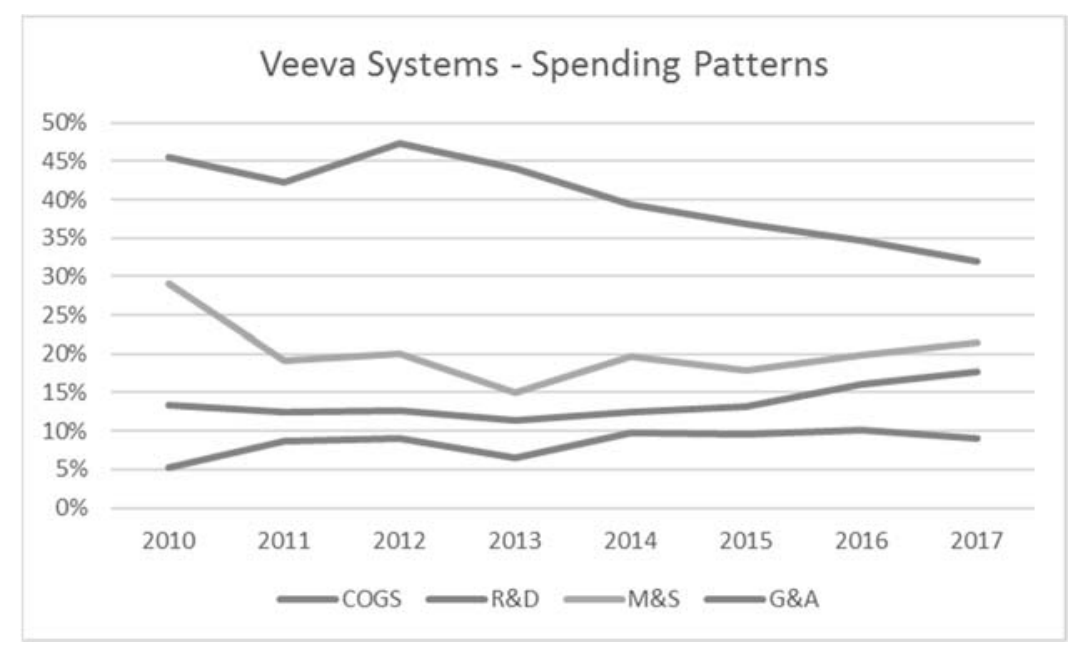

Figure 9: Veeva Systems - Spending Patterns

\section{The Case of Ellie Mae}

Ellie Mae was also a top 10-performer in the sample in terms of Performance Factor $(0.08)$ and Enterprise Value. Like Veeva Systems, the firm was valued at over 10 times revenue ( $\$ 2.5$ billion in the case of Ellie Mae) as of the date of the business valuation data in my earlier study (July 15, 2016). The case of Ellie Mae serves here as a second example of a strong firm valuation achieved as a result of both revenue growth and profitability. 
Table 26: Ellie Mae - Performance Summary

\begin{tabular}{|c|c|c|}
\hline \multicolumn{3}{|c|}{ Ellie Mae - Performance Summary } \\
\hline Variable & Result & Legend \\
\hline RevM & 10.3 & $\begin{array}{l}\text { RevM = Enterprise Value (EV) measured as the Revenue Multiple } \\
\text { (or EV/Revenue) as of July 15, } 2016 .\end{array}$ \\
\hline FY Revenue (\$M) & 254 & Annual revenue reported in prior fiscal year. \\
\hline AVGYOYG & $41 \%$ & $\begin{array}{l}\text { YOYG also referred to as AVGYOYG }=\text { average YoY revenue } \\
\text { growth over the prior three fiscal years. }\end{array}$ \\
\hline AVGEB & $20 \%$ & $\begin{array}{l}\text { AVGEB = average EBITDA \% of revenue over the prior three } \\
\text { fiscal years. }\end{array}$ \\
\hline PF & 0.08 & PF (Performance Factor) $=$ YOYG $*$ AVGEB \\
\hline ROF* & 61 & ROF $($ Rule of Forty Score $)=($ YOYG + AVGEB $) * 100$ \\
\hline
\end{tabular}

* ROF is alternative measure to PF (for validity testing) discussed in Appendix G.

Ellie Mae is a leading provider of software solutions and services for the residential mortgage industry in the United States. The firm was formed in 1997 and provides mortgage loan origination applications including customer relationship management, loan application and loan processing, underwriting, funding, and closing, including preparation of related documents and compliance. Clients include banks, credit unions, mortgage lenders and mortgage brokers. The firm has over 1,000 employees and competes with firms such as Black Knight, Accenture (Mortgage Cadence), Byte Software, Calyx, Wipro Gallagher Solutions, LendingQB, Altisource Portfolio Solutions (Mortgage Builder Software), and DH Corporation (now Finastra).

Ellie Mae completed its initial public offering in April 2011 at a market capitalization of approximately $\$ 150$ million (FT Partners, n.d.).

The firm was originally a provider of consumer-facing websites and on-premises software, entering the mortgage loan processing software business via two acquisitions (Genesis 2000 and Contour Software) in 2000 and 2001. It introduced its internally developed loan 
origination system, Encompass, in 2003 and made various other acquisitions to extend its offerings in complementary areas such as document preparation (ODI), compliance (Mavent), pricing (MPS), and others. Historically, Ellie Mae offered Encompass as an onpremises solution. Following the adverse economic conditions in the mortgage industry caused by the financial crisis in $2007-2008$, the company started to shift its focus to the cloud and, beginning in late 2009, focused its marketing and sales efforts on its Encompass SaaS offering. The company thought that its SaaS solution would be more attractive in the new residential mortgage business environment (mainly because, with the SaaS model, customers do not have to pay a significant up-front licensing fee). As part of its SaaS strategy, the firm engaged a critical effort to migrate its on-premises software clients to the SaaS solution. In its latest SEC filings (12-31-2016 10-K report filed in February 2017), the company reported that it completed the migration of its Encompass customers to the on-demand Encompass offering around mid-2016.

Here again the company adopted a progressive approach in building its key capabilities in the new cloud environment. Ellie Mae's consistency of spending patterns is illustrated in the table 27 . 
Table 27: Ellie Mae - Spending Patterns

\begin{tabular}{|c|c|c|c|c|}
\hline \multirow{2}{*}{\multicolumn{5}{|c|}{ Type of SaaS firm: Hybrid, Vertical (Financial Services) }} \\
\hline & & & & \\
\hline & Year 1 & Year 2 & Year 3 & STD \\
\hline Revenue (\$M) & 128 & 162 & 254 & \\
\hline COGS & $25 \%$ & $29 \%$ & $33 \%$ & 0.04 \\
\hline GM & $75 \%$ & $71 \%$ & $67 \%$ & \\
\hline $\mathrm{R} \& \mathrm{D}$ & $19 \%$ & $17 \%$ & $16 \%$ & 0.02 \\
\hline M\&S & $17 \%$ & $16 \%$ & $15 \%$ & 0.01 \\
\hline G\&A & $24 \%$ & $24 \%$ & $23 \%$ & 0.01 \\
\hline AVG STD & & & & 0.02 \\
\hline EBITDA & $20 \%$ & $19 \%$ & $20 \%$ & \\
\hline AVGYOYG & $41 \%$ & & & \\
\hline Revenue Multiple & 10.3 & & & \\
\hline
\end{tabular}

Over the three years, the firm doubled its size in terms of annual revenues (from $\$ 128 \mathrm{M}$ in Year 1 to $\$ 254 \mathrm{M}$ in year 3), while maintaining both R\&D spending and M\&S spending below $20 \%$ of revenue. Like Veeva Systems, Ellie Mae illustrates that vertical SaaS firms tend to spend less as a percentage of revenue compared to generalist SaaS firms. Although its gross margin contracted from $75 \%$ to $67 \%$, the firm maintained its R\&D, M\&S, and G\&A spending at relatively consistent levels (as a percentage of revenue) during the three year-period, resulting in an overall average standard deviation of 0.02 .

When examining Ellie Mae's spending trends prior to the three year-period of my initial analysis, we find that spending levels are again relatively consistent over the years (Table 28). The average standard deviation for pre-IPO and post-IPO periods was respectively 0.04 and 0.03 . Again, the increase from the earlier 0.02 score can be attributed to the longer period and the scale effects, particularly notable in the R\&D and M\&S areas (Table 28 and Figure 10). 
Table 28: Ellie Mae - Spending Patterns over a Longer Period

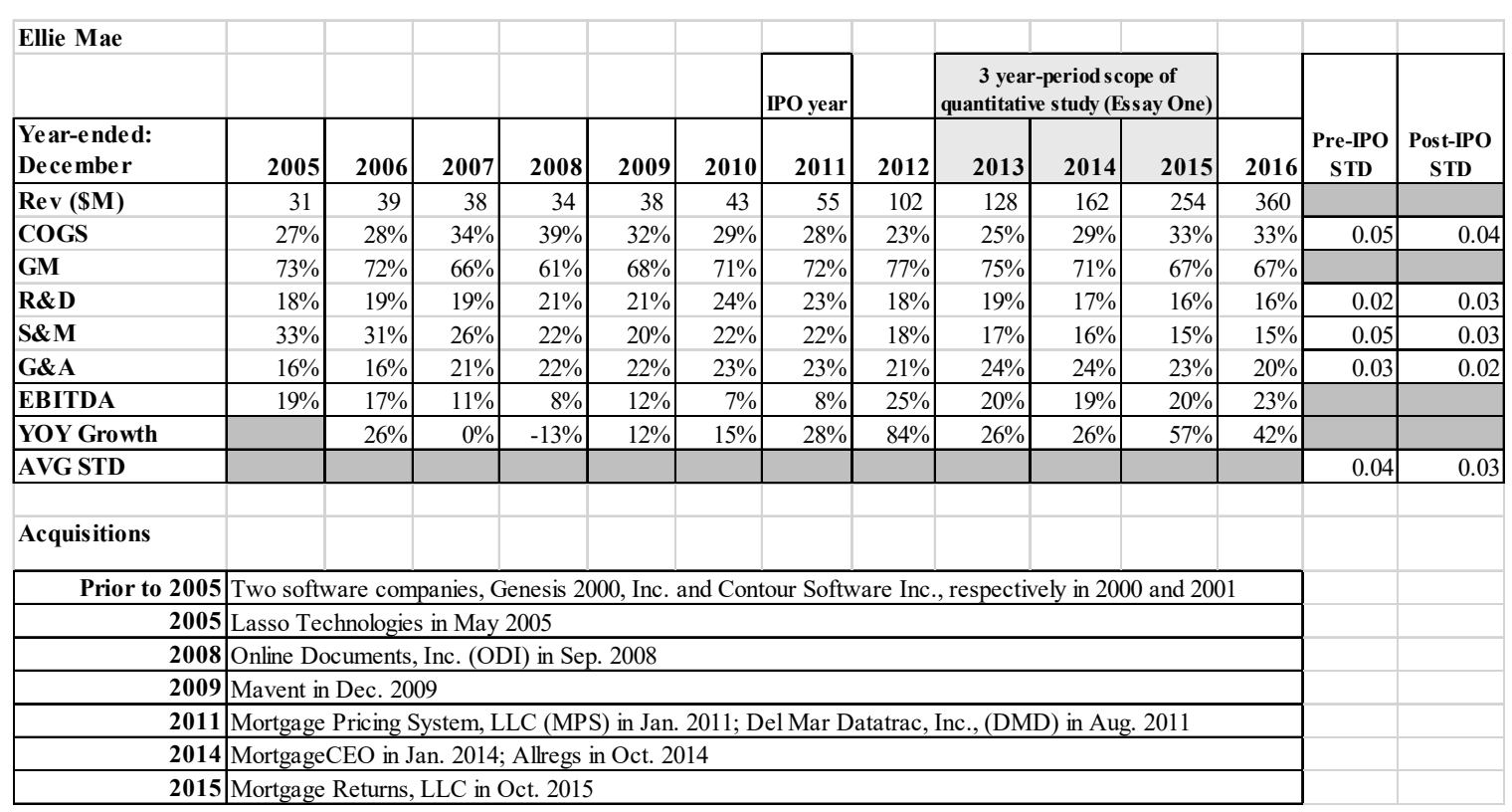

It's interesting to note that R\&D spending as a percentage of revenue trended above $20 \%$ from 2008 to 2011 , peaking at $24 \%$ in 2010 , as the company shifted its focus to the cloud prior to the completion of its IPO in 2011. It's also interesting to note that the company's revenue growth was flat in 2007 and negative $13 \%$ in 2008. In its initial prospectus dated April 30, 2010, the firm indicated:

Our research and development expenses have remained relatively constant over the period covered by this prospectus and our business is not capital intensive. We have responded to adverse economic conditions, such as those that commenced in 2007 , by reducing headcount, which is a major component of our operating expenses.

The company was able to transition to SaaS while optimizing its spending and maintaining EBITDA profitability in an adverse economic environment (2007-2008 mortgage industry meltdown and financial crisis). In addition, the company made strategic acquisitions which extended the firm's capabilities, indicating that the firm's strong performance was the result of both organic and inorganic growth strategies. 


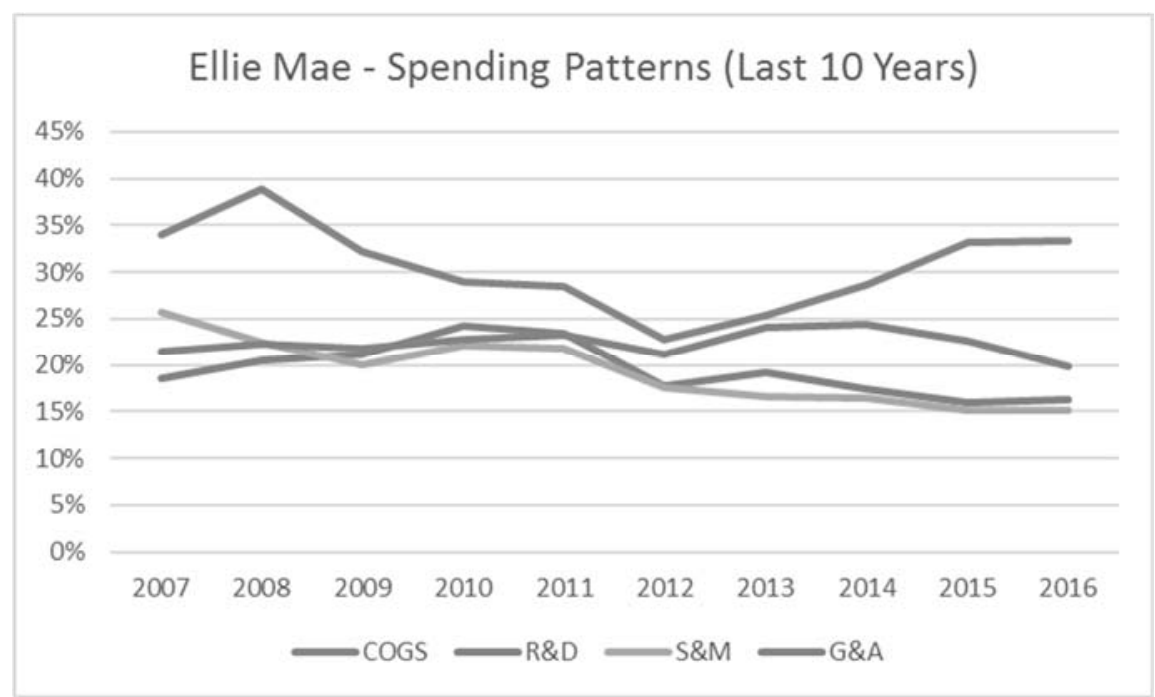

Figure 10: Ellie Mae - Spending Patterns (Last 10 Years)

\section{The Case of Covisint}

Covisint was one of the bottom 10-performers in the sample in terms of Performance Factor (PF) and Enterprise Value. The PF result was not meaningful due to the firm's negative growth and negative profitability (a result which I referred to as a double-negative in my quantitative study). Regarding its Enterprise Value, the firm was valued at less than one time revenue: revenue multiple of 0.6 or approximately $\$ 50$ million, as of the time of the measure in my quantitative analysis study (July 15, 2016), one of the lowest valuations in the sample in terms of revenue multiple. The case of Covisint provides an example of laggard firm performance for purpose of illustrating the volatility of spending patterns, compared to top performers. 
Table 29: Covisint - Performance Summary

Covisint - Performance Summary
\begin{tabular}{|l|r|l|}
\hline \multicolumn{1}{|c|}{ Variable } & \multicolumn{1}{c|}{ Result } & \multicolumn{1}{c|}{ Legend } \\
\hline RevM & 0.6 & $\begin{array}{l}\text { RevM = Enterprise Value (EV) measured as the Revenue Multiple } \\
\text { (or EV/Revenue) as of July } 15,2016 .\end{array}$ \\
\hline FY Revenue (\$M) & 76 & Annual revenue reported in prior fiscal year. \\
\hline AVGYOYG & $-11 \%$ & $\begin{array}{l}\text { YOYG also referred to as AVGYOYG = average YoY revenue } \\
\text { growth over the prior three fiscal years. }\end{array}$ \\
\hline AVGEB & $-20 \%$ & $\begin{array}{l}\text { AVGEB = average EBITDA \% of revenue over the prior three } \\
\text { fiscal years. }\end{array}$ \\
\hline PF & n.m. $* *$ & PF (Performance Factor) $=$ YOYG * AVGEB \\
\hline ROF* & -32 & ROF (Rule of Forty Score) $=($ YOYG+AVGEB) $* 100$ \\
\hline
\end{tabular}

* ROF is alternative measure to PF (for validity testing) discussed in Appendix G.

** Not meaningful (double negative).

Covisint provides a SaaS platform to build applications for digital identity management and internet of things (IoT) and connected vehicle solutions for the automotive and various other industries. The firm was founded in 2000 by a consortium of automotive manufacturers to streamline collaboration with their network of suppliers. The effort gave birth to a SaaS application called the Auto Supply Portal in 2003. Compuware, a large software firm, purchased the assets of Covisint in 2004 and expanded its capabilities to position the technology suite as a business-to-business (B2B) cloud collaboration platform for enterprises in the automotive and other industries. Then, in 2013, Compuware spun off Covisint and took it public. Covisint completed its IPO in October 2013 at a market value of approximately $\$ 365$ million (Henderson, 2013).

According to its latest SEC filings (10-K report filed on June 5, 2017), the firm has approximately 300 employees and more than 2,000 customers in various industries, including automotive, energy, travel, life sciences, consumer goods and insurance. It competes with large systems integrators such as IBM, Hewlett Packard Enterprise, and 
Dell, as well as cloud-based platform vendors, such as Salesforce.com and Microsoft Azure, and B2B integration and data exchange vendors, such as Open Text and Sterling Commerce (division of IBM), and other specialized firms.

At the time the company filed its latest $10-\mathrm{K}$ report, Open Text announced it entered into a definitive agreement to acquire Covisint for $\$ 103$ million (Open Text, 2017, June 5). The acquisition was completed in July 2017 (Open Text, 2017, July 26).

During the three year-period of my quantitative analysis, Covisint was in revenue decline position and had to take cost reduction measures to contain its losses. The firm's size contracted from annual revenues of $\$ 97$ million, 3,000 customers and 631 employees in fiscal year 2014 to annual revenues of $\$ 76$ million, more than 2,000 customers, and 338 employees in fiscal year 2016.

In its 2014 10-K report (filed on May 30, 2014), the company reported that it was undertaking a series of strategic initiatives to refocus the business, reposition the company for success as a cloud-based enterprise software firm focused on products and core industry verticals, and shift away from its lower margin service business. Among these initiatives, the firm reported that it was moving to align its costs to match its revenue plan through a reduction in workforce anticipated to reduce the Company's expense structure by $\$ 19$ million. These restructuring and transformation efforts resulted in volatility in spending patterns during the period, with an average standard deviation of 0.06 (Table 30). 
Table 30: Covisint - Spending Patterns

\begin{tabular}{|c|c|c|c|c|}
\hline Covisint & & & & \\
\hline \multicolumn{5}{|c|}{ Type of SaaS firm: Pure Play, Cross-Industry } \\
\hline & Year 1 & Year 2 & Year 3 & STD \\
\hline Revenue (\$M) & 97 & 89 & 76 & \\
\hline COGS & $58 \%$ & $75 \%$ & $46 \%$ & 0.15 \\
\hline GM & $42 \%$ & $25 \%$ & $54 \%$ & \\
\hline$R \& D$ & $13 \%$ & $12 \%$ & $17 \%$ & 0.03 \\
\hline$M \& S$ & $36 \%$ & $37 \%$ & $39 \%$ & 0.01 \\
\hline G\&A & $30 \%$ & $20 \%$ & $17 \%$ & 0.06 \\
\hline AVG STD & & & & 0.06 \\
\hline EBITDA & $-28 \%$ & $-23 \%$ & $-10 \%$ & \\
\hline AVGYOYG & $-11 \%$ & & & \\
\hline Revenue Multiple & 0.6 & & & \\
\hline
\end{tabular}

As Table 30 shows, volatility in spending patterns was primarily in the areas of cost of goods sold (COGS) and G\&A, reflecting the company's efforts to transform its business away from lower margin services to higher margin software platform revenue and overall expense structure alignment to match revenue plans and reduce its EBITDA loss. In its 2014 10-K report, Covisint indicated:

We expect our cost of revenue may fluctuate as a percentage of total revenue due to relative changes in our services revenue, changes in the percentage of services recognized using the proportional performance method, the amount and timing of depreciation and amortization, changes in the amount of services performed by our customers or other vendors and the mix of subscription and support revenue relative to services revenue.

Regarding the high level of G\&A spending in 2014 and plans moving forward, the company provided the following information (in the same 10-K report):

During 2014, general and administrative costs were primarily comprised of the allocated costs related to the services provided by our parent Compuware for facilities, information technology, tax, internal audit, accounting, finance, human resources, legal and other services, as well as 
salaries and personnel-related expenses including stock and cash incentive compensation. Since August 2013, we have invested in hiring staff required to become a fully independent company. As of April 1, 2014, we have largely completed our general and administrative separation from Compuware, and we do not anticipate any significant allocation from Compuware in the future.

When reviewing Covisint's spending patterns prior to fiscal year 2014 (the fiscal year of its IPO), we note that the company was growing $(20 \%+$ to $30 \%+$ year over year) while maintaining near EBITDA breakeven or slightly positive and that it had a more consistent cost structure over time, with an average standard deviation of 0.02 (Table 31).

Table 31: Covisint - Spending Patterns over a Longer Period

\begin{tabular}{|c|c|c|c|c|c|c|c|c|c|c|}
\hline \multirow[t]{2}{*}{ Covisint } & & & & & IPO year & & & \multirow[b]{3}{*}{2017} & \multirow{3}{*}{$\begin{array}{c}\text { Pre-IPO } \\
\text { STD } \\
\end{array}$} & \multirow{3}{*}{$\begin{array}{c}\text { Post-IPO } \\
\text { STD }\end{array}$} \\
\hline & & & & & \multicolumn{3}{|c|}{$\begin{array}{c}\text { 3 year-period scope of } \\
\text { quantitative study (Essay One) }\end{array}$} & & & \\
\hline Year-e nded: March & 2010 & 2011 & 2012 & 2013 & 2014 & 2015 & 2016 & & & \\
\hline $\operatorname{Rev}(\$ M)$ & 40 & 54 & 75 & 91 & 97 & 89 & 76 & 70 & & \\
\hline COGS & $47 \%$ & $51 \%$ & $56 \%$ & $52 \%$ & $58 \%$ & $75 \%$ & $46 \%$ & $47 \%$ & 0.03 & 0.13 \\
\hline GM & $53 \%$ & $49 \%$ & $44 \%$ & $48 \%$ & $42 \%$ & $25 \%$ & $54 \%$ & $53 \%$ & & \\
\hline R\&D & $10 \%$ & $3 \%$ & $2 \%$ & $4 \%$ & $13 \%$ & $12 \%$ & $17 \%$ & $16 \%$ & 0.04 & 0.03 \\
\hline $\mathbf{S \& M}$ & $32 \%$ & $31 \%$ & $30 \%$ & $29 \%$ & $36 \%$ & $37 \%$ & $39 \%$ & $38 \%$ & 0.01 & 0.01 \\
\hline G\&A & $20 \%$ & $19 \%$ & $17 \%$ & $20 \%$ & $30 \%$ & $20 \%$ & $17 \%$ & $16 \%$ & 0.02 & 0.06 \\
\hline EBITDA & $-1 \%$ & $4 \%$ & $2 \%$ & $1 \%$ & $-28 \%$ & $-23 \%$ & $-10 \%$ & $-8 \%$ & & \\
\hline YOY Growth & & $34 \%$ & $38 \%$ & $22 \%$ & $7 \%$ & $-9 \%$ & $-14 \%$ & $-8 \%$ & & \\
\hline AVG STD & & & & & & & & & 0.02 & 0.06 \\
\hline & & & & & & & & & & \\
\hline Acquisitions & & & & & & & & & & \\
\hline Prior to 2010 & Covisint a & uired by & Compuw & $\mathrm{re} \mathrm{in} \mathrm{Ma}$ & $\operatorname{arch} 2004$ & i $\$ 7$ mill & & & & \\
\hline (FY) 2011 & DocSite in & ep 2010 & & & & & & & & \\
\hline After (FY) 2017 & Covisint a & uired by & DenTex & in Jun. & 2017 for $\$$ & 33 millior & & & & \\
\hline
\end{tabular}

Of note, Covisint's gross margin was below the median of approximately $65 \%+$ in the sample, indicating that the company's service delivery capability was not as efficient as other SaaS companies, due to factors such as a significant portion of its revenues consisting of lower margin services as discussed earlier. The decrease in $R \& D$ spending as a percentage of the revenue in 2011-2013 was attributed by the company to the increase in 
software capitalization made possible by the firm's improved time tracking system according to its prospectus (Form S-1 filed on May 14, 2013). The increase in fiscal year 2014 was explained in the firm's 2014 10-K report (filed on May 30, 2014) as follows:

We capitalized a smaller portion of our research and development costs in fiscal 2014 as a result of the change to the agile delivery methodology for our platform enhancements, which resulted in significantly shorter development cycles thereby reducing our capitalized costs.

Again, these points illustrate that lower performance often comes with greater volatility of spending patterns as firms are working through restructuring and transformation efforts to improve their competitiveness and performance (as shown in Table 31 and Figure 11).

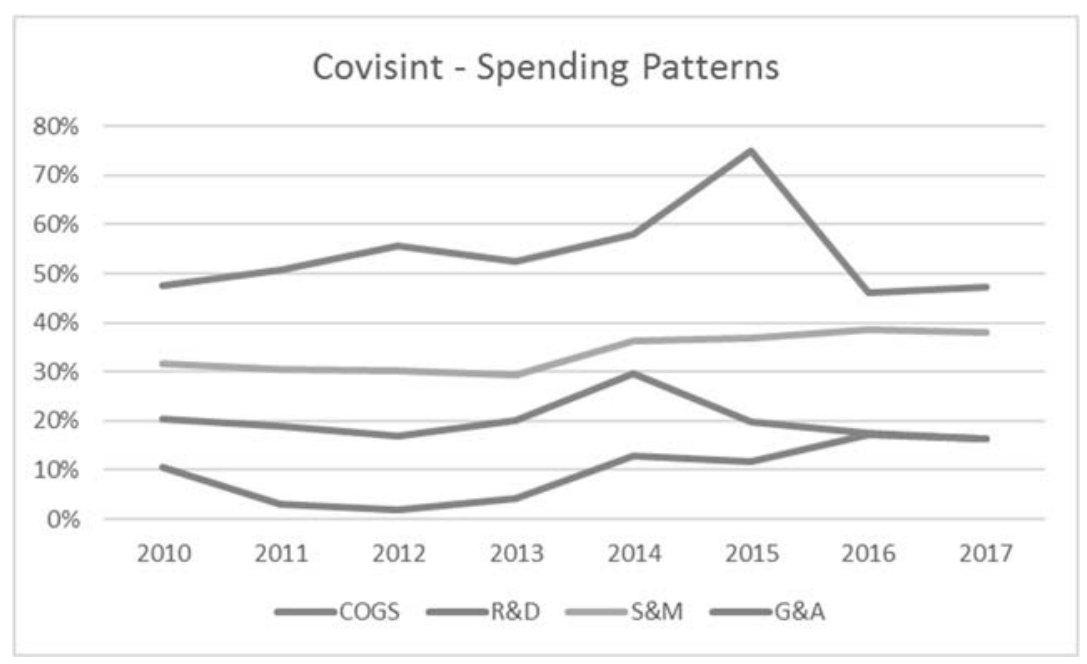

Figure 11: Covisint - Spending Patterns

\section{The Case of BroadVision}

BroadVision was also one of the bottom 10-performers in the sample. Like Covisint, BroadVision's Performance Factor was not meaningful (due to the firm's negative growth and negative profitability) and its Enterprise Value was less than one time revenue: revenue multiple of 0.5 or less than $\$ 5$ million, as of the time of the measure in my quantitative 
analysis study (July 15, 2016). The case of BroadVsion provides another example of laggard firm performance for purpose of illustrating the volatility of spending patterns, compared to top performers.

Table 32: BroadVision - Performance Summary

BroadVision - Performance Summary
\begin{tabular}{|l|r|l|}
\hline \multicolumn{1}{|c|}{ Variable } & \multicolumn{1}{c|}{ Result } & \multicolumn{1}{c|}{ Legend } \\
\hline RevM & 0.5 & $\begin{array}{l}\text { RevM = Enterprise Value (EV) measured as the Revenue Multiple } \\
\text { (or EV/Revenue) as of July 15, 2016. }\end{array}$ \\
\hline FY Revenue (\$M) & 9 & Annual revenue reported in prior fiscal year. \\
\hline AVGYOYG & $-22 \%$ & $\begin{array}{l}\text { YOYG also referred to as AVGYOYG = average YoY revenue } \\
\text { growth over the prior three fiscal years. }\end{array}$ \\
\hline AVGEB & $-64 \%$ & $\begin{array}{l}\text { AVGEB = average EBITDA \% of revenue over the prior three } \\
\text { fiscal years. }\end{array}$ \\
\hline PF & n.m.** & PF (Performance Factor) = YOYG * AVGEB \\
\hline ROF* & -85 & ROF (Rule of Forty Score) = (YOYG+AVGEB) * 100 \\
\hline
\end{tabular}

* ROF is alternative measure to PF (for validity testing) discussed in Appendix G.

** Not meaningful (double negative).

BroadVision is an e-business solutions provider offering a wide range of applications for cloud-based and mobile collaboration, information sharing, knowledge management, and e-commerce. The firm was founded in 1993 and went public in 1996 at a market value of approximately \$200 million (BroadVision, Inc.: Filing for IPO is entered by internet software firm, 1996, May 13). BroadVision's customers consist of enterprises of all sizes and from all industries. The company had 145 employees as of December 31, 2016.

BroadVision's competitors include e-commerce and portal system vendors (e.g., JDA, IBM, Microsoft, Oracle, SAP), enterprise social networking and collaboration platform vendors (e.g., Microsoft's Yammer, Jive Software, Salesforce Chatter, Slack, and Facebook's Facebook@Work), and various vendors that provide custom software development and integration services. 
During the three year-period of my quantitative analysis, BroadVision was in revenue decline position with significant EBITDA losses. The firm's size contracted from annual revenues of \$16 million and 186 employees in fiscal year 2013 to annual revenues of \$9 million and 156 employees in fiscal year 2015. Pressures from revenue decline resulted in volatility in spending patterns during the period, with an average standard deviation of 0.08 (Table 33).

Table 33: BroadVision - Spending Patterns

\begin{tabular}{|l|r|r|r|r|}
\hline \multicolumn{2}{|l|}{ BroadVision } & \multicolumn{1}{l|}{} \\
\hline Type of SaaS firm: Hybrid, Cross-Industry & & & \\
\cline { 2 - 5 } & Year 1 & Year 2 & Year 3 & STD \\
\hline Revenue (\$M) & 16 & 14 & 9 & \\
\hline COGS & $31 \%$ & $34 \%$ & $37 \%$ & 0.03 \\
\hline GM & $69 \%$ & $66 \%$ & $63 \%$ & \\
\hline R\&D & $45 \%$ & $54 \%$ & $76 \%$ & 0.16 \\
\hline M\&S & $36 \%$ & $38 \%$ & $52 \%$ & 0.09 \\
\hline G\&A & $25 \%$ & $29 \%$ & $37 \%$ & 0.06 \\
\hline AVG STD & & & & 0.08 \\
\hline EBITDA & $-36 \%$ & $-54 \%$ & $-101 \%$ & \\
\hline & & & & \\
\hline AVGYOYG & $-22 \%$ & & & \\
\hline Revenue Multiple & 0.5 & & & \\
\hline
\end{tabular}

In its latest 10-K report (filed on March 30, 2017), the company commented:

Our operations face two key challenges: maturity of our major revenuegenerating legacy products, and competing in a crowded ESN (enterprise social networking) solution space. We continue to invest heavily in cloudbased, mobile, messaging and collaboration technologies, while continuing to support our legacy base. Total 2016 revenues of $\$ 7.9$ million were lower compared to total 2015 revenues of $\$ 9.4$ million, with the decrease mainly in legacy revenue. We expect that the decline in our legacy revenue, which is the majority of our revenue mix, will continue to dominate our overall financial performance until a significant installed base of new product revenues is established. We are continuing to diligently invest in new technologies in an effort to maintain our competitive advantages in the mobile communications and collaboration and knowledge management spaces. 
The longer historical view of BroadVision's financial performance indicates that the company has been in continued decline since 2000 with sporadic EBITDA performance between 1998 and 2009. The firm has not generated positive EBITDA since 2009 (Table 34).

Table 34: BroadVision - Spending Patterns over a Longer Period

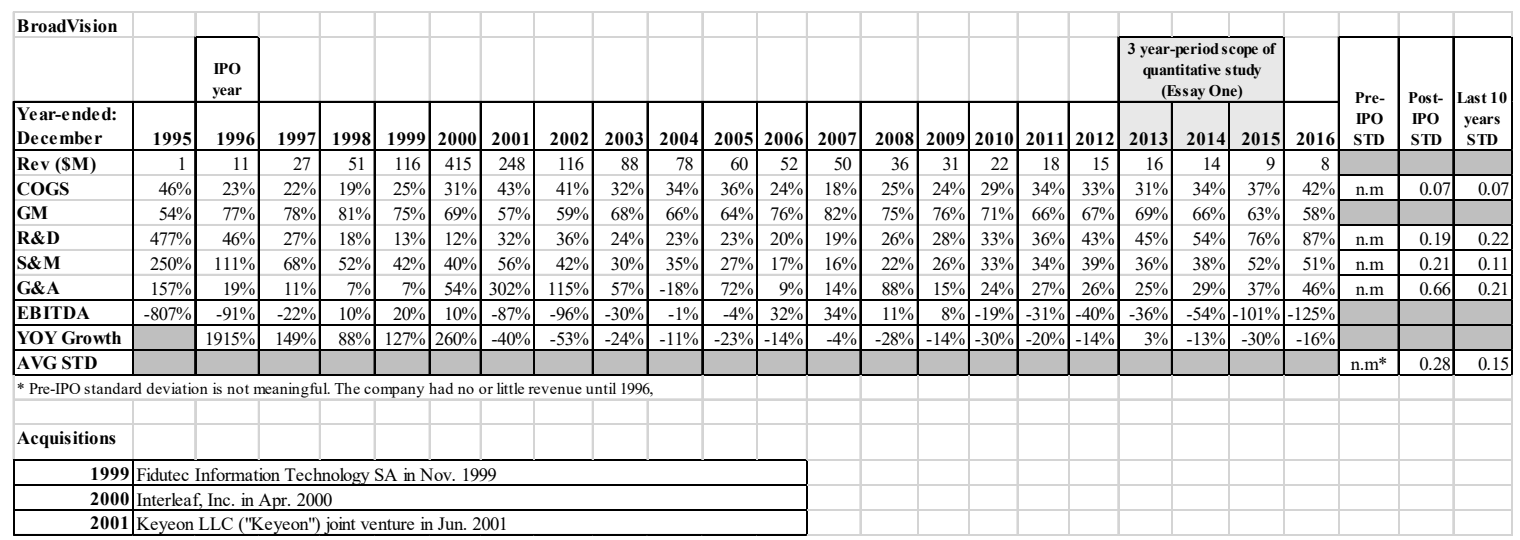

Since its IPO, the average standard deviation was 0.28 . In the last 10 years, it was 0.15 . These results again illustrate the greater volatility of spending patterns of underperforming firms (as shown in Table 34 and Figure 12).

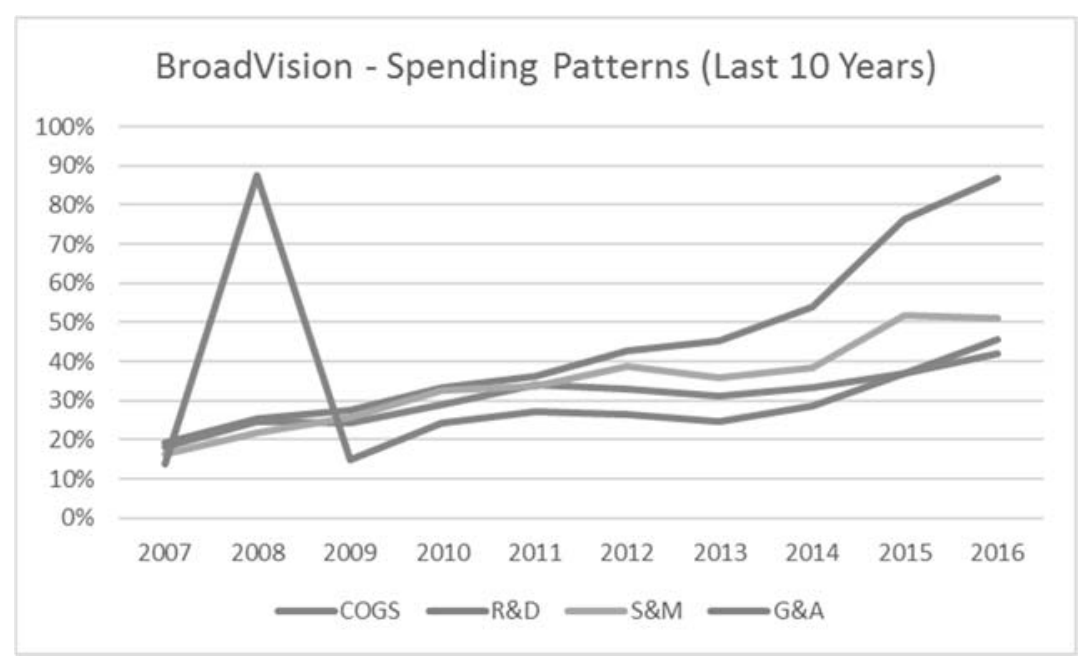

Figure 12: BroadVision - Spending Patterns (Last 10 Years) 


\section{The Case of Salesforce}

A pioneer of SaaS technology, Salesforce.com (Salesforce) is one of the most well-known SaaS firms in the world and it is widely used as an example in the SaaS business community. In my study, Salesforce achieved a Performance Factor of 0.02 with an Enterprise Value of 7.8 times revenue (more than $\$ 55$ billion) as of July 15, 2016. The case of Salesforce provides an example of a pure-play SaaS firm with a long history of growth and that has reached a certain level of maturity in the industry as the firm was among the first firms to introduce a SaaS application on the market.

Table 35: Salesforce - Performance Summary

\begin{tabular}{|l|r|l|}
\hline \multicolumn{1}{|c|}{ Salesforce - Performance Summary } \\
\hline Variable & \multicolumn{1}{|c|}{ Result } & \multicolumn{1}{c|}{ Legend } \\
\hline RevM & 7.8 & $\begin{array}{l}\text { RevM = Enterprise Value (EV) measured as the Revenue Multiple } \\
\text { (or EV/Revenue) as of July 15, 2016. }\end{array}$ \\
\hline FY Revenue (\$M) & 6,667 & Annual revenue reported in prior fiscal year. \\
\hline AVGYOYG & $28 \%$ & $\begin{array}{l}\text { YOYG also referred to as AVGYOYG = average YoY revenue } \\
\text { growth over the prior three fiscal years. }\end{array}$ \\
\hline AVGEB & $7 \%$ & $\begin{array}{l}\text { AVGEB = average EBITDA \% of revenue over the prior three } \\
\text { fiscal years. }\end{array}$ \\
\hline PF & 0.02 & PF (Performance Factor) = YOYG * AVGEB \\
\hline ROF* & 35 & ROF (Rule of Forty Score) = (YOYG+AVGEB) * 100 \\
\hline
\end{tabular}

* ROF is alternative measure to PF (for validity testing) discussed in Appendix G.

Salesforce is a leading provider of cloud-based enterprise software, with a focus on customer relationship management (CRM). Formed in 1999, the firm serves the needs of enterprises of all sizes and industries. Its offerings encompass sales force automation, customer service and support, marketing automation, digital commerce, community management, analytics, application development, internet of things (IoT) integration, 
collaborative productivity tools and professional cloud services. The firm counted more than 25,000 employees as of January 31, 2017.

Salesforce's competitors include enterprise software vendors (such as Oracle, SAP, Microsoft, Sage and many others) and various marketing automation and e-business vendors as well as platform and cloud computing application service providers.

The company completed its IPO in June 2004 at a market capitalization of approximately $\$ 1.1$ billion (Salesforce.com boosts IPO price, 2004, June 23).

The firm has pursued a continuous innovation strategy over the years (e.g., continuously expanding offerings, platform-as-a-service strategy, analytics, etc.) with ongoing investments in $R \& D$ as well as via acquisitions. In addition, Marketing and Sales (M\&S) expenses have consistently represented a substantial portion of its spending as a percentage of revenue. The higher spending in M\&S compared to the earlier cases of Veeva Systems and Ellie Mae is consistent with the findings of my quantitative study (i.e., generalist firms spend more in M\&S as a percentage of revenue than vertical firms because they address a much broader market). The high level of spending in M\&S and the overall consistency in spending patterns of the firm are illustrated in Table 36. 
Table 36: Salesforce - Spending Patterns

\begin{tabular}{|c|c|c|c|c|}
\hline Sales force & & & & \\
\hline \multicolumn{5}{|c|}{ Type of SaaS firm: Pure Play, Cross-Industry } \\
\hline & Year 1 & Year 2 & Year 3 & STD \\
\hline Revenue (\$M) & 4,071 & 5,374 & 6,667 & \\
\hline COGS & $24 \%$ & $24 \%$ & $25 \%$ & 0.01 \\
\hline GM & $76 \%$ & $76 \%$ & $75 \%$ & \\
\hline R\&D & $15 \%$ & $15 \%$ & $14 \%$ & 0.01 \\
\hline$M \& S$ & $53 \%$ & $51 \%$ & $49 \%$ & 0.02 \\
\hline G\&A & $15 \%$ & $13 \%$ & $11 \%$ & 0.02 \\
\hline AVG STD & & & & 0.01 \\
\hline EBITDA & $3 \%$ & $6 \%$ & $10 \%$ & \\
\hline AVGYOYG & $28 \%$ & & & \\
\hline Revenue Multiple & 7.8 & & & \\
\hline
\end{tabular}

During the three year-period of my quantitative analysis, the firm's size grew from annual revenues of $\$ 4.1$ billion and 13,300 employees in fiscal year 2014 to annual revenues of \$6.7 billion and 19,000 employees in fiscal year 2016. Despite this significant growth, the firm's spending patterns were the same year over year: the average standard deviation was 0.01 .

When reviewing the full history of the firm's financials since its IPO, we again find that the firm's spending patterns have been consistent for many years. The average standard deviation since 2005, the fiscal year of its IPO, was 0.02. It was also 0.02 in the last 10 years of the firm (Table 37). The increase from 0.01 is again explained by the longer period of observation. 
Table 37: Salesforce - Spending Patterns over a Longer Period

\begin{tabular}{|c|c|c|c|c|c|c|c|c|c|c|c|c|c|c|c|c|c|c|c|c|}
\hline \multicolumn{21}{|l|}{ Sale sforce } \\
\hline & & & & & $\begin{array}{l}\text { IPO } \\
\text { year }\end{array}$ & & & & & & & & & \multicolumn{3}{|c|}{$\begin{array}{l}3 \text { year-period scope of } \\
\text { quantitative study (Essay } \\
\text { One) }\end{array}$} & & \multirow[b]{2}{*}{$\begin{array}{c}\text { Pre-IPO } \\
\text { STD }\end{array}$} & \multirow{2}{*}{$\begin{array}{l}\text { Post- } \\
\text { IPO } \\
\text { STD }\end{array}$} & \multirow{2}{*}{$\begin{array}{c}\text { Last } 10 \\
\text { years } \\
\text { STD }\end{array}$} \\
\hline $\begin{array}{l}\text { Year-ended: } \\
\text { January }\end{array}$ & 2001 & 2002 & 2003 & 2004 & 2005 & 2006 & 2007 & 2008 & 2009 & 2010 & 2011 & 2012 & 2013 & 2014 & 2015 & 2016 & 2017 & & & \\
\hline $\operatorname{Rev}(\$ M)$ & 5 & 22 & 51 & 96 & 176 & 310 & 497 & 749 & 1,077 & 1,306 & 1,657 & \begin{tabular}{l|}
2,267 \\
\end{tabular} & \begin{tabular}{l|l}
3,050 \\
\end{tabular} & \begin{tabular}{l|l}
4,071 \\
\end{tabular} & 5,374 & \begin{tabular}{ll|}
6,667 \\
\end{tabular} & 8,392 & & & \\
\hline COGS & $63 \%$ & $27 \%$ & $20 \%$ & $18 \%$ & $19 \%$ & $22 \%$ & $24 \%$ & $23 \%$ & $20 \%$ & $20 \%$ & $20 \%$ & $22 \%$ & $22 \%$ & $24 \%$ & $24 \%$ & $25 \%$ & $27 \%$ & 0.21 & 0.02 & 0.02 \\
\hline GM & $37 \%$ & $73 \%$ & $80 \%$ & $82 \%$ & $81 \%$ & $78 \%$ & $76 \%$ & $77 \%$ & $80 \%$ & $80 \%$ & $80 \%$ & $78 \%$ & $78 \%$ & $76 \%$ & $76 \%$ & $75 \%$ & $73 \%$ & & & \\
\hline R\&D & $62 \%$ & $24 \%$ & $9 \%$ & $7 \%$ & $6 \%$ & $8 \%$ & $9 \%$ & $9 \%$ & $9 \%$ & $10 \%$ & $11 \%$ & $13 \%$ & $14 \%$ & $15 \%$ & $15 \%$ & $14 \%$ & $14 \%$ & 0.25 & 0.03 & 0.02 \\
\hline S\&M & $467 \%$ & $110 \%$ & $66 \%$ & $57 \%$ & $55 \%$ & $48 \%$ & $51 \%$ & $50 \%$ & $50 \%$ & $46 \%$ & $48 \%$ & $52 \%$ & $53 \%$ & $53 \%$ & $51 \%$ & $49 \%$ & $47 \%$ & 1.96 & 0.03 & 0.02 \\
\hline G\&A & $126 \%$ & $71 \%$ & $25 \%$ & $14 \%$ & $17 \%$ & $15 \%$ & $17 \%$ & $16 \%$ & $15 \%$ & $15 \%$ & $15 \%$ & $15 \%$ & $14 \%$ & $15 \%$ & $13 \%$ & $11 \%$ & $12 \%$ & 0.51 & 0.02 & 0.02 \\
\hline EBITDA & $-581 \%$ & $-121 \%$ & $-15 \%$ & $7 \%$ & $5 \%$ & $8 \%$ & $2 \%$ & $6 \%$ & $9 \%$ & $13 \%$ & $12 \%$ & $6 \%$ & $4 \%$ & $3 \%$ & $6 \%$ & $10 \%$ & $9 \%$ & & & \\
\hline YOY Growth & & $312 \%$ & $128 \%$ & $88 \%$ & $84 \%$ & $76 \%$ & $60 \%$ & $51 \%$ & $44 \%$ & $21 \%$ & $27 \%$ & $37 \%$ & $35 \%$ & $33 \%$ & $32 \%$ & $24 \%$ & $26 \%$ & & & \\
\hline AVG STD & & & & & & & & & & & & & & & & & & 0.73 & 0.02 & 0.02 \\
\hline \multirow{2}{*}{\multicolumn{21}{|c|}{ Acquisitions }} \\
\hline & & & & & & & & & & & & & & & & & & & & \\
\hline 2001 & \multicolumn{17}{|c|}{ Joint venture agreement with SunBridge, Inc. to establish Salesforce Japan in Dec 2000 (2001 fiscal year) } & & & \\
\hline 2007 & \multicolumn{17}{|c|}{ Sendia Corporation in Apr 2006 (2007 fiscal year); additional shares of its joint venture in Salesforce Japan for \$2.8 million in cash. } & & & \\
\hline 2009 & \multicolumn{17}{|c|}{ InStranet, Inc. in Aug 2008; minority interests of its joint venture, Salesforce Japan (2009 fiscal year) } & & & \\
\hline 2010 & \multicolumn{17}{|c|}{ Two privately-held companies for $\$ 12.0$ million in cash } & & & \\
\hline 2011 & \multicolumn{17}{|c|}{$\begin{array}{l}\text { Jigsaw Data Corporation in May 2010; Heroku, Inc. in Jan 2011; DimDim, Inc. in Jan 2011; and three other companies for \$18.1 million in aggregate } \\
\text { cash and \$2.8 million in contingent consideration (2011 fiscall year) }\end{array}$} & & & \\
\hline 2012 & \multicolumn{17}{|c|}{$\begin{array}{l}\text { Radian6 Technologies Inc. in May 2011; Assistly, Inc. in Sep 2011; Model Metrics, Inc. in Dec 2011; and other acquisitions including Manymoon } \\
\text { Corporation ("Manymoon") for \$13.6 million in cash in Feb } 2011 \text { and two other companies for \$21.2 million in cash (2012 fiscal year). }\end{array}$} & & & \\
\hline 2013 & \multicolumn{17}{|c|}{$\begin{array}{l}\text { 2Catalyze, Inc. ("Rypple") in Feb 2012; Buddy Media, Inc. in Aug 2012; GoInstant, Inc. in Sep 2012; and five additional companies for \$15.1 million } \\
\text { in cash, net of cash acquired (2013 fiscal year) }\end{array}$} & & & \\
\hline 2014 & \multicolumn{17}{|c|}{$\begin{array}{l}\text { EdgeSpring in Jun 2013; ExactTarget, Inc in Jul 2013; and three other companies for an aggregate of \$31.7 million in cash, net of cash acquired (2014 } \\
\text { fiscal year) }\end{array}$} & & & \\
\hline 2015 & \multicolumn{17}{|c|}{ RelateIQ, Inc. in Aug 2014 (2015 fiscal year) } & & & \\
\hline 2016 & \multicolumn{17}{|c|}{ Several companies for an aggregate of $\$ 60.1$ million in cash, net of cash acquired. } & & & \\
\hline 2017 & $\begin{array}{l}\text { SteelBric } \\
\text { Krux Dig }\end{array}$ & $\begin{array}{l}\mathrm{k} \text {, Inc. in } \\
\text { ital, Inc. }\end{array}$ & $\begin{array}{ll}\text { Feb } 201 \\
\text { in Nov } 2\end{array}$ & Metal & $\begin{array}{l}\text { Sind, Inc } \\
7 \text { fiscal } y\end{array}$ & $\begin{array}{l}\text { in Apr } \\
\text { ear) }\end{array}$ & 2016; D & emandw & are, Inc. & in Jul 201 & ; Quip, & Inc. in $\mathrm{Al}$ & g 2016; & 3eyondCc & ore, Inc. in & Sep 201 & & & & \\
\hline
\end{tabular}

It is interesting to note that, while achieving significant growth over a long period of time, the firm has maintained positive EBITDA since 2004, although higher EBITDA profitability would be expected from an organization as large and mature as Salesforce (in fact, when adding depreciation and amortization, the firm had operating losses still recently: i.e., fiscal years 2012-2015). For purpose of comparison with other cases in the sample, Salesforce's EBITDA performance is not as high and constant as a percentage of revenue as in the cases of Veeva Systems and Ellie Mae (i.e., compared to their EBITDA results as percentage of revenue post IPO). Nevertheless, the consistency in spending patterns shows that Salesforce has not been pursuing an erratic growth strategy. Instead, 
the firm has been using a disciplined and consistent approach over time, combining internal R\&D strategies, acquisitions (as illustrated in Table 37), and other strategic investments.

Regarding its strategic investments, the firm stated in its latest 10-K report (filed on March 6, 2017):

Since 2009, we have been investing in early-to-late stage technology and professional cloud service companies across the globe to support our key business initiatives, which include, among other things, extending the capabilities of our platform and CRM offerings, increasing the ecosystem of enterprise cloud companies and partners, accelerating the adoption of cloud technologies and creating the next-generation of mobile applications and connected products. Our minority investments in over 180 companies as of January 31, 2017 also help us stay connected with the pace of innovation that is currently occurring within the technology industry. In some cases, we have acquired companies in which we have previously invested.

The company also stated in the same report: "We drive innovation organically and to a lesser extent through acquisitions".

The following graph (Figure 13) serves as another illustration of the consistency of Salesforce's spending patterns over time.

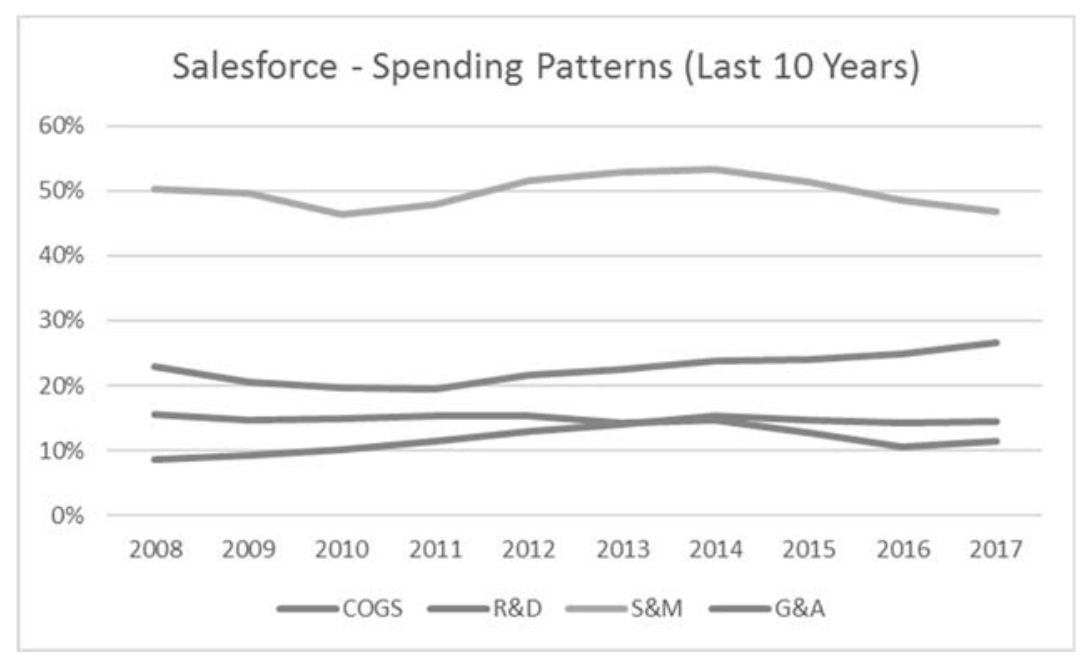

Figure 13: Salesforce - Spending Patterns (Last 10 Years) 
Salesforce has followed a deliberate strategy to maintain its M\&S spending on the higher side, at around $50 \%$, which is higher than the median of $41 \%$ I found for pure-play SaaS firms in the sample (refer to Table 12, earlier in the quantitative study). This still relatively high level of spending in $\mathrm{M} \& \mathrm{~S}$ for a mature SaaS firm such as Salesforce explains the lower profitability than would be expected at this stage of firm scale, an indication that Salesforce may not be spending at optimum level in the M\&S area. Note that the performance factor and the valuation of the firm (in terms of revenue multiple) are both below the results of top performing firms such as the earlier two cases of Veeva Systems and Ellie Mae.

\section{The Case of Box}

A popular SaaS cloud content management platform provider, Box, Inc. (Box) is among the top 10 fastest growing SaaS firms in the sample (average year-over-year revenue growth of $57 \%$ during the three year-period of study), pursuing an accelerated growth strategy at the cost of heavy losses. The firm spends significantly more than others in R\&D (average of $34 \%$ of revenue during the three years, among the top $10 \mathrm{R} \& \mathrm{D}$ spenders as a percentage of revenue in the sample) as well as in marketing and sales (average of 105\% of revenue during the three years, also among the top $10 \mathrm{M} \& \mathrm{~S}$ spenders as a percentage of revenue in the sample). Box provides an example of diminishing returns on aggressive spending in capabilities. The firm achieved a Performance Factor of -0.44 (or ROF of -20) with an Enterprise Value of 3.7 times revenue (more than $\$ 1$ billion) as of July 15, 2016 (Table 38), a lower revenue multiple compared to high performers in the sample. The lower revenue multiple can be attributed to the continued heavy losses (although trending 
downward over time as a percentage of revenue) and the higher risks represented by the aggressive growth strategy for shareholders.

Table 38: Box - Performance Summary

Box - Performance Summary

\begin{tabular}{|l|r|l|}
\hline \multicolumn{1}{|c|}{ Variable } & \multicolumn{1}{c|}{ Result } & \multicolumn{1}{c|}{ Legend } \\
\hline RevM & 3.7 & $\begin{array}{l}\text { RevM = Enterprise Value (EV) measured as the Revenue Multiple } \\
\text { (or EV/Revenue) as of July 15, 2016. }\end{array}$ \\
\hline FY Revenue (\$M) & 303 & Annual revenue reported in prior fiscal year. \\
\hline AVGYOYG & $57 \%$ & $\begin{array}{l}\text { YOYG also referred to as AVGYOYG = average YoY revenue } \\
\text { growth over the prior three fiscal years. }\end{array}$ \\
\hline AVGEB & $-77 \%$ & $\begin{array}{l}\text { AVGEB = average EBITDA \% of revenue over the prior three } \\
\text { fiscal years. }\end{array}$ \\
\hline PF & -0.44 & PF (Performance Factor) $=$ YOYG* AVGEB \\
\hline ROF* & -20 & ROF (Rule of Forty Score) $=($ YOYG+AVGEB) $* 100$ \\
\hline
\end{tabular}

* ROF is alternative measure to PF (for validity testing) discussed in Appendix G.

Formed in 2005, Box provides a SaaS content management platform that enables users to manage cloud content, allow access and information sharing, and collaborate on content with internal and external parties. The platform can also be used to automate business processes, manage compliance with policies and regulations, and develop custom applications. Box's clients are organizations of all sizes and industries. As of January 31, 2017, the firm had approximately 1,500 employees and 52 million registered users, 84\% of whom were non-paying users and $16 \%$ were paying users, representing 71,000 paying organizations worldwide.

The firm competes primarily with other content management vendors such as Microsoft, Google, Dropbox, and Open Text.

Box completed its IPO in January 2015 at a market capitalization of $\$ 1.7$ billion, down from the $\$ 2.4$ billion valuation received from late-stage investors less than a year earlier (Konrad, A., 2015). 
Box's growth and spending patterns are illustrated in Table 39.

Table 39: Box - Spending Patterns

\begin{tabular}{|c|c|c|c|c|}
\hline Box, Inc. & & & & \\
\hline \multicolumn{5}{|c|}{ Type of SaaS firm: Pure Play, Cross-Industry } \\
\hline & Year 1 & Year 2 & Year 3 & STD \\
\hline Revenue (\$M) & 124 & 216 & 303 & \\
\hline COGS & $21 \%$ & $22 \%$ & $29 \%$ & 0.04 \\
\hline GM & $79 \%$ & $78 \%$ & $71 \%$ & \\
\hline$R \& D$ & $37 \%$ & $31 \%$ & $34 \%$ & 0.03 \\
\hline$M \& S$ & $138 \%$ & $96 \%$ & $80 \%$ & 0.30 \\
\hline$G \& A$ & $32 \%$ & $28 \%$ & $24 \%$ & 0.04 \\
\hline AVG STD & & & & 0.10 \\
\hline EBITDA & $-113 \%$ & $-64 \%$ & $-53 \%$ & \\
\hline AVGYOYG & $57 \%$ & & & \\
\hline Revenue Multiple & 3.7 & & & \\
\hline
\end{tabular}

As shown above, the average standard deviation over the three year-period is 0.10 , with the highest variability in $M \& S$ as the firm is attempting to establish a path to profitability.

The increase in COGS from 22\% in year 2 (fiscal year 2015) to 29\% in year 3 (fiscal year 2016) was explained by the firm, in its 2016 10-K report (filed on March 30, 2016), as follows:

Cost of revenue as a percentage of revenue increased 7 points year-overyear primarily due to our continued investments in our data center infrastructure and Box Consulting to support our expected growth in paying customers and new products, as well as the expenses related to our new Redwood City headquarters in addition to the temporarily concurrent expenses related to our former Los Altos headquarters.

In its S-1 report (filed on March 24, 14), the firm stated:

We intend to continue scaling our organization to meet the increasingly complex needs of our customers. Our sales and customer success teams are organized to efficiently serve organizations ranging from small businesses to the world's largest global organizations. We have invested and expect to 
continue to invest heavily in our sales and marketing teams to sell our services around the world, as well as in our development efforts to deliver additional features and capabilities of our cloud services to address customers' evolving needs. We also expect to continue to make significant investments in both our datacenter infrastructure to meet the needs of our growing user base and our professional services organization to address the strategic needs of our customers in more complex deployments and to drive broader adoption across a wide array of use cases. As a result of our continuing investments to scale our business in each of these areas, we do not expect to be profitable for the foreseeable future.

The firm's subsequent $10-\mathrm{K}$ reports include a similar statement, including the latest $10-\mathrm{K}$ report filed on March 24, 2017.

When examining the full history of the firm's financials (reported in its SEC filings), I find that the average standard deviation was 0.13 prior to its IPO and 0.07 since its IPO (Table 40). 
Table 40: Box - Spending Patterns over a Longer Period

\begin{tabular}{|c|c|c|c|c|c|c|c|c|}
\hline \multirow[t]{2}{*}{ Box Inc. } & \multirow[b]{2}{*}{13 months* } & & & IPO year & & & \multirow[b]{3}{*}{$\begin{array}{c}\text { Pre-IPO } \\
\text { STD }\end{array}$} & \multirow[b]{3}{*}{$\begin{array}{c}\text { Post-IPO } \\
\text { STD }\end{array}$} \\
\hline & & & \multicolumn{3}{|c|}{$\begin{array}{l}3 \text { year-period scope of quantitative } \\
\text { study (Ess ay One) }\end{array}$} & & & \\
\hline $\begin{array}{l}\text { Year-ende d: } \\
\text { January }\end{array}$ & 2012 & 2013 & 2014 & 2015 & 2016 & 2017 & & \\
\hline $\operatorname{Rev}(\$ M)$ & 24 & 59 & 124 & 216 & 303 & 399 & & \\
\hline COGS & $32 \%$ & $24 \%$ & $21 \%$ & $22 \%$ & $29 \%$ & $28 \%$ & 0.05 & 0.04 \\
\hline GM & $68 \%$ & $76 \%$ & $79 \%$ & $78 \%$ & $71 \%$ & $72 \%$ & & \\
\hline R\&D & $67 \%$ & $49 \%$ & $37 \%$ & $31 \%$ & $34 \%$ & $29 \%$ & 0.15 & 0.02 \\
\hline S\&M & $165 \%$ & $169 \%$ & $138 \%$ & $96 \%$ & $80 \%$ & $63 \%$ & 0.17 & 0.16 \\
\hline G\&A & $60 \%$ & $43 \%$ & $32 \%$ & $28 \%$ & $24 \%$ & $17 \%$ & 0.14 & 0.06 \\
\hline EBITDA & $-210 \%$ & $-171 \%$ & $-113 \%$ & $-64 \%$ & $-53 \%$ & $-28 \%$ & & \\
\hline YOY Growth & & $140 \%$ & $111 \%$ & $74 \%$ & $40 \%$ & $32 \%$ & & \\
\hline AVG STD & & & & & & & 0.13 & 0.07 \\
\hline \multicolumn{9}{|c|}{ * $2011+$ Jan'12. Year-ended: December up to 2011 changed to January in Jan 2012.} \\
\hline & & & & & & & & \\
\hline \multicolumn{9}{|l|}{ Acquisitions } \\
\hline 2014 & \multicolumn{8}{|c|}{$\begin{array}{l}\text { Crocodoc, Inc. (Crocodoc) in May } 2013 \text { (2014 fiscal year) for total purchase consideration } \\
\text { of } \$ 13.2 \text { million. }\end{array}$} \\
\hline 2015 & \multicolumn{8}{|c|}{ Two companies for an aggregate purchase price of $\$ 5.5$ million. } \\
\hline 2016 & \multicolumn{8}{|c|}{$\begin{array}{l}\text { Verold Inc. in May } 2015 \text { (2016 fiscal year) for a total purchase price of } \$ 5.4 \text { million; and } \\
\text { two other companies for an aggregate purchase price of } \$ 764,000 \text {. }\end{array}$} \\
\hline 2017 & \multicolumn{8}{|c|}{$\begin{array}{l}\text { Agreement to license certain technology and hire certain employees from Wagon } \\
\text { Analytics, Inc. in Aug } 2016 \text { (2017 fiscal year) for a total purchase price of \$2.0 million. }\end{array}$} \\
\hline
\end{tabular}

Table 40 also shows a rapid deceleration of the firm's year-over-year growth. In 2017, the growth is down to $32 \%$, which is close to the median growth rate of $31 \%$ among the pureplay SaaS firms in the sample. At that growth rate, the median spending as percentage of revenue among pure-play SaaS firms was $19 \%$ in $R \& D$ and $41 \%$ in M\&S (refer to Table 12). Considering that Box is spending more in $R \& D$ and $M \& S$ than other SaaS firms, you would expect that the firm would sustain a higher growth rate to justify such level of spending. The aggressive spending strategy appears to be costly to the company and to produce no better than median growth results. For comparison purposes, Salesforce was 
achieving higher growth rates when the firm was around the same size as Box and it was more efficient (refer to Table 37 in the Salesforce case study).

Box's spending patterns and the firm's efforts to establish a path to profitability are again illustrated in the following graph (Figure 14).

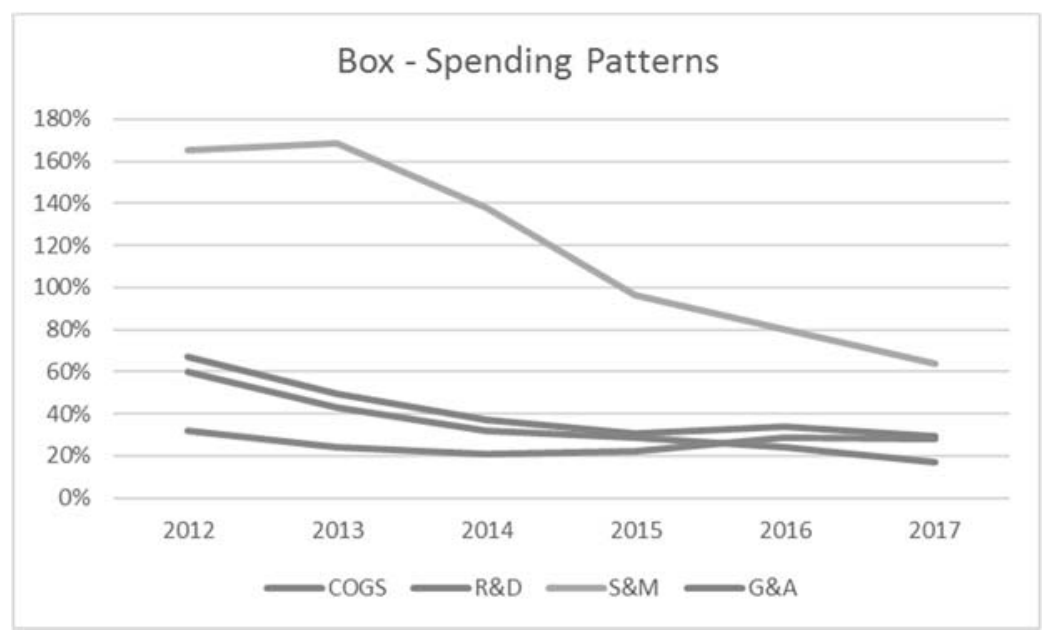

Figure 14: Box - Spending Patterns

As part of its IPO process, the firm refined its strategy to focus its resources on the enterprise market and position itself as an enterprise cloud platform provider. Box has faced pressures from investors since its IPO to improve its financial performance, in particular to reduce its cash burn (e.g.: Waters, R., 2015; Konrad, A., 2017; Whilhelm, A., 2017). Its progress toward reducing its EBITDA losses (as a percentage of revenue) is a positive trend.

In summary, the firm's aggressive spending strategy does not appear to have been as efficient as the more progressive approach followed by other SaaS firms. As indicated earlier, the losses (and uncertainties and risks associated with them) have been reflected in 
the lower valuation of the firm (in terms of revenue multiple) compared to other SaaS firms in my study, an illustration of the influence of EBITDA profitability on SaaS valuations.

\section{Insights from the Literature}

Key managerial insights from the literature, relative to optimum spending in capabilities to maximize firm performance in new markets, are summarized hereafter.

Examining the effects of spending in capabilities (e.g., R\&D, M\&S) using multiple measures of firm performance is likely to provide a more complete understanding of these effects:

When examining the effects of investments in capabilities such as R\&D or M\&S on firm performance, the literature uses various measures of firm performance, including revenue growth, employment growth, profitability (e.g., EBITDA, EBIT or operating income, return on equity, return on assets), business valuation (e.g., enterprise value, market capitalization, stock price, Tobin's Q) or other measures such as survival time or survival rate (e.g., Ugur et al., 2016) or competitive advantage (such as the construct of technology gap in Krcal's study: Krcal, 2014). Incorporating multiple measures of firm performance is critical to better understanding the effects of resource allocation. For example, in his study on the effects of technology and innovation on firm performance, Koellinger (2008) demonstrates that the firm's innovation efforts are positively associated with revenue and employment growth. However, as he analyzes the effects on profitability, he finds that innovative firms are more likely to grow, but not necessarily more likely to be profitable. 
Managers of emerging technology firms should be aware of diminishing returns of spending in $R \& D$ and $M \& S$ :

As discussed in the extended literature review, recent studies have exposed the phenomenon of diminishing returns of spending in R\&D or M\&S. For Krcal (2014), the relationship between $R \& D$ expenditures and firm financial performance is non-linear; has the shape of an inverted U-shaped relationship, and the phenomenon is likely to generalize across multiple industries. According to the researcher, the shape of the inverted U-shaped relationships will vary depending on the differences in profitability in each industry. Eisenmann (2006) studied the spending in marketing by Internet companies. He showed that Internet companies spent heavily in marketing and indicated an inverted U-shaped relationship between marketing spending and the firm's return on invested capital. At industry level, Lin (2014) observed that industrial performance decreases after an optimal level as diversity of R\&D sources increases. He measured the diversity of R\&D sources by the R\&D expenditures and the diversity of R\&D personnel. The diminishing returns on excessive spending were also studied by Lantz and Sahut (2005), Tokic (2005), Yeh et al. (2010), Ugur et al. (2016), Coccia (2009), and Joglekar and Levesque (2009).

Firms' aggressive spending behaviors in new technology markets are likely influenced by $\underline{\text { speculative valuation bubbles and the pursuit of first mover advantage, which may or may }}$ not materialize:

Eisenmann (2006), who studied the marketing spending of internet companies, identified the following factors influencing growth acceleration strategies: competitive dynamics, speculative valuation bubbles (i.e., excessive valuations accorded to firms with high 
revenue growth), and management incentives. He explained that the pursuit of first mover advantage was a significant factor driving spending decisions among internet firms. He compared the spending and performance results of first movers and late-movers and found that there were diminishing returns from investments in customer acquisition efforts for both first movers and late-movers, and that late-mover advantages were greater than firstmover advantages. He concluded that first movers may gain advantage by acquiring customers before competitors, however, absent entry barriers, first movers quickly face rivals and fierce competition may dissipate rents.

Tokic $(2004,2005)$, who also analyzed the dotcom bubble, explained that R\&D spending and spending in advertising represented investments in the firm's intangible assets, and that high levels of investments in these areas led investors to overestimate the benefits from these investments, especially for firms with negative profitability, which caused the overvaluation. For him, investors valued internet firms mostly based on the level of their intangible investments and ignored the value of earnings. The lesson learned during the dotcom valuation bubble was that the value of a growth firm is a function of a firm's ability to create consistent positive earnings in addition to the value of potential growth opportunities (Tokic, 2005).

While stable growth is a prerequisite in an emerging technology market, business valuations are rewarded for predictability and profitability over volatility:

As Mousa et al. (2015) found, in their study of emerging technology IPO firms (that went public between 2001 and 2005), higher levels of an entrepreneurial orientation (EO) strategic posture (i.e., risk-taking, innovativeness, proactiveness) may be viewed by 
investors as excessive exploration at a time when increased discipline and focus toward exploitation is necessary to achieve stable growth when entering the public market. They explain that, given that the firms are already operating in highly dynamic environments, a certain level of EO is likely to be assumed by investors and that above-average EO signals among these firms may be viewed as imprudent or excessive by underwriters evaluating their potential as public companies. In addition, as explained by Lantz and Sahut (2005), high levels of R\&D expenditure ratios may generate a doubt about the economic effectiveness of the research activities and increase the perceived risk from the investors' perspective. The literature seems to indicate that the same would be true with high levels of marketing expenditure ratios or ratios of other expense areas. Finally, a recent study from Mudambi and Swift (2014) offers a more nuanced view on the volatility of spending patterns. Indeed, the study suggests that the periods of exploitation of existing competencies require stable and consistent R\&D investment, while the periods of transition to new competencies require changes in $\mathrm{R} \& \mathrm{D}$ expenditures. According to the authors, significant changes in $R \& D$ spending are positively associated with shifts between exploitation and exploration activities, with higher levels of R\&D-related outputs and with overall firm performance (Mudambi and Swift, 2014).

\section{Discussion}

The purpose of this second essay was to validate the model and the results of the quantitative study by triangulating the findings with insights from the latest literature and from practice. In addition, I attempted to illustrate my results with examples and to further 
assess the generalizability of the study to firms in other contexts than SaaS. As Michael Myers defined it in his book (Myers, 2013):

Triangulation is the idea that you should do more than just one thing in a study. That is, you should use more than one research method, use two or more techniques to gather data, or combine qualitative and quantitative research methods in the one study. Triangulation is an excellent idea if you want to look at the same topic from different angles. It allows you to gain a "fuller" picture of what is happening (Myers, 2013, p 9).

I accomplished this by combining my earlier quantitative research method with a qualitative research approach consisting of an extended review of relevant articles for further insights from the literature, interviews of practitioners, and mini case studies. In this section, I will summarize the findings of my second essay, by revisiting and evaluating the pertinence of my propositions.

My first proposition (P \# 1) was that profitability or a clear path to profitability positively influences firm performance, even in an emerging technology market and that it is not only about revenue growth. There is no question that during technology bubbles, there is a greater appetite for risk and a greater tolerance among investors for money losingbusinesses for the sake of "land grab" or the pursuit of first mover advantage. This is particularly the case in markets that present "winner take all" (WTA) attributes. WTA attributes include strong network effects, static scale economies, and high customer switching costs (Eisenmann, 2006). However, my quantitative research shows that, in the case of the SaaS market, these strategies come at the cost of lower performance and lower firm valuation (Hypothesis \# 1). This was also illustrated in the mini case studies, with Veeva Systems or Ellie Mae achieving a better financial performance and, ultimately, a higher business valuation than a firm with an aggressive spending strategy such as Box. 
The insights collected from practice indicated that there was consensus on this topic among the practitioners I interviewed. Finally, the literature seems to converge on this topic as well, explaining the mixed results of growth acceleration strategies by factors such as:

- The higher uncertainties about the effectiveness of the firm's investments (e.g., Ciftci and Cready, 2011; Coccia, 2009; Lantz and Sahut, 2005; Yeh et al., 2010),

- The rapid pace of technological change (e.g., Levesque et al., 2012-2010; Lin, 2014),

- The fierce competition (e.g., Eisenmann, 2006; Krcal, 2014),

- The rapid dissipation of rents in markets where barriers of entry or switching costs may not be as high as originally expected (e.g., Koellinger, 2008; Eisenmann, 2006),

- Other factors such as the lack of complementary assets (e.g., Yeh et al., 2010).

Regarding the relationship between consistency of spending patterns and firm performance (Hypothesis \# 5), the mini case studies provided clear illustrations of my earlier findings. The patterns of Veeva Systems, Ellie Mae, and Salesforce were more consistent over time than the other cases (when examining the three year-period of the quantitative study as well as a longer period). The common themes among the practitioners I interviewed were that the firm needed to adopt a progressive approach (as opposed to trying to do too much all at once), to control resource spending, and to optimize returns while recognizing the importance of scale and EBITDA as the firm grows. Finally, my findings are consistent with the insights from the literature (discussed in the previous section), in particular regarding investors' general preference for stable growth, predictability, and profitability over volatility. As discussed in the previous section, Mudambi and Swift (2014) offer an 
alternative view to my study regarding the consistency of spending patterns by suggesting that firms that need to operate a major shift or radical change may benefit from a significant change in $R \& D$ spending as the firm is transitioning from exploitative to explorative $R \& D$ activities. Their study was based on a dataset of US manufacturing firms covering the years 1997-2006. More research would be needed to examine these factors in the context of an emerging technology market such as SaaS, in particular as traditional software firms shift to the SaaS model. For example, in the case of Ellie Mae, I noted earlier that the firm's R\&D spending (as a percentage of revenue) increased from 2008 to 2011, as the company shifted its focus from its on-premises software business to the cloud. This could be an illustration of the phenomenon described in the Mudambi and Swift study (2014). In such case, the firm's need to operate a major shift or radical change would explain the volatility in resource allocation and such volatility could be beneficial to the firm in the long term under these circumstances. Indeed, there may be circumstances where spending patterns fluctuate due to punctual changes (e.g., restructuring, shift). In addition, spending patterns may evolve over time due to economies of scale. Nevertheless, even after considering these fluctuations, my quantitative research provided some empirical evidence that, in an emerging technology market such as SaaS, predictability in terms of relative consistency of overall spending patterns (as a percentage of revenue) over time was positively associated with firm performance, and this finding was also illustrated by the mini case studies.

My following proposition (P \# 2a) was that firms that pursue optimum R\&D and M\&S spending levels achieve higher long-term firm performance. My extended literature review seems to provide support for the existence of optimums in firms' R\&D and M\&S spending 
and indications that these optimums are likely to vary depending on the industry. This was also pointed out several times by the practitioners I interviewed. They mentioned the need for managers to find the right balance between growth and profitability and that this was involving finding the levels of investment that optimize the returns for the firm. They discussed that trying to grow too fast was costly (in terms of cost of capital or risk of running out of cash) and increased the risks of building inefficient or unproven capabilities as opposed to companies that are adopting a more balanced approach. They also cited examples of firms who, although growing rapidly, were facing pressures from their investors to improve their margins and cash flow, again illustrating the need for firms to find spending levels in $R \& D$ and M\&S that optimize the returns for the firm and demonstrate the efficiency of its capabilities and scale. In the mini case studies, top performers Veeva Systems and Ellie Mae were examples of firms that adopted progressive growth strategies, maintaining their spending in $R \& D$ and $M \& S$ at efficient levels compared to other SaaS firms and as a result achieved among the highest firm valuations (in terms of revenue multiple) in the sample.

My next proposition (P \# 2b) was that firms that pursue "growth at all cost" achieve lower long-term firm performance. In my quantitative study focused on the SaaS market, I found some evidence that aggressive spending strategies in $R \& D$ and $M \& S$ lead to lower financial performance and lower firm valuation (in terms of revenue multiple). The mini case study of Box provided an illustration of this finding as well as the case of Salesforce to some extent (with its relatively high level of spending in M\&S for a mature SaaS firm, resulting in lower performance than would be expected at its stage of firm scale). My study results are consistent with the emerging literature on the diminishing returns of $R \& D$ and 
M\&S spending as well as with the insights collected from practice via the interviews. In addition, I observed that firms can enhance their performance over time by improving the efficiency of their capabilities as they grow. This was illustrated in the mini case studies by examining the firms' spending patterns and financial performance over a longer period than the three years of my original quantitative study: i.e., from their pre-IPO years to today.

Finally, my last proposition (P \# 3) was that the study was generalizable to other contexts than SaaS, subject to differences in spending and firm performance levels depending on the industry. The insights collected from the interviews of practitioners seem to be consistent with my last proposition. Indeed, the interviewees generally agreed that the study was potentially generalizable to other industries and contexts to some extent (refer to the Results section for examples of responses obtained). In addition, my extended literature review provided examples of studies conducted in other contexts than SaaS with similar findings (e.g., Eisenmann 2006; Joglekar and Levesque, 2009; Krcal, 2014; Yeh et al., 2010). Although further research is needed to validate the generalizability of my study to other contexts and highlight the differences among the various contexts, these insights from practice and from the literature provide further support for my last proposition.

In summary, the propositions provide a solid foundation for future research to further test my hypotheses in different contexts as well as to build on for future research (as I will discuss in the next section). In my first essay, I discussed the limitations of the quantitative study and touched on potential opportunities for new research. Regarding my second essay, I identified the following additional limitations: 
My search for relevant articles was centered on the relationships between resource allocation and firm performance, with a focus on R\&D and M\&S investments in new markets and the outcomes in terms of firm performance, and ultimately business valuation. The search could be extended to other expense areas such as infrastructure costs or G\&A costs and other factors influencing the relationships.

Regarding the interviews of practitioners, the interviewees were selected among my industry contacts. The interviewees were clearly explained the purpose of the interview and were requested to be objective in their responses. However, some of their responses may have been biased by the fact that the interviewees knew me (the interviewer) and that the interviewer, who conducted the study as a doctoral student, is also a CFO of a technology firm. In addition, I conducted thirteen interviews in total, out of an initial list of twenty-one contacts in the industry. More practitioners could be surveyed using additional survey instruments and methods.

Finally, I created six mini case studies for purpose of illustrating the findings of the first essay. More case studies could be added, for example to compare peers within a particular market (i.e., comparison of a top performer vs. its competitors) or other criteria (e.g., within a comparable range of firm size) or for other purposes.

In conclusion, I believe that my second essay was helpful in illustrating the findings of the quantitative study and in expanding it with additional insights from practice and from the literature. It helped me frame grounded propositions to test their generalizability to other contexts and identify differences across industries and other characteristics in future research. 
In addition, beyond this study, new questions arise. For example, are there circumstances where my findings would not matter, such as in a "winner take all" (WTA) market where a firm has reasonable chances to remain as the only survivor and sources of funding (to fund the erratic growth) are abundant and inexpensive? Do these situations exist and if so, for how long? In such circumstances, would a "growth at all cost" strategy for an extended period be worth it in the long run despite the significant cash losses, the risks, and the dilution of the company? When examining the case of Salesforce, I found that the firm did not pursue an erratic growth strategy but a disciplined and consistent approach over time. The firm has been consistently spending more in M\&S than other SaaS firms (as a percentage of revenue), however, the firm has maintained a positive EBITDA since 2004 demonstrating efficiency and scale, even if not at optimum level. Assuming that Salesforce will succeed in transforming the customer relationship management (CRM) market into a WTA market with itself as the only survivor (which remains to be proven considering the current state of the market and continued fierce competition from Oracle, SAP, Microsoft, and many others in the space), is Salesforce pursuing the right spending strategy to win this competitive war? Could Salesforce have achieved the same or better results with a different spending strategy? Are there lessons to be learned from other firms pursuing similar WTA strategies in other markets such as Amazon or Facebook? Outside the world of publicly traded firms (i.e., in the private equity world), what factors explain the many unicorns (i.e., privately held startups valued at $\$ 1$ billion or more such as Uber, Airbnb, Dropbox, Spotify, and many others) today on the market? Why do they stay private so long and what are their long-term prospects? 
Indeed, more research is needed to deepen our understanding of the relationships between resource allocation and firm performance in emerging technology markets. The literature review, interviews of practitioners and case studies led me to many new questions, ideas and suggestions for future research, which I will summarize in the following section.

\section{Research Agenda for Future Research}

My approach for this final section was to use my extended literature review as a start point to identify gaps in the literature (Appendix J) and create a research agenda for future research consisting of new, interesting and novel research avenues derived from the literature and from my study.

\section{Gaps in the Literature}

I summarize hereafter the gaps in the literature in three main themes:

- Theme \# 1: How resource allocation strategies influence firm performance in various emerging technology markets. More research is needed to deepen our understanding of investment decision making processes and strategies in various emerging technology markets and the factors influencing them such as firm characteristics, the scale effects, the investor base, the competition, or market characteristics such as WTA attributes or international aspects.

- Theme \# 2: How resource allocation strategies change when firms need to operate a shift or a radical change. The effects of drastic changes on resource allocation are still relatively unexplored as well as the risks involved with such radical strategies and how to mitigate them. 
- Theme \# 3: How resource allocation strategies differ between private and public firms. There is growing interest in developing a better understanding of investments strategies among private firms and how they differ from public firms, including growth optimization strategies throughout the development stages of the firm (from startup to IPO).

These main themes can be sub-divided in sub-themes in which we can outline the key gaps in the literature as follows.

Theme \# 1: How resource allocation strategies influence firm performance in various emerging technology markets:

- Sub-theme \# 1.1: Growth optimization strategies in various contexts and industries: more research is needed to further explore how resource allocation strategies and related risks influence firm performance, and ultimately firm valuation in various contexts and industries.

- Sub-theme \# 1.2: Understanding the scale effects of investments in R\&D and other capabilities (M\&S, other): the scale effects of R\&D and other capabilities on firm performance and growth risks in emerging technology markets are still relatively under-researched.

- Sub-theme \# 1.3: The emergence of new business models (BMs) and their influence on firm performance: there is a growing need for more studies on emerging software BMs in the new digital business environment and a framework to guide companies in the adoption of a new software BM, considering all the relevant factors (market, economic, other). 
Theme \# 2: How resource allocation strategies change when firms need to operate a shift or a radical change:

- Sub-theme \# 2.1: Resource allocation strategies when the firm needs to operate a radical change (shift, restructuring): future research is needed to investigate the characteristics of firms that operate drastic changes in spending patterns (e.g., R\&D, M\&S), their decision-making processes, and the effects on firm performance. Future research is also needed on the effectiveness of various modes of exploration, including alliances and corporate venture capital (CVC).

- Sub-theme \# 2.2: Best practices for resource allocation shifting strategies and measurement: there is a dearth of research on best practices for shifting resource allocation strategies to improve firm performance. This includes developing our understanding of best practices in the measurement of resource allocation decisions and their outcomes in terms of firm performance. In addition, more research is needed to improve our understanding of the value and the risk of intangible assets and their effects on firm performance and valuation, in the context of an emerging technology industry.

- Sub-theme \# 2.3: The effects of resource allocation strategies on survival: More studies are needed to examine the causes of business failure from a resource allocation perspective or to compare firms who survived vs. firms who failed. Other opportunities for future research would be resource allocation strategies of firms in a declining market and the influence of the obsolescence rate in the industry. 
Theme \# 3: How resource allocation strategies differ between private and public firms:

- Sub-theme \# 3.1: Differences in resource allocation strategies between private and public firms: the literature suggests more research to expand our understanding of the dynamics of market entry and likelihood of acquisition for startups in technology markets, linkages to industry networks, and corporate venture strategies of established firms. This includes developing a better understanding of resource allocation strategies among private-equity owned firms and the relatively new phenomenon of unicorns.

- Sub-theme \# 3.2: Differences in resource allocation strategies by firm stage from startup to post-IPO: finally, the literature indicates significant interest for more research on the effects of resource allocation on firm performance using a longitudinal research approach throughout the life of the firm, from startup to postIPO. This includes studying the resource allocation effects on competitive advantage and survival as well as the influence of other factors over time such as the firm's governance and board composition.

\section{New Research Avenues}

To fill the above-mentioned gaps in the literature, I propose an illustrative list of new research avenues that are relevant to my study (Table 41). 
Table 41: Summary of Gaps and New Research Avenues

\begin{tabular}{|c|c|c|c|}
\hline Themes & Sub-themes & Gaps & New Research Avenues \\
\hline $\begin{array}{l}\text { \# 1: How } \\
\text { resource } \\
\text { allocation } \\
\text { strategies } \\
\text { influence } \\
\text { firm } \\
\text { performanc } \\
\text { e in various } \\
\text { emerging } \\
\text { technology } \\
\text { markets. }\end{array}$ & $\begin{array}{l}\text { \# 1.1: Growth } \\
\text { optimization } \\
\text { strategies in } \\
\text { various contexts } \\
\text { and industries. }\end{array}$ & $\begin{array}{l}\text { Need to further } \\
\text { explore how } \\
\text { resource } \\
\text { allocation } \\
\text { strategies and } \\
\text { related risks } \\
\text { influence firm } \\
\text { performance, } \\
\text { and ultimately } \\
\text { firm valuation in } \\
\text { various contexts } \\
\text { and industries. }\end{array}$ & $\begin{array}{l}\text { How do factors such as firm characteristics, } \\
\text { customer characteristics, industry/market } \\
\text { characteristics, competition, } \\
\text { country/international, socio-economic and } \\
\text { political environment, financing and VC } \\
\text { investments influence firms' decision-making } \\
\text { on investments and their relationship to firm } \\
\text { performance? } \\
\text { How do these factors and related risks (firm- } \\
\text { level risks, market risks etc.) influence business } \\
\text { valuation? What is the role of growth } \\
\text { expectations in business valuation? How to } \\
\text { improve the valuation methods to better assess } \\
\text { the value of emerging technology growth firms? } \\
\text { What are the effects of WTA attributes on the } \\
\text { relationship between resource allocation and } \\
\text { firm performance and ultimately firm } \\
\text { valuation? What factors influence investment } \\
\text { strategies in a WTA market? What are the } \\
\text { different types of firm behaviors and best } \\
\text { practices in a WTA market? }\end{array}$ \\
\hline & $\begin{array}{l}\text { \# 1.2: } \\
\text { Understanding } \\
\text { the scale effects } \\
\text { of investments } \\
\text { in R\&D and } \\
\text { other } \\
\text { capabilities } \\
\text { (M\&S, other). }\end{array}$ & $\begin{array}{l}\text { Understanding } \\
\text { the scale effects } \\
\text { of R\&D and } \\
\text { other capabilities } \\
\text { on firm } \\
\text { performance and } \\
\text { risks. }\end{array}$ & $\begin{array}{l}\text { What is the influence of scale on resource } \\
\text { allocation? } \\
\text { What is the impact of scale in the relationship } \\
\text { between resource allocation and firm } \\
\text { performance? } \\
\text { What are the portfolio effects? }\end{array}$ \\
\hline
\end{tabular}


Table 41: Summary of Gaps and New Research Avenues (Continued)

\begin{tabular}{|c|c|c|c|}
\hline & $\begin{array}{l}\text { \# 1.3: The } \\
\text { emergence of } \\
\text { new business } \\
\text { models (BMs) } \\
\text { and their } \\
\text { influence on } \\
\text { firm } \\
\text { performance. }\end{array}$ & $\begin{array}{l}\text { Need for more } \\
\text { studies on } \\
\text { emerging } \\
\text { software BMs in } \\
\text { the new digital } \\
\text { business } \\
\text { environment and } \\
\text { a framework to } \\
\text { guide companies } \\
\text { in the adoption } \\
\text { of a new } \\
\text { software BM } \\
\text { considering all } \\
\text { the relevant } \\
\text { factors (market, } \\
\text { economic, } \\
\text { other). }\end{array}$ & $\begin{array}{l}\text { What are the effects of revenue composition } \\
\text { (i.e., subscription vs. professional services } \\
\text { revenues, or recurring vs. non-recurring } \\
\text { revenues) on firm performance? } \\
\text { What level of success is achieved by the various } \\
\text { BMs emerging in the various sectors of the } \\
\text { economy (subscription, transaction-based, etc.)? } \\
\text { What do future BMs look like? What are the } \\
\text { implications of these new BMs on firms' R\&D } \\
\text { and other capabilities (marketing and } \\
\text { distribution, etc.)? What are the implications of } \\
\text { these BMs on organizations' resource allocation } \\
\text { strategies and firm performance? } \\
\text { What are the effects of product life cycle, } \\
\text { product innovation and process innovation on } \\
\text { firm performance in various contexts of the } \\
\text { modern economy, considering both quantitative } \\
\text { and qualitative performance variables? }\end{array}$ \\
\hline $\begin{array}{l}\text { \# 2: How } \\
\text { resource } \\
\text { allocation } \\
\text { strategies } \\
\text { change } \\
\text { when firms } \\
\text { need to } \\
\text { operate a } \\
\text { shift or a } \\
\text { radical } \\
\text { change. }\end{array}$ & $\begin{array}{l}\# \text { 2.1: Resource } \\
\text { allocation } \\
\text { strategies when } \\
\text { the firm needs to } \\
\text { operate a radical } \\
\text { change (shift, } \\
\text { restructuring). }\end{array}$ & $\begin{array}{l}\text { Future research } \\
\text { is needed to } \\
\text { investigate the } \\
\text { characteristics of } \\
\text { firms that } \\
\text { operate drastic } \\
\text { changes in } \\
\text { spending } \\
\text { patterns (e.g., } \\
\text { R\&D, M\&S), } \\
\text { their decision- } \\
\text { making } \\
\text { processes, and } \\
\text { the effects on } \\
\text { firm } \\
\text { performance. } \\
\text { Future research } \\
\text { is also needed on } \\
\text { the effectiveness } \\
\text { of various modes } \\
\text { of exploration, } \\
\text { including } \\
\text { alliances and } \\
\text { corporate } \\
\text { venture capital. }\end{array}$ & $\begin{array}{l}\text { In what circumstances would a drastic change in } \\
\text { resource allocation lead to superior } \\
\text { performance? } \\
\text { What are the processes involved and best } \\
\text { practices? } \\
\text { How do acquisitions complement or substitute } \\
\text { internal R\&D or other internal investments? } \\
\text { How do corporate venture investments } \\
\text { influence the relationship between resource } \\
\text { allocation and firm performance? }\end{array}$ \\
\hline
\end{tabular}


Table 41: Summary of Gaps and New Research Avenues (Continued)

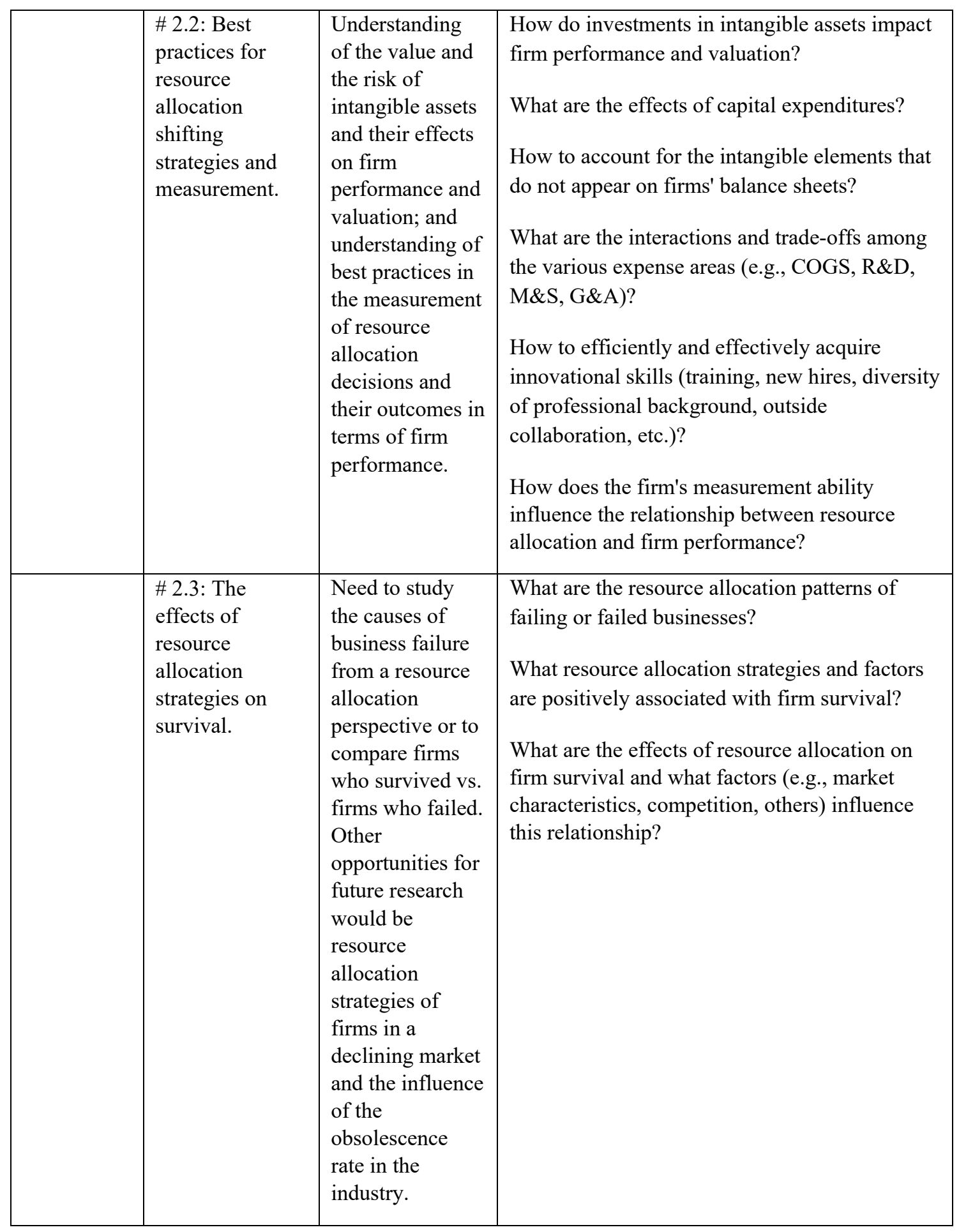


Table 41: Summary of Gaps and New Research Avenues (Continued)

\begin{tabular}{|c|c|c|c|}
\hline $\begin{array}{l}\text { \# 3: How } \\
\text { resource } \\
\text { allocation } \\
\text { strategies } \\
\text { differ } \\
\text { between } \\
\text { private and } \\
\text { public } \\
\text { firms. }\end{array}$ & $\begin{array}{l}\# 3.1 \text { : } \\
\text { Differences in } \\
\text { resource } \\
\text { allocation } \\
\text { strategies } \\
\text { between private } \\
\text { and public firms. }\end{array}$ & $\begin{array}{l}\text { Understanding } \\
\text { of the dynamics } \\
\text { of market entry } \\
\text { and likelihood of } \\
\text { acquisition for } \\
\text { startups in } \\
\text { technology } \\
\text { markets, } \\
\text { linkages to } \\
\text { industry } \\
\text { networks, and } \\
\text { corporate } \\
\text { venture } \\
\text { strategies of } \\
\text { established } \\
\text { firms. }\end{array}$ & $\begin{array}{l}\text { What are the dynamics of disruptive innovation } \\
\text { and how do they compare between private and } \\
\text { public firms? } \\
\text { What are the (resource allocation) strategies of } \\
\text { private firms? How do established / public firms } \\
\text { respond? } \\
\text { What are firms' acquisition patterns and how do } \\
\text { they compare between private and public firms? } \\
\text { How does persistence (e.g., persistent } \\
\text { innovation) affect firm performance and what } \\
\text { are its effects? }\end{array}$ \\
\hline & $\begin{array}{l}\text { \#3.2: } \\
\text { Differences in } \\
\text { resource } \\
\text { allocation } \\
\text { strategies by } \\
\text { firm stage from } \\
\text { startup to post- } \\
\text { IPO. }\end{array}$ & $\begin{array}{l}\text { Need for more } \\
\text { research on the } \\
\text { effects of } \\
\text { resource } \\
\text { allocation on } \\
\text { firm } \\
\text { performance, } \\
\text { competitive } \\
\text { advantage, and } \\
\text { survival as well } \\
\text { as the influence } \\
\text { of other factors } \\
\text { such as the firm's } \\
\text { governance and } \\
\text { board } \\
\text { composition in } \\
\text { different } \\
\text { environmental } \\
\text { contexts from } \\
\text { early stage } \\
\text { startup to pre- } \\
\text { IPO and post- } \\
\text { IPO. }\end{array}$ & $\begin{array}{l}\text { How do resource allocation effects (on firm } \\
\text { performance) manifest themselves and evolve in } \\
\text { the context of a startup, early stage growth firm } \\
\text { and at subsequent stages of development of the } \\
\text { firm? } \\
\text { What are the effects of financing, including the } \\
\text { different types of equity and debt financing and } \\
\text { various borrowing options? } \\
\text { What is the role of the entrepreneurial } \\
\text { orientation (EO) in firm performance and } \\
\text { valuation at each stage of development and } \\
\text { what factors (e.g., governance mechanisms, } \\
\text { board composition) influence the relationships? }\end{array}$ \\
\hline
\end{tabular}

In the following paragraphs, I indicate how these new research avenues relate to my propositions and I suggest a methodology approach for each sub-theme. 
- Sub-theme \# 1.1: Growth optimization strategies in various contexts and industries:

o Proposition(s) these new research avenues relate to: Proposition \# 3 (generalizability).

o Explanation and approach: this field of research would explore the various contexts and factors (e.g., firm and industry characteristics, international aspects) that influence the relationship between resource allocation and firm performance to deepen our understanding of the role of profitability and growth optimization strategies in various emerging technology markets in North America and other regions of the world. This research could be based on a combination of quantitative and qualitative research methods (such as the ones used in this study) in various markets and industries.

- Sub-theme \# 1.2: Understanding the scale effects of investments in R\&D and other capabilities (M\&S, other):

o Proposition(s) these new research avenues relate to: Propositions \# 1, 2a, and $2 \mathrm{~b}$ (role of profitability and optimization of spending in capabilities).

o Explanation and approach: this field of investigation would examine the effects of scale on spending strategies and their effects on performance. For example, how do firms with a large market share differ from firms with a smaller market share in terms of spending behaviors and what are their outcomes in terms of firm performance and ultimately business valuation? This includes examining the effects of complementary capabilities and portfolio effects. This research could again be based on a combination of 
quantitative and qualitative research methods, by comparing firms that have large scale effects with firms that do not have reached such scale levels. A longitudinal research approach could also be used to examine the progression of the firm's spending behaviors (and the outcomes) at various stages of scale.

- Sub-theme \# 1.3: The emergence of new business models (BMs) and their influence on firm performance:

o Proposition(s) these new research avenues relate to: Proposition \# 3 (generalizability).

o Explanation and approach: this new area of research would explore changes or differences in the firm's revenue composition and business models and their effects on firm performance, and ultimately business valuation. A quantitative approach would be particularly appropriate to measure the effects of factors such as revenue composition or product maturity stage (life cycle) on firm financial performance. In addition, case studies and other qualitative methods would be helpful to examine these effects at a more granular level and how firms adopt and transition to new business models.

- Sub-theme \# 2.1: Resource allocation strategies when the firm needs to operate a radical change (shift, restructuring):

o Proposition(s) these new research avenues relate to: Proposition \# 3 (generalizability). 
o Explanation and approach: this emerging research area would explore circumstances where consistency of spending patterns no longer leads to higher firm financial performance due to the firm's need to operate a punctual change (e.g., technology shift, restructuring) as suggested by Mudambi and Swift (2014). This would include the study of alternative strategies to developing capabilities internally, such as corporate venture investments and their effects on firm performance. These studies could be developed using a quantitative and/or qualitative research approach by comparing the spending behaviors between transforming firms (firms operating a significant shift to a new technology) and exploiting firms (firms already exploiting that new technology). Comparative studies could also include acquisitive firms vs. non-acquisitive firms.

- Sub-theme \# 2.2: Best practices for resource allocation shifting strategies and measurement:

o Proposition(s) these new research avenues relate to: Propositions \# 1, 2a, and $2 \mathrm{~b}$ (role of profitability and optimization of spending in capabilities).

o Explanation and approach: this field of research would focus on the study of best practices for optimizing firm financial performance (from a resource allocation perspective) in the context of a radical change. Qualitative studies such as case studies, interviews, or action research would be of great interest in this area to better understand the decision-making processes involved with radical change, spending patterns, and their linkages to firm financial performance. 


\section{- Sub-theme \# 2.3: The effects of resource allocation strategies on survival:}

o Proposition(s) these new research avenues relate to: Propositions \# 1, 2a, and $2 \mathrm{~b}$ (role of profitability and optimization of spending in capabilities).

o Explanation and approach: this field of investigation would study the factors that lead firms to survive or to a failure to survive as a standalone business (e.g., business failure, sale of the business to a competitor) with a focus on spending behaviors and their linkages to the types of exits (strategic sale, bankruptcy) and the outcomes of the exit for the owners (such as business valuation at time of exit or return on capital invested). Considering the difficulty in collecting this type of data, a qualitative research approach (e.g., case studies) would likely be used. This type of research would provide useful insights into the lessons to be learned from exiting firms.

- Sub-theme \# 3.1: Differences in resource allocation strategies between private and public firms:

o Proposition(s) these new research avenues relate to: Proposition \# 3 (generalizability).

o Explanation and approach: this exciting new field of research would examine the differences between private and public firms from a resource allocation perspective and the comparative effects on firm performance and ultimately business valuation. This would include the study of factors explaining the relatively recent phenomenon of unicorns (i.e., privately held startups valued at $\$ 1$ billion or more) and their long-term prospects. Due to the difficulty in gathering financial information on private firms, a 
qualitative research approach (e.g., case studies, interviews) would likely be best suited for this area of research. However, a quantitative study could also be developed in collaboration with benchmarking firms (e.g., OPEXEngine, Siemer, River Cities, Openview) or private equity firms willing to share anonymously financial data on their portfolio companies in exchange for access to the study results.

- Sub-theme \# 3.2: Differences in resource allocation strategies by firm stage from startup to post-IPO:

o Proposition(s) these new research avenues relate to: Propositions \# 1, 2a, and $2 \mathrm{~b}$ (role of profitability and optimization of spending in capabilities).

o Explanation and approach: this new field of investigation would study the resource allocation patterns (and their effects on firm financial performance and business valuation) throughout the life of the firm, from its startup stage to its maturity stage. Using a qualitative research approach (such as case studies), this type of study would allow researchers to identify valuable best practices according to firm stage. As public firms provide pre-IPO financial data in their prospectus, a longitudinal quantitative study approach could also be used based on a sample of public firms and data collected from their pre-IPO to post IPO years (similar to the approach I used for the case studies). 


\section{CHAPTER 4}

\section{CONCLUSION}

This dissertation work gave rise to important takeaways for researchers and practitioners. In Essay One, the results of the study indicated that, although industry practice neglects profitability in emerging technology markets, such as SaaS, firm valuations are not only about revenue growth, but also profitability. Also, spending in capabilities (R\&D, marketing \& sales) has diminishing returns to firm performance, and high-performing SaaS firms are relatively consistent in their spending patterns over time. In Essay Two, these findings were illustrated with six mini case studies and additional insights from practice and from the literature, which provided additional support for the generalizability of the study. As I progressed through my investigations, I uncovered tremendous interest for more research on my topic, in particular on resource optimization strategies in the context of an emerging technology market, such as the SaaS market, as well as in other contexts. I concluded my essay with a suggested research agenda for future research, building on my study and the latest literature. I proposed an illustrative list of new research avenues, demonstrating that the topic of the study is fertile for new investigations and empirical studies. The most important point from the research agenda is that there are multiple ways future research could extend the study to new contexts for more learning on improving firm financial performance in an emerging technology market. Notably, my finding that "growth at all cost" strategies lead to suboptimal results compared to more progressive spending strategies could be tested in the context of private equity-owned firms. This would include the study of unicorns (most of whom are privately held) and their long-term prospects, 
which would be particularly timely and of great interest to both practitioners and researchers, as a follow-on study to my research.

\section{Concluding Remarks}

Understanding the dynamics between relative spending in the proposed key capabilities (e.g., service delivery, R\&D, marketing and sales) and the outcomes in terms of revenue growth, profitability, and business valuation is critical to assessing the quality of execution of SaaS growth strategies and improving software firms' financial performance in the emerging cloud computing environment. This research provides a valuable contribution to both researchers and practitioners in the fields of strategic management, information systems, and finance, and offers many additional research opportunities to further assess the generalizability of the findings to firms in other industries and further develop our understanding of firm resource allocation and investments in capabilities toward firm development best practices in emerging technology firms.

\section{REFERENCES}

Barney, J. (1991). Firm resources and sustained competitive advantage. Journal of Management, 17(1), 99. Retrieved from http://search.proquest.com.libproxy.temple.edu/docview/215258436?accountid=1 4270

Barney, J., Wright, M., \& Ketchen Jr., D. J. (2001). The resource-based view of the firm: ten years after 1991. Journal of Management, 27(6), 625-641. doi:http://dx.doi.org.libproxy.temple.edu/10.1016/S0149-2063(01)00114-3

Boer, F. P. (2002). Financial management of RD 2002. Research-Technology Management, 45(4), 23-35

Boillat, T., \& Legner, C. (2013). From on-premise software to cloud services: the impact of cloud computing on enterprise software vendors' business models. Journal of 
Theoretical and Applied Electronic Commerce Research, 8(3), 39-58. doi: $10.4067 / \mathrm{S} 0718-18762013000300004$

BroadVision, Inc.: Filing for IPO is entered by internet software firm. (1996, May 13). Wall Street Journal. Retrieved from https://search-proquestcom.libproxy.temple.edu/docview/398482532?accountid $=14270$

Brockman, C. M., \& Russell, J. W. (2012). EBITDA: Use it .. or lose it? International Journal of Business, Accounting and Finance (IJBAF), 6(2), 84.

Capasso, M., Treibich, T. G., \& Verspagen, B. (2015). The medium-term effect of R\&D on firm growth. Small Business Economics, 45(1), 39-62. doi:10.1007/s11187015-9640-6

Chen, E. L., Katila, R., McDonald, R., \& Eisenhardt, K. M. (2010). Life in the fast lane: origins of competitive interaction in new vs. established markets. Strategic Management Journal, 31(13), 1527-1547. doi:10.1002/smj.894

Ciftci, M., \& Cready, W. M. (2011). Scale effects of R\&D as reflected in earnings and returns. Journal of Accounting and Economics, 52(1), 62-80. doi:10.1016/j.jacceco.2011.02.003

Coccia, M. (2009). What is the optimal rate of R\&D investment to maximize productivity growth? Technological Forecasting \& Social Change, 76(3), 433-446. doi:10.1016/j.techfore.2008.02.008

Demirel, P., \& Mazzucato, M. (2012). Innovation and firm growth: Is R\&D worth it? Industry and Innovation, 19(1), 45-62. doi:10.1080/13662716.2012.649057

Dubey A. and Wagle D. (2007). Delivering software as a service. The McKinsey Quarterly. May 2007, pp 1-12. Retrieved from: http://www.mckinsey.com/search.aspx?q=dubey

Eisenmann, T. R. (2006). Internet companies' growth strategies: Determinants of investment intensity and long-term performance. Strategic Management Journal, 27(12), 1183-1204. doi:10.1002/smj.567

Fan, M., Kumar, S., \& Whinston, A. B. (2009). Short-term and long-term competition between providers of shrink-wrap software and software as a service. European Journal of Operational Research, 196(2), 661-671. doi:http://dx.doi.org.libproxy.temple.edu/10.1016/j.ejor.2008.04.023

FASB (2016). Accounting Standards Codification (ASC). Software development capitalization guidance (ASC subtopics 350-40 and 985-20) retrieved from the FASB ASC website on November 26, 2016:

https://asc.fasb.org/section\&trid=2144515\#topic-350-40-25-subsect-01-109279, and https://asc.fasb.org/section\&trid=2197806 
FT Partners advises Ellie Mae in its $\$ 45$ million IPO (n.d.). Financial Technology Partners. Retrieved from: http://www.ftpartners.com/transactions/elliemae

Fung, M. K. (2004). Technological opportunity and productivity of R\&D activities. Journal of Productivity Analysis, 21(2), 167-181. doi:10.1023/B:PROD.0000016871.95892.41

Gartner (2015). Gartner says modernization and digital transformation projects are behind growth in enterprise application software market. August 27, 2015. Retrieved from: http://www.gartner.com/newsroom/id/3119717

Ge, C., \& Huang, K. (2014). Analyzing the economies of scale of software as a service software firms: A stochastic frontier approach. IEEE Transactions on Engineering Management, 61(4), 610-622. doi:10.1109/TEM.2014.2359975

Grant Thornton (2010). Insights on revenue recognition: navigating the maze of authoritative literature. Grant Thornton publication, 2010. Retrieved from: http://www.revenuerecognition.com/pdf/grant-thornton-insights-on-revenuerecognition-2010

Gray, W. R., \& Vogel, J. (2012). Analyzing valuation measures: A performance horse race over the past 40 years. Journal of Portfolio Management, 39(1), 112-121. doi:10.3905/jpm.2012.39.1.112

Hamilton R.D., Han T., \& Mudambi R. (2014). Organizational core capability, strategic intent and performance: a study of the hospitality industry. Under review: Long Range Planning.

Helfat, C. E. and Winter, S. G. (2011), Untangling dynamic and operational capabilities: strategy for the (n)ever-changing world. Strategic Management Journal, 32: 1243-1250. doi: 10.1002/smj.955

Henderson, T. (2013, September 11). Compuware prices Covisint IPO, aims to raise at least $\$ 64$ million. Crain's Detroit Business. Retrieved from: http://www.crainsdetroit.com/article/20130911/NEWS/130919962/compuwareprices-covisint-ipo-aims-to-raise-at-least-64-million

Heredia, A., Colomo-Palacios, R., \& de Amescua, A. (2015). Software business models from a distribution perspective: A systematic mapping study. Procedia Computer Science, 64, 395-402. doi:10.1016/j.procs.2015.08.516

IDC (2014). Worldwide SaaS enterprise applications 2014-2018 forecast and 2013 vendor shares, Dec 2014. Doc \# 252568. Market Analysis. Retrieved from: http://www.idc.com/getdoc.jsp?containerId=252568

IPO Preview: Veeva Systems (2013, October 15). Seeking Alpha. Retrieved from: https://seekingalpha.com/article/1746982-ipo-preview-veeva-systems 
Joglekar, N. R., \& Levesque, M. (2009). Marketing, R\&D, and startup valuation. IEEE Transactions on Engineering Management, 56(2), 229-242. doi:10.1109/TEM.2008.927827

Koellinger, P. (2008). The relationship between technology, innovation, and firm performance-Empirical evidence from e-business in Europe. Research Policy, 37(8), 1317-1328. doi:10.1016/j.respol.2008.04.024

Konrad, A. (2015, January 22). Box raises IPO price to \$14, will look for big first day trading pop. Forbes. Retrieved from:

https://www.forbes.com/sites/alexkonrad/2015/01/22/box-raises-its-ipo-pricewill-trade-friday/\#5c7a533a7e2f

Konrad, A. (2017, March 1). BoxCEO Aaron Levie's advice for Snap on eve of IPO: Be predictable. Forbes. Retrieved from:

https://www.forbes.com/sites/alexkonrad/2017/03/01/box-ceo-aaron-levie-talksearnings-and-snap-ipo/\#520fc8d57fd7

KPMG (2012). Building a successful cloud provider service: accounting and tax implications. KPMG publication, 2012. Retrieved from:

http://www.kpmg.com/us/en/issuesandinsights/articlespublications/documents/bui lding-successful-cloud-provider-service.pdf

KPMG (2016). Transforming your SaaS business: A strategic guide to optimizing business performance. Cadambi, P. and Easwaran, S., KPMG publication. June 30, 2016. Retrieved from:

https:/home.kpmg.com/us/en/home/insights/2016/06/transforming-your-saasbusiness.html

Krčál, O. (2014). The relationship between profitability, innovation and technology gap: A basic model. Review of Economic Perspectives, 14(3), 215-231. doi:10.2478/revecp-2014-0011

Lantz, J., \& Sahut, J. (2005). R\&D investment and the financial performance of technological firms. International Journal of Business, 10(3), 251-270

Lee, C., Lee, K., \& Pennings, J. M. (2001). Internal capabilities, external networks, and performance: a study on technology-based ventures. Strategic Management Journal, 22(6/7), 615-640. Retrieved from http://www.jstor.org/stable/3094323

Leonard-Barton, D. (1992). Core capabilities and core rigidities: a paradox in managing new product development. Strategic Management Journal, 13, 111-125. Retrieved from http://www.jstor.org/stable/2486355

Lévesque, M., Joglekar, N., \& Davies, J. (2012;2010). A comparison of revenue growth at recent-IPO and established firms: The influence of SG\&A, R\&D and COGS. Journal of Business Venturing, 27(1), 47-61. doi:10.1016/j.jbusvent.2010.08.001 
Lin, J. (2014). Effects on diversity of R\&D sources and human capital on industrial performance. Technological Forecasting and Social Change, 85, 168-184 doi:10.1016/j.techfore.2013.08.010

Ma, D., \& Kauffman, R. J. (2014). Competition between software-as-a-service vendors. IEEE Transactions on Engineering Management, 61(4), 717-729. doi:10.1109/TEM.2014.2332633

Montclare (2014). Building a high value SaaS business. White paper. Retrieved from: https://montclare.com/assets/building-high-value-saas-business

Mousa, F.T., Wales W.J., \& Harper, S. R. (2015). When less is more: EO's influence upon funds raised by young technology firms at IPO. Journal of Business Research, 68(2), 306-313

Mudambi, R., \& Swift, T. (2014). Knowing when to leap: Transitioning between exploitative and explorative R\&D. Strategic Management Journal, 35(1), 126-145

Myers, M. (2013). Qualitative research in business \& management. 2nd edition. London: SAGE Publications Ltd

Open Text (2017, June 5). Open Text to acquire Covisint. Retrieved from: https://www.prnewswire.com/news-releases/opentext-to-acquire-covisint300468917.html

Open Text (2017, July 26). OpenText Buys Covisint. Retrieved from: http://files.shareholder.com/downloads/AMDA267TY1/5597559300x0x950862/282C9D21-9A79-433A-A7CDE7710AB24623/OTEX_News_2017_7_26_Mergers_and_Acquisitions_Releases. pdf

Openview (2013). Exploring some of the SaaS metrics that matter most at the expansion stage. Peer Review report. Openview Venture Partners. Retrieved from: http://openviewpartners.com/report/peer-review-exploring-saas-metrics-matterexpansion-stage-companies/

O'Sullivan, D., Abela, A. V., \& Hutchinson, M. (2009). Marketing performance measurement and firm performance: Evidence from the european high-technology sector. European Journal of Marketing, 43(5-6), 843-862. doi:10.1108/03090560910947070

Pacific Crest (2015). 2015 Pacific Crest private SaaS company survey results. Pacific Crest Securities. October 16, 2015. Retrieved from: http://www.pacificcrest.com/2015-saas-survey/

Pacific Crest (2016). 2016 Pacific Crest private SaaS company survey results. Pacific Crest Securities. October 17, 2016. Retrieved from: http://www.pacificcrest.com/2016-saas-survey/ 
Pang, A. (2015). Top 25 cloud applications vendors score big in 2014, Market attracts millions cloud subscribers with more growth to come. September 15, 2015. Retrieved from: https:/www.appsruntheworld.com/top-25-cloud-applicationsvendors-score-big-in-2014/

Rader D., (2012). How cloud computing maximizes growth opportunities for a firm challenging established rivals. Strategy \& Leadership, Vol. 40 Iss 3 pp. 36-43 http://dx.doi.org/10.1108/10878571211221202

Razi M.A., Tarn J.M., Siddiqui F.A., (2004). Exploring the failure and success of dotcoms. Information Management \& Computer Security, Vol. 12 Iss 3 pp. $228-$ 244. Permanent link to this document:

http://dx.doi.org/10.1108/09685220410542598

River Cities (2014). 2014 SaaS operating metrics \& valuation benchmarking study. River Cities Capital Funds. Retrieved from: http://rccf.com/wp-content/uploads/2014/11/River-Cities-2014-SaaSBenchmarking-Study.pdf

Rosenbloom, R. S. (2000). Leadership, capabilities, and technological change: the transformation of NCR in the electronic era. Strategic Management Journal, 21(10/11), 1083-1103. Retrieved from http://www.jstor.org/stable/3094428

Sahaym, A., Steensma, H. K., \& Barden, J. Q. (2010;2009). The influence of R\&D investment on the use of corporate venture capital: An industry-level analysis. Journal of Business Venturing, 25(4), 376-388. doi:10.1016/j.jbusvent.2008.12.001

Salesforce.com boosts IPO price (2004, June 23). Wall Street Journal. Retrieved from: https://www.wsj.com/articles/SB108791002243543945

Siemer (2013). 2013 SaaS Report. Siemer and Associates, LLC. Retrieved from: http://www.siemer.com/summer-2013-saas-industry-report/

Suarez, F. F., Cusumano, M. A., \& Kahl, S. J. (2013). Services and the business models of product firms: An empirical analysis of the software industry. Management Science, 59(2), 420-435. doi:10.1287/mnsc.1120.1634

Tokic D. (2004). R\&D, advertising and the market value of internet firms: Part I, Journal of Internet Commerce, 3:2, 79-99, DOI: 10.1300/J179v03n02_05

Tokic D (2005). R\&D, advertising and the market value of internet firms: Part II, Journal of Internet Commerce, 4:4, 23-40, DOI: 10.1300/J179v04n04_02

Trusculescu, A., Draghici, A., \& Albulescu, C. T. (2015). Key metrics and key drivers in the valuation of public enterprise resource planning companies. Procedia Computer Science, 64, 917-923. doi:http://dx.doi.org.libproxy.temple.edu/10.1016/j.procs.2015.08.608 
Ugur, M., Trushin, E., \& Solomon, E. (2016). Inverted-U relationship between R\&D intensity and survival: Evidence on scale and complementarity effects in UK data. Research Policy, 45(7), 1474-1492. doi:10.1016/j.respol.2016.04.007

Wagner, M. (2016). Managing disruptive innovation with technology acquisitions: The informing case of software-based high-technology industries. Technology Analysis \& Strategic Management, 28(8), 979-991. doi:10.1080/09537325.2016.1181736

Waters, R. (2015, August 27). Box and its lessons for ambitious technology startups. Financial Times. Retrieved from: https://www.ft.com/content/9446c232-4c98$11 \mathrm{e} 5-9 \mathrm{~b} 5 \mathrm{~d}-89 \mathrm{a} 026 \mathrm{fda}$ c9

Wernerfelt, B. (1984). A resource-based view of the firm. Strategic Management Journal, 5(2), 171-180. Retrieved from http://www.jstor.org/stable/2486175

Whilhelm, A. (2017, August 31). What Box and Workday earnings may signal for private SaaS companies. Crunchbase News. Retrieved from:

https://news.crunchbase.com/news/box-workday-earnings-may-signal-privatesaas-companies/

Yeh, M., Chu, H., Sher, P. J., \& Chiu, Y. (2010). R\&D intensity, firm performance and the identification of the threshold: Fresh evidence from the panel threshold regression model. Applied Economics, 42(3), 389-401. doi:10.1080/00036840701604487 


\section{APPENDICES}

\section{A. IMPACT OF SAAS MODEL ON CAPABILITIES}

The impact of the SaaS model on software companies' capabilities include:

- Changes in the Service Delivery Capability: the software no longer has to be shipped and installed at the client sites. SaaS applications are more intuitive and require less training. Implementations are less time consuming than traditional software implementations. As all clients use the same instance of the software, there is no software customization involved (or the customization is generally made also available to all clients). All these changes mean less training and consulting staff and significantly different business processes for the SaaS vendor. In addition, software contracts come with service level agreements (SLAs) that may involve penalties if SLA obligations are not met, which again requires specific business processes in place to monitor performance against these SLAs at the software vendor organization.

- Changes in the Product Development Capability: innovation, development methods, and tools are more agile in a SaaS environment. Software delivery is accelerated. Upgrades no longer have to be shipped to customers and installed at their sites. Upgrades can be delivered more frequently (over the internet). This means a high level of software quality assurance in place for software vendors because each new release rolled into production impacts the entire client base at once. A system defect or release issue could create significant business disruptions. Technologies themselves are different in a SaaS environment. New Web user interface design and user experience skills are required. SaaS applications handle 
very large volumes of users and data. They require advanced methodologies and technologies in areas such as architecture, IT security, high performance data and document management, and data analytics. These mean acquiring, developing, and retaining skills that are hard to find due to the newness of these tools and the high demand for these skills.

- Changes in the Marketing and Distribution Capability: the internet offers many opportunities to rapidly increase presence and market share via online marketing channels (advertising, online stores, social media, etc.) as well as via seamless and dynamic Web integration with third party software and data providers. Web marketing and content management, social media and third-party integration capabilities are essential to competitiveness and success in the SaaS environment. Finally, sales commissions, referral agreements, and other sales compensation structures are also impacted as revenue recognition is significantly different in a SaaS model. 


\section{B. THE MODERATING EFFECT OF THE FIRM'S DEVELOPMENT}

\section{STAGE}

The regression analysis indicated that, although the overall model was statistically significant (R square of 0.93; p-value $<0.01$ ), the individual moderating effects (i.e., effects of moderator and moderating factors: AVGGM*S100, AVGRD*S100, etc.) were not statistically significant when all variables were included in the model (Appendix B - Model $1)$.

Collinearity among the variables might have contributed to this result. After eliminating the most insignificant variables, the analysis arrived at a simpler regression model showing improved statistical significance for the moderator and the moderating effects on R\&D and M\&S relationships (Appendix B - Model 2).

In the simpler regression model, the moderator effect on the relationship between $R \& D$ and EBITDA (i.e., AVGRD*S100) was statistically significant (p-value $<0.05$ ). The moderating effect on the relationship between M\&S and EBITDA (AVGSM*S100) was statistically significant at a $\mathrm{p}$-value $<0.01$. And the moderator (AtScale_S100M_Dummy) was statistically significant at a p-value $<0.01$.

Moderating effect on the relationships to EBITDA: 
Table 42: Moderating Effect of the Firm's Development Stage on the Relationships to EBITDA

\begin{tabular}{|c|c|c|c|c|c|c|c|c|c|c|}
\hline \multirow[b]{3}{*}{ Predictor } & \multicolumn{10}{|c|}{ Dependent variable: EBITDA } \\
\hline & \multicolumn{5}{|c|}{ Model 1} & \multicolumn{5}{|c|}{ Model 2} \\
\hline & $B$ & $S E B$ & B & $t$ & $p$-value & $B$ & $S E B$ & B & $t$ & $p$-value \\
\hline Constant & 0.36 & 0.10 & 0.00 & 3.51 & 0.001 & 0.68 & 0.05 & 0.00 & 12.71 & 0.000 \\
\hline GM & 0.50 & 0.10 & 0.21 & 4.83 & 0.000 & & & & & \\
\hline$R \& D$ & -1.31 & 0.22 & -0.38 & -5.94 & 0.000 & -1.55 & 0.27 & -0.45 & -5.74 & 0.000 \\
\hline M\&S & -1.03 & 0.12 & -0.61 & -8.71 & 0.000 & -1.32 & 0.14 & -0.79 & -9.41 & 0.000 \\
\hline G\&A & -0.56 & 0.23 & -0.17 & -2.46 & 0.016 & & & & & \\
\hline AVGGM*S100 & \multicolumn{5}{|c|}{ Variable excluded by SPSS due to collinearity } & & & & & \\
\hline AVGRD*S100 & 0.41 & 0.28 & 0.11 & 1.50 & 0.138 & 0.86 & 0.35 & 0.23 & 2.44 & 0.017 \\
\hline AVGSM*S100 & 0.10 & 0.15 & 0.06 & 0.62 & 0.535 & 0.48 & 0.17 & 0.28 & 2.80 & 0.006 \\
\hline AVGGA*S100 & -0.33 & 0.27 & -0.10 & -1.22 & 0.227 & & & & & \\
\hline At Scale (\$100M)_Dummy & 0.03 & 0.08 & 0.03 & 0.34 & 0.735 & -0.21 & 0.07 & -0.25 & -3.13 & 0.002 \\
\hline$R^{2}$ & \multicolumn{5}{|c|}{0.93} & \multicolumn{5}{|c|}{0.86} \\
\hline$F$ & \multicolumn{5}{|c|}{132.75} & \multicolumn{5}{|c|}{111.48} \\
\hline$p$-value & \multicolumn{5}{|c|}{0.000} & \multicolumn{5}{|c|}{0.000} \\
\hline
\end{tabular}




\section{THE MODERATING EFFECT OF THE FIRM'S DEVELOPMENT \\ STAGE (CONTINUED)}

The same exercise was repeated with YOY growth as a dependent variable (instead of EBITDA) and arrived at a simplified regression model with only M\&S and its related moderating effects as individual statistically significant variables (Appendix C).

In the regression model, the moderator effect on the relationship between M\&S and YOY Growth $(\mathrm{AVGSM} * \mathrm{~S} 100)$ was statistically significant $(\mathrm{p}$-value $=0.01)$ and the moderator (AtScale_S100M_Dummy) was also statistically significant (p-value $<0.01$ ).

Moderating effect on the relationships to YOY Growth:

Table 43: Moderating Effect of the Firm's Development Stage on the Relationships to Growth

\begin{tabular}{|l|r|r|r|r|r|}
\cline { 2 - 7 } \multicolumn{1}{c|}{} & \multicolumn{6}{|c|}{ Dependent variable: YOY Growth } \\
\hline \multirow{2}{*}{ Predictor } & \multicolumn{6}{|c|}{ M } & SE B & \multicolumn{1}{c|}{6} & $t$ & $p$-value \\
\hline Constant & -0.18 & 0.06 & 0.00 & -2.94 & 0.004 \\
\hline M\&S & 0.98 & 0.14 & 0.88 & 7.25 & 0.000 \\
AVGSM*S100 & -0.47 & 0.18 & -0.40 & -2.63 & 0.010 \\
\hline At Scale (\$100M)_Dummy & 0.23 & 0.08 & 0.42 & 3.07 & 0.003 \\
\hline$R^{2}$ & & & 0.44 & & \\
\hline$F$ & & & 24.37 & & \\
\hline$p$-value & & & 0.000 & & \\
\hline
\end{tabular}




\section{THE MODERATING EFFECT OF THE FIRM'S SPECIALIZATION}

Again, the regression analysis indicated that, although the overall model was statistically significant (R squared value of 0.92 ; p-value $<0.01$ ), the individual moderating effects (i.e., effects of moderator and moderating factors: AVGGM*VERT, AVGRD*VERT, etc.) were not statistically significant when all variables were included in the model (Appendix D - Model 1).

After eliminating the most insignificant variables, the simpler regression model including the moderator and the moderating effects on the $R \& D$ and $M \& S$ relationships was still not statistically significant at individual variable level for the moderator and the moderating factors (AVGRD*VERT and AVGSM*VERT).

In other words, in the simpler regression model, the moderator (Vertical Dummy) and both the moderator effect on the relationship between R\&D and EBITDA (AVGRD*VERT) and the moderator effect on the relationship between $M \& S$ and EBITDA (AVGSM*VERT) were not statistically significant (Appendix D - Model 2).

Moderating effect on the relationships to EBITDA: 
Table 44: Moderating Effect of the Firm's Specialization on the Relationships to EBITDA

\begin{tabular}{|c|c|c|c|c|c|c|c|c|c|c|}
\hline \multirow[b]{3}{*}{ Predictor } & \multicolumn{10}{|c|}{ Dependent variable: EBITDA } \\
\hline & \multicolumn{5}{|c|}{ Model 1} & \multicolumn{5}{|c|}{ Model 2} \\
\hline & $B$ & SE B & 8 & $t$ & $p$-value & $B$ & SEB & 8 & $t$ & $p$-value \\
\hline Constant & 0.35 & 0.07 & 0.00 & 4.99 & 0.00 & 0.65 & 0.04 & 0.00 & 15.36 & 0.00 \\
\hline GM & 0.58 & 0.09 & 0.24 & 6.51 & 0.00 & & & & & \\
\hline$R \& D$ & -1.07 & 0.14 & -0.31 & -7.42 & 0.00 & -1.21 & 0.22 & -0.35 & -5.56 & 0.00 \\
\hline$M \& S$ & -0.96 & 0.07 & -0.57 & -13.11 & 0.00 & -1.12 & 0.11 & -0.67 & -10.33 & 0.00 \\
\hline G\&A & -0.85 & 0.13 & -0.26 & -6.56 & 0.00 & & & & & \\
\hline AVGGM*VERT & 0.15 & 0.19 & 0.12 & 0.79 & 0.433 & & & & & \\
\hline AVGRD*VERT & -0.25 & 0.41 & -0.06 & -0.60 & 0.551 & -0.76 & 0.52 & -0.17 & -1.46 & 0.147 \\
\hline AVGSM*VERT & -0.14 & 0.23 & -0.05 & -0.62 & 0.535 & 0.50 & 0.32 & 0.17 & 1.57 & 0.120 \\
\hline AVGGA*VERT & -0.18 & 0.30 & -0.05 & -0.62 & 0.537 & & & & & \\
\hline Vertical_Dummy & 0.03 & 0.12 & 0.03 & 0.20 & 0.839 & -0.05 & 0.09 & -0.06 & -0.52 & 0.604 \\
\hline$R^{2}$ & \multicolumn{5}{|c|}{0.92} & \multicolumn{5}{|c|}{0.80} \\
\hline$F$ & \multicolumn{5}{|c|}{106.50} & \multicolumn{5}{|c|}{72.00} \\
\hline$p$-value & \multicolumn{5}{|c|}{0.000} & \multicolumn{5}{|c|}{0.000} \\
\hline
\end{tabular}




\section{E. THE MODERATING EFFECT OF THE FIRM'S SPECIALIZATION (CONTINUED)}

The exercise was repeated with YOY growth as a dependent variable (instead of EBITDA) and arrived at a simplified regression model with only M\&S and its related moderating effects. However, even in this simpler regression model, the individual moderator and moderating factor were not statistically significant (Appendix E).

Indeed, in this regression model, neither the moderator effect on the relationship between M\&S and YOY Growth (AVGSM*VERT) or the moderator (Vertical Dummy) were statistically significant.

Moderating effect on the relationships to YOY Growth:

Table 45: Moderating Effect of the Firm's Specialization on the Relationships to Growth

\begin{tabular}{|c|c|c|c|c|c|}
\hline \multirow[b]{3}{*}{ Predictor } & \multicolumn{5}{|c|}{ Dependent variable: YOY Growth } \\
\hline & \multicolumn{5}{|c|}{ Model } \\
\hline & $B$ & $S E B$ & b & $t$ & $p$-value \\
\hline Constant & -0.08 & 0.04 & 0.00 & -1.75 & 0.084 \\
\hline$M \& S$ & 0.75 & 0.10 & 0.68 & 7.66 & 0.000 \\
\hline AVGSM*VERT & -0.10 & 0.30 & -0.05 & -0.34 & 0.738 \\
\hline Vertical_Dummy & 0.11 & 0.09 & 0.21 & 1.29 & 0.200 \\
\hline$R^{2}$ & \multicolumn{5}{|c|}{0.41} \\
\hline$F$ & \multicolumn{5}{|c|}{21.39} \\
\hline$p$-value & \multicolumn{5}{|c|}{0.000} \\
\hline
\end{tabular}




\section{F. BOX PLOTS AND HISTOGRAMS \\ Box Plots: COGS, GM, R\&D, M\&S, G\&A}

Table 46: Box Plots (COGS, GM, R\&D, G\&A) - Data Summary

Legend:

\begin{tabular}{|l|r|r|r|r|r|}
\cline { 2 - 6 } \multicolumn{1}{c|}{} & AVGCO & AVGGM & AVGRD & AVGSM & AVGGA \\
\hline Minimum & $5 \%$ & $17 \%$ & $1 \%$ & $2 \%$ & $5 \%$ \\
\hline 25th Percentile & $25 \%$ & $57 \%$ & $12 \%$ & $21 \%$ & $13 \%$ \\
\hline Median & $35 \%$ & $65 \%$ & $16 \%$ & $33 \%$ & $18 \%$ \\
\hline 75th Percentile & $43 \%$ & $75 \%$ & $21 \%$ & $44 \%$ & $23 \%$ \\
\hline Maximum & $83 \%$ & $95 \%$ & $69 \%$ & $162 \%$ & $79 \%$ \\
\hline
\end{tabular}

- $\mathrm{AVGCO}=$ average COGS $\%$ of revenue over the prior 3 fiscal years.

- $\mathrm{AVGGM}=$ average GM \% of revenue over the prior 3 fiscal years.

- $\quad \mathrm{AVGRD}=$ average $\mathrm{R} \& \mathrm{D} \%$ of revenue over the prior 3 fiscal years.

- $\quad \mathrm{AVGSM}=$ average $\mathrm{M} \& \mathrm{~S} \%$ of revenue over the prior 3 fiscal years.

- $\quad$ AVGGA = average G\&A \% of revenue over the prior 3 fiscal years.

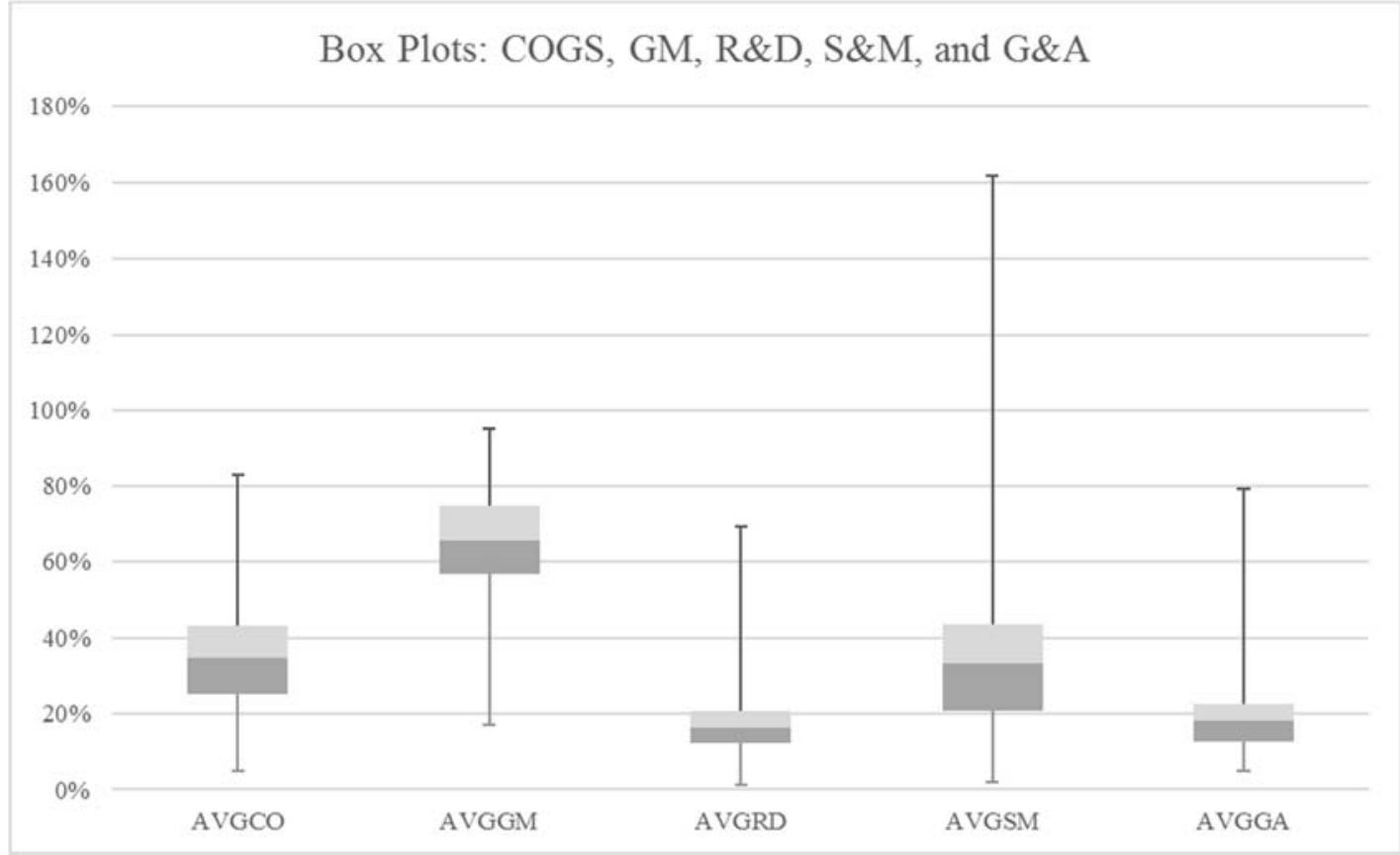

Figure 15: Box Plots (COGS, GM, R\&D, G\&A) 
Box Plot: EBITDA

Table 47: Box Plot (EBITDA) - Data Summary

\begin{tabular}{|l|r|}
\cline { 2 - 2 } \multicolumn{1}{c|}{} & \multicolumn{1}{c|}{ AVGEB } \\
\hline Minimum & $-255 \%$ \\
\hline 25 th Percentile & $-11 \%$ \\
\hline Median & $11 \%$ \\
\hline 75 th Percentile & $23 \%$ \\
\hline Maximum & $58 \%$ \\
\hline
\end{tabular}

Legend:

- $\quad \mathrm{AVGEB}=$ average EBITDA \% of revenue over the prior 3 fiscal years.

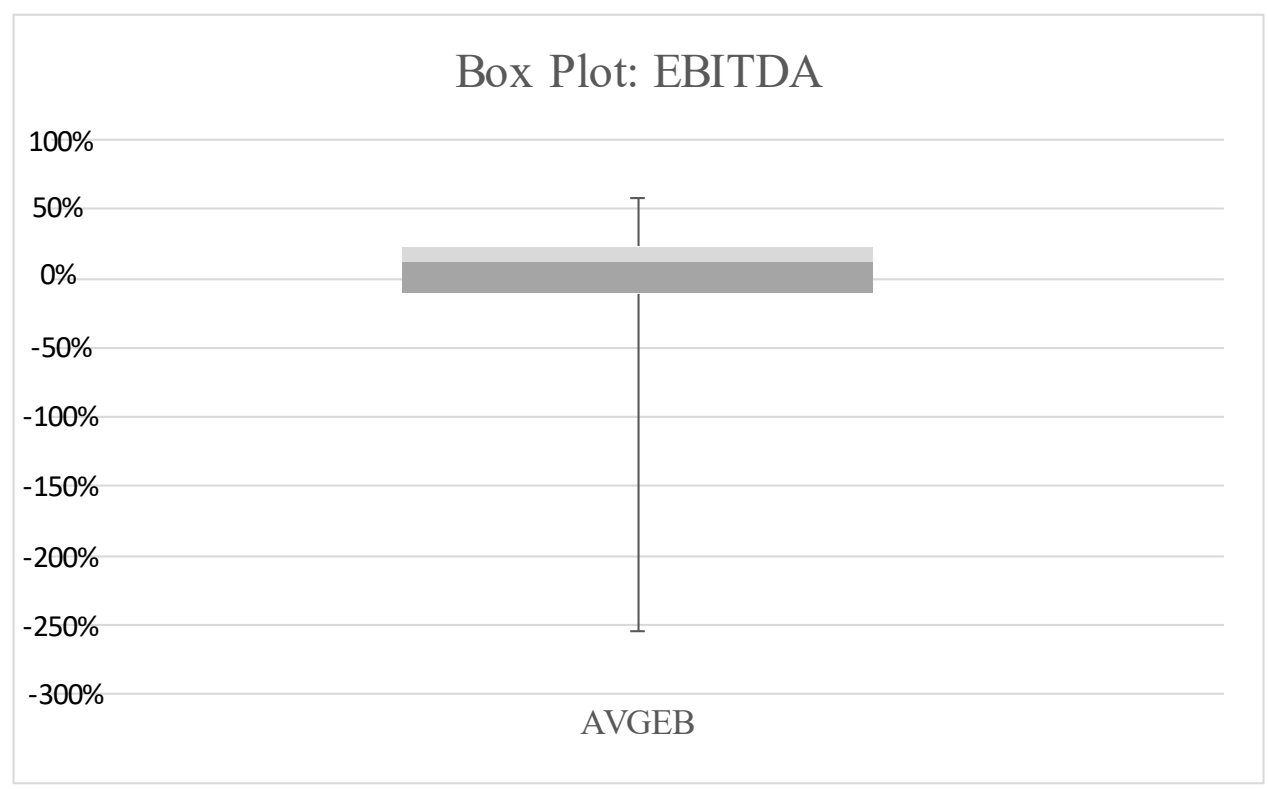

Figure 16: Box Plot (EBITDA) 


\section{Box Plot: YOY Growth}

Table 48: Box Plot (Growth) - Data Summary

\begin{tabular}{|l|r|}
\cline { 2 - 2 } \multicolumn{1}{c|}{} & \multicolumn{1}{c|}{} \\
\hline Minimum & AVGYOYG \\
\hline 25th Percentile & $-22 \%$ \\
\hline Median & $7 \%$ \\
\hline 75 th Percentile & $16 \%$ \\
\hline Maximum & $30 \%$ \\
\hline
\end{tabular}

Legend:

- $\quad$ AVGYOYG also referred to as YOYG = Year over year (YOY) growth measured as the average YoY revenue growth over the prior 3 fiscal years (i.e., average of growth from year 1 to year 2 and growth from year 2 to year 3 ).

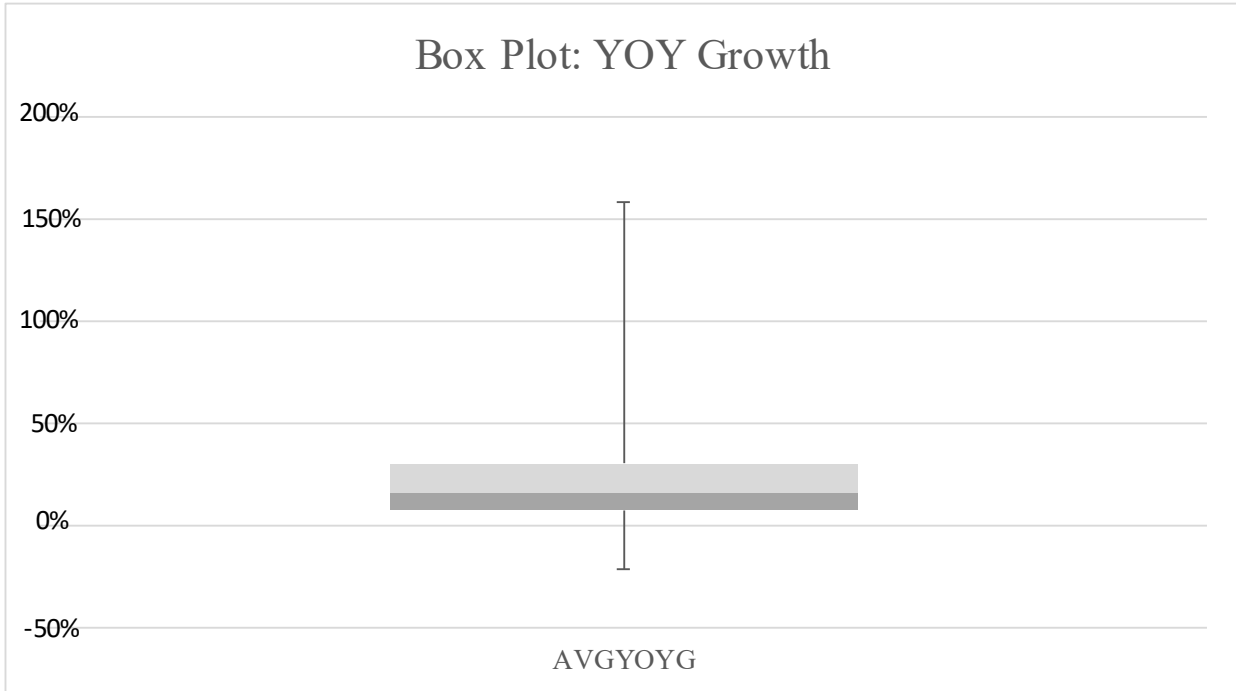

Figure 17: Box Plot (Growth) 


\section{Box Plot: Enterprise Value (Rev. Multiple)}

Table 49: Box Plot (Enterprise Value) - Data Summary

\begin{tabular}{|l|r|}
\cline { 2 - 2 } \multicolumn{1}{c|}{} & \multicolumn{1}{c|}{ RevM } \\
\hline Minimum & 0.48 \\
\hline 25th Percentile & 2.33 \\
\hline Median & 3.86 \\
\hline 75th Percentile & 6.29 \\
\hline Maximum & 12.16 \\
\hline
\end{tabular}

Legend:

- RevM = Enterprise Value (EV) measured as the Revenue Multiple (or EV/Revenue).

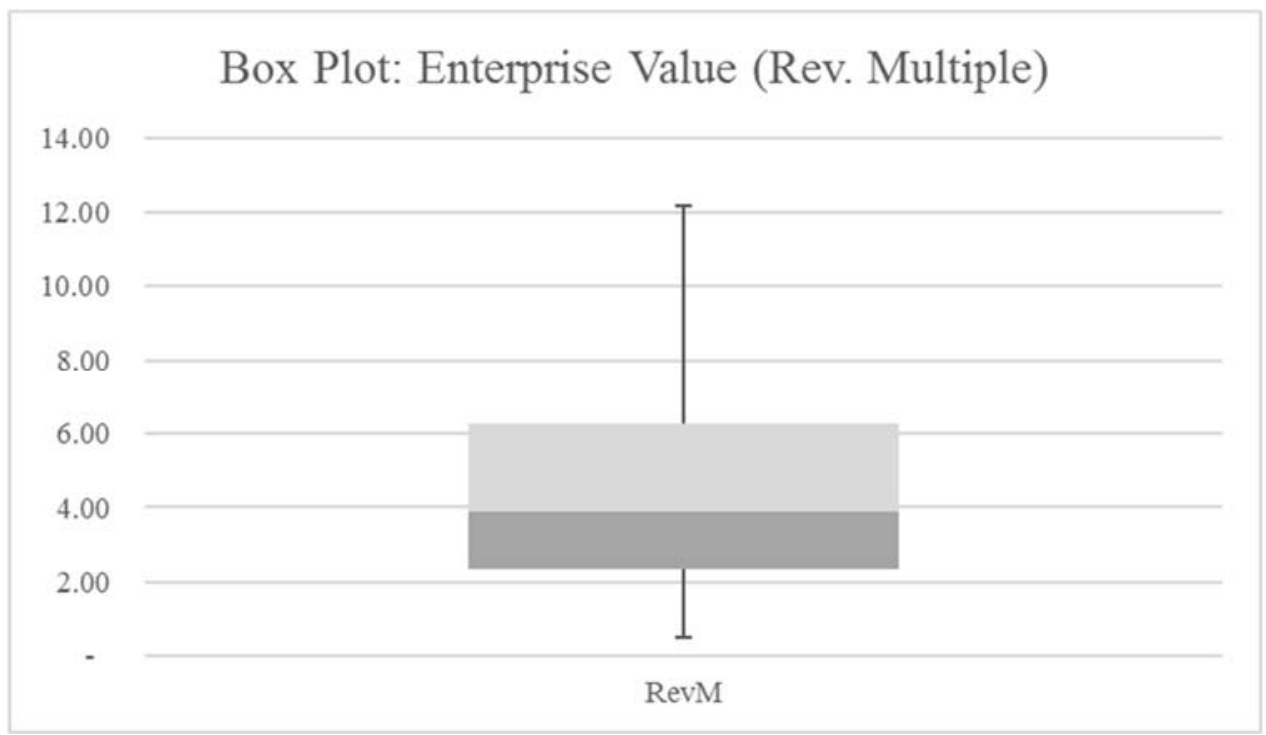

Figure 18: Box Plot (Enterprise Value) 
Histograms: COGS, GM, R\&D, M\&S, G\&A

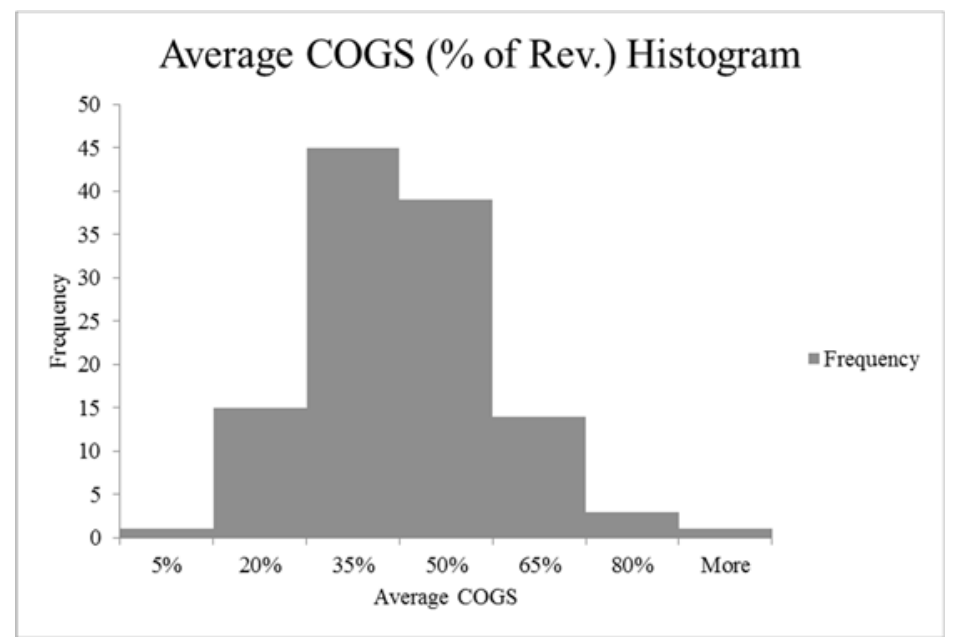

Figure 19: Average COGS (as a \% of Revenue) Histogram

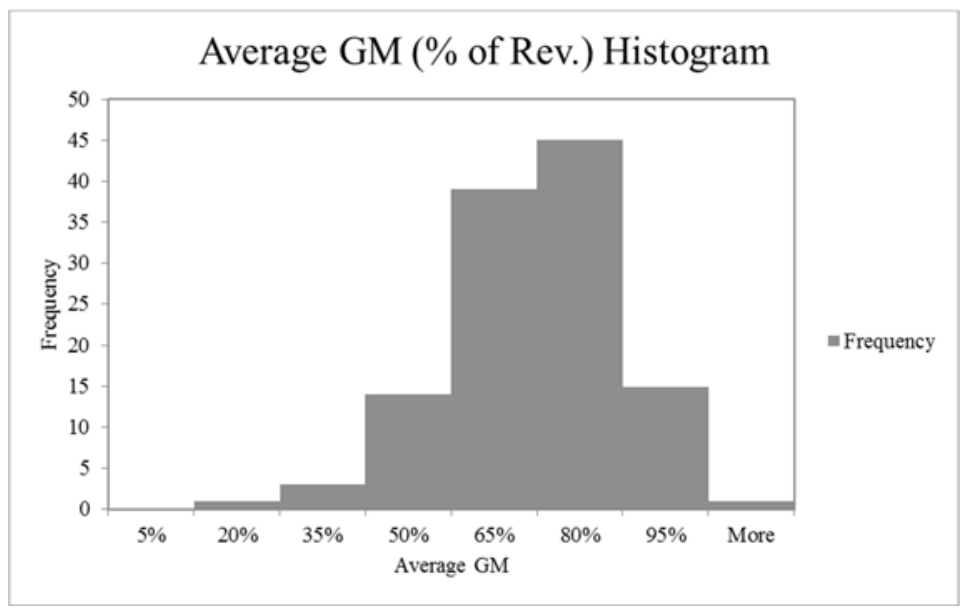

Figure 20: Average Gross Margin (as a \% of Revenue) Histogram 


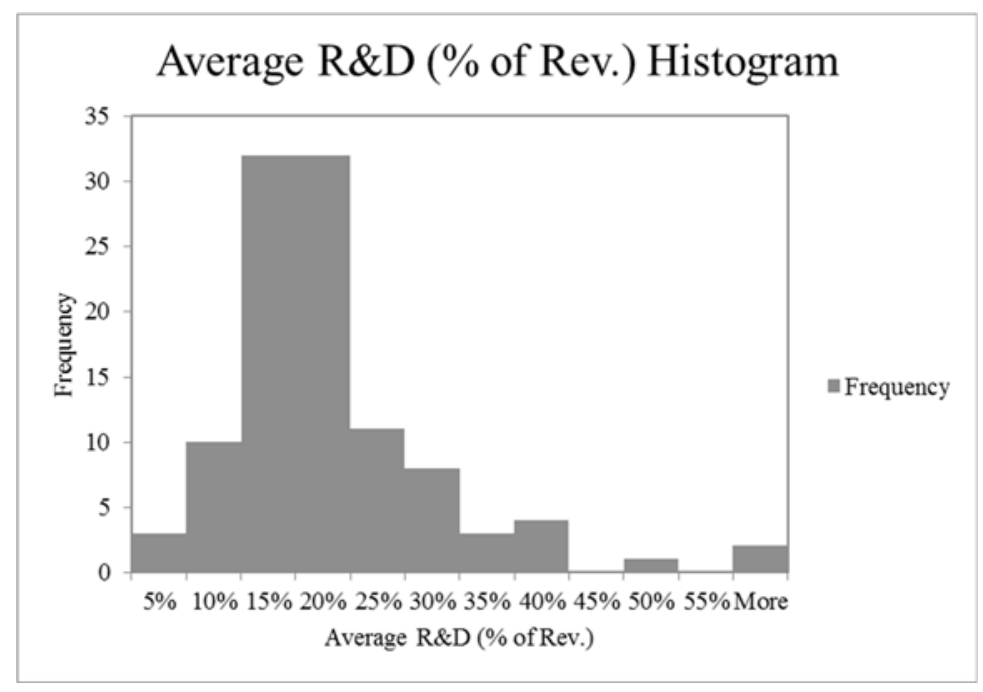

Figure 21: Average R\&D Spending (as a \% of Revenue) Histogram

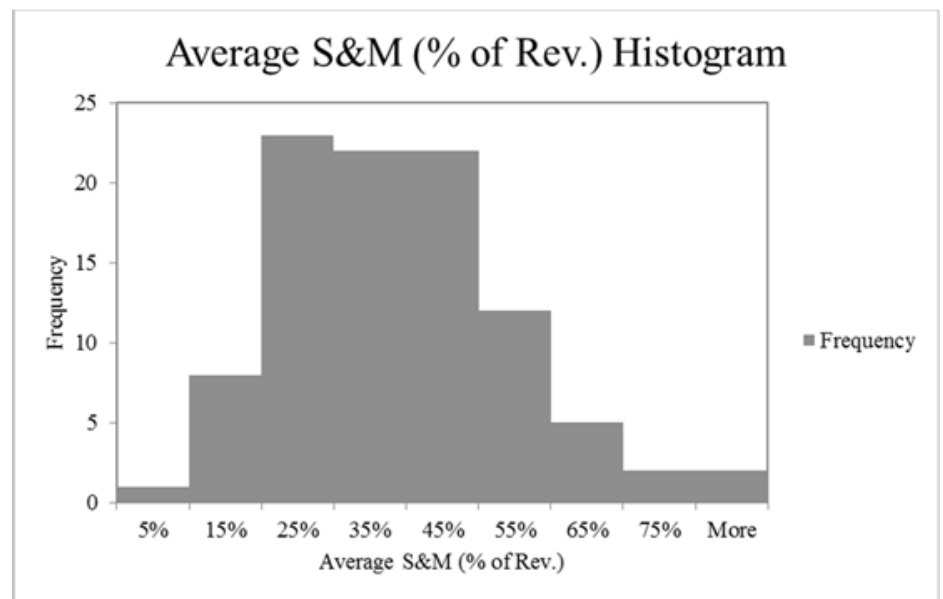

Figure 22: Average M\&S Spending (as a \% of Revenue) Histogram 


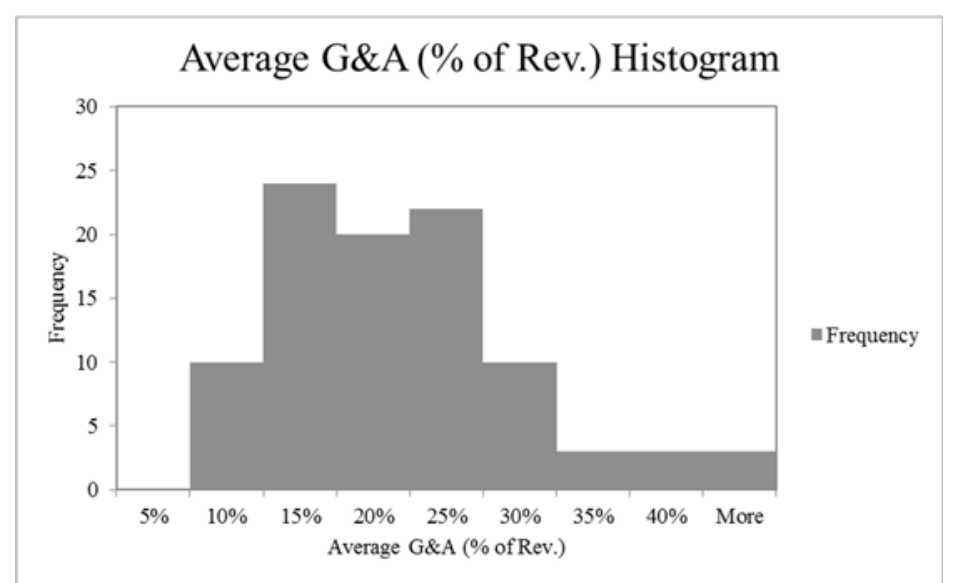

Figure 23: Average G\&A Spending (as a \% of Revenue) Histogram

Histograms: EBITDA, Growth, Enterprise Value (Rev. Multiple)

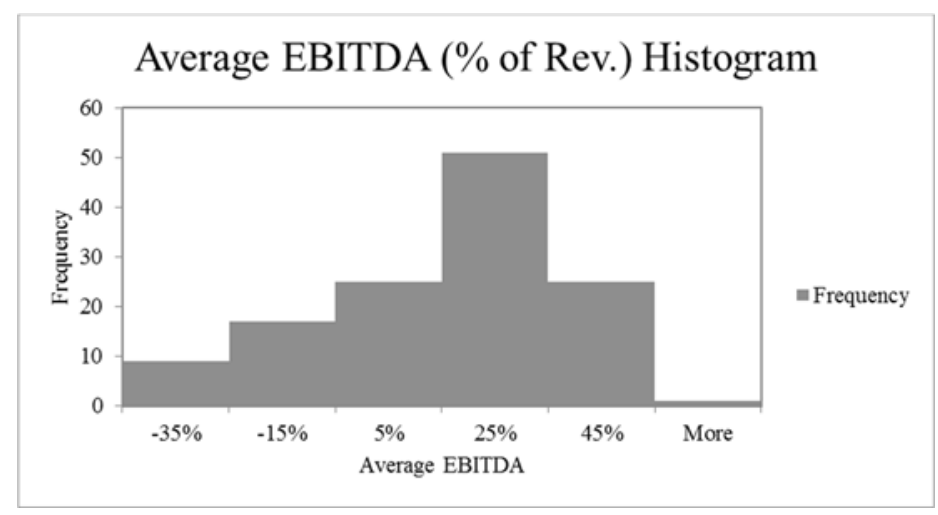

Figure 24: Average EBITDA (as a \% of Revenue) Histogram 


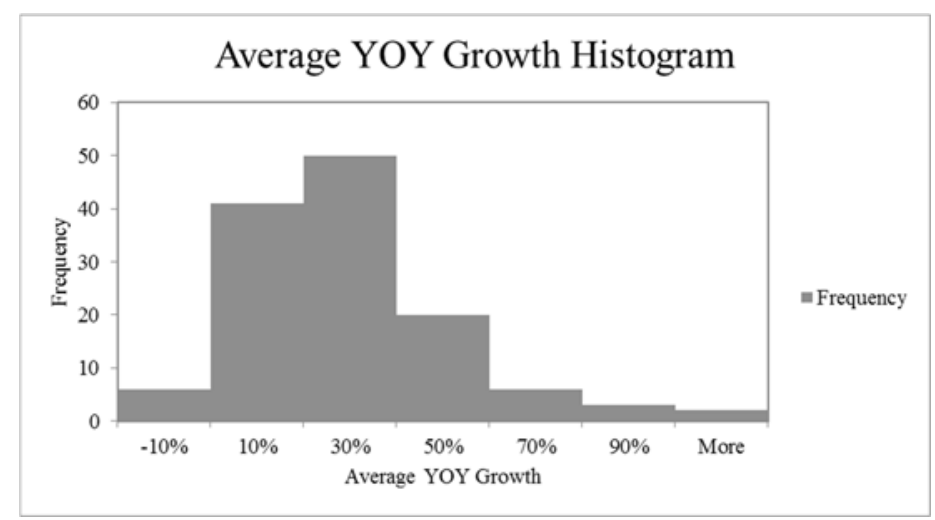

Figure 25: Average Growth Histogram

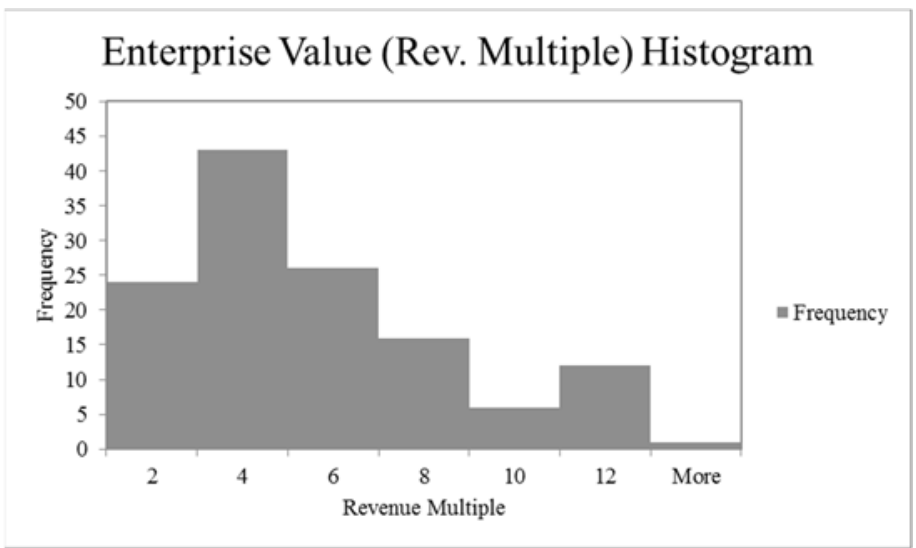

Figure 26: Average Enterprise Value (Revenue Multiple) Histogram 


\section{G. ADDITIONAL VALIDITY TESTS}

\section{Rule of Forty (ROF) as an alternative measure of firm performance:}

As part of additional validity tests, I substituted the Performance Factor (PF) measure by an alternative measure of financial performance consisting of the aggregate of the two variables (YOY growth rate and EBITDA \%), instead of their multiplication, as follows:

Rule of Forty $($ ROF $)=($ YOY growth rate + EBITDA \% $) * 100$.

I call this measure the "Rule of Forty" (ROF) measure because it is inspired by a metric known in the industry as the "Rule of 40". Indeed, the "Rule of 40" is a known metric for measuring the financial performance of SaaS firms among financial professionals in the industry. It is defined as YOY growth \% + pretax operating income \%. The aggregate of the two should be at least $40 \%$ (KPMG, 2016). EBITDA is also commonly used by financial analysts instead of pretax operating income. For the purpose of this study, I used the EBITDA \%. For example, if EBITDA is negative $10 \%$ and growth is $30 \%$, the ROF score is 20 . To achieve 40 , a firm having a negative EBITDA of $10 \%$ would have to achieve a $50 \%$ YOY growth rate.

The relationship between $R \& D$ and firm performance measured by using the ROF measure indicated again a downward slope past a certain point, confirming the existence of diminishing returns of R\&D spending to firm performance (H3). I found the same result for the relationship between $\mathrm{M} \& \mathrm{~S}$ and firm performance measured by using the ROF 
measure, confirming again the diminishing returns of M\&S spending on firm performance (H4).

Similarly, I performed additional validation tests on the relationship between average standard deviation (AVGSTD) and firm performance using ROF as an alternative measure (instead of the PF). The results indicated a negative correlation between the two variables (AVGSTD and ROF) of - 0.57. As demonstrated earlier using PF as a measure, the higher the average standard deviation, the lower the performance. The regression statistics indicated a $\mathrm{R}$ square of 0.33 with $\mathrm{p}$ value $<.01$.

After removing the outliers (three cases with an average standard deviation above 10\%), the results showed again a negative relationship with a correlation of -0.50 and regression statistics indicating a $\mathrm{R}$ square of 0.25 with $\mathrm{p}$ value $<.01$. In summary, I reached a similar conclusion regarding the influence of consistency of spending patterns on firm performance (H5) when using ROF instead of PF as a measure. 


\section{H. DISCUSSIONS WITH PRACTITIONERS - STUDY DESIGN}

\section{Recruitment Method}

I am planning to engage a dozen practitioners in one-on-one phone discussions to obtain their feedback on the findings of the study. The main goal of these discussions is to validate the analysis from a practitioner's perspective and enrich the research with insights coming from practitioners.

The investigator will be the author of the study.

The author, who is also the CFO of a technology company, created a list of contacts from his personal contacts in the industry. The contacts consist of investment bankers, executives at accounting and business valuation companies, executives at private equity firms, and a few CFOs of SaaS companies, all located in the United States.

The approach will consist of the following steps:

- The investigator will send to the participants an invitation email (please refer to the Email Template below)

- If the participant agrees to participate, the investigator will send him or her a summary of the findings along with a draft copy of the research paper, and the investigator will set up a call with him or her in the following days.

- The investigator will take notes from the phone discussions.

\section{Email Template}


Dear ...,

Hope all is well. As you may be aware, I am enrolled in a doctoral program for working professionals at Temple University. As part of my doctoral research, I have studied publicly-traded SaaS companies and I have done analysis on their relative spending in capabilities $(R \& D$, Marketing \& Sales) and the effects on financial performance.

Would you be interested in reviewing the summary results of the study and provide feedback?

If you are interested, I will send you a summary of the findings and we will go over it on a call to be scheduled in the coming days.

As part of the call, we will discuss your feedback using the seven questions below. I don't expect the call to take more than 45 minutes.

In exchange for your participation, I will provide a draft copy of the research paper.

Let me know.

Thank you

John

Note: the seven questions:

- What are your thoughts on the findings of this research?

- What do you think are the main practical implications for business managers?

- Do you think that these findings would be applicable or generalizable to companies in other industries and contexts?

- What do you perceive as the main limitations of the research?

- Are there any additional questions that you think would be valuable to address as a next step or as an extension of this research?

- Are there any other measures of performance or factors that you think would be valuable to include in the research?

- Any other thoughts you would like to add?

Also, if you have any suggestions regarding other practitioners who might have an interest in providing feedback, please let me know. Thank you. 


\section{Study Timeline}

The one-on-one phone discussions will occur during the summer 2017 (June-August 2017).

\section{Study Procedures and Data Analysis}

The feedback will be analyzed during the fall and conclusions (in terms of validation and new insights) will be included in the research paper and will be part of Essay Two of the dissertation. The identity of the participants and of their firm will not be disclosed in the research paper or essay unless a formal consent is obtained.

\section{Withdrawal of Subjects}

Participants are not expected to withdraw from the study. However, if that should happen, it would not be an issue.

\section{Privacy \& Confidentiality}

No sensitive personal information or health information will be collected during the study.

\section{Risks to Subjects}

There are no anticipated risks to the study or participants, all data will be collected at the firm level and/or industry level. The discussions will be conducted during business hours at the convenience of the participant.

\section{Potential Benefits to Subjects}

Potential benefits include: 
- Learning about the key findings of the study via the materials provided and the oneon-one discussions.

- In addition, a copy of the study will be offered to the participants if they are interested.

\section{Costs to Subjects}

There is no cost expected to be incurred by the participant.

\section{Informed Consent}

It is expected that consent to participate in the one-on-one discussion will be given by accepting the invitation via an email acceptance prior to the discussion. Refer to the Email Template (above). The discussion will occur over the phone once the participant accepted to participate.

\section{IRB Exemption}

IRB forms (i.e., Consent for Minimal Risk Research and Protocol Minimal Risk forms) were submitted for this project to Temple University's IRB. After examination of the forms by Temple University's IRB Program Coordinator, the author was notified on June 7, 2017 that this project was not human subjects research, and that, therefore, IRB approval was not required for this project. 


\section{INSIGHTS FROM THE LITERATURE (EXTENDED LITERATURE}

REVIEW) - TABLES OF KEY FINDINGS AND MANAGERIAL IMPLICATIONS 


\section{Extended Literature Review - Key Findings}

Table 50: Extended Literature Review - Key Findings

\begin{tabular}{|c|c|c|c|c|}
\hline $\begin{array}{l}\text { Author } \\
\text { (Date) }\end{array}$ & Title & Research Question & Key Findings & Research Approach \\
\hline $\begin{array}{l}\text { Boer, F. P. } \\
(2002) .\end{array}$ & $\begin{array}{l}\text { Financial management } \\
\text { of RD 2002. Research- } \\
\text { Technology } \\
\text { Management, 45(4), } \\
\text { 23-35 }\end{array}$ & $\begin{array}{l}\text { How to measure the } \\
\text { profitability of R\&D } \\
\text { investments? }\end{array}$ & $\begin{array}{l}\text { Financial performance management of R\&D has evolved } \\
\text { beyond the basic discount cash flow (DCF) models that } \\
\text { emerged in the industrial world in 1970s. DCF analysis } \\
\text { replaced older methods such as the "years to payback" } \\
\text { method. The era of DCF dominance ended in the 1980s in } \\
\text { part because of a crisis in business valuations, with sky- } \\
\text { high valuations accorded to companies with promising } \\
\text { intellectual capital property but minuscule or negative } \\
\text { short-term cash flow. This was the case in the } \\
\text { biotechnology boom in the 1980s, followed by a major } \\
\text { run in technology stocks in 1990s that underscored the } \\
\text { valuation problem. The valuation crisis was also caused } \\
\text { by unprecedent flood of money into venture capital (VC) } \\
\text { investments. New approaches emerged such as the } \\
\text { economic value added (EVA) and real options analysis. } \\
\text { Real options analysis is a better suited method to account } \\
\text { for risks (e.g., R\&D/technology risks, market risks) and } \\
\text { strategic value. Real options theory can go a long way } \\
\text { toward explaining the turbocharged valuations accorded } \\
\text { to companies that are experiencing high growth and that } \\
\text { are subject to high volatility. }\end{array}$ & $\begin{array}{l}\text { Conceptual paper on the } \\
\text { evolution of R\&D } \\
\text { financial management } \\
\text { approaches since the mid- } \\
80 \text { s. }\end{array}$ \\
\hline
\end{tabular}


Table 50: Extended Literature Review - Key Findings (Continued)

\begin{tabular}{|c|c|c|c|c|}
\hline $\begin{array}{l}\text { Capasso, } \\
\text { M., } \\
\text { Treibich, T. } \\
\text { G., \& } \\
\text { Verspagen, } \\
\text { B. (2015). }\end{array}$ & $\begin{array}{l}\text { The medium-term } \\
\text { effect of R\&D on firm } \\
\text { growth. Small } \\
\text { Business Economics, } \\
45(1), 39-62 . \\
\text { doi:10.1007/s11187- } \\
015-9640-6\end{array}$ & $\begin{array}{l}\text { What is the effect of } \\
\mathrm{R} \& \mathrm{D} \text { expenditure on firm } \\
\text { growth? }\end{array}$ & $\begin{array}{l}\text { This study analyses the effect of R\&D expenditure on } \\
\text { firm employment growth and concludes that a higher level } \\
\text { of R\&D expenditure has a positive effect on firm growth } \\
\text { among higher growth organizations and allows a higher } \\
\text { number of firms to become high growth firms. The study } \\
\text { also demonstrates that a high level of R\&D expenditure } \\
\text { does not reduce the likelihood of a bad performance. }\end{array}$ & $\begin{array}{l}\text { Quantitative research } \\
\text { approach: quantile } \\
\text { regression analysis based } \\
\text { on a sample of more than } \\
13,000 \text { firms using data } \\
\text { from surveys and a } \\
\text { business register database } \\
\text { in the Netherlands. }\end{array}$ \\
\hline $\begin{array}{l}\text { Ciftci, M., \& } \\
\text { Cready, W. } \\
\text { M. (2011). }\end{array}$ & $\begin{array}{l}\text { Scale effects of R\&D } \\
\text { as reflected in earnings } \\
\text { and returns. Journal of } \\
\text { Accounting and } \\
\text { Economics, 52(1), 62- } \\
80\end{array}$ & $\begin{array}{l}\text { What are the effects of } \\
\text { R\&D scale on earnings, } \\
\text { earnings volatility } \\
\text { (variability) and market } \\
\text { returns? }\end{array}$ & $\begin{array}{l}\text { The study shows that the effects of R\&D on earnings, } \\
\text { earnings volatility (variability) and market returns vary } \\
\text { depending on size. R\&D investments by larger firms are } \\
\text { associated with higher future earnings and lower earnings } \\
\text { variability. They appear to be less risky than R\&D } \\
\text { investments from smaller firms. Because of economies of } \\
\text { scope and scale, larger R\&D efforts are more productive } \\
\text { and less uncertain. }\end{array}$ & 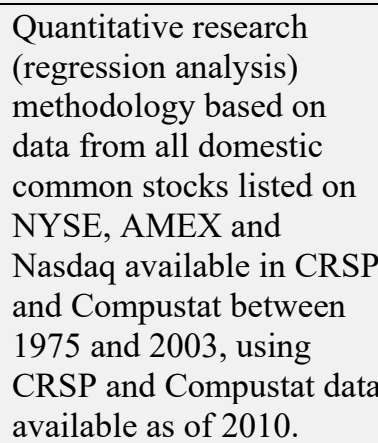 \\
\hline
\end{tabular}


Table 50: Extended Literature Review - Key Findings (Continued)

\begin{tabular}{|c|c|c|c|c|}
\hline $\begin{array}{l}\text { Coccia, M. } \\
(2009) .\end{array}$ & $\begin{array}{l}\text { What is the optimal } \\
\text { rate of R\&D } \\
\text { investment to } \\
\text { maximize productivity } \\
\text { growth? Technological } \\
\text { Forecasting \& Social } \\
\text { Change, } 76(3), 433- \\
446\end{array}$ & $\begin{array}{l}\text { What is the optimal } \\
\text { amount of R\&D } \\
\text { investments that } \\
\text { maximizes the } \\
\text { productivity growth in the } \\
\text { long run? }\end{array}$ & $\begin{array}{l}\text { The author analyzes the relationship between R\&D } \\
\text { investments and productivity growth at country level. } \\
\text { R\&D investments are measured by the Gross Domestic } \\
\text { Expenditure on R\&D as a \% of GDP. Productivity growth } \\
\text { is measured by } 2 \text { metrics: labor growth and total factor } \\
\text { productivity (TFP). The study finds that, contrary to } \\
\text { expectations and to much of the literature, it is not true } \\
\text { that the higher R\&D investment as a percentage of GDP } \\
\text { is, the higher productivity growth is. The results show that } \\
\text { the relationship follows a function that is concave } \\
\text { downwards due to diminishing returns to R\&D } \\
\text { investments. The same amount of R\&D investments } \\
\text { generates effects that can change over time and space. }\end{array}$ & $\begin{array}{l}\text { Quantitative research } \\
\text { approach: econometric } \\
\text { estimation and } \\
\text { mathematical optimization } \\
\text { model tested using data } \\
\text { from Eurostat for the } \\
\text { European Union countries, } \\
\text { Japan, and the USA and } \\
\text { regression analysis } \\
\text { methodology. }\end{array}$ \\
\hline $\begin{array}{l}\text { Demirel, P., } \\
\& \\
\text { Mazzucato, } \\
\text { M. (2012). }\end{array}$ & $\begin{array}{l}\text { Innovation and firm } \\
\text { growth: Is R\&D worth } \\
\text { it? Industry and } \\
\text { Innovation, 19(1), 45- } \\
62\end{array}$ & $\begin{array}{l}\text { What is the effect of } \\
\text { R\&D investments on firm } \\
\text { growth and do firm } \\
\text { characteristics affect the } \\
\text { relationship? }\end{array}$ & $\begin{array}{l}\text { The paper studies the role of R\&D in driving firm growth } \\
\text { in the US pharmaceutical industry between } 1950 \text { and } \\
2008 \text {, a period during which the size composition of firms } \\
\text { and the characteristics of innovation evolved significantly. } \\
\text { In the case of the pharmaceutical industry, evaluated at } \\
\text { the industry level, the authors find that R\&D has been } \\
\text { effective at boosting firm growth through the whole } \\
\text { industry history. However, by looking into the different } \\
\text { types of firms, they find that the expected positive impact } \\
\text { of R\&D only applies to a subset of firms. More } \\
\text { specifically, they find a positive relationship between } \\
\text { R\&D and firm growth only for small pharmaceutical } \\
\text { firms, conditional on the firms patenting persistently. In } \\
\text { other words, in this industry, they find that persistent } \\
\text { innovations and persistent patenting are key for firms to } \\
\text { reap economic returns to their R\&D efforts. }\end{array}$ & $\begin{array}{l}\text { Quantitative research } \\
\text { approach: regression } \\
\text { analysis based on a sample } \\
\text { of } 248 \text { firms from the } \\
\text { pharmaceutical industry } \\
\text { publicly traded in the USA } \\
\text { over the period 1950-2008 } \\
\text { using data from Compustat } \\
\text { and NBER patent } \\
\text { databases. }\end{array}$ \\
\hline
\end{tabular}


Table 50: Extended Literature Review - Key Findings (Continued)

\begin{tabular}{|c|c|c|c|c|}
\hline $\begin{array}{l}\text { Eisenmann, } \\
\text { T. R. (2006) }\end{array}$ & $\begin{array}{l}\text { Internet companies' } \\
\text { growth strategies: } \\
\text { Determinants of } \\
\text { investment intensity } \\
\text { and long-term } \\
\text { performance. Strategic } \\
\text { Management Journal, } \\
27(12), 1183-1204\end{array}$ & $\begin{array}{l}\text { What were the factors } \\
\text { that encouraged } \\
\text { accelerated growth } \\
\text { strategies among internet } \\
\text { companies and what were } \\
\text { the long-term } \\
\text { consequences of such } \\
\text { strategies? Accelerated } \\
\text { growth strategies are } \\
\text { defined as efforts to } \\
\text { acquire customers rapidly } \\
\text { in new markets through } \\
\text { heavy marketing } \\
\text { spending, discounting } \\
\text { aggressively, or } \\
\text { absorbing rivals through } \\
\text { mergers. }\end{array}$ & $\begin{array}{l}\text { Internet companies spent heavily in marketing to } \\
\text { accelerate growth. For the } 117 \text { internet companies that } \\
\text { comprise this paper's sample, marketing spending equaled } \\
46 \% \text { of total capital invested. Results indicate that first } \\
\text { movers spent significantly more in marketing than non- } \\
\text { pioneers. The results suggest that firms invested in } \\
\text { marketing at levels that maximized the predicted ROI } \\
\text { (measured as the return on invested capital) and indicates } \\
\text { an inverted U-shaped relationship between marketing } \\
\text { spending and ROI. }\end{array}$ & $\begin{array}{l}\text { Quantitative study } \\
\text { (regression analysis) based } \\
\text { on a sample of } 117 \\
\text { publicly-traded internet } \\
\text { companies selected from } \\
\text { various internet stock } \\
\text { indexes and Internet IPO } \\
\text { data. }\end{array}$ \\
\hline $\begin{array}{l}\text { Fung, M. K. } \\
\text { (2004). }\end{array}$ & $\begin{array}{l}\text { Technological } \\
\text { opportunity and } \\
\text { productivity of R\&D } \\
\text { activities. Journal of } \\
\text { Productivity Analysis, } \\
21(2), 167-181\end{array}$ & $\begin{array}{l}\text { What is the effect of } \\
\text { technological opportunity } \\
\text { on the productivity of } \\
\text { R\&D activities? }\end{array}$ & $\begin{array}{l}\text { Using patent citation statistics, the study measures the } \\
\text { effects of three aspects of technological opportunity on } \\
\text { R\&D productivity: intensities of knowledge spillovers } \\
\text { (industry-level patent citations), inter-firm research } \\
\text { overlap (frequency of common citations among firms) and } \\
\text { scope of research (diversity of research topics of patents } \\
\text { granted to firms as per the US patent classification). R\&D } \\
\text { productivity is measured by the cumulative number of } \\
\text { historical patents granted to firms in the industry. The } \\
\text { results confirm a positive relationship between } \\
\text { technological opportunity and the productivity of R\&D. }\end{array}$ & $\begin{array}{l}\text { Quantitative research } \\
\text { approach: regression } \\
\text { analysis based on patent } \\
\text { statistics from USPTO and } \\
\text { a sample of } 224 \text { firms in } \\
\text { three industries: chemical, } \\
\text { computer, and } \\
\text { electrical/electronic. }\end{array}$ \\
\hline
\end{tabular}


Table 50: Extended Literature Review - Key Findings (Continued)

\begin{tabular}{|c|c|c|c|c|}
\hline $\begin{array}{l}\text { Heredia, A., } \\
\text { Colomo- } \\
\text { Palacios, R., } \\
\& \text { de } \\
\text { Amescua, A. } \\
(2015) .\end{array}$ & $\begin{array}{l}\text { Software business } \\
\text { models from a } \\
\text { distribution } \\
\text { perspective: A } \\
\text { systematic mapping } \\
\text { study. Procedia } \\
\text { Computer Science, 64, } \\
\text { 395-402 }\end{array}$ & $\begin{array}{l}\text { What is the state of the } \\
\text { art of software business } \\
\text { models (BMs)? }\end{array}$ & $\begin{array}{l}\text { Software BMs is a wide research topic that covers } \\
\text { multiple aspects regarding how a software company } \\
\text { creates and delivers value to customers, the products or } \\
\text { services that it offers, and the compensation for them. The } \\
\text { study structures and characterizes the state of the art on } \\
\text { software BMs with a focus on sales and distribution } \\
\text { models from a business management perspective. The } \\
\text { analysis reveals the most relevant sources of papers with } \\
\text { regard to the research on software BMs, and also provides } \\
\text { researchers with insights to select relevant publications for } \\
\text { future studies. It also discusses the broad interest of } \\
\text { researchers on this topic. Most of the primary studies were } \\
\text { related to service-based BMs, and to a lesser extent to } \\
\text { product-based or open-source-based BMs; there is also an } \\
\text { increase in the attention of researchers towards models } \\
\text { built around mobile apps. }\end{array}$ & $\begin{array}{l}\text { Systematic mapping study } \\
\text { using relevant keywords to } \\
\text { identify primary studies in } \\
\text { the existing literature } \\
\text { related to software BMs } \\
\text { from a business } \\
\text { management perspective. } \\
\text { The search strategy } \\
\text { returned } 1,871 \text { papers of } \\
\text { which } 51 \text { were selected as } \\
\text { primary studies to be } \\
\text { included in the systematic } \\
\text { mapping study. }\end{array}$ \\
\hline $\begin{array}{l}\text { Joglekar, N. } \\
\text { R., \& } \\
\text { Levesque, } \\
\text { M. (2009). }\end{array}$ & $\begin{array}{l}\text { Marketing, R\&D, and } \\
\text { startup valuation. } \\
\text { IEEE Transactions on } \\
\text { Engineering } \\
\text { Management, 56(2), } \\
229-242\end{array}$ & $\begin{array}{l}\text { When should a startup } \\
\text { owner acquire working } \\
\text { capital, and how should } \\
\text { she/he distribute that } \\
\text { capital between R\&D (to } \\
\text { improve product quality) } \\
\text { and marketing (to } \\
\text { increase sales) to } \\
\text { ultimately grow } \\
\text { valuation? Also, should } \\
\text { the startup owner cap the } \\
\text { total R\&D and marketing } \\
\text { budgets to increase } \\
\text { profitability during staged } \\
\text { venture financing? }\end{array}$ & $\begin{array}{l}\text { The authors propose a model to optimize resource } \\
\text { acquisition and allocation across successive stages of } \\
\text { startup growth to minimize equity dilution and maximize } \\
\text { business valuation. The model incorporates a funding } \\
\text { process whereby the startup valuation is positively } \\
\text { impacted by improved product quality and market growth. } \\
\text { This model provides insights on optimal resource } \\
\text { allocation practices and illustrates conditions for optimal } \\
\text { capping of R\&D and marketing expenses as a percentage } \\
\text { of revenues. }\end{array}$ & $\begin{array}{l}\text { Qualitative research } \\
\text { approach: case study on a } \\
\text { manufacturer of electronic } \\
\text { design automation (EDA) } \\
\text { leading to the development } \\
\text { of a conceptual model. The } \\
\text { model is then validated } \\
\text { using a dataset from the } \\
\text { case study. }\end{array}$ \\
\hline
\end{tabular}


Table 50: Extended Literature Review - Key Findings (Continued)

\begin{tabular}{|c|c|c|c|c|}
\hline $\begin{array}{l}\text { Koellinger, } \\
\text { P. (2008) }\end{array}$ & $\begin{array}{l}\text { The relationship } \\
\text { between technology, } \\
\text { innovation, and firm } \\
\text { performance-- } \\
\text { Empirical evidence } \\
\text { from e-business in } \\
\text { Europe. Research } \\
\text { Policy, 37(8), 1317- } \\
1328\end{array}$ & $\begin{array}{l}\text { What is the effect of } \\
\text { technology and } \\
\text { innovation on firm } \\
\text { performance? }\end{array}$ & $\begin{array}{l}\text { The author proposes a conceptual framework for the } \\
\text { relationship between technology, innovation, and firm } \\
\text { performance. He argues that the relationship between use } \\
\text { of IT and firm performance is mediated by innovative } \\
\text { activities that result from the adoption of these } \\
\text { technologies. The empirical part of the study compares the } \\
\text { performance of innovative and non-innovative companies. } \\
\text { Performance is measured in terms of revenue growth, } \\
\text { employment growth, and profitability. The study shows } \\
\text { that all types of innovation included in this analysis are } \\
\text { positively associated with revenue and employment } \\
\text { growth at firm level. However, only product/service } \\
\text { innovations are positively associated with profitability. } \\
\text { Process innovations do not show significant inter-relation } \\
\text { with profits in the study. Innovative firms are significantly } \\
\text { more likely to grow than non-innovative firms. This holds } \\
\text { for all types of innovations included in this study. Finally, } \\
\text { this study shows that innovative firms are more likely to } \\
\text { grow, but not necessarily more likely to be profitable. }\end{array}$ & $\begin{array}{l}\text { Quantitative research } \\
\text { approach: regression } \\
\text { analysis based a dataset } \\
\text { from the } 2003 \text { enterprise } \\
\text { survey of the e-Business } \\
\text { Market W@tch, a large } \\
\text { scale observatory initiative } \\
\text { that is sponsored by the } \\
\text { European Commission DG } \\
\text { Enterprise and Industry: } \\
\text { more than 6,000 firms } \\
\text { randomly selected from } 10 \\
\text { industries and } 25 \text { European } \\
\text { countries. }\end{array}$ \\
\hline
\end{tabular}


Table 50: Extended Literature Review - Key Findings (Continued)

\begin{tabular}{|l|l|l|l|l|}
\hline $\begin{array}{l}\text { Krčál, O. } \\
(2014)\end{array}$ & $\begin{array}{l}\text { The relationship } \\
\text { between profitability, } \\
\text { innovation and } \\
\text { technology gap: A } \\
\text { basic model. Review } \\
\text { of Economic } \\
\begin{array}{l}\text { Perspectives, 14(3), } \\
215-231\end{array}\end{array}$ & $\begin{array}{l}\text { Understanding the } \\
\text { relationship between } \\
\text { innovation (measured in } \\
\text { terms of R\&D } \\
\text { expenditures) and firm } \\
\text { profits. }\end{array}$ & $\begin{array}{l}\text { The author proposes a model to explain an Inverted U- } \\
\text { relationship between profitability and innovation (R\&D } \\
\text { expenditures) building on prior literature. The nonlinear } \\
\text { relationship is influenced by industry factors and firm- } \\
\text { specific factors. R\&D expenditures are constrained by } \\
\text { firm factors such as credit constraints (i.e., access to } \\
\text { financing). Each firm chooses R\&D expenditures that } \\
\text { maximize its expected profit subject to the R\&D- } \\
\text { expenditure constraints. The return to R\&D expenditures } \\
\text { varies depending on industry factors (intensity of } \\
\text { competition, etc.) and firm-specific factors (competitive } \\
\text { position, innovation capability). The model proposes that, } \\
\text { as R\&D expenditures increase, profits and technology gap } \\
\text { first increase then decrease. The technology gap is defined } \\
\text { as the average difference between profits of leaders and } \\
\text { other firms in the industry due to technology and/or other } \\
\text { firm-specific factors. }\end{array}$ & \\
\hline
\end{tabular}


Table 50: Extended Literature Review - Key Findings (Continued)

\begin{tabular}{|c|c|c|c|c|}
\hline $\begin{array}{l}\text { Lantz, J., \& } \\
\text { Sahut, J. } \\
\text { (2005). }\end{array}$ & $\begin{array}{l}\text { R\&D investment and } \\
\text { the financial } \\
\text { performance of } \\
\text { technological firms. } \\
\text { International Journal } \\
\text { of Business, 10(3), } \\
251-270\end{array}$ & $\begin{array}{l}\text { Understanding the } \\
\text { relationship between } \\
\text { R\&D investment and the } \\
\text { financial performance of } \\
\text { technological firms. }\end{array}$ & $\begin{array}{l}\text { Existing literature shows contradictory results on the } \\
\text { incidence of the R\&D expenditures on the firm's financial } \\
\text { performance. The study highlights that R\&D expenditures } \\
\text { signal the strategic positioning of a firm and significantly } \\
\text { put strain on the financial performance. The authors } \\
\text { define companies with intensive investments in R\&D as } \\
\text { companies that have a high R\&D expenses ratio (R\&D } \\
\text { expenses/EBIT) and a high R\&D capitalization ratio } \\
\text { (Intangible assets/R\&D expenses). Firms with an } \\
\text { intensive investment strategy in R\&D have significantly } \\
\text { lower financial performance. }\end{array}$ & $\begin{array}{l}\text { Quantitative research } \\
\text { approach (regression } \\
\text { analysis) using data from } \\
213 \text { European, publicly- } \\
\text { traded technological firms } \\
\text { in the software, } \\
\text { telecommunications, } \\
\text { biotechnology, and } \\
\text { aerospace sectors. }\end{array}$ \\
\hline $\begin{array}{l}\text { Lévesque, } \\
\text { M., } \\
\text { Joglekar, N., } \\
\text { \& Davies, J. } \\
\text { (2012;2010). }\end{array}$ & $\begin{array}{l}\text { A comparison of } \\
\text { revenue growth at } \\
\text { recent-IPO and } \\
\text { established firms: The } \\
\text { influence of SG\&A, } \\
\text { R\&D and COGS. } \\
\text { Journal of Business } \\
\text { Venturing, 27(1), 47- } \\
61\end{array}$ & $\begin{array}{l}\text { Understanding the } \\
\text { influence of resource } \\
\text { allocation among SG\&A, } \\
\text { R\&D, and COGS } \\
\text { expenses on a firm's } \\
\text { revenue at recent-IPO and } \\
\text { established firms. }\end{array}$ & $\begin{array}{l}\text { The article examines spending patterns (variations in } \\
\text { resources' growth rates) at pre-IPO and established firms } \\
\text { relative to their revenue growth and shows differences } \\
\text { between the } 2 \text { samples. SG\&A spending (proxy for } \\
\text { investments in sales and marketing) acts as a substitute for } \\
\text { COGS for both the established and recent-IPO firms. In } \\
\text { other words, for a given level of revenue, increasing } \\
\text { SG\&A spending reduces COGS. However, R\&D } \\
\text { spending complements COGS (increasing R\&D spending } \\
\text { augments COGS) in generating revenue only for recent- } \\
\text { IPO firms. In addition, R\&D and SG\&A investments by } \\
\text { recent-IPO firms exhibit greater elasticity in generating } \\
\text { revenue with respect to COGS productivity. }\end{array}$ & $\begin{array}{l}\text { Quantitative approach: } \\
\text { econometric model tested } \\
\text { using a panel dataset of } \\
128 \text { firms spread over } \\
1993 \text { to 2007, each tracked } \\
\text { for five contiguous years } \\
\text { of growth, starting at their } \\
\text { IPO date. Half of these } \\
\text { firms are randomly } \\
\text { selected, recent-IPO firms } \\
\text { from four industry sectors: } \\
\text { electronics, energy, } \\
\text { medical devices and } \\
\text { software. The other half } \\
\text { consists of a comparable } \\
\text { sample of established } \\
\text { firms (drawn randomly } \\
\text { from the same sectors and } \\
\text { the same years). }\end{array}$ \\
\hline
\end{tabular}


Table 50: Extended Literature Review - Key Findings (Continued)

\begin{tabular}{|c|c|c|c|c|}
\hline $\begin{array}{l}\text { Lin, J. } \\
(2014)\end{array}$ & $\begin{array}{l}\text { Effects on diversity of } \\
\text { R\&D sources and } \\
\text { human capital on } \\
\text { industrial } \\
\text { performance. } \\
\text { Technological } \\
\text { Forecasting and Social } \\
\text { Change, 85, 168-184 }\end{array}$ & $\begin{array}{l}\text { What is the effect of } \\
\text { diversity of R\&D sources } \\
\text { on industrial } \\
\text { performance? Diversity } \\
\text { of R\&D sources is } \\
\text { defined as the level of } \\
\text { diversification of R\&D } \\
\text { knowledge sources } \\
\text { (internal and external } \\
\text { sources, including } \\
\text { linkages, and } \\
\text { associations). }\end{array}$ & $\begin{array}{l}\text { The author finds that the relationship between diversity of } \\
\text { R\&D sources and industrial performance is an inverted U- } \\
\text { shaped relationship. The diversity of R\&D sources was } \\
\text { measured by the R\&D expenditures by private and public } \\
\text { sectors of the industry and the diversity of R\&D personnel } \\
\text { according to OECD industrial classification. Industrial } \\
\text { performance was measured by the sales or production } \\
\text { values belonging to the industry. The author identifies } \\
\text { also two moderators: innovation infrastructure (facilities } \\
\text { and equipment dedicated to R\&D activities) and academic } \\
\text { knowledge (knowledge and skills accumulated in a } \\
\text { country). According to the study, both moderators } \\
\text { decrease performance gains attributable to diversity of } \\
\text { R\&D sources/knowledge. }\end{array}$ & $\begin{array}{l}\text { Quantitative research } \\
\text { methodology (regression } \\
\text { analysis) based on } \\
\text { Taiwanese industrial data. }\end{array}$ \\
\hline $\begin{array}{l}\text { Mousa, F.T., } \\
\text { Wales W.J., } \\
\text { \& Harper, S. } \\
\text { R. (2015). }\end{array}$ & $\begin{array}{l}\text { When less is more: } \\
\text { EO's influence upon } \\
\text { funds raised by young } \\
\text { technology firms at } \\
\text { IPO. Journal of } \\
\text { Business Research, } \\
68(2), 306-313\end{array}$ & $\begin{array}{l}\text { The effect of } \\
\text { entrepreneurial } \\
\text { orientation (EO) on } \\
\text { market firm valuation at } \\
\text { time of IPO. EO is } \\
\text { defined as the firm's } \\
\text { orientation or strategic } \\
\text { posture toward } \\
\text { innovativeness, risk- } \\
\text { taking, and proactiveness. }\end{array}$ & $\begin{array}{l}\text { EO, as signaled within the firm prospectus, is negatively } \\
\text { related to the amount of capital raised by young } \\
\text { technology firms at IPO. While EO may enable young } \\
\text { technology firms to reach IPO by fostering above-average } \\
\text { growth, the same EO may contribute to lower valuations } \\
\text { at IPO. Young technology firms approaching IPO with } \\
\text { more conservative signals may receive higher valuations } \\
\text { as they are presumed more likely to achieve steady growth } \\
\text { through focusing more on exploiting their existing } \\
\text { competencies rather than exploring for new ones. Higher } \\
\text { levels of an EO strategic posture may be viewed as } \\
\text { excessive exploration at a time when increased discipline } \\
\text { and focus toward exploitation is necessary to achieve } \\
\text { stable growth when entering the public market. }\end{array}$ & $\begin{array}{l}\text { Quantitative study based } \\
\text { on } 106 \text { young IPO } \\
\text { technology firms (less than } \\
8 \text { years of operation) and } \\
\text { secondary data } \\
\text { (prospectus, etc.) from } \\
\text { Edgar and Compustat. The } \\
\text { firms in the sample went } \\
\text { public between } 2001 \text { and } \\
2005 \text {. }\end{array}$ \\
\hline
\end{tabular}


Table 50: Extended Literature Review - Key Findings (Continued)

\begin{tabular}{|c|c|c|c|c|}
\hline $\begin{array}{l}\text { Mudambi, } \\
\text { R., \& Swift, } \\
\text { T. (2014). }\end{array}$ & $\begin{array}{l}\text { Knowing when to } \\
\text { leap: Transitioning } \\
\text { between exploitative } \\
\text { and explorative R\&D. } \\
\text { Strategic Management } \\
\text { Journal, 35(1), 126- } \\
145\end{array}$ & $\begin{array}{l}\text { What are the effects of } \\
\text { R\&D expenditure } \\
\text { volatility on firm } \\
\text { performance? }\end{array}$ & $\begin{array}{l}\text { The authors suggest that the long periods of exploitation } \\
\text { of extant competencies require stable and consistent R\&D } \\
\text { investment, while the periods of transition to new } \\
\text { competencies require uprooting entrenched R\&D interests } \\
\text { in the firm. The authors offer evidence that compact, } \\
\text { significant changes in firm-level R\&D spending are } \\
\text { positively associated with shifts between R\&D-based } \\
\text { exploration and exploitation, with higher levels of R\&D- } \\
\text { related outputs and with overall firm performance. }\end{array}$ & $\begin{array}{l}\text { Quantitative study based } \\
\text { on a dataset of US } \\
\text { publicly-traded } \\
\text { manufacturing firms } \\
\text { covering the years 1997- } \\
2006 \text { from Compustat and } \\
\text { the NBER US Patent } \\
\text { Citations database. }\end{array}$ \\
\hline $\begin{array}{l}\text { O'Sullivan, } \\
\text { D., Abela, } \\
\text { A. V., \& } \\
\text { Hutchinson, } \\
\text { M. (2009). }\end{array}$ & $\begin{array}{l}\text { Marketing } \\
\text { performance } \\
\text { measurement and firm } \\
\text { performance: } \\
\text { Evidence from the } \\
\text { European high- } \\
\text { technology sector. } \\
\text { European Journal of } \\
\text { Marketing, 43(5-6), } \\
843-862\end{array}$ & $\begin{array}{l}\text { What is the effect of } \\
\text { marketing performance } \\
\text { measurement (MPM) on } \\
\text { firm performance and } \\
\text { does reporting frequency } \\
\text { influence the } \\
\text { relationship? }\end{array}$ & $\begin{array}{l}\text { The study replicates findings from prior literature } \\
\text { confirming a positive relationship between MPM ability } \\
\text { and firm performance (objectively and subjectively } \\
\text { measured). The study also finds that marketing } \\
\text { performance reporting frequency mediates the relationship } \\
\text { between MPM ability and objectively measured firm } \\
\text { performance and partially mediates the relationship with } \\
\text { subjectively measured firm performance. Firms with an } \\
\text { ability to measure marketing performance utilize the } \\
\text { ability and that performance reporting leads ultimately to } \\
\text { an improvement in overall firm performance. }\end{array}$ & $\begin{array}{l}\text { Qualitative and } \\
\text { quantitative research } \\
\text { approach: primary } \\
\text { (survey) and secondary } \\
\text { data for objectively } \\
\text { measured firm } \\
\text { performance data (ROA } \\
\text { and stock returns). The } \\
\text { survey was conducted } \\
\text { online among marketing } \\
\text { managers of European } \\
\text { high-tech firms between } \\
\text { February and March } 2005 \\
\text { (157 respondents). }\end{array}$ \\
\hline
\end{tabular}


Table 50: Extended Literature Review - Key Findings (Continued)

\begin{tabular}{|c|c|c|c|c|}
\hline $\begin{array}{l}\text { Sahaym, A., } \\
\text { Steensma, } \\
\text { H. K., \& } \\
\text { Barden, J. } \\
\text { Q. } \\
(2010 ; 2009) .\end{array}$ & $\begin{array}{l}\text { The influence of R\&D } \\
\text { investment on the use } \\
\text { of corporate venture } \\
\text { capital: An industry- } \\
\text { level analysis. Journal } \\
\text { of Business Venturing, } \\
25(4), 376-388\end{array}$ & $\begin{array}{l}\text { Understanding the } \\
\text { relationship between } \\
\text { R\&D investment and use } \\
\text { of corporate venture } \\
\text { capital (CVC). Corporate } \\
\text { venture investments are } \\
\text { minority equity } \\
\text { investments by } \\
\text { established firms in } \\
\text { entrepreneurial ventures. }\end{array}$ & $\begin{array}{l}\text { There is growing evidence in the literature that CVC and } \\
\text { R\&D are complements rather than substitutes. This article } \\
\text { contributes to this new stream of research. It demonstrates } \\
\text { that industries with rapidly changing technology (i.e., high } \\
\text { total factor productivity growth) and higher levels of } \\
\text { munificence (i.e., higher levels of revenue growth) will be } \\
\text { more engaged in CVC activities. Industries that are } \\
\text { munificent and experiencing rapid technological change } \\
\text { use the expertise derived through R\&D to find and exploit } \\
\text { CVC opportunities to a greater extent than relatively } \\
\text { stable, low-growth industries do. }\end{array}$ & $\begin{array}{l}\text { Quantitative research } \\
\text { approach: regression } \\
\text { analysis based on US } \\
\text { manufacturing industry } \\
\text { data ( } 400 \text { industries) and } \\
\text { data aggregated from } \\
\text { various financial and } \\
\text { economic databases } \\
\text { (VentureXpert, Compustat, } \\
\text { US Census Bureau, } \\
\text { Bureau of Economic } \\
\text { Analysis). }\end{array}$ \\
\hline $\begin{array}{l}\text { Suarez, F. } \\
\text { F., } \\
\text { Cusumano, } \\
\text { M. A., \& } \\
\text { Kahl, S. J. } \\
(2013) .\end{array}$ & $\begin{array}{l}\text { Services and the } \\
\text { business models of } \\
\text { product firms: An } \\
\text { empirical analysis of } \\
\text { the software industry. } \\
\text { Management Science, } \\
59(2), 420-435\end{array}$ & $\begin{array}{l}\text { Understanding the } \\
\text { influence of services in } \\
\text { the financial performance } \\
\text { of firms in the pre- } \\
\text { packaged software } \\
\text { products industry. }\end{array}$ & $\begin{array}{l}\text { The authors find a convex, nonlinear relationship between } \\
\text { a product firm's fraction of total sales coming from } \\
\text { services and its overall operating margins. Firms with a } \\
\text { very high level of product sales are most profitable, and } \\
\text { rising services are associated with declining profitability. } \\
\text { However, the authors find that additional services start to } \\
\text { have a positive marginal effect on the firm's overall } \\
\text { profits when services reach a majority of a product firm's } \\
\text { sales. In the study, product sales consisted of license sales } \\
\text { and subscription sales (including emerging SaaS } \\
\text { subscriptions at the time) while service sales consisted of } \\
\text { maintenance, support, and professional services. The } \\
\text { importance of services, on average for the sample of } \\
\text { prepackaged-software product firms, has steadily } \\
\text { increased from approximately } 30 \% \text { in } 1990 \text { to } \\
\text { approximately } 52 \% \text { in } 2006 \text {. In the study, firm } \\
\text { performance was measured by the operating margin } \\
\text { (operating income divided by sales). }\end{array}$ & $\begin{array}{l}\text { Quantitative research } \\
\text { methodology (regression } \\
\text { analysis) based on a } \\
\text { sample of approximately } \\
390 \text { publicly-traded } \\
\text { software firms and data } \\
\text { from } 1990 \text { to } 2006 \text {. }\end{array}$ \\
\hline
\end{tabular}


Table 50: Extended Literature Review - Key Findings (Continued)

\begin{tabular}{|c|c|c|c|c|}
\hline $\begin{array}{l}\text { Tokic D } \\
(2005) .\end{array}$ & $\begin{array}{l}\text { R\&D, advertising and } \\
\text { the market value of } \\
\text { internet firms: Part II, } \\
\text { Journal of Internet } \\
\text { Commerce, } 4: 4,23-40\end{array}$ & $\begin{array}{l}\text { How to explain the } \\
\text { valuation of Internet } \\
\text { firms during the dot.com } \\
\text { bubble period from } 1996 \\
\text { to } 2000 ?\end{array}$ & $\begin{array}{l}\text { This study is a continuation of the Part I published a year } \\
\text { earlier and consists of the testing phase of the hypotheses } \\
\text { proposed in the earlier study. The results confirm positive } \\
\text { and statistically significant relations between the market } \\
\text { value of Internet firms and investments in R\&D and } \\
\text { advertising in each year of the sample period. The results } \\
\text { also suggest that investors valued Internet firms mostly } \\
\text { based on the level of their intangible investments and } \\
\text { ignored the value of earnings. The lesson learned during } \\
\text { the dot.com valuation bubble is that the value of a growth } \\
\text { firm is a function of a firm's ability to create consistent } \\
\text { positive earnings in addition to the value of potential } \\
\text { growth opportunities. }\end{array}$ & $\begin{array}{l}\text { Quantitative study } \\
\text { (regression analysis) based } \\
\text { on financial data on } 518 \\
\text { internet firms from } 1996 \text { to } \\
2000 \text { using Computstat. } \\
\text { The measure used for the } \\
\text { value of the firm was the } \\
\text { revenue multiple. }\end{array}$ \\
\hline $\begin{array}{l}\text { Tokic D. } \\
(2004) .\end{array}$ & $\begin{array}{l}\text { R\&D, advertising and } \\
\text { the market value of } \\
\text { internet firms: Part I, } \\
\text { Journal of Internet } \\
\text { Commerce, 3:2, 79-99 }\end{array}$ & $\begin{array}{l}\text { How to explain the } \\
\text { valuation of Internet } \\
\text { firms during the dot.com } \\
\text { bubble period from } 1996 \\
\text { to } 2000 ?\end{array}$ & $\begin{array}{l}\text { This study investigates the relations between R\&D and } \\
\text { advertising expenditures and the market value of Internet } \\
\text { firms during the period 1996-2000. Building on prior } \\
\text { literature (on the investment opportunities approach, life } \\
\text { cycle theory, and the real options valuation theory), the } \\
\text { author proposes that R\&D spending and spending in } \\
\text { advertising represent investments in the firm's intangible } \\
\text { assets, and that there is a positive relation between these } \\
\text { investments and the market value of the firm. In addition, } \\
\text { the degree of international involvement positively } \\
\text { influences the value of the firm. In his literature review, } \\
\text { he discusses how high levels of investments relative to } \\
\text { sales (such as R\&D intensity) provide a positive signal of } \\
\text { managerial confidence in future prospects and that } \\
\text { sometimes investors overestimate the benefits from these } \\
\text { investments, especially for firms with negative } \\
\text { profitability, which causes the overvaluation. }\end{array}$ & Conceptual paper. \\
\hline
\end{tabular}


Table 50: Extended Literature Review - Key Findings (Continued)

\begin{tabular}{|c|c|c|c|c|}
\hline $\begin{array}{l}\text { Ugur, M., } \\
\text { Trushin, E., } \\
\text { \& Solomon, } \\
\text { E. (2016). }\end{array}$ & $\begin{array}{l}\text { Inverted-U } \\
\text { relationship between } \\
\text { R\&D intensity and } \\
\text { survival: Evidence on } \\
\text { scale and } \\
\text { complementarity } \\
\text { effects in UK data. } \\
\text { Research Policy, } \\
45(7), 1474-1492\end{array}$ & $\begin{array}{l}\text { What is the effect of } \\
\text { R\&D intensity (R\&D as a } \\
\text { percentage of sales) on } \\
\text { firms' survival? }\end{array}$ & $\begin{array}{l}\text { Survival time increases with R\&D intensity at decreasing } \\
\text { rates and eventually falls as R\&D intensity exceeds an } \\
\text { optimum level. R\&D intensity is associated with longer } \\
\text { survival times when R\&D-active firms are in more } \\
\text { concentrated industries. Smaller firms that focus on } \\
\text { growth as a means of enhancing market share face a } \\
\text { higher risk of exit, perhaps due to a gap between their } \\
\text { growth ambitions and growth management capacity. }\end{array}$ & $\begin{array}{l}\text { Quantitative research } \\
\text { (regression analysis) } \\
\text { methodology based on UK } \\
\text { data for } 37,930 \text { firms from } \\
1998 \text { to } 2012 \text {. }\end{array}$ \\
\hline $\begin{array}{l}\text { Wagner, M. } \\
(2016) \text {. }\end{array}$ & $\begin{array}{l}\text { Managing disruptive } \\
\text { innovation with } \\
\text { technology } \\
\text { acquisitions: The } \\
\text { informing case of } \\
\text { software-based high- } \\
\text { technology industries. } \\
\text { Technology Analysis } \\
\text { \& Strategic } \\
\text { Management, 28(8), } \\
\text { 979-991 }\end{array}$ & $\begin{array}{l}\text { Is acquisition in software- } \\
\text { based industries } \\
\text { motivated by } \\
\text { substitutivity with } \\
\text { internal R\&D? Do } \\
\text { acquisitions relate mainly } \\
\text { to specific technology } \\
\text { segments and when are } \\
\text { targets acquired? }\end{array}$ & $\begin{array}{l}\text { The author establishes that acquisitions substitute for } \\
\text { internal R\&D and that the specificity and timing of } \\
\text { acquisitions are not primarily driven by acquisition waves } \\
\text { or other irrationalities, but competitive moves focused on } \\
\text { the largest weaknesses of acquirers. In other words, } \\
\text { acquirers use acquisitions to compensate for R\&D } \\
\text { weaknesses or counter challenges from disruptive } \\
\text { innovation. }\end{array}$ & $\begin{array}{l}\text { Mixed methods } \\
\text { (quantitative and } \\
\text { qualitative research } \\
\text { methodology): } \\
\text { econometric analysis on } \\
\text { the acquisitions between } \\
1981-2005 \text { by } 14 \text { firms in } \\
\text { the electronic design } \\
\text { automation (EDA) } \\
\text { industry, representing } 80 \% \\
\text { of the sales in that industry } \\
\text { combined with descriptive } \\
\text { analysis and case study } \\
\text { analysis. }\end{array}$ \\
\hline
\end{tabular}


Table 50: Extended Literature Review - Key Findings (Continued)

\begin{tabular}{|l|l|l|l|}
\hline $\begin{array}{l}\text { Yeh, M., } \\
\text { Chu, H., } \\
\text { Sher, P. J., } \\
\text { \& Chiu, Y. } \\
(2010)\end{array}$ & $\begin{array}{l}\text { R\&D intensity, firm } \\
\text { performance and the } \\
\text { identification of the } \\
\text { threshold: Fresh } \\
\text { evidence from the } \\
\text { panel threshold } \\
\text { regression model. } \\
\text { Applied Economics, } \\
42(3), 389-401\end{array}$ & $\begin{array}{l}\text { What is the optimal level } \\
\text { of R\&D intensity (i.e., } \\
\text { ratio of R\&D } \\
\text { expenditures to sales) at } \\
\text { which point a firm is able } \\
\text { to maximize its } \\
\text { performance? }\end{array}$ & $\begin{array}{l}\text { The research empirically tests whether there is an optimal } \\
\text { level of R\&D investment at which point firms attain their } \\
\text { maximum level of performance, and it clarifies whether } \\
\text { firms should invest as much as they possibly can in R\&D. } \\
\text { For the authors, R\&D threshold values vary across } \\
\text { different industries. In this study, firm performance was } \\
\text { operationalized using 3 measures: return on assets (ROA), } \\
\text { analysis) based on a } \\
\text { sample of 99 IT and } \\
\text { electronic firms in Taiwan. } \\
\text { return on equity (ROE), and net profit growth rate. The } \\
\text { article provides a summary of prior studies that have } \\
\text { investigated the relationship between R\&D and firm } \\
\text { performance and concludes that studies that have } \\
\text { investigated the R\&D spending optimization issue (i.e., } \\
\text { inverted U-shaped relationship) are scant. }\end{array}$ \\
\hline
\end{tabular}




\section{Extended Literature Review - Managerial Implications}

Table 51: Extended Literature Review - Managerial Implications

\begin{tabular}{|c|c|c|c|c|}
\hline $\begin{array}{l}\text { Author } \\
\text { (Date) }\end{array}$ & Title & Relevant Managerial Insights & $\begin{array}{l}\text { To What Extent Does the Article } \\
\text { Provide Additional Support for the } \\
\text { Generalizability of the Study? }\end{array}$ & Theme \\
\hline $\begin{array}{l}\text { Boer, F. P. } \\
(2002) .\end{array}$ & $\begin{array}{l}\text { Financial } \\
\text { management of RD } \\
\text { 2002. Research- } \\
\text { Technology } \\
\text { Management, 45(4), } \\
\text { 23-35 }\end{array}$ & $\begin{array}{l}\text { Managers can now use a broad range of tools to } \\
\text { evaluate the financial performance of R\&D } \\
\text { investments and better explain their influence in } \\
\text { business valuation. }\end{array}$ & $\begin{array}{l}\text { The article provides insights into the } \\
\text { approaches to measuring the } \\
\text { profitability of R\&D investments and } \\
\text { their influence on business valuation } \\
\text { with examples from multiple } \\
\text { industries (biotechnology, } \\
\text { pharmaceutical, internet, energy), } \\
\text { which indicate similarities across } \\
\text { industries on issues surrounding } \\
\text { resource allocation decision-making } \\
\text { and firm performance (phenomenon of } \\
\text { sky-high valuations, impact of VC } \\
\text { investments, etc.). }\end{array}$ & $\begin{array}{l}\text { Other potential variables } \\
\text { influencing the } \\
\text { relationship between } \\
\text { resource allocation and } \\
\text { firm performance: } \\
\text { market characteristics, } \\
\text { VC investments. }\end{array}$ \\
\hline $\begin{array}{l}\text { Capasso, } \\
\text { M., } \\
\text { Treibich, T. } \\
\text { G., \& } \\
\text { Verspagen, } \\
\text { B. (2015). }\end{array}$ & $\begin{array}{l}\text { The medium-term } \\
\text { effect of R\&D on } \\
\text { firm growth. Small } \\
\text { Business } \\
\text { Economics, } 45(1) \text {, } \\
39-62 \text {. } \\
\text { doi:10.1007/s11187- } \\
015-9640-6\end{array}$ & $\begin{array}{l}\text { For R\&D investors, the study provides evidence } \\
\text { about the heterogeneity in R\&D's returns on } \\
\text { employment growth and survival among firms } \\
\text { and over time. }\end{array}$ & $\begin{array}{l}\text { The study discusses the complexity of } \\
\text { the relationship between R\&D } \\
\text { expenditure and employment growth } \\
\text { and the comparative R\&D behaviors } \\
\text { between exiting firms and surviving } \\
\text { ones, suggesting the need for an } \\
\text { optimum balance. This study indicates } \\
\text { that exiting firms have a more extreme } \\
\text { R\&D behavior than surviving ones. If } \\
\text { very low investment in R\&D can } \\
\text { weaken the firms' competitiveness and } \\
\text { therefore its market share, } \\
\text { overinvestment given the firms' } \\
\text { internal resources, and the uncertainty } \\
\text { regarding the success of the innovative } \\
\text { process, can also lead to firm death. }\end{array}$ & $\begin{array}{l}\text { The relationship between } \\
\text { R\&D spending and firm } \\
\text { performance. }\end{array}$ \\
\hline
\end{tabular}


Table 51: Extended Literature Review - Managerial Implications (Continued)

\begin{tabular}{|c|c|c|c|c|}
\hline $\begin{array}{l}\text { Ciftci, M., \& } \\
\text { Cready, W. } \\
\text { M. (2011). }\end{array}$ & $\begin{array}{l}\text { Scale effects of } \\
\text { R\&D as reflected in } \\
\text { earnings and } \\
\text { returns. Journal of } \\
\text { Accounting and } \\
\text { Economics, 52(1), } \\
62-80\end{array}$ & $\begin{array}{l}\text { Profits per dollar invested in innovative activities } \\
\text { increase with firm size. An explanation for this } \\
\text { apparent coexistence of higher profitability and } \\
\text { lower innovation productivity is that the } \\
\text { underlying advantage stems primarily from post- } \\
\text { innovation development and marketing stages- } \\
\text { that is, in the D portion of R\&D, where size- } \\
\text { related attributes such as organizational stability, } \\
\text { market presence, and reputational capital seem } \\
\text { likely to be key factors in maximizing innovation } \\
\text { value. }\end{array}$ & $\begin{array}{l}\text { The study highlights the importance of } \\
\text { the scale effect in explaining the } \\
\text { relationship between resource } \\
\text { allocation (here, R\&D spending) and } \\
\text { firm performance. Scale is one the } \\
\text { moderators in our study. }\end{array}$ & $\begin{array}{l}\text { Scale (or size) as a } \\
\text { moderator to the } \\
\text { relationship between } \\
\text { resource allocation and } \\
\text { firm performance. }\end{array}$ \\
\hline $\begin{array}{l}\text { Coccia, M. } \\
(2009) .\end{array}$ & $\begin{array}{l}\text { What is the optimal } \\
\text { rate of R\&D } \\
\text { investment to } \\
\text { maximize } \\
\text { productivity } \\
\text { growth? } \\
\text { Technological } \\
\text { Forecasting \& } \\
\text { Social Change, } \\
76(3), 433-446\end{array}$ & $\begin{array}{l}\text { Policy makers should be aware that the ultimate } \\
\text { impact of any increase in spending on R\&D } \\
\text { depends critically upon complex, interwoven } \\
\text { strings of causations which are not necessarily } \\
\text { constant over time and across countries, because } \\
\text { of countries' economics, specificity and } \\
\text { turbulence of markets. The future challenge for } \\
\text { policy makers is how to ensure that such research } \\
\text { policy implications are integrated in national } \\
\text { political economy, considering the country's } \\
\text { economic structure, to maximize the positive } \\
\text { long run impact on productivity and economic } \\
\text { growth. }\end{array}$ & $\begin{array}{l}\text { The study finds diminishing returns of } \\
\text { R\&D investments at country level } \\
\text { using data from EU countries, Japan, } \\
\text { and the USA. }\end{array}$ & $\begin{array}{l}\text { The relationship between } \\
\text { R\&D spending and firm } \\
\text { performance; Other } \\
\text { potential variables } \\
\text { influencing the } \\
\text { relationship between } \\
\text { resource allocation and } \\
\text { firm performance: } \\
\text { country, socio-economic } \\
\text { and political } \\
\text { environment. }\end{array}$ \\
\hline
\end{tabular}


Table 51: Extended Literature Review - Managerial Implications (Continued)

\begin{tabular}{|c|c|c|c|c|}
\hline $\begin{array}{l}\text { Demirel, P., } \\
\& \\
\text { Mazzucato, } \\
\text { M. (2012). }\end{array}$ & $\begin{array}{l}\text { Innovation and firm } \\
\text { growth: Is R\&D } \\
\text { worth it? Industry } \\
\text { and Innovation, } \\
\text { 19(1), 45-62 }\end{array}$ & $\begin{array}{l}\text { This study has implications primarily for } \\
\text { policymakers, allowing them to better target } \\
\text { innovation-led growth policies. }\end{array}$ & $\begin{array}{l}\text { The study provides insights into what } \\
\text { types of factors are necessary for R\&D } \\
\text { to affect growth, and how these factors } \\
\text { might differ among sectors. }\end{array}$ & $\begin{array}{l}\text { Other potential variables } \\
\text { influencing the } \\
\text { relationship between } \\
\text { resource allocation and } \\
\text { firm performance: } \\
\text { market characteristics }\end{array}$ \\
\hline $\begin{array}{l}\text { Eisenmann, } \\
\text { T. R. (2006) }\end{array}$ & $\begin{array}{l}\text { Internet companies' } \\
\text { growth strategies: } \\
\text { Determinants of } \\
\text { investment intensity } \\
\text { and long-term } \\
\text { performance. } \\
\text { Strategic } \\
\text { Management } \\
\text { Journal, } 27(12) \text {, } \\
\text { 1183-1204 }\end{array}$ & $\begin{array}{l}\text { Factors influencing growth acceleration strategies } \\
\text { include competitive dynamics, speculative } \\
\text { valuation bubbles (excessive valuations to firms } \\
\text { with strong revenue growth), and management } \\
\text { incentives. First movers may gain advantage by } \\
\text { acquiring customers before competitors, } \\
\text { however, absent entry barriers, first movers } \\
\text { quickly face rivals and fierce competition may } \\
\text { dissipate rents. There are diminishing returns } \\
\text { from investments in customer acquisition efforts } \\
\text { for both first movers and non-pioneers. In the } \\
\text { study's sample, the curve for non-pioneers peaked } \\
\text { at a higher ROI than the curve for first movers, } \\
\text { which implies that late-mover advantages were } \\
\text { greater than first-mover advantages. }\end{array}$ & $\begin{array}{l}\text { The author proposes that the } \\
\text { generalizability of this study is not } \\
\text { limited to internet companies as } \\
\text { boom-bust valuation cycles occur } \\
\text { regularly. Thus, he proposes that we } \\
\text { might expect to see similar outcomes } \\
\text { in other industries when speculative } \\
\text { excess leads investors to place undue } \\
\text { emphasis on revenue and market share } \\
\text { growth. }\end{array}$ & $\begin{array}{l}\text { The relationship between } \\
\text { M\&S spending and firm } \\
\text { performance. }\end{array}$ \\
\hline
\end{tabular}


Table 51: Extended Literature Review - Managerial Implications (Continued)

\begin{tabular}{|c|c|c|c|c|}
\hline $\begin{array}{l}\text { Fung, M. K. } \\
(2004) .\end{array}$ & $\begin{array}{l}\text { Technological } \\
\text { opportunity and } \\
\text { productivity of } \\
\text { R\&D activities. } \\
\text { Journal of } \\
\text { Productivity } \\
\text { Analysis, 21(2), } \\
167-181\end{array}$ & $\begin{array}{l}\text { Economists have managed to find a positive } \\
\text { impact of R\&D effort on productivity. However, } \\
\text { the empirical results of their studies have not } \\
\text { explained the observed sectoral differences in } \\
\text { this important relationship. This study } \\
\text { demonstrates possible ways to make different } \\
\text { aspects of technological opportunity operational } \\
\text { and to analyze sectorial differences in the } \\
\text { productivity of R\&D activities. }\end{array}$ & $\begin{array}{l}\text { Using a sample from the chemical, } \\
\text { computer, and electrical/electronic } \\
\text { industries, this study analyzes the } \\
\text { effect of R\&D effort on productivity at } \\
\text { industry level and calls for more } \\
\text { research to increase our understanding } \\
\text { of this relationship at industry and } \\
\text { firm levels. }\end{array}$ & $\begin{array}{l}\text { Other potential variables } \\
\text { influencing the } \\
\text { relationship between } \\
\text { resource allocation and } \\
\text { firm performance: } \\
\text { technological } \\
\text { opportunity. }\end{array}$ \\
\hline $\begin{array}{l}\text { Heredia, A., } \\
\text { Colomo- } \\
\text { Palacios, R., } \\
\& \text { de } \\
\text { Amescua, A. } \\
(2015) .\end{array}$ & $\begin{array}{l}\text { Software business } \\
\text { models from a } \\
\text { distribution } \\
\text { perspective: A } \\
\text { systematic mapping } \\
\text { study. Procedia } \\
\text { Computer Science, } \\
64,395-402\end{array}$ & $\begin{array}{l}\text { Software organizations no longer describe } \\
\text { architectures solely in terms of their technical } \\
\text { characteristics; instead, they view them in } \\
\text { relationship to BMs. Business models (BMs) } \\
\text { describe how a company creates and delivers } \\
\text { value to customers, the products or services that } \\
\text { it offers and the compensation for them. Software } \\
\text { companies need to be able to adopt different BMs } \\
\text { to be successful in modern economy. }\end{array}$ & $\begin{array}{l}\text { Companies need to be able to create } \\
\text { and capture value through an effective } \\
\text { BM. The success of innovations in } \\
\text { modern economy highly depends on } \\
\text { the respective BM, especially in fast } \\
\text { evolving sectors such as the software } \\
\text { industry. (In the new digital economy, } \\
\text { the issue of defining successful BMs } \\
\text { moving forward is not limited to } \\
\text { technology companies but is affecting } \\
\text { all industries). }\end{array}$ & $\begin{array}{l}\text { Other potential variables } \\
\text { influencing the } \\
\text { relationship between } \\
\text { resource allocation and } \\
\text { firm performance: the } \\
\text { type of business model } \\
\text { (BM). }\end{array}$ \\
\hline $\begin{array}{l}\text { Joglekar, N. } \\
\text { R., \& } \\
\text { Levesque, } \\
\text { M. (2009). }\end{array}$ & $\begin{array}{l}\text { Marketing, R\&D, } \\
\text { and startup } \\
\text { valuation. IEEE } \\
\text { Transactions on } \\
\text { Engineering } \\
\text { Management, 56(2), } \\
\text { 229-242 }\end{array}$ & $\begin{array}{l}\text { The model can help startup owners improve their } \\
\text { understanding of the effect of their resource } \\
\text { allocation decisions on their working capital and } \\
\text { firm valuation at various stages of startup growth. }\end{array}$ & $\begin{array}{l}\text { While this article is based on data } \\
\text { from a case study in the software } \\
\text { industry, the authors discuss that the } \\
\text { underlying resource-allocation } \\
\text { tradeoff is a common phenomenon in } \\
\text { the literature on startup and that, } \\
\text { therefore, it may apply to startups in } \\
\text { other contexts. }\end{array}$ & $\begin{array}{l}\text { Scale (or size) as a } \\
\text { moderator to the } \\
\text { relationship between } \\
\text { resource allocation and } \\
\text { firm performance. }\end{array}$ \\
\hline
\end{tabular}


Table 51: Extended Literature Review - Managerial Implications (Continued)

\begin{tabular}{|c|c|c|c|c|}
\hline $\begin{array}{l}\text { Koellinger, } \\
\text { P. (2008) }\end{array}$ & $\begin{array}{l}\text { The relationship } \\
\text { between technology, } \\
\text { innovation, and firm } \\
\text { performance- } \\
\text { Empirical evidence } \\
\text { from e-business in } \\
\text { Europe. Research } \\
\text { Policy, 37(8), 1317- } \\
1328\end{array}$ & $\begin{array}{l}\text { Innovation is critical to firm performance. What a } \\
\text { firm innovates (product/service innovation) is } \\
\text { more important than how it innovates (process } \\
\text { innovation), but the most important is that it } \\
\text { innovates at all. }\end{array}$ & $\begin{array}{l}\text { The study discusses internet-based } \\
\text { innovations as being a critical part of } \\
\text { firms' innovation strategies in multiple } \\
\text { industries with a focus on European } \\
\text { countries. }\end{array}$ & $\begin{array}{l}\text { The relationship between } \\
\text { R\&D spending and firm } \\
\text { performance. }\end{array}$ \\
\hline $\begin{array}{l}\text { Krčál, O. } \\
(2014)\end{array}$ & $\begin{array}{l}\text { The relationship } \\
\text { between } \\
\text { profitability, } \\
\text { innovation and } \\
\text { technology gap: A } \\
\text { basic model. } \\
\text { Review of } \\
\text { Economic } \\
\text { Perspectives, 14(3), } \\
\text { 215-231 }\end{array}$ & $\begin{array}{l}\text { The research has potential implications in several } \\
\text { fields such as formulation of optimal R\&D } \\
\text { investment strategies and competition policy. }\end{array}$ & $\begin{array}{l}\text { The article is theoretical and suggests } \\
\text { that further research should test the } \\
\text { model at individual firm level. It } \\
\text { discusses the relevance of the } \\
\text { resource-based view of the firm and } \\
\text { the concept that the relationship } \\
\text { between R\&D expenditures and firm } \\
\text { financial performance is non-linear } \\
\text { and that the phenomenon is likely to } \\
\text { generalize across multiple industries. } \\
\text { For the author, the shape of the } \\
\text { inverted U-shaped relationships will } \\
\text { vary depending on the differences in } \\
\text { profitability in each industry. }\end{array}$ & $\begin{array}{l}\text { The relationship between } \\
\text { R\&D spending and firm } \\
\text { performance. }\end{array}$ \\
\hline
\end{tabular}


Table 51: Extended Literature Review - Managerial Implications (Continued)

\begin{tabular}{|c|c|c|c|c|}
\hline $\begin{array}{l}\text { Lantz, J., \& } \\
\text { Sahut, J. } \\
\text { (2005). }\end{array}$ & $\begin{array}{l}\text { R\&D investment } \\
\text { and the financial } \\
\text { performance of } \\
\text { technological firms. } \\
\text { International Journal } \\
\text { of Business, 10(3), } \\
251-270\end{array}$ & $\begin{array}{l}\text { It is preferable to capitalize R\&D expenditures if } \\
\text { the firm is able to draw an immediate commercial } \\
\text { exploitation from them. When the benefits are } \\
\text { expected in the future, R\&D expenditures will } \\
\text { have a strong negative impact on firm financial } \\
\text { performance. In this case, managers should } \\
\text { consider externalizing projects (spin-off) which } \\
\text { require significant investments in R\&D, rather } \\
\text { than developing them in-house. }\end{array}$ & $\begin{array}{l}\text { The study indicates some similarities } \\
\text { with our research. It was conducted in } \\
\text { Europe and across multiple industries. }\end{array}$ & $\begin{array}{l}\text { The relationship between } \\
\text { R\&D spending and firm } \\
\text { performance. }\end{array}$ \\
\hline $\begin{array}{l}\text { Lévesque, } \\
\text { M., } \\
\text { Joglekar, N., } \\
\text { \& Davies, J. } \\
\text { (2012;2010). }\end{array}$ & $\begin{array}{l}\text { A comparison of } \\
\text { revenue growth at } \\
\text { recent-IPO and } \\
\text { established firms: } \\
\text { The influence of } \\
\text { SG\&A, R\&D and } \\
\text { COGS. Journal of } \\
\text { Business Venturing, } \\
27(1), 47-61\end{array}$ & $\begin{array}{l}\text { From a management perspective, the findings } \\
\text { suggest that early in the post-IPO growth period, } \\
\text { firms may benefit from tracking and accounting } \\
\text { for growth-rate adjustments while making } \\
\text { aggregate SG\&A and/or R\&D allocation } \\
\text { decisions and continually tweak them based on } \\
\text { revenue growth rates, recognizing that SG\&A } \\
\text { spending reductions can be short-sighted when } \\
\text { SG\&A acts as a substitute for COGS. }\end{array}$ & $\begin{array}{l}\text { There is a similarity in the motivation } \\
\text { for this study and our research, which } \\
\text { is to better understand the effects of } \\
\text { resource allocation on firm } \\
\text { performance. This study used data } \\
\text { from publicly-traded firms in the } \\
\text { United States in four industry sectors: } \\
\text { electronics, energy, medical devices } \\
\text { and software. }\end{array}$ & $\begin{array}{l}\text { Other potential variables } \\
\text { influencing the } \\
\text { relationship between } \\
\text { resource allocation and } \\
\text { firm performance: firm } \\
\text { size, private vs. public. }\end{array}$ \\
\hline
\end{tabular}


Table 51: Extended Literature Review - Managerial Implications (Continued)

\begin{tabular}{|c|c|c|c|c|}
\hline $\begin{array}{l}\text { Lin, J. } \\
(2014)\end{array}$ & $\begin{array}{l}\text { Effects on diversity } \\
\text { of R\&D sources and } \\
\text { human capital on } \\
\text { industrial } \\
\text { performance. } \\
\text { Technological } \\
\text { Forecasting and } \\
\text { Social Change, } 85 \text {, } \\
168-184\end{array}$ & $\begin{array}{l}\text { R\&D knowledge heterogeneity and integration } \\
\text { through multiplicity of R\&D resources are the } \\
\text { keys to industrial success. An optimal level of } \\
\text { R\&D diversity of R\&D sources exists. Industrial } \\
\text { performance decreases as diversity of R\&D } \\
\text { sources increases after the optimal level. } \\
\text { Industrial firms need to recruit various types of } \\
\text { R\&D human capital to tap into innovation } \\
\text { knowledge sources. However, they have to } \\
\text { simultaneously focus their managerial attentions } \\
\text { and resources on excessive diversity of R\&D } \\
\text { human capital so as to minimize negative costs. } \\
\text { In doing so, they will see their industries gain in } \\
\text { terms of industrial performance. }\end{array}$ & $\begin{array}{l}\text { The research implies that an inverted } \\
\text { U-shaped relationship exists between } \\
\text { R\&D expenditures and firm } \\
\text { performance across various industries. }\end{array}$ & $\begin{array}{l}\text { The relationship between } \\
\text { R\&D spending and firm } \\
\text { performance. }\end{array}$ \\
\hline $\begin{array}{l}\text { Mousa, F.T., } \\
\text { Wales W.J., } \\
\text { \& Harper, S. } \\
\text { R. (2015). }\end{array}$ & $\begin{array}{l}\text { When less is more: } \\
\text { EO's influence upon } \\
\text { funds raised by } \\
\text { young technology } \\
\text { firms at IPO. } \\
\text { Journal of Business } \\
\text { Research, 68(2), } \\
\text { 306-313 }\end{array}$ & $\begin{array}{l}\text { The influence of EO signals on young firm } \\
\text { outcomes is more complex and nuanced than } \\
\text { intuition might suggest. Operating within high } \\
\text { technology industries does not appear to lessen } \\
\text { investor apprehensions concerning stronger EO } \\
\text { signals. Given that the firms are already } \\
\text { operating in highly dynamic environments, a } \\
\text { certain level of EO is likely to be assumed by } \\
\text { investors. Within this population of firms, above- } \\
\text { average EO signals may be viewed as imprudent, } \\
\text { perhaps even excessive, by underwriters } \\
\text { evaluating their potential as public companies. }\end{array}$ & $\begin{array}{l}\text { The young technology firms included } \\
\text { in this study operated in the industries } \\
\text { of computer hardware or software, } \\
\text { medical devices and biotechnology, } \\
\text { electronics, telephone equipment, } \\
\text { communication, and communication } \\
\text { services. }\end{array}$ & $\begin{array}{l}\text { Other potential variables } \\
\text { influencing the } \\
\text { relationship between } \\
\text { resource allocation and } \\
\text { firm performance: } \\
\text { strategic posture / } \\
\text { entrepreneurial } \\
\text { orientation. }\end{array}$ \\
\hline
\end{tabular}


Table 51: Extended Literature Review - Managerial Implications (Continued)

\begin{tabular}{|c|c|c|c|c|}
\hline $\begin{array}{l}\text { Mudambi, } \\
\text { R., \& Swift, } \\
\text { T. (2014). }\end{array}$ & $\begin{array}{l}\text { Knowing when to } \\
\text { leap: Transitioning } \\
\text { between exploitative } \\
\text { and explorative } \\
\text { R\&D. Strategic } \\
\text { Management } \\
\text { Journal, 35(1), 126- } \\
145\end{array}$ & $\begin{array}{l}\text { For the authors, firms that are able to time these } \\
\text { changes in R\&D spending with shifts in their } \\
\text { market positions generate superior performance } \\
\text { by proactively abandoning the exploitation of } \\
\text { prior competencies and discovering new ones at } \\
\text { the right times. }\end{array}$ & $\begin{array}{l}\text { This article offers an alternative view } \\
\text { to our study regarding the consistency } \\
\text { of spending patterns by suggesting } \\
\text { that firms that need to transition to a } \\
\text { new technology requiring radical } \\
\text { change may benefit from a significant } \\
\text { change in R\&D spending as the firm is } \\
\text { transitioning from exploitative to } \\
\text { explorative R\&D activities. }\end{array}$ & $\begin{array}{l}\text { Other potential variables } \\
\text { influencing the } \\
\text { relationship between } \\
\text { resource allocation and } \\
\text { firm performance: the } \\
\text { firm's need to make a } \\
\text { major shift or radical } \\
\text { change. }\end{array}$ \\
\hline $\begin{array}{l}\text { O'Sullivan, } \\
\text { D., Abela, } \\
\text { A. V., \& } \\
\text { Hutchinson, } \\
\text { M. (2009). }\end{array}$ & $\begin{array}{l}\text { Marketing } \\
\text { performance } \\
\text { measurement and } \\
\text { firm performance: } \\
\text { Evidence from the } \\
\text { European high- } \\
\text { technology sector. } \\
\text { European Journal of } \\
\text { Marketing, 43(5-6), } \\
843-862\end{array}$ & $\begin{array}{l}\text { Marketers, particularly those in high-tech firms, } \\
\text { are under intense pressure to communicate } \\
\text { marketing's contribution and as a means of } \\
\text { securing top management support. Findings from } \\
\text { this study indicate that, for European high-tech } \\
\text { firms, enhanced MPM ability has an impact on } \\
\text { firm performance with marketing. While } \\
\text { measurement of marketing performance is } \\
\text { complex, the results highlight the merits of } \\
\text { developing a measurement competency. }\end{array}$ & $\begin{array}{l}\text { The study provides insights into the } \\
\text { chain effects linking marketing } \\
\text { performance measurement and } \\
\text { ultimately firm performance in the } \\
\text { high-tech sector in Europe. It } \\
\text { illustrates the positive effect of } \\
\text { resource allocation measurement on } \\
\text { firm performance in the context of } \\
\text { marketing in the European high-tech } \\
\text { business environment. }\end{array}$ & $\begin{array}{l}\text { Other potential variables } \\
\text { influencing the } \\
\text { relationship between } \\
\text { resource allocation and } \\
\text { firm performance: } \\
\text { performance } \\
\text { measurement ability. }\end{array}$ \\
\hline
\end{tabular}


Table 51: Extended Literature Review - Managerial Implications (Continued)

\begin{tabular}{|c|c|c|c|c|}
\hline $\begin{array}{l}\text { Sahaym, A., } \\
\text { Steensma, } \\
\text { H. K., \& } \\
\text { Barden, J. } \\
\text { Q. } \\
(2010 ; 2009) .\end{array}$ & $\begin{array}{l}\text { The influence of } \\
\text { R\&D investment on } \\
\text { the use of corporate } \\
\text { venture capital: An } \\
\text { industry-level } \\
\text { analysis. Journal of } \\
\text { Business Venturing, } \\
25(4), 376-388\end{array}$ & $\begin{array}{l}\text { Environmental pressures and opportunities } \\
\text { associated with technological change and } \\
\text { industry munificence create conducive conditions } \\
\text { for the use of CVC. Both R\&D and CVC play an } \\
\text { important role in producing innovation outputs. It } \\
\text { is important to pursue and enhance the } \\
\text { complementary aspects of these two modes. } \\
\text { Managers should find an optimum balance } \\
\text { between the two based on their industry } \\
\text { environment. }\end{array}$ & $\begin{array}{l}\text { This article is another illustration that } \\
\text { firms' critical need to find optimal } \\
\text { levels of R\&D investment is shared } \\
\text { across multiple industries. }\end{array}$ & $\begin{array}{l}\text { Other potential variables } \\
\text { influencing the } \\
\text { relationship between } \\
\text { resource allocation and } \\
\text { firm performance: } \\
\text { acquisitions (i.e., } \\
\text { creating internally vs. } \\
\text { buying capabilities or } \\
\text { making vs. buying } \\
\text { R\&D), corporate venture } \\
\text { investments. }\end{array}$ \\
\hline $\begin{array}{l}\text { Suarez, F. } \\
\text { F., } \\
\text { Cusumano, } \\
\text { M. A., \& } \\
\text { Kahl, S. J. } \\
(2013) .\end{array}$ & $\begin{array}{l}\text { Services and the } \\
\text { business models of } \\
\text { product firms: An } \\
\text { empirical analysis } \\
\text { of the software } \\
\text { industry. } \\
\text { Management } \\
\text { Science, 59(2), 420- } \\
435\end{array}$ & $\begin{array}{l}\text { Firms that remain focused on products tend to } \\
\text { have higher profitability than product firms that } \\
\text { rely more heavily on services. However, } \\
\text { remaining a product focused firm may not be an } \\
\text { option open to all managers. The study shows } \\
\text { that services can improve the profitability of } \\
\text { product firms in certain situations, as the sign and } \\
\text { extent of services' contribution to margins } \\
\text { compared to that of product sales can vary } \\
\text { depending on certain factors specific to the firm } \\
\text { and industry. In addition, one should look not } \\
\text { only at the separate contribution of services } \\
\text { versus products, but also at the relationship and } \\
\text { dynamics between the two. }\end{array}$ & $\begin{array}{l}\text { Focused on the software industry, this } \\
\text { study suggests that revenue } \\
\text { composition (i.e., product vs. services } \\
\text { revenue) might influence resource } \\
\text { allocation and firm performance, and } \\
\text { that, subject to a number of caveats } \\
\text { (specificities of the software industry: } \\
\text { information-intensive goods, fierce } \\
\text { competition, rapid pace of change), } \\
\text { these dynamics are likely to hold in at } \\
\text { least some other industrial contexts. }\end{array}$ & $\begin{array}{l}\text { Other potential variables } \\
\text { influencing the } \\
\text { relationship between } \\
\text { resource allocation and } \\
\text { firm performance: } \\
\text { revenue composition or } \\
\text { quality of revenue (i.e., } \\
\text { subscription vs. } \\
\text { professional services } \\
\text { revenues, or recurring vs. } \\
\text { non-recurring revenues). }\end{array}$ \\
\hline
\end{tabular}


Table 51: Extended Literature Review - Managerial Implications (Continued)

\begin{tabular}{|c|c|c|c|c|}
\hline $\begin{array}{l}\text { Tokic D } \\
(2005) .\end{array}$ & $\begin{array}{l}\text { R\&D, advertising } \\
\text { and the market } \\
\text { value of internet } \\
\text { firms: Part II, } \\
\text { Journal of Internet } \\
\text { Commerce, } 4: 4,23 \text { - } \\
40\end{array}$ & $\begin{array}{l}\text { Investors ignored the negative profitability of } \\
\text { internet firms in their valuation estimations. The } \\
\text { main reason for negative profitability for internet } \\
\text { firms was the over-investment in R\&D and } \\
\text { advertising. The industry sales increased as the } \\
\text { number of people on-line increased. Therefore, a } \\
\text { rational investor would expect internet firms to } \\
\text { take advantage of increasing sales and thus, } \\
\text { earning profits. However, investors focused } \\
\text { solely on the value of growth, where the value of } \\
\text { firm is positively affected by investments and } \\
\text { volatility. This irrational valuation behavior is the } \\
\text { main reason for the sharp increase in internet } \\
\text { stock prices in } 1999 \text {. }\end{array}$ & $\begin{array}{l}\text { This study suggests that some of the } \\
\text { research questions of our study are not } \\
\text { limited to SaaS firms but already } \\
\text { existed with internet firms in the late } \\
\text { 1990s. }\end{array}$ & $\begin{array}{l}\text { The relationship between } \\
\text { R\&D and M\&S spending } \\
\text { and firm performance. }\end{array}$ \\
\hline $\begin{array}{l}\text { Tokic D. } \\
\text { (2004). }\end{array}$ & $\begin{array}{l}\text { R\&D, advertising } \\
\text { and the market } \\
\text { value of internet } \\
\text { firms: Part I, Journal } \\
\text { of Internet } \\
\text { Commerce, } 3: 2,79 \text { - } \\
99\end{array}$ & $\begin{array}{l}\text { A firm can enhance its value by maintaining high } \\
\text { R\&D and advertising intensity as long as it } \\
\text { increases its opportunity for growth or keeps it } \\
\text { constant. A firm can also enhance its value by } \\
\text { expanding abroad and controlling its foreign } \\
\text { operations. The value of a growth firm is a } \\
\text { function of R\&D investments, advertising } \\
\text { investments, earnings and volatility. }\end{array}$ & $\begin{array}{l}\text { This study suggests that some of the } \\
\text { research questions of our study are not } \\
\text { limited to SaaS firms but already } \\
\text { existed with internet firms in the late } \\
\text { 1990s. }\end{array}$ & $\begin{array}{l}\text { The relationship between } \\
\text { R\&D and M\&S spending } \\
\text { and firm performance. }\end{array}$ \\
\hline
\end{tabular}


Table 51: Extended Literature Review - Managerial Implications (Continued)

\begin{tabular}{|c|c|c|c|c|}
\hline $\begin{array}{l}\text { Ugur, M., } \\
\text { Trushin, E., } \\
\text { \& Solomon, } \\
\text { E. (2016). }\end{array}$ & $\begin{array}{l}\text { Inverted-U } \\
\text { relationship between } \\
\text { R\&D intensity and } \\
\text { survival: Evidence } \\
\text { on scale and } \\
\text { complementarity } \\
\text { effects in UK data. } \\
\text { Research Policy, } \\
45(7), 1474-1492\end{array}$ & $\begin{array}{l}\text { In terms of implications for practice, the authors } \\
\text { indicate that there may be an optimal level of } \\
\text { R\&D investment for maximizing survival time } \\
\text { and that the optimal level is likely to differ } \\
\text { depending on the level of creative destruction in } \\
\text { the industry, the level of product-market } \\
\text { competition, and the extent of skewness in the } \\
\text { distribution of R\&D intensity. }\end{array}$ & $\begin{array}{l}\text { The study finds an inverted U } \\
\text { relationship between R\&D spending } \\
\text { and survival time (another measure of } \\
\text { firm performance particularly relevant } \\
\text { to new markets) in the UK. }\end{array}$ & $\begin{array}{l}\text { The relationship between } \\
\text { R\&D spending and firm } \\
\text { performance. }\end{array}$ \\
\hline $\begin{array}{l}\text { Wagner, M. } \\
(2016) .\end{array}$ & $\begin{array}{l}\text { Managing disruptive } \\
\text { innovation with } \\
\text { technology } \\
\text { acquisitions: The } \\
\text { informing case of } \\
\text { software-based } \\
\text { high-technology } \\
\text { industries. } \\
\text { Technology } \\
\text { Analysis \& } \\
\text { Strategic } \\
\text { Management, 28(8), } \\
\text { 979-991 }\end{array}$ & $\begin{array}{l}\text { As a substitute for internal R\&D efforts, } \\
\text { incumbents should consider investments in } \\
\text { startups and smaller firms to meet the same } \\
\text { objectives as through internal corporate } \\
\text { venturing. They should develop acquisition } \\
\text { capabilities that enable periodic monitoring of } \\
\text { potential targets early on in order to make } \\
\text { sufficiently informed decisions in the context of } \\
\text { corporate venture capital investment. That is, } \\
\text { prior to an acquisition, incumbents can improve } \\
\text { their negotiation position and choice set by } \\
\text { making seed investments, thereby funding } \\
\text { experiments to illuminate which are the best } \\
\text { target firms to acquire. }\end{array}$ & $\begin{array}{l}\text { The study implies that software-based } \\
\text { firms that are challenged by disrupting } \\
\text { innovation should consider } \\
\text { acquisitions as an alternative to more } \\
\text { expensive internal R\&D efforts (thus, } \\
\text { helping maintain R\&D efforts at } \\
\text { optimum levels and mitigating risks of } \\
\text { exit). The EDA market where the } \\
\text { study was conducted forms part of the } \\
\text { semiconductor ecosystem. }\end{array}$ & $\begin{array}{l}\text { Other potential variables } \\
\text { influencing the } \\
\text { relationship between } \\
\text { resource allocation and } \\
\text { firm performance: } \\
\text { acquisitions (i.e., } \\
\text { creating internally vs. } \\
\text { buying capabilities or } \\
\text { making vs. buying } \\
\text { R\&D), corporate venture } \\
\text { investments. }\end{array}$ \\
\hline
\end{tabular}


Table 51: Extended Literature Review - Managerial Implications (Continued)

\begin{tabular}{|c|c|c|c|c|}
\hline $\begin{array}{l}\text { Yeh, M., } \\
\text { Chu, H., } \\
\text { Sher, P. J., } \\
\& \text { Chiu, Y. } \\
(2010)\end{array}$ & $\begin{array}{l}\text { R\&D intensity, firm } \\
\text { performance and the } \\
\text { identification of the } \\
\text { threshold: Fresh } \\
\text { evidence from the } \\
\text { panel threshold } \\
\text { regression model. } \\
\text { Applied Economics, } \\
\text { 42(3), 389-401 }\end{array}$ & $\begin{array}{l}\text { By and large, R\&D should not be treated as an } \\
\text { unlimited investment; there is a level beyond } \\
\text { which increased R\&D expenditure does not yield } \\
\text { proportional rewards. The objective of the R\&D } \\
\text { strategy of a particular firm is to renew and } \\
\text { upgrade technology, thereby reinforcing that } \\
\text { firm's competitive advantage. However, deciding } \\
\text { on the direction and level of R\&D should not be } \\
\text { made random and intuitive. }\end{array}$ & $\begin{array}{l}\text { This study provides some support for } \\
\text { the generalizability of our study for } \\
\text { both other industries (the sample of } \\
\text { this research consisted of IT and } \\
\text { electronic firms) and other regions } \\
\text { (this research was based on firms in } \\
\text { Taiwan). The net profit growth rate, } \\
\text { one of the measures used for firm } \\
\text { performance in this article, is a similar } \\
\text { measure as the Performance Factor } \\
\text { measure (EBITDA times YOY } \\
\text { revenue growth rate) in our study. }\end{array}$ & $\begin{array}{l}\text { The relationship between } \\
\text { R\&D spending and firm } \\
\text { performance. }\end{array}$ \\
\hline
\end{tabular}




\section{J. FROM THE EXTENDED LITERATURE REVIEW - GAPS AND NEW}

RESEARCH AVENUES 


\section{Extended Literature Review - Gaps and New Research Avenues}

Table 52: Extended Literature Review - Gaps and New Research Avenues

\begin{tabular}{|l|l|l|l|}
\hline Author (Date) & Title & Gaps & New Research Avenues \\
\hline $\begin{array}{l}\text { Boer, F. P. } \\
\text { (2002). }\end{array}$ & $\begin{array}{l}\text { Financial management of } \\
\text { RD 2002. Research- } \\
\text { Technology Management, } \\
45(4), 23-35\end{array}$ & $\begin{array}{l}\text { Need to further explore how risks influence firm } \\
\text { valuations and how risk-taking can be a competitive } \\
\text { advantage. Need for new tools to estimate and } \\
\text { manage risks and their pay-offs to improve decision } \\
\text { making in R\&D and other investments. Need for } \\
\text { guidance to implement these tools into practice to } \\
\text { ensure actual adoption. }\end{array}$ & $\begin{array}{l}\text { How do market characteristics and VC investments } \\
\text { influence firms' decision-making on investments } \\
\text { and resource allocation? How do risks (firm-level } \\
\text { risks, market risks etc.) influence business } \\
\text { valuations? }\end{array}$ \\
$\begin{array}{l}\text { Capasso, M., } \\
\text { Treibich, T. G., } \\
\text { (2015). Verspagen, B. }\end{array}$ & $\begin{array}{l}\text { The medium-term effect of } \\
\text { R\&D on firm growth. } \\
\text { Small Business Economics, }\end{array}$ & $\begin{array}{l}\text { The authors suggest that further research is needed to } \\
\text { disentangle the respective roles of organizational, } \\
\text { project and industry characteristics in the } \\
\text { relationships between the R\&D investments and the } \\
\text { outcomes (firm growth and firm survival). }\end{array}$ & $\begin{array}{l}\text { What is the role of firm, project, and industry } \\
\text { characteristics in the relationship between R\&D } \\
\text { investment and firm performance? }\end{array}$ \\
$\begin{array}{l}9640-6 \\
\text { ciftci, M., \& } \\
\text { Cready, W. M. } \\
\text { (2011). }\end{array}$ & $\begin{array}{l}\text { Scale effects of R\&D as } \\
\text { reflected in earnings and } \\
\text { returns. Journal of } \\
\text { Accounting and } \\
\text { Economics, 52(1), 62-80 }\end{array}$ & $\begin{array}{l}\text { Understanding the scale effects of R\&D and } \\
\text { complementary capabilities (e.g., post-innovation } \\
\text { development, marketing) on firm performance and } \\
\text { risks. }\end{array}$ & $\begin{array}{l}\text { What is the influence of scale on resource } \\
\text { allocation? What is the impact of scale in the } \\
\text { relationship between resource allocation and firm } \\
\text { performance? }\end{array}$ \\
\hline
\end{tabular}


Table 52: Extended Literature Review - Gaps and New Research Avenues (Continued)

\begin{tabular}{|l|l|l|l|}
\hline $\begin{array}{l}\text { Coccia, M. } \\
\text { (2009). }\end{array}$ & $\begin{array}{l}\text { What is the optimal rate of } \\
\text { R\&D investment to } \\
\text { maximize productivity } \\
\text { growth? Technological } \\
\text { Forecasting \& Social } \\
\text { Change, 76(3), 433-446 }\end{array}$ & $\begin{array}{l}\text { Models of R\&D-induced growth can serve as } \\
\text { empirical templates to assess the potential of } \\
\text { different growth policies at country level. Only a few } \\
\text { studies have examined whether semi-endogenous } \\
\text { growth can account for the relationship between } \\
\text { R\&D expenditure and Total Factor Productivity } \\
\text { (TFP). }\end{array}$ & $\begin{array}{l}\text { What are the effects of factors such as the country, } \\
\text { country policies, and the socio-economic and } \\
\text { political environment on the relationship between } \\
\text { resource allocation and firm performance? }\end{array}$ \\
\hline $\begin{array}{l}\text { Demirel, P., \& } \\
\text { Mazzucato, M. } \\
(2012) .\end{array}$ & $\begin{array}{l}\text { Innovation and firm } \\
\text { growth: Is R\&D worth it? } \\
\text { Industry and Innovation, } \\
19(1), 45-62\end{array}$ & $\begin{array}{l}\text { There are many national and transnational level } \\
\text { policies that call for firms to invest more in R\&D. } \\
\text { However, there is a scarcity of empirical studies that } \\
\text { provide evidence on whether this will have any } \\
\text { effect on firm growth. }\end{array}$ & $\begin{array}{l}\text { How do market characteristics and economic } \\
\text { growth policies impact the relationship between } \\
\text { R\&D investments/resource allocation and firm } \\
\text { performance? How does persistence (e.g., persistent } \\
\text { innovation) affect firm performance and what are } \\
\text { its effects? }\end{array}$ \\
& & & \\
& & & \\
&
\end{tabular}


Table 52: Extended Literature Review - Gaps and New Research Avenues (Continued)

\begin{tabular}{|c|c|c|c|}
\hline $\begin{array}{l}\text { Eisenmann, T. R. } \\
\text { (2006) }\end{array}$ & $\begin{array}{l}\text { Internet companies' growth } \\
\text { strategies: Determinants of } \\
\text { investment intensity and } \\
\text { long-term performance. } \\
\text { Strategic Management } \\
\text { Journal, 27(12), 1183-1204 }\end{array}$ & $\begin{array}{l}\text { Need to further test the generalizability of the study } \\
\text { to other industries and to deepen our understanding } \\
\text { of firms' investment strategies and their outcomes } \\
\text { during boom-burst valuation cycles. Further research } \\
\text { could develop valid measures of growth expectations } \\
\text { and test their impact on early investments. Further } \\
\text { research could also develop firm-level measures of } \\
\text { "winner take all" (WTA) attributes (network effects, } \\
\text { static scale economies, switching costs). Studying } \\
\text { the tactics used by firms to accelerate growth such as } \\
\text { aggressive discounting or mergers. Studying the } \\
\text { behavior of firms pursuing accelerated growth } \\
\text { strategies via a longitudinal research approach: e.g., } \\
\text { racing behavior (strategic interactions with rivals) vs. } \\
\text { "one shot" investment commitments. Further studies } \\
\text { are needed to test whether firms underinvest or } \\
\text { overinvest in a WTA market and analyze the factors } \\
\text { influencing firms' investment strategies in WTA } \\
\text { markets. }\end{array}$ & $\begin{array}{l}\text { What is the role of growth expectations in business } \\
\text { valuation? What are the effects of WTA attributes } \\
\text { on the relationships between resource allocation } \\
\text { and firm performance and ultimately firm } \\
\text { valuation? What factors influence investment } \\
\text { strategies in a WTA market? What are the different } \\
\text { types of firm behaviors and best practices in a } \\
\text { WTA market? }\end{array}$ \\
\hline $\begin{array}{l}\text { Fung, M. K. } \\
\text { (2004). }\end{array}$ & $\begin{array}{l}\text { Technological opportunity } \\
\text { and productivity of R\&D } \\
\text { activities. Journal of } \\
\text { Productivity Analysis, } \\
\text { 21(2), 167-181 }\end{array}$ & $\begin{array}{l}\text { New research opportunities exist to further analyze } \\
\text { the missing link between R\&D effort and } \\
\text { productivity and explain the sectorial differences. }\end{array}$ & $\begin{array}{l}\text { What is the contribution of R\&D to productivity } \\
\text { and what are the differences among the industries? } \\
\text { What is the role of technological opportunity in the } \\
\text { relationship between resource allocation and firm } \\
\text { performance? }\end{array}$ \\
\hline
\end{tabular}


Table 52: Extended Literature Review - Gaps and New Research Avenues (Continued)

\begin{tabular}{|c|c|c|c|}
\hline $\begin{array}{l}\text { Heredia, A., } \\
\text { Colomo- } \\
\text { Palacios, R., \& } \\
\text { de Amescua, A. } \\
\text { (2015). }\end{array}$ & $\begin{array}{l}\text { Software business models } \\
\text { from a distribution } \\
\text { perspective: A systematic } \\
\text { mapping study. Procedia } \\
\text { Computer Science, 64, 395- } \\
402\end{array}$ & $\begin{array}{l}\text { Need for more comparative studies of software BMs } \\
\text { with regard to company size, sector and moment in } \\
\text { time. Need for a framework to guide companies in } \\
\text { the adoption of a software BM taking into account } \\
\text { cultural, economic and technical factors. Need to } \\
\text { study new business models emerging with new } \\
\text { technologies and the level of success achieved by } \\
\text { firms adopting them. This topic is not limited to } \\
\text { technology companies but is affecting all industries } \\
\text { in the new digital business environment. }\end{array}$ & $\begin{array}{l}\text { What level of success is achieved by the various } \\
\text { BMs emerging in the industry in the various sectors } \\
\text { of the economy (subscription, transaction-based, } \\
\text { etc.)? What do future BMs look like? What are the } \\
\text { implications of these new BMs on firms' sales and } \\
\text { distribution channels? What are the implications of } \\
\text { these BMs on organizations' agility and innovation } \\
\text { capabilities? }\end{array}$ \\
\hline $\begin{array}{l}\text { Joglekar, N. R., } \\
\text { \& Levesque, M. } \\
\text { (2009). }\end{array}$ & $\begin{array}{l}\text { Marketing, R\&D, and } \\
\text { startup valuation. IEEE } \\
\text { Transactions on } \\
\text { Engineering Management, } \\
\text { 56(2), 229-242 }\end{array}$ & $\begin{array}{l}\text { Although studies in the literature have been carried } \\
\text { out to measure R\&D productivity under uncertainty, } \\
\text { most studies have not focused on the changing } \\
\text { nature of productivity and inherently transient nature } \\
\text { of startup valuation problems. }\end{array}$ & $\begin{array}{l}\text { What is the effect of scale on the relationship } \\
\text { between resource allocation and firm performance? } \\
\text { How do these effects manifest themselves in the } \\
\text { context of a startup or early stage growth firm? } \\
\text { What are the effects of financing, including the } \\
\text { different types of equity and debt financing and } \\
\text { various borrowing options? What is the role of } \\
\text { other factors such as portfolio effects and } \\
\text { competition? }\end{array}$ \\
\hline $\begin{array}{l}\text { Koellinger, P. } \\
(2008)\end{array}$ & $\begin{array}{l}\text { The relationship between } \\
\text { technology, innovation, and } \\
\text { firm performance- } \\
\text { Empirical evidence from e- } \\
\text { business in Europe. } \\
\text { Research Policy, 37(8), } \\
\text { 1317-1328 }\end{array}$ & $\begin{array}{l}\text { The author calls for more research on the effects of } \\
\text { product innovation and process innovation on firm } \\
\text { performance in other industries and other countries } \\
\text { to evaluate the generalizability of his findings and } \\
\text { reveal differences across different contexts. }\end{array}$ & $\begin{array}{l}\text { What are the effects of product innovation and } \\
\text { process innovation on firm performance in various } \\
\text { contexts of the modern economy, considering both } \\
\text { quantitative and qualitative performance variables? }\end{array}$ \\
\hline
\end{tabular}


Table 52: Extended Literature Review - Gaps and New Research Avenues (Continued)

\begin{tabular}{|c|c|c|c|}
\hline Krčál, O. (2014) & $\begin{array}{l}\text { The relationship between } \\
\text { profitability, innovation } \\
\text { and technology gap: A } \\
\text { basic model. Review of } \\
\text { Economic Perspectives, } \\
\text { 14(3), 215-231 }\end{array}$ & $\begin{array}{l}\text { It would be interesting to test whether there is an } \\
\text { inverted-U relationship between profitability and } \\
\text { innovation of individual firms, or whether the shape } \\
\text { of the relationship between profitability and } \\
\text { technology gap depends on average differences in } \\
\text { profitability in the industry. }\end{array}$ & $\begin{array}{l}\text { What are the effects of profitability on innovation } \\
\text { and technology gap? To what extent do these } \\
\text { effects differ across industries? What explains the } \\
\text { differences across industries? }\end{array}$ \\
\hline $\begin{array}{l}\text { Lantz, J., \& } \\
\text { Sahut, J. (2005). }\end{array}$ & $\begin{array}{l}\text { R\&D investment and the } \\
\text { financial performance of } \\
\text { technological firms. } \\
\text { International Journal of } \\
\text { Business, 10(3), 251-270 }\end{array}$ & $\begin{array}{l}\text { Understanding of the value and the risk of intangible } \\
\text { assets and their effects on firm performance and } \\
\text { valuation. }\end{array}$ & $\begin{array}{l}\text { How do investments in intangible assets impact } \\
\text { firm performance and valuation? What are the } \\
\text { effects of capitalization of expenditures? How to } \\
\text { account for the intangible elements that do not } \\
\text { appear on firms' balance sheets? }\end{array}$ \\
\hline $\begin{array}{l}\text { Lévesque, M., } \\
\text { Joglekar, N., \& } \\
\text { Davies, J. } \\
(2012 ; 2010) .\end{array}$ & $\begin{array}{l}\text { A comparison of revenue } \\
\text { growth at recent-IPO and } \\
\text { established firms: The } \\
\text { influence of SG\&A, R\&D } \\
\text { and COGS. Journal of } \\
\text { Business Venturing, 27(1), } \\
47-61\end{array}$ & $\begin{array}{l}\text { Based on the limitations cited in the article, there } \\
\text { would be opportunities for new research that does } \\
\text { not suffer from survival bias (for example, to study } \\
\text { causes of business failure from a resource allocation } \\
\text { perspective or to compare firms who survived vs. } \\
\text { firms who failed). Other opportunities for future } \\
\text { research would be resource allocation strategies of } \\
\text { firms in a declining economy or with capital } \\
\text { constraints, product versus process innovation } \\
\text { effects, and the influence of the obsolescence rate in } \\
\text { the industry. }\end{array}$ & $\begin{array}{l}\text { What are the effects of firm characteristics (e.g., } \\
\text { size, private vs. public), product life cycle, process } \\
\text { innovation, and market characteristics (e.g., } \\
\text { growing vs. declining) on resource allocation } \\
\text { decisions? What are the interactions and trade-offs } \\
\text { among the various expense areas (e.g., COGS, } \\
\text { R\&D, SG\&A)? What are the patterns of failing or } \\
\text { failed businesses? }\end{array}$ \\
\hline
\end{tabular}


Table 52: Extended Literature Review - Gaps and New Research Avenues (Continued)

\begin{tabular}{|c|c|c|c|}
\hline Lin, J. (2014) & $\begin{array}{l}\text { Effects on diversity of } \\
\text { R\&D sources and human } \\
\text { capital on industrial } \\
\text { performance. } \\
\text { Technological Forecasting } \\
\text { and Social Change, } 85, \\
168-184\end{array}$ & $\begin{array}{l}\text { A growing body of work on outward technology } \\
\text { transfer and external knowledge exploitations needs } \\
\text { to be examined in future research (e.g., R\&D } \\
\text { outsourcing, alliances, M\&A) to avoid the high cost } \\
\text { of internal development, achieve faster growth, and } \\
\text { gain access to 'state of the art' innovation. }\end{array}$ & $\begin{array}{l}\text { How to efficiently and effectively acquire } \\
\text { innovational skills (training, new hires, diversity of } \\
\text { professional background, outside collaboration, } \\
\text { etc.)? Future research could use additional } \\
\text { measures of firm performance (e.g., ROA, Tobin's } \\
\text { Q), additional measures of innovation (e.g., product } \\
\text { announcements, R\&D intensity, and non- } \\
\text { accounting measures), and include new moderators } \\
\text { such as country-specific characteristics. }\end{array}$ \\
\hline $\begin{array}{l}\text { Mousa, F.T., } \\
\text { Wales W.J., \& } \\
\text { Harper, S. R. } \\
\text { (2015). }\end{array}$ & $\begin{array}{l}\text { When less is more: EO's } \\
\text { influence upon funds raised } \\
\text { by young technology firms } \\
\text { at IPO. Journal of Business } \\
\text { Research, 68(2), 306-313 }\end{array}$ & $\begin{array}{l}\text { The authors call for more research in different } \\
\text { environmental contexts (different industries, } \\
\text { additional IPO years throughout the bubble/burst } \\
\text { cycles, early stage startups) and to study the longer- } \\
\text { term effects of entrepreneurial orientation (EO) on } \\
\text { firm performance, competitive advantage, and } \\
\text { survival as well as other factors such as the firm's } \\
\text { governance mechanisms and the board composition. }\end{array}$ & $\begin{array}{l}\text { What is the role of the EO in firm performance and } \\
\text { valuation and what factors (e.g., governance } \\
\text { mechanisms, board composition) influence the } \\
\text { relationships? }\end{array}$ \\
\hline $\begin{array}{l}\text { Mudambi, R., \& } \\
\text { Swift, T. (2014). }\end{array}$ & $\begin{array}{l}\text { Knowing when to leap: } \\
\text { Transitioning between } \\
\text { exploitative and explorative } \\
\text { R\&D. Strategic } \\
\text { Management Journal, } \\
\text { 35(1), 126-145 }\end{array}$ & $\begin{array}{l}\text { Future research could investigate whether firms that } \\
\text { successfully link drastic changes in R\&D } \\
\text { expenditure to superior firm performance have } \\
\text { distinguishing structural characteristics. In addition, } \\
\text { more research (e.g., case studies) would be helpful to } \\
\text { better understand the processes involved within the } \\
\text { firm. }\end{array}$ & $\begin{array}{l}\text { In what circumstances would a drastic change in } \\
\text { resource allocation lead to superior performance? }\end{array}$ \\
\hline
\end{tabular}


Table 52: Extended Literature Review - Gaps and New Research Avenues (Continued)

\begin{tabular}{|c|c|c|c|}
\hline $\begin{array}{l}\text { O'Sullivan, D., } \\
\text { Abela, A. V., \& } \\
\text { Hutchinson, M. } \\
\text { (2009). }\end{array}$ & $\begin{array}{l}\text { Marketing performance } \\
\text { measurement and firm } \\
\text { performance: Evidence } \\
\text { from the European high- } \\
\text { technology sector. } \\
\text { European Journal of } \\
\text { Marketing, 43(5-6), 843- } \\
862\end{array}$ & $\begin{array}{l}\text { The authors call for more research on the factors } \\
\text { influencing the relationship between measurement } \\
\text { and performance, and suggest extending the research } \\
\text { to include other measures of performance. }\end{array}$ & $\begin{array}{l}\text { How does the firm's measurement ability influence } \\
\text { the relationship between resource allocation and } \\
\text { firm performance? }\end{array}$ \\
\hline $\begin{array}{l}\text { Sahaym, A., } \\
\text { Steensma, H. K., } \\
\text { \& Barden, J. Q. } \\
(2010 ; 2009) .\end{array}$ & $\begin{array}{l}\text { The influence of R\&D } \\
\text { investment on the use of } \\
\text { corporate venture capital: } \\
\text { An industry-level analysis. } \\
\text { Journal of Business } \\
\text { Venturing, 25(4), 376-388 }\end{array}$ & $\begin{array}{l}\text { According to the authors, future research on the } \\
\text { effectiveness of various modes of exploration is a } \\
\text { worthy area for investigation. Comparing and } \\
\text { contrasting the effectiveness of R\&D and CVC } \\
\text { would take this research further. There is a dearth of } \\
\text { literature on the use and application of learning } \\
\text { gained from external venturing activities. It would be } \\
\text { valuable to explore the ways in which firms apply } \\
\text { the knowledge gained from their CVC activity and } \\
\text { the role of managers and boards in using R\&D and } \\
\text { CVC programs. }\end{array}$ & $\begin{array}{l}\text { How do acquisitions complement or substitute } \\
\text { internal R\&D or other internal investments? How } \\
\text { do corporate venture investments influence the } \\
\text { relationship between resource allocation and firm } \\
\text { performance? }\end{array}$ \\
\hline $\begin{array}{l}\text { Suarez, F. F., } \\
\text { Cusumano, M. } \\
\text { A., \& Kahl, S. J. } \\
(2013) .\end{array}$ & $\begin{array}{l}\text { Services and the business } \\
\text { models of product firms: } \\
\text { An empirical analysis of } \\
\text { the software industry. } \\
\text { Management Science, } \\
59(2), 420-435\end{array}$ & $\begin{array}{l}\text { The authors suggest further empirical research on the } \\
\text { role of services in firm financial performance in } \\
\text { other product industries than the software industry } \\
\text { for a better understanding of the differences among } \\
\text { the industries. }\end{array}$ & $\begin{array}{l}\text { What are the effects of revenue composition (i.e., } \\
\text { subscription vs. professional services revenues, or } \\
\text { recurring vs. non-recurring revenues) on firm } \\
\text { performance? }\end{array}$ \\
\hline
\end{tabular}


Table 52: Extended Literature Review - Gaps and New Research Avenues (Continued)

\begin{tabular}{|l|l|l|l|}
\hline Tokic D (2005). & $\begin{array}{l}\text { R\&D, advertising and the } \\
\text { market value of internet } \\
\text { firms: Part II, Journal of } \\
\text { Internet Commerce, 4:4, } \\
23-40\end{array}$ & $\begin{array}{l}\text { Future research in the area of internet firm valuation } \\
\text { should further examine whether there are differences } \\
\text { in underlying volatility and value between R\&D- } \\
\text { intensive internet firms and advertising-intensive } \\
\text { internet firms in a global valuation model. }\end{array}$ & $\begin{array}{l}\text { What are the differences in firm performance and } \\
\text { valuation between R\&D intensive firms and } \\
\text { marketing intensive firms? }\end{array}$ \\
\hline Tokic D. (2004). & $\begin{array}{l}\text { R\&D, advertising and the } \\
\text { market value of internet } \\
\text { firms: Part I, Journal of } \\
\text { Internet Commerce, 3:2, } \\
79-99\end{array}$ & $\begin{array}{l}\text { Need for a new valuation approach for growth firms } \\
\text { with high proportion of intangible assets such as } \\
\text { internet companies, taking into account the value of } \\
\text { earnings. For the author, the value of a growth firm } \\
\text { is a function of R\&D investments, advertising } \\
\text { investments, earnings and volatility as well as the } \\
\text { degree of international involvement (DFI). }\end{array}$ & $\begin{array}{l}\text { How to improve the valuation methods to better } \\
\text { assess the value of emerging technology growth } \\
\text { firms? }\end{array}$ \\
\hline $\begin{array}{l}\text { Ugur, M., } \\
\text { Trushin, E., \& } \\
\text { Solomon, E. } \\
\text { (2016). }\end{array}$ & $\begin{array}{l}\text { Inverted-U relationship } \\
\text { between R\&D intensity and } \\
\text { survival: Evidence on scale } \\
\text { and complementarity } \\
\text { effects in UK data. } \\
\text { Research Policy, 45(7), } \\
1474-1492\end{array}$ & $\begin{array}{l}\text { Opportunities for a new line of research that can } \\
\text { shed additional light on whether the survival effects } \\
\text { of R\&D investment are mediated through market } \\
\text { power (escape-competition effect) or increased } \\
\text { efficiency (competition effect). }\end{array}$ & $\begin{array}{l}\text { What are the effects of resource allocation on firm } \\
\text { survival and what factors (e.g., market } \\
\text { characteristics, others) influence this relationship? }\end{array}$ \\
\hline
\end{tabular}


Table 52: Extended Literature Review - Gaps and New Research Avenues (Continued)

\begin{tabular}{|c|c|c|c|}
\hline $\begin{array}{l}\text { Wagner, M. } \\
\text { (2016). }\end{array}$ & $\begin{array}{l}\text { Managing disruptive } \\
\text { innovation with technology } \\
\text { acquisitions: The informing } \\
\text { case of software-based } \\
\text { high-technology industries. } \\
\text { Technology Analysis \& } \\
\text { Strategic Management, } \\
\text { 28(8), 979-991 }\end{array}$ & $\begin{array}{l}\text { Understanding of the dynamics of market entry and } \\
\text { likelihood of acquisition for startups in technology } \\
\text { markets, linkages to industry networks, and } \\
\text { corporate venture strategies of established firms. }\end{array}$ & $\begin{array}{l}\text { Future work should address in more depth the } \\
\text { interaction of business models and disruptive } \\
\text { innovation and acquisition patterns of established } \\
\text { firms. }\end{array}$ \\
\hline $\begin{array}{l}\text { Yeh, M., Chu, } \\
\text { H., Sher, P. J., \& } \\
\text { Chiu, Y. (2010) }\end{array}$ & $\begin{array}{l}\text { R\&D intensity, firm } \\
\text { performance and the } \\
\text { identification of the } \\
\text { threshold: Fresh evidence } \\
\text { from the panel threshold } \\
\text { regression model. Applied } \\
\text { Economics, 42(3), 389-401 }\end{array}$ & $\begin{array}{l}\text { Investigating the time-lag effect of R\&D on firm } \\
\text { performance in the modern business environment. } \\
\text { The life cycles of many new products are shorter } \\
\text { than before, especially in hi-tech industries; hence, } \\
\text { considering such time-lag concerns in } R \& D \\
\text { intensity-performance nexus might be an important } \\
\text { issue that is worth a thorough investigation in the } \\
\text { future. }\end{array}$ & $\begin{array}{l}\text { What is the effect of R\&D intensity on firm } \\
\text { performance when it is further time-lagged or } \\
\text { considered as cumulative over time? Understanding } \\
\text { the differences in time span of R\&D factors among } \\
\text { the industries' maturity and product life cycle stage. } \\
\text { Beyond the effect of R\&D intensity on firm } \\
\text { performance, how do firm strategies, such as those } \\
\text { related to marketing, financial leverage and human } \\
\text { resources, influence firm performance as well as } \\
\text { R\&D investment, and what are the interactions or } \\
\text { trade-off effects among these variables? }\end{array}$ \\
\hline
\end{tabular}

